$$
\begin{aligned}
& \text { University of Szeged } \\
& \text { Faculty of Pharmacy }
\end{aligned}
$$

Institute of Pharmaceutical Technology and Regulatory Affairs

Head: Dr. habil. Ildikó Csóka, PhD.

\title{
STUDY OF FLUID BED GRANULATION PROCESSES WITH NEW TECHNOLOGY APPROACHES
}

\author{
PhD Thesis
}

By

Yasmine Korteby

Pharmaceutical Engineer

Supervisor:

Dr. habil. Géza Regdon jr., PhD.

Szeged

2018 


\section{LIST OF ORIGINAL PUBLICATIONS}

I. Korteby, Y., Mahdi, Y., Azizou, A., Daoud, K., Regdon, G. jr., Implementation of an artificial neural network as a PAT tool for the prediction of temperature distribution within a pharmaceutical fluidized bed granulator, Eur. J. Pharm. Sci., 88 (2016) 219-232

IF: 3.756

II. Regdon, G. jr., Korteby, Y., Quantitative and qualitative use of thermal analysis for the investigation of the properties of granules during fluid bed melt granulation, J. Therm. Anal. Cal. (2017). DOI: 10.1007/s10973-017-6848-5

IF: 1.953

III. Korteby, Y., Sovány, T., Kristó, K., Regdon, G. jr., The use of machine learning tool and differential scanning calorimetry to elucidate and characterize the growth mechanism of an in situ fluid bed melt granulation. Powder Technol., 331 (2018) 286-295

IF: 2.942

IV. Korteby, Y., Mahdi, Y., Daoud, K., Regdon, G. jr., A novel insight into Fluid Bed Melt Granulation: Temperature mapping for the determination of granule formation with the Insitu and spray-on techniques. Eur. J. Pharm. Sci. EJPS-D-18-00247. Under revision.

(IF: 3.756) 


\section{PRESENTATIONS RELATED TO THE THESIS}

\section{Verbal presentations:}

1. Yasmine Korteby, Katalin Kristó, Tamás Sovány, Géza Regdon jr.: Preparation of granules via fluid hot melt granulation and characterization by thermal analysis. MKE Termoanalitikai Szakcsoport és az MTA Termoanalitikai Munkabizottság közös szervezésében rendezett ülés 2016. Budapest, Hungary.

2. Yasmine Korteby: Characterization of a fluid hot melt granulation by thermal analysis and investigation of the influence of different process parameters. XII. Clauder Ottó Emlékverseny 2016. Budapest, Hungary.

3. Yasmine Korteby, Yassine Mahdi, Amel Azizou, Kamel Daoud, Géza Regdon jr.: In-line temperature monitoring of a fluid bed granulation for the prediction of temperature distribution profiles via artificial neural networks. Kristályosítási és Gyógyszerformulálási Szakosztály 10. Kerekasztal Konferenciája. Balatonszemes May 19-20, 2017.

4. Yasmine Korteby, Géza Regdon jr.: Quantitative and qualitative use of thermal analysis to depict fluid bed melt granulation growth and granules structure. JTACC+V4 1st Journal of Thermal Analysis and Calorimetry Conference and 6th V4 (Joint Czech-Hungarian-PolishSlovakian) Thermoanalytical Conference June 6-9, 2017. Budapest, Hungary.

5. Yasmine Korteby, Katalin Kristó, Tamás Sovány, Géza Regdon jr.: Evaluation of in-situ fluid bed melt granulation growth using ANN modelling and thermal analysis. MTA Szerves és Biomolekuláris Kémiai Bizottság Gyógyszerkémiai és Gyógyszertechnológiai Munkabizottsága. September 11-12, 2017. Szeged, Hungary.

6. Yasmine Korteby, Yassine Mahdi, Kamel Daud, Géza Regdon jr.: A novel insight into fluid bed melt granulation: temperature mapping for the determination of granule formation with the in-situ and spray-on techniques. $7^{\text {th }}$ BBBB International Conference of Pharmaceutical Sciences. October 5-7, 2017. Balatonfüred, Hungary.

7. Yasmine Korteby, Yassine Mahdi, Kamel Daud, Géza Regdon jr.: Heat transfer zones determination inside a fluid bed granulator for the optimization of melt granulation processes.Az MTA Termoanalitikai Munkabizottságának valamit az MKE Termoanalitikai Szak-csoportjának közös rendezvényére. December, 2017. Budapest, Hungary.

\section{Poster presentations:}

8. Yasmine Korteby, Yassine Mahdi, Amel Azizou, Kamel Daoud, Géza Regdon jr.: In-line monitoring of temperature distribution profiles for a quality by design approach to the prediction of fluid bed granulation via artificial neural networks. 11th Central European Symposium on Pharmaceutical Technology. September 22-24, 2016. Belgrade, Serbia.

9. Yasmine Korteby, Katalin Kristó, Tamás Sovány, Géza Regdon jr.: Characterization of a fluid hot melt granulation by thermal analysis and investigation of the influence of different process parameters. 11th Central European Symposium on Pharmaceutical Technology. September 22-24, 2016. Belgrade, Serbia. 
10. Yasmine Korteby, Yassine Mahdi, Kamel Daud, Géza Regdon jr.: Investigation of in-situ and spray-on FBMG granule compression and dissolution behavior. $11^{\text {th }}$ World Meeting on Pharmaceutics, Biopharmaceutics and Pharmaceutical Technology, March19-22, 2018. Granada, Spain.

\section{PRESENTATIONS NOT RELATED TO THE THESIS}

1. Farid Agouillal, Houria Moghrani, Daya Mancer, Yasmine Korteby, Nouradine Nasrallah. Development of alginate microspheres containing essential oils microemulsions: Laser diffractometry characterization and loading capacity optimization by response surface methodology. $7^{\text {th }}$ BBBB International Conference of Pharmaceutical Sciences. October 57, 2017. Balatonfüred, Hungary.

2. Daya Mancer, Ahmed Zaid, Yasmine Zanoune, Yasmine Korteby, Kamel Daoud. Design of experiment of hydrophobic drug encapsulation using biopolymers : Particles size based study. $7^{\text {th }}$ BBBB International Conference of Pharmaceutical Sciences. October 5-7, 2017. Balatonfüred, Hungary.

3. Wissem Boutraa, Samah Belkacemi, Amel Toubane, Yasmine Korteby, Kamel Daoud. Extraction, purification and crystallisation of rebaudioside A, a sweetener from Algerian cultivated Stevia rebaudiana. $7^{\text {th }}$ BBBB International Conference of Pharmaceutical Sciences. October 5-7, 2017. Balatonfüred, Hungary. 
TABLE OF CONTENT

LIST OF ORIGINAL PUBLICATIONS

PRESENTATIONS RELATED TO THE THESIS

PRESENTATIONS NOT RELATED TO THE THESIS

ABBREVIATIONS

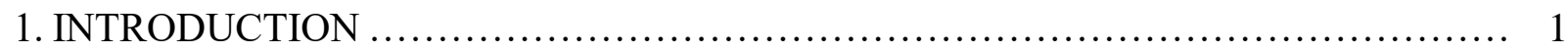

2. THEORETICAL BACKGROUND .......................................................... 2

2.1. Advances in granulation process control - An engineering approach ................... 2

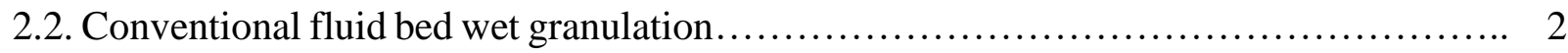

2.3. Non-conventional fluid bed melt granulation....................................... 4

2.4. Granulation processes modelling...................................................... 7

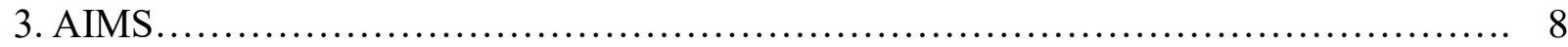

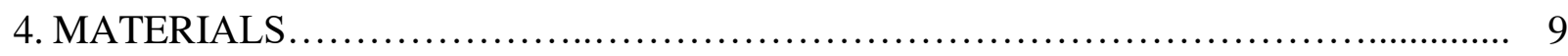

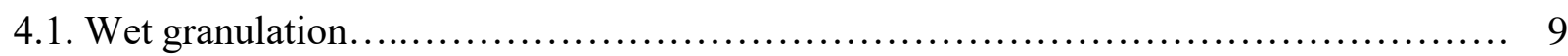

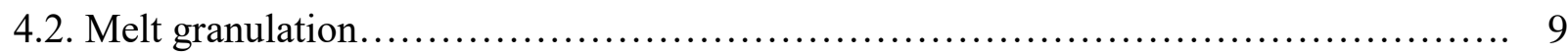

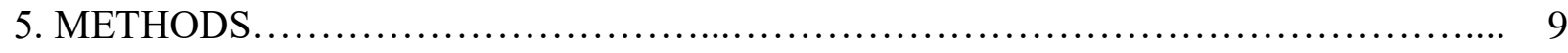

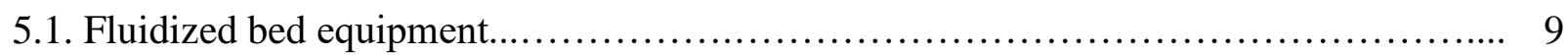

5.1.1. Wet granulation - Description of operating procedures.............................. 9

5.1.2. Melt granulation - Description of operating procedures............................... 10

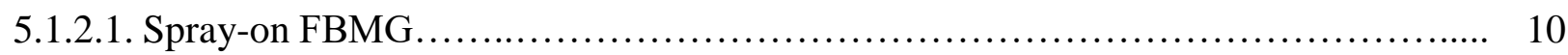

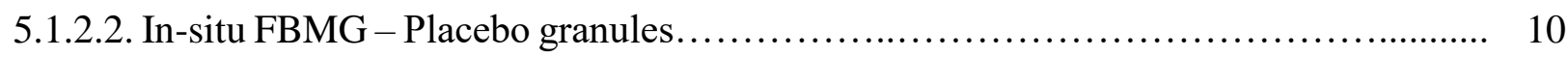

5.1.2.3. In-situ FBMG - Granules with API............................................ 10

5.2. Spraying angle and wetting surface determination.................................. 11

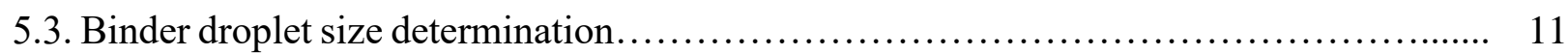

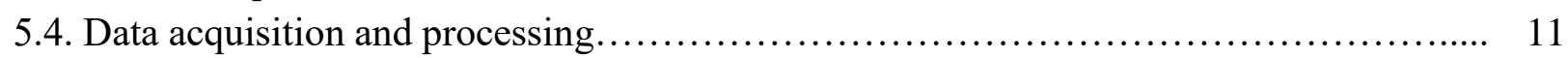

5.5. Modelling using artificial neural networks........................................ 12

5.6. Relative importance of input variables................................................. 13

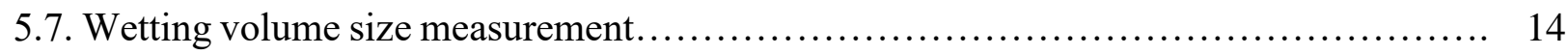

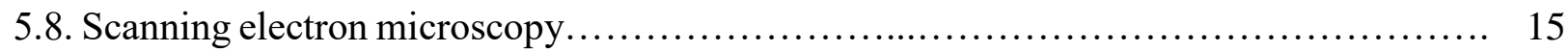

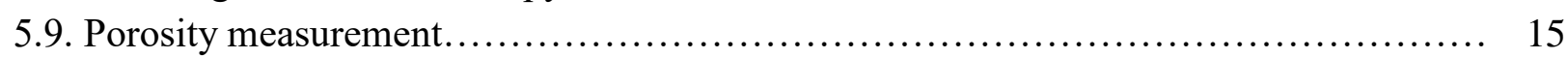

5.10. Granules strength measurement and yield ....................................... 15

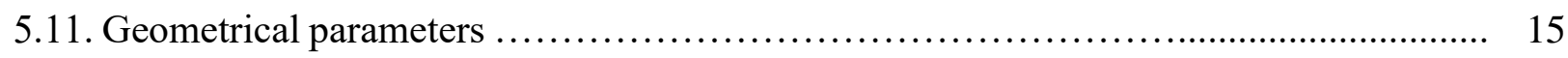

5.12. Flowability properties and moisture content....................................... 15

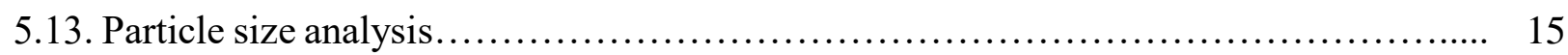

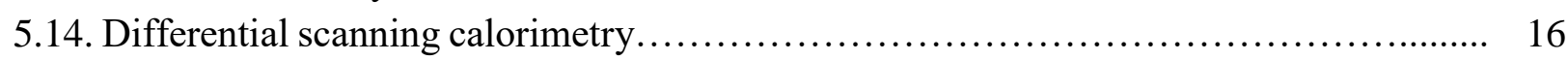

5.15. Thermogravimetric analysis-mass spectrometry ................................. 16

5.16. Dissolution and compression studies............................................ 16 


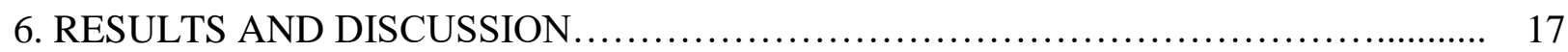

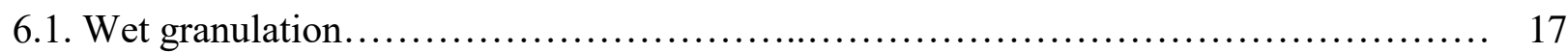

6.1.1. Characterisation and architecture of the ANN .................................. 17

6.1.2. Shapes of predicted temperature profiles and particle patterns...................... 18

6.1.3. Particle growth and temperature profiles................................... 20

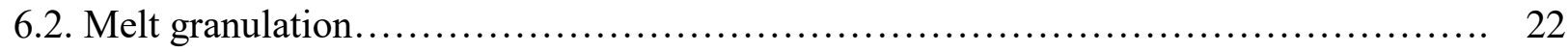

6.2.1. In-situ FBMG - Placebo granules........................................... 22

6.2.1.1. Model architecture and simulation ......................................... 22

6.2.1.2. Agglomerate growth mechanism and morphology............................ 26

6.2.1.3. Effect of process variables on granule size, size distribution and yield .............. 27

6.2.1.4. Effect of input variables on granule hardness................................ 27

6.2.1.5. Effect of process variables on granule porosity............................... 28

6.2.1.6. Melt granulation optimization............................................ 29

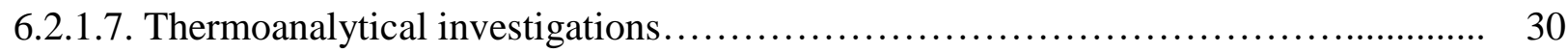

6.2.1.7.1. Differential scanning calorimetry.................................... 30

6.2.1.7.2. Thermogravimetric analysis - mass spectrometry......................... 33

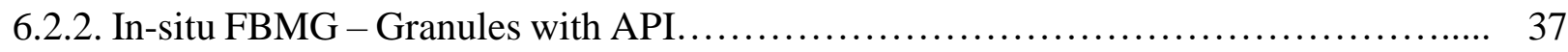

6.2.2.1. Temperature mapping and volume of the wetting zone ......................... 37

6.2.2.2. Granule size distribution and the volume of the wetting zone....................... 38

6.2.2.3. Tablet hardness and dissolution testing .................................. 40

6.2.3. Spray-on FBMG - Granules with API............................................... 40

6.2.3.1. Spraying air pressure.................................................. 40

6.2.3.2. Binder spraying rate ..................................................... 41

6.2.3.3. Droplet size and size distribution........................................... 41

6.2.3.4. Temperature mapping and volume of the wetting zone....................... 42

6.2.3.5. Granule size distribution and the volume of the wetting zone....................... 44

6.2.3.6. Tablet hardness and dissolution testing .................................... 45

7. CONCLUSIONS AND PRACTICAL USEFULNESS ............................ 46

\section{REFERENCES}

ACKNOWLEDGEMENTS

ANNEX 


\section{ABBREVIATIONS}

ANNs Artificial neural networks

API Active pharmaceutical ingredient

CV Coefficient of variation

DDS Drug delivery system

DEM Discrete element method

DSC Differential scanning calorimetry

FBA Fluid bed in Algeria

FBH Fluid bed in Hungary

FBMG Fluid bed Melt Granulation

MS Mass spectroscopy

PAT Process analytical technology

PCT Paracetamol

PEG Polyethylene glycol

PSD Particle size distribution

PVP Polyvinylpyrrolidone

Q1 $\quad$ Spraying rate

RH Relative humidity

SEM Scanning electron microscopy

$\mathrm{T}_{\mathrm{f}} \quad$ Fluidizing temperature

$\mathrm{T}_{\mathrm{m}} \quad$ Melting temperature

TGA Thermogravimetric analysis

$\mathrm{U}_{\mathrm{f}} \quad$ Fluidizing velocity

$\Delta \mathrm{P} \quad$ Pressure drop

$\varepsilon \quad$ Porosity

$\rho_{\mathrm{a}} \quad$ True density

$\rho_{\mathrm{a}} \quad$ Bulk density

$\mathrm{R}^{2} \quad$ Root mean square error 


\section{INTRODUCTION}

Pharmaceutical granulation is a critical unit operation that is frequently utilized to modulate attributes of powder mixtures to aid in further processing. The granulation processes must be designed to impart a high degree of control on many important physical attributes, such as granule size distribution, shape, content uniformity, moisture content and distribution, porosity, density, tensile strength, and surface morphology. These physical attributes are often critical to process-ability of granulations and for final product quality and performance. An optimally designed granulation unit operation can be an excellent tool for minimizing variability and thereby reducing the risk of poor quality.

Implementing the PAT framework and having a greater understanding of the manufacturing process has obvious advantages to the pharmaceutical industry, the regulators, and the public health. The PAT Initiative provides a regulatory environment that encourages and facilitates pharmaceutical companies to innovate and employ the tools necessary to achieve an in-depth understanding of the manufacturing process. The true goal is to understand the fundamental governing phenomena at work during the process and incorporate this understanding during product development. Doing so will reduce the degree of empiricism that is necessary.

Granulation modelling is an area of growing importance. It is dominated by the population balance approach for developing mechanistic models. However, it requires an improved understanding of the key factors involved in particle growth and breakage. The growing importance of particulate flow patterns is being addressed through approaches such as DEM, which will hopefully provide a microscale view of particle motions in the granulation device. The challenge is in addressing the multiscale nature of granulation modelling that spans from particle interactions up to the plant level. The development of empirically based models has provided a simple means of addressing quickly a number of control-related applications. Application of models to design, advanced control, and diagnosis will require mechanistic models that continue to incorporate the latest understanding of the underlying mechanisms. Much work is currently underway in these areas and the incorporation into existing models of new knowledge will help extend the applicability of process models for granulation. 


\section{THEORETICAL BACKGROUND}

\subsection{Advances in granulation process control - An engineering approach}

There is an increasing need to formulate products using a science-based approach. To bring robust products to the market with minimal trial and error, it is important to completely understand the thermodynamics, kinetics, and physics of the concurrent processes occurring during granulation [1-7]. Fundamental understanding of the processes will allow for the appropriate modelling and monitoring of granulation that is necessary to facilitate control over the process [8-11]. The knowledge surrounding granulation technology has vastly improved over the last few decades with no signs of losing momentum [12].

Process understanding with emphasis on PAT and QbD has been an initiative of the FDA. This initiative has contributed significantly to the understanding and development of process control in order to provide an elegant product to patients while ensuring that every dosage taken will elicit the intended therapeutic response [13-14].

The degree of the instrumentation of pharmaceutical unit operations has increased. This instrumentation provides information on the state of the process and can be used for both process control and research. Besides monitoring the process parameters, a number of approaches are being developed for measuring the moisture of the product to determine the end point of the process using near-infrared, image analysis, Raman spectroscopy [15-17].

An ideal end-point determination system would be one that is minimally invasive to the process, has rapid data acquisition, and provides reliable information to the operator. This routine should also supply suggested corrective actions to bring the granulation within prespecified end-point control limits [18]. Using this methodology could lead to the optimization of the granulation process and applied for control. Such systems are still under development and ongoing research is being carried out in this field.

\subsection{Conventional fluid bed wet granulation}

\section{Principle}

The size enlargement of primary particles has been carried out in the pharmaceutical industry in a variety of ways. One of the most common unit operations used in the pharmaceutical industry is the fluid-bed processing where fine solids are transformed into a fluid-like state through contact with a gas [19]. At certain gas velocities, the gas will support the particles, giving them freedom of mobility without entrainment. Such a fluidized bed resembles a 
vigorously boiling fluid, with solid particles undergoing extremely turbulent motion, which increases with gas velocity. The smooth fluidization of gas-solid particles is the result of equilibrium between the hydrodynamic, gravitational, and interparticle forces. Wet granulation is a subset of size enlargement [20]. The goal is to form agglomerated particles through the use of binder bridges between the particles as shown in Figure 1.

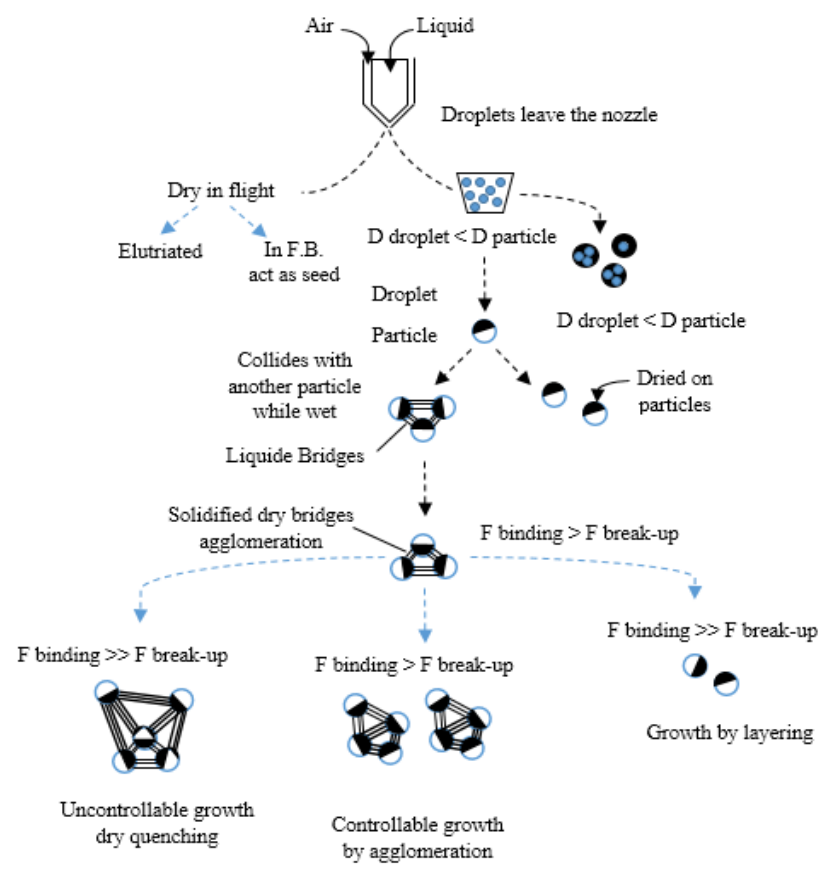

Figure 1: Mechanism of granulation in fluid bed.

To achieve a good granulation, particles must be uniformly mixed, and liquid bridges between the particles must be strong and easy to dry. Therefore, this system is sensitive to the particle movement of the product in the unit, the addition of the liquid binder, and the drying capacity of the air. The formulation, equipment and process variables affecting the quality of the final granule are listed in Table 1.

Table 1: Formulation, equipment and process variables affecting fluidized bed granulation.

\begin{tabular}{lll}
\hline Formulation variables & Equipment variables & Process variables \\
\hline Starting material & Design & Inlet air temperature \\
Low-dose drug content & Air distribution plate & Atomization air pressure \\
Type of binder & Pressure drop & Fluidization air velocity \\
Quantity of binder & Shaker/blow back cycle & Fluidization air volume \\
Binder solvent & & Liquid spray rate \\
& & Nozzle position and type \\
& Filter porosity \\
& Cleaning frequency \\
& Bowl capacity \\
\hline
\end{tabular}




\section{End point and control techniques}

Future advances in the understanding of granulation phenomena rest on engineering process design. A change in granule size or voidage is akin to a change in chemical species, and so analogies exist between granulation growth kinetics and chemical kinetics and the unit operations of size enlargement and chemical reaction. For this reason, it is desirable to control the dynamic process of drying and wetting during fluid-bed granulation as they affect the critical quality attributes of the final product [21].

Systematic studies of the role of both temperature and humidity factors in the fluid-bed have been performed describing the relationship between temperature distribution within the fluidized bed and particle formation during granulation by the establishment of temperature profiles within the bed. For continuous monitoring of moisture, NIR spectroscopy has been applied where water content and median particle size have been extracted during processing [22-23].

\subsection{Non-conventional fluid bed melt granulation}

Melt granulation operates via similar principles as wet granulation, but uses a molten binder as granulation fluid to establish liquid bridges between particles in a heated powder bed. Following particle agglomeration and consolidation, the granules are cooled to room temperature and the solidified binder forms bridges between individual powder particles to yield a solid end product with a granular structure [24].

This granulation approach has several advantages over conventional wet granulation: 1) the drying step is eliminated since no solvents (water, alcohol, organic solvents) are used during the process, significantly reducing the process time and energy requirements, 2) moisturesensitive materials can be agglomerated without organic solvents, resulting in an environment friendly process, 3) the amount of liquid added during granulation is carefully controlled (ensuring a consistent granule quality), since uncontrolled solvent evaporation during agglomeration will not occur, and 4) all unit operations of a melt granulation process (mixing, agglomeration, formation of solid bridges) are carried out in the same equipment, offering a safe and simple single-pot process with minimal loss during material transfer.

These advantages must be balanced against the risk of thermal degradation of the active ingredient at higher process temperature [25-27]. 
The binder used during melt granulation is one of the main determinants of granule quality: using hydrophilic binders immediate-release systems are formed as the granules quickly disintegrate or dissolve in aqueous media [24, 25].

In contrast, a sustained-release dosage form is prepared via melt granulation using lipophilic binders as the water insoluble binder retains its matrix structure in aqueous media [24, 28]. In general, melt granulation yields denser agglomerates compared with wet granulation since the binder liquid is not removed from the end product. This property can be advantageous for sustained-release formulations, but could hamper water penetration into the granules in case of an immediate-release formulation. Binders used during melt granulation are listed in Table 2.

Table 2: Commonly used binders during melt granulation.

\begin{tabular}{ll}
\hline Lipophilic binders & Hydrophilic binders \\
\hline Bee wax & Polyethylene glycol 2000-20000 \\
Carnauba wax & Ethylene oxide/Poloxamers \\
Microcrystalline wax & Gelucire 50/13 \\
Paraffin wax & Gelucire 44/14 \\
Cetostearyl alcohol & \\
Stearyl alcohol & \\
Stearic acid & \\
Palmitic acid & \\
Glyceryl tripalmitate & \\
Glyceryl tristearate & \\
Glyceryl palmito stearate & \\
Glyceryl behenate & \\
Glyceryl monostearate & \\
Hydrogenated soybean oil & \\
Hydrogenated castor oil &
\end{tabular}

HMG in fluidized beds can be performed with two techniques depending on the binder addition procedure. The binder can be added either in a molten state sprayed onto the fluidized solid particles (Spray-on procedure) or as solid binder particles added and fluidized together with drug particles and excipients (In-situ/Co-melt procedure), which melt during the increase in air temperature [9-11, 25, 27] as shown in Figure 2.

Many authors have focused on revealing the influence of some of the most important experimental variables on product quality, starting with the work of Schaefer's group [28-30] on the effects of binder spray rate, binder viscosity, droplet size, bed temperature on the performance of spray-on fluid bed melt granulation, showing that the granule growth mechanism is dependent on the ratio of binder droplet size to powder size and that a low ratio led to the nucleation mechanism and gave rise to coalescence enabling further granule growth. 

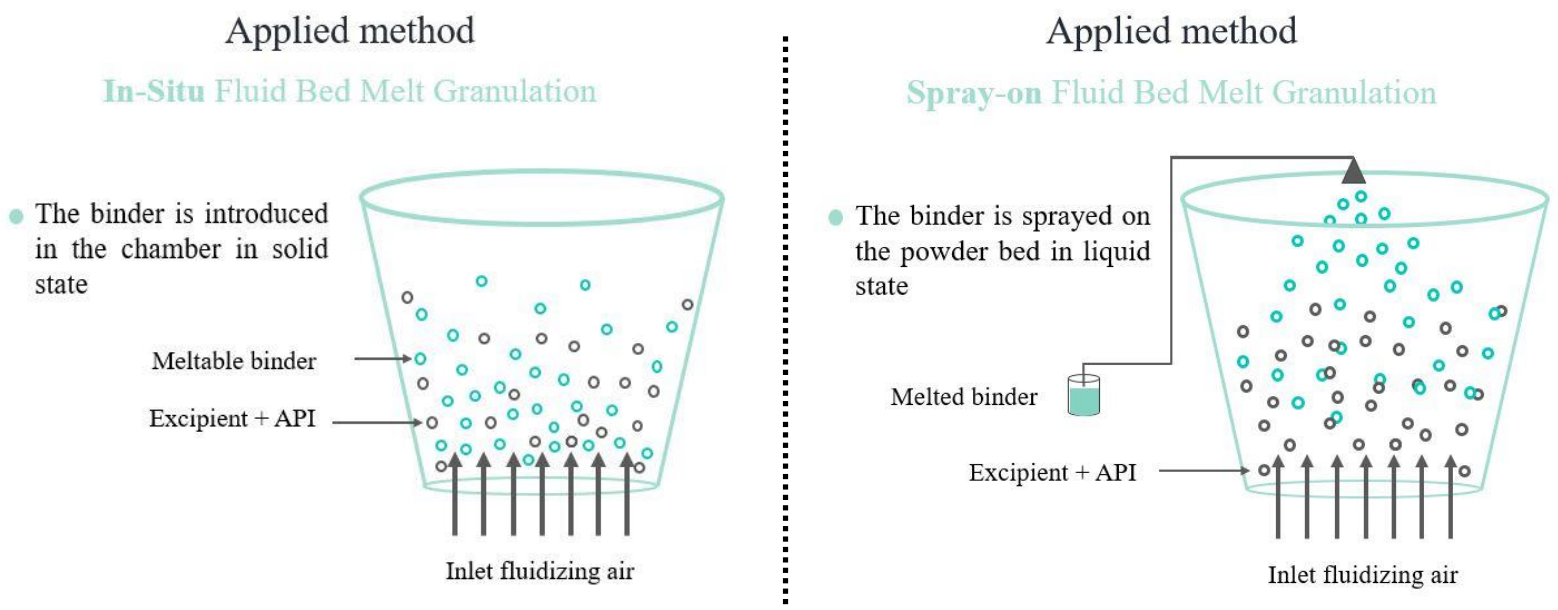

Figure 2: Schematic representation of the in-situ and spray-on FBMG.

However, when the binder droplet is larger than the size of the powder particles, the dominating agglomeration formation mechanism will be the immersion mechanism, where nuclei are formed where the powder particles adhere to the surface of the molten binder and get immersed (Figure 3). With regards to in-situ granulation, studies of the effect of formulation variables on the characteristics of granules by using different types of meltable binders were made [30].

(A)

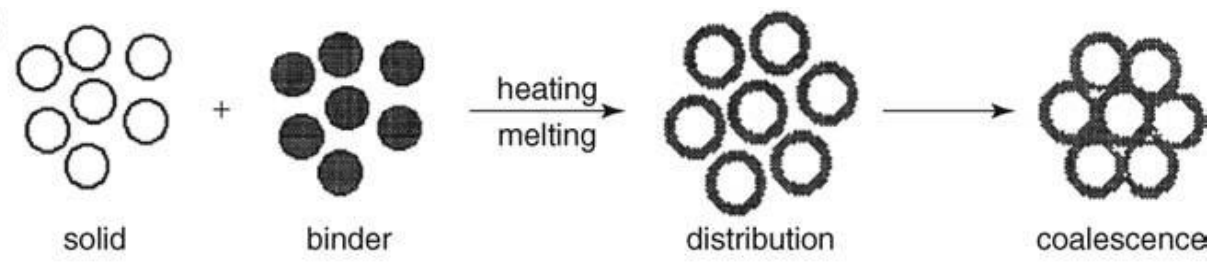

(B)

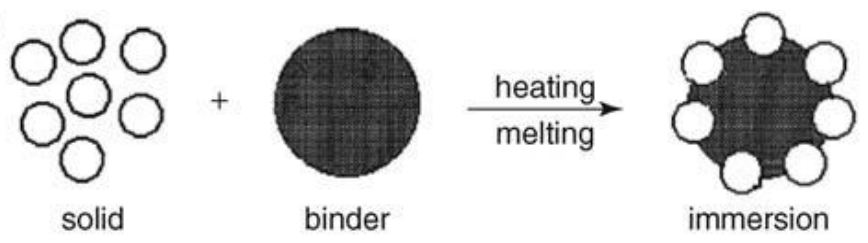

Figure 3: Agglomerate formation in melt granulation. (A) Distribution mechanism and (B) immersion mechanism.

While the initial studies on agglomerate formation and growth mechanism in a fluidized hotmelt granulator were done via off-line analysis of granule structure and size distribution, Walker et al. [31] showed that Raman spectroscopy can be used to gain in-situ information about the structure, density, composition, and nucleation/consolidation of fluidized particles as a function of time. 


\subsection{Granulation processes modelling}

Quality by design approach suggests the establishment of a relevant design space that leads to the development of a controllable and robust manufacturing process, emphasizing that quality should be built into the product during the development phase [32]. Several approaches have been reported to predict and control the growth regime such as population balance, design of experiment and statistical models. Also, the awareness of and the use of artificial intelligence such as rule-based systems, fuzzy logic, genetic algorithm, artificial neural networks (ANNs) in the areas of preformulation, formulations and process development, regulatory affairs, new drug delivery system development, project management, and all other areas of pharmaceutical science increased dramatically [33-37].

\section{Artificial Neural Network}

Neural networks have been used for optimizing formulations for their simplicity of use and potential to provide detailed information. Recently, there has been interest in using ANN for process control. Similarly to the human brain, an ANN predicts events or information based on learned pattern recognition (Figure 4).

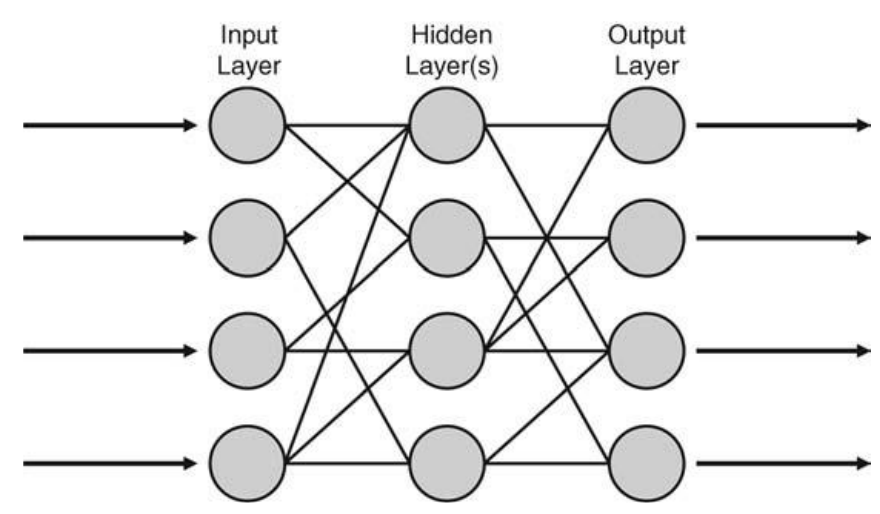

Figure 4: Schematic representation of a feed forward ANN architecture.

ANNs are computer systems developed to mimic the operations of the human brain, by mathematically modelling its neurophysiological structure. In an ANN, the nerve cells are replaced by computational units called neurons, and the strengths of the interconnections are represented by weights [39-41]. Using the process control system, quality assurance results, or energy usage data, an ANN develops supervisory set points for the system. When ANNs and process control systems are used together, they form a product control system. Product control occurs when a system measures defined product attributes in real time, and uses the knowledge to adjust the control system. While the process control system runs the process, the ANN controls the product. 


\section{AIMS}

Real time data acquisition and probe versatility makes monitoring and control of processes possible, but the numerous apparatus, process and product variables has led to fluidized bed granulation not fulfilling its full potential in pharmaceutical production.

For this purpose, a study was conducted where both wet and melt fluid bed granulation processes were controlled by the use of thermal sensors and computational tools to enable the acquisition of temperature maps for the quantification of the volume of the thermal zones inside the bed chamber under different material attributes and process parameters. The goal is the determination of the safe interval of granulation volume fraction for optimum granule size and size distribution by adjusting operating conditions during both FBMG processes.

The main steps in the experiments were as follows:

I. Use of conventional wet and innovative, solvent free melt granulation processes to ascertain their limitations and recognize the common individual variables to propose a novel way for process control.

II. Development of an in-line temperature acquisition tool for insight into the conditions governing during granule growth mechanisms by mapping the operating space and depicting the established thermal zones.

III. Investigation of the predictive capacity of ANN models for designing the optimal conditions for the desired quality attributes of products and estimation of the relative importance of variables controlling the granulation process.

IV. Demonstration of the correlation between granule size distribution and heat transfer zones and wetting volume inside the fluid bed for optimal control space.

V. Demonstration of the qualitative and quantitative use of thermal analysis in characterizing the structure, growth and properties of the final granules as a validation tool.

VI. Proposal of a real time data assessment for a developed and optimized process control system for industrial use. 


\section{MATERIALS}

\subsection{Wet granulation}

In this study, $\alpha$-lactose monohydrate (Biopharm Industry, Algeria) was used as a model filler. An aqueous solution of 5\% w/w of Povidone K30 (Prochima Sigma, Algeria) was used as a binder to granulate the dry lactose powder.

\subsection{Melt granulation}

For the melt granulation, $\alpha$-lactose monohydrate (Ph. Eur. Biopharm, Algeria) was used as a model filler. Two low melting point polymers (polyethylene glycol 2000 and 6000; PEG 2000 and PEG 6000, Fluka, Switzerland) were used as meltable binders. For the API, paracetamol was used as a model drug to study the granule formation, drug uniformity and release (Biopharm, Algeria).

\section{METHODS}

\subsection{Fluidized bed equipment}

Experiments were performed in two different pieces of equipment. A conical fluidized bed built for this study (U.S.T.H.B., Algeria) labelled FBA and a Strea-1 conical fluidized bed (Niro Aeromatic, Bubendorf, Switzerland) labelled FBH. The procedures for both wet and melt granulations are summarized in Table 3.

Table 3: Equipment used and samples prepared for wet and melt granulation processes.

\begin{tabular}{lcccc}
\hline \multirow{2}{*}{ Process } & \multirow{2}{*}{ Wet granulation } & \multicolumn{3}{c}{ Melt granulation } \\
\cline { 3 - 5 } & Placebo & Spray-on & In-situ \\
\hline Sample & With API & Placebo & With API \\
Equipment & FBA & FBA & FBH & FBH \\
\hline
\end{tabular}

\subsubsection{Wet granulation - Description of operating procedures}

The granulation process of spray-on and in-situ techniques is demonstrated in Figure 5.

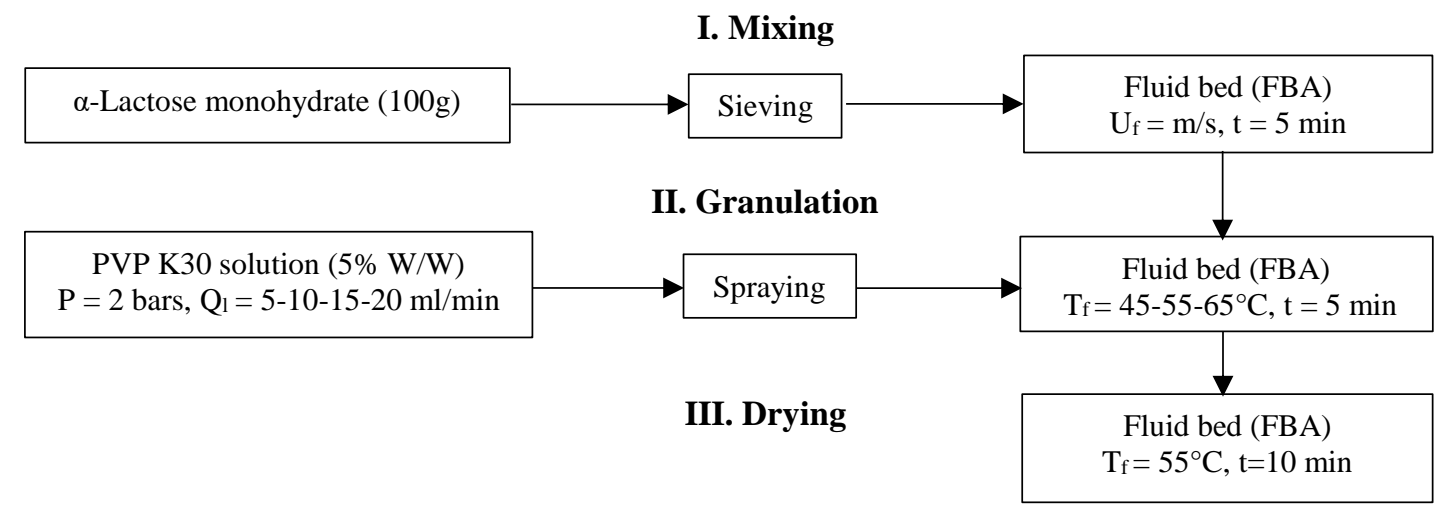

Figure 5: Flow chart of wet granulation - placebo granules. 


\subsubsection{Melt granulation - Description of operating procedures}

The granulation process of spray-on and in-situ techniques is demonstrated in Figure 6, 7, 8 .

\subsubsection{Spray-on FBMG}

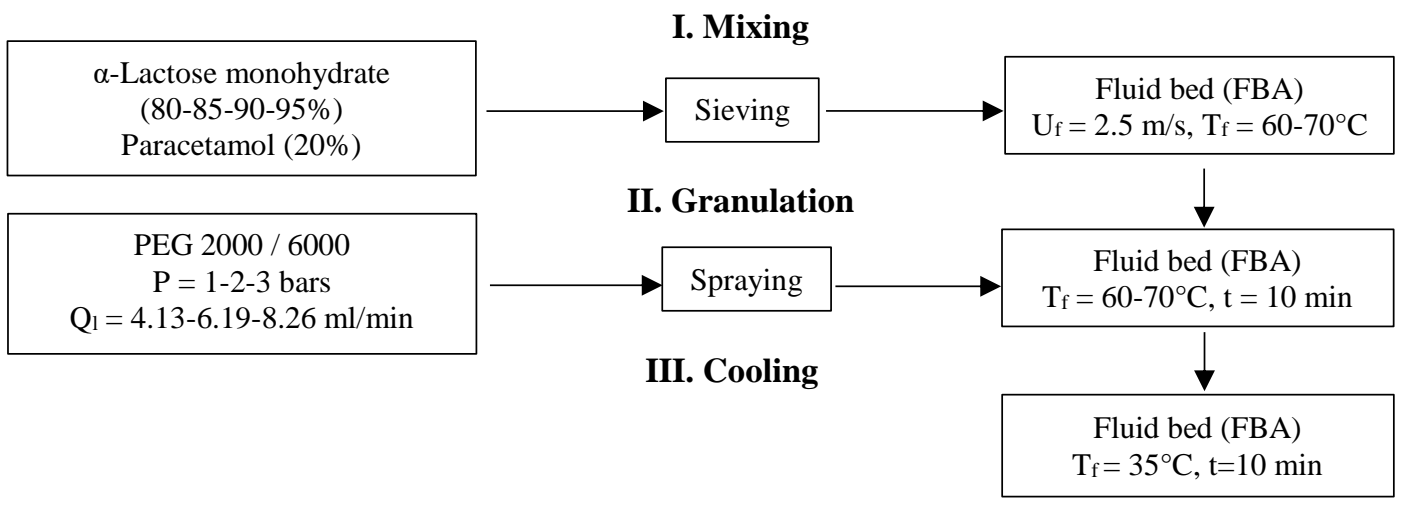

Figure 6: Flow chart of in-situ melt granulation - Granules with API.

\subsubsection{In-situ FBMG - Placebo granules}

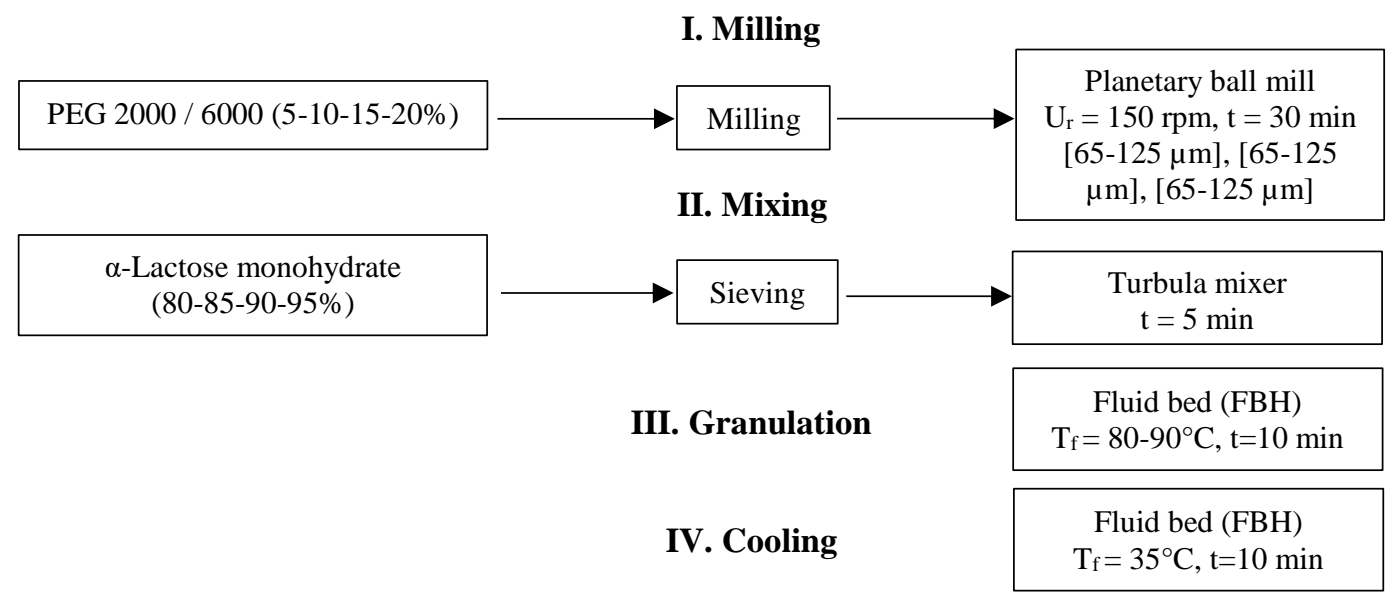

Figure 7: Flow chart of in-situ melt granulation - Placebo granules.

\subsubsection{In-situ FBMG - Granules with API}

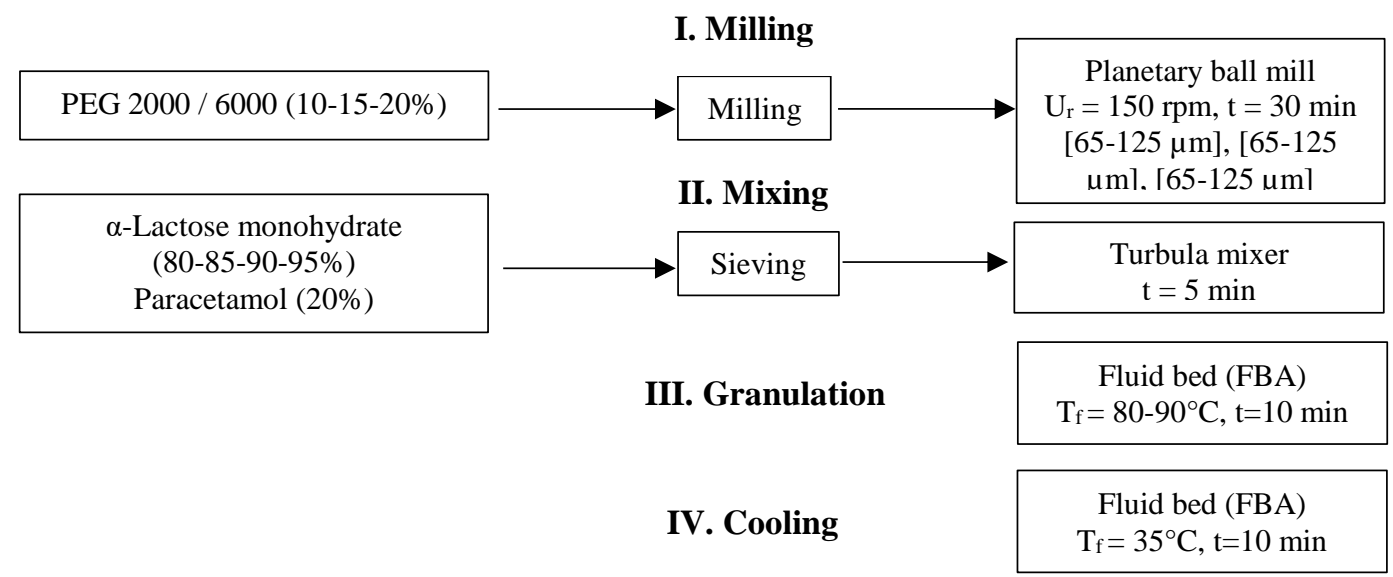

Figure 8: Flow chart of in-situ melt granulation - Granules with API. 


\subsection{Spraying angle and wetting surface determination}

Trials for the determination of the spaying angle were performed in an external measuring setup. The spraying was made using a bi-fluid nozzle held by a steel support with the possibility to vary the distance from the spraying surface. A hydrophobic paper was placed under the nozzle and kept at room temperature $\left(20^{\circ} \mathrm{C}\right)$ for measuring the diameter of the sprayed surface. The spraying angle can be determined using the following equation:

$\tan \left(\frac{\theta}{2}\right)=\frac{D}{2 \cdot H}$

where $\mathrm{D}$ is the mean diameter of the highest and lowest diameters of the sprayed surface on the paper $[\mathrm{cm}], \mathrm{H}$ is the distance between the nozzle and the paper $[\mathrm{cm}]$, and $\theta$ is the spraying angle $\left({ }^{\circ}\right)$.

The wetting surface is influenced by the distance between the nozzle and the fluidized powder bed's height $(\mathrm{cm})$ and the spraying angle $\left(^{\circ}\right)$. The equation for the determination of the wetting surface is as follows:

$S=\pi \cdot H^{2} \cdot\left[\tan \left(\frac{\theta}{2}\right)\right]^{2}$

The wetting surfaces describe the evolution of the wetting volume and the determination of the optimal interval of the applied process variables affecting the wetting volume.

\subsection{Binder droplet size determination}

Binder droplet size was determined through the evaluation of the sprayed surface of the paper by means of image acquisition and analysed using "Image J" software, which enabled the measurement of the diameter of the individual droplets and thus and the droplet size distribution could be analysed.

\subsection{Data acquisition and processing}

The temperatures inside the fluid bed chamber were measured using thermocouples connected to data acquisition hardware (Pico technology, Germany) (Figure 9).

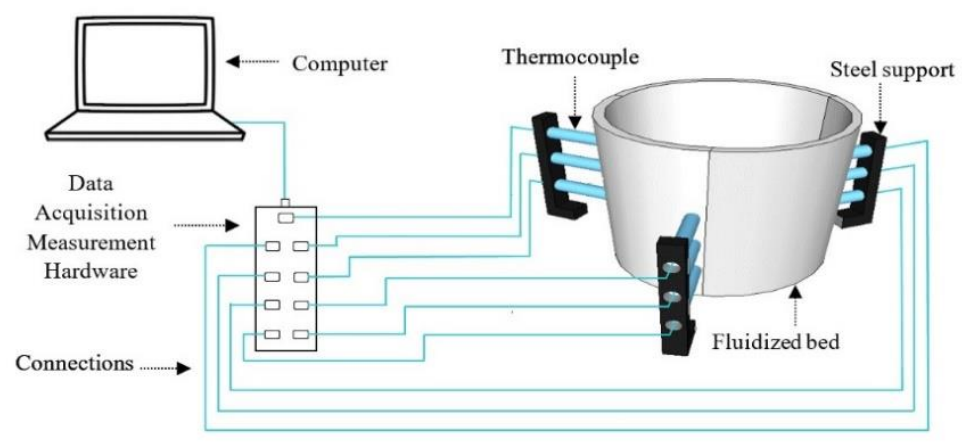

Figure 9: Bed cross-section showing the position and path of the probes. 
All signals were analysed in-line with Pico program (Pico Technology, Germany), allowing the acquisition and recording of temperatures every 1s. Each thermocouple was moved along the $\mathrm{X}$ axis to provide temperature measurement every $1 \mathrm{~cm}$ from the centre to the bed chamber's wall. Measurements were performed for both wet and melt granulation techniques in order to evaluate their differences and characteristics and the potential of each technique (Figure 10).

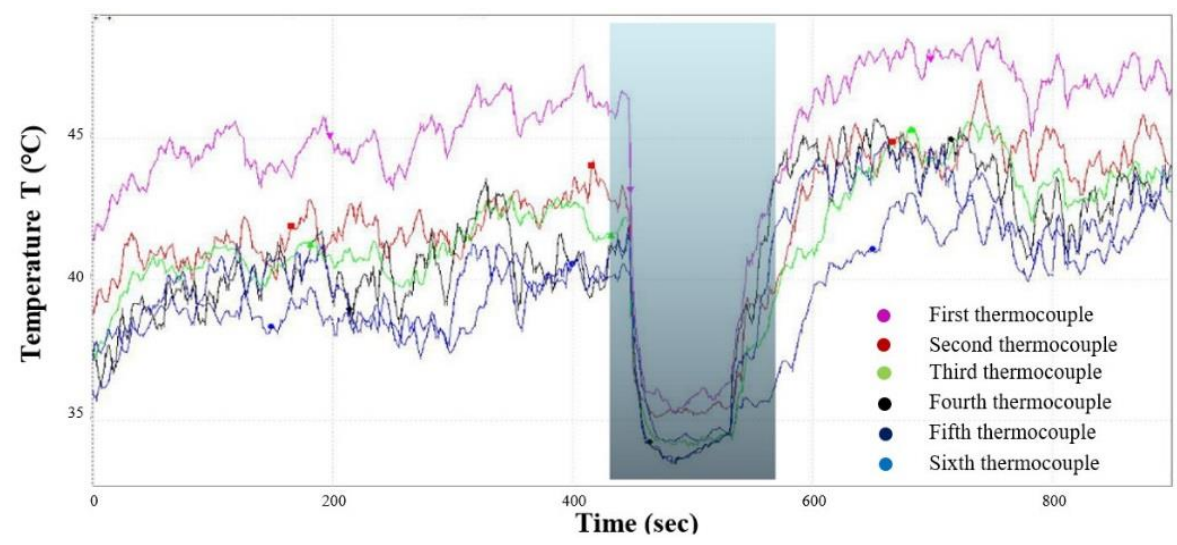

Figure 10: Variation of the measured temperatures as a function of time for different positions from the distribution plate $\left(\mathrm{T}=45^{\circ} \mathrm{C}, \mathrm{QL}=20 \mathrm{ml} / \mathrm{min}, \mathrm{P}=2\right.$ bars, $\left.\mathrm{M}=200 \mathrm{~g}\right)$.

\subsection{Modelling using artificial neural networks}

For the evaluation of the experimental data, a multilayer perceptron neural network was developed. The ANNs toolbox on MATLAB ${ }^{\circledR}\left(\mathrm{R}^{2015 b}\right.$, MathWorks $\left.{ }^{\circledR}\right)$ was used in this study to design the architecture of the models for the wet and melt granulation. The inputs and outputs for both granulation techniques representing the independent and dependent variables, respectively, are summarized in Table 4. The ANN model also provides values of input strengths (weights), which indicate the significance of the effect of each input on the output [39] and predicts the evolution of temperature profiles.

Table 4: Selected inputs and outputs for wet and melt granulation.

\begin{tabular}{lcc}
\hline Process & Inputs & Outputs \\
\hline Wet granulation & $\begin{array}{c}\text { Fluidizing temeprature } \\
\text { Binder spraying rate } \\
\text { X position }\end{array}$ & $\begin{array}{c}\text { Temperature inside the fluid bed } \\
\text { chamber }\end{array}$ \\
& Y position & Granule yield \\
Melt granulation & Binder content & Granule mean diameter \\
(In-situ FBH) & Binder particle size & Coefficient of variation \\
& Binder viscosity grade & Hardness \\
& & Aspect ratio \\
\hline
\end{tabular}


The data was divided into three categories, where $70 \%$ was used for training, $15 \%$ as the test and $15 \%$ as the validation randomly selected from the available database. The input data were combined with random weights as in a linear regression model $(\Sigma)$ and then were transformed through a non-linear function, which enabled the modelling of an ANN. The activation function in the hidden layer and output layer is tangent hyperbolic according to the following equation:

$$
F(n)=\left(\exp ^{n}-\exp ^{-n}\right) /\left(\exp ^{n}+\exp ^{-n}\right)
$$

For this, all inputs must be normalized to facilitate the calculation with the transfer function. The training phase of the neural network is performed using the feedforward back propagation algorithm, the connection weights of the network are adjusted using the delta rule based on the Levenberg-Marquardt method 'TRAINLM'. The selection of the appropriate ANN model is based on its learning ability and predictability, i.e. the model which presents the lowest mean square error (MSE) between the experimental and predicted (output) data. The latter (MSE) is calculated according to the following equation:

$$
M S E=\frac{1}{n} \sum_{m=1}^{n}\left(y_{\text {exp }, m}-y_{\text {pred }, m}\right)^{2}
$$

where $\mathrm{N}$ is the number of data points, $\mathrm{y}_{\text {exp,m }}$ is the experimental response, $\mathrm{y}_{\text {pred,m }}$ is the network prediction and $\mathrm{m}$ is an index of data.

The experimental and predicted data are compared through a linear regression model with the equation $\mathrm{Y}=\mathrm{a}^{*} \mathrm{x}+\mathrm{b}$. The coefficient of correlation indicates the proportion of the variance in the predicted response that is predictable from the experimental input data, according to the following equation:

$$
R^{2}=1-\frac{\sum_{m=1}^{n}\left(y_{\text {exp }, m}-y_{\text {pred }, m}\right)^{2}}{\sum_{m=1}^{n}\left(y_{\text {exp }, m}-\bar{y}_{\text {pred }, m}\right)^{2}}
$$

If the coefficient of determination is equal to 1 , there is perfect correlation between targets and outputs. The simulation of a neural network model in MATLAB ${ }^{\circledR}$ is done with the sim command. The values are denormalized for the comparison with the targeted data.

\subsection{Relative importance of input variables}

The ANN used provides the weights that are coefficients between the artificial neurons. This neural network weight matrix can help assess the relative importance of the various input data (independent variables) on the output (dependent variables) using the equation based on partitioning of connection weights proposed by Garson [41]: 
$I_{j}=\frac{\sum_{m=1}^{m=N h}\left(\left(\left|W_{j m}^{i h}\right| / \sum_{k=1}^{N i}\left|W_{k m}^{i h}\right|\right) \times\left|W_{m n}^{h o}\right|\right)}{\sum_{k=1}^{k=N i}\left\{\sum_{m=1}^{m=N h}\left(\left|W_{k m}^{i h}\right| / \sum_{k=1}^{N i}\left|W_{k m}^{i h}\right|\right) \times\left|W_{m n}^{h o}\right|\right\}}$

where $I_{j}$ is the relative importance of the $j^{\text {th }}$ input variable on output variable, $\mathrm{Ni}$ and $\mathrm{Nh}$ are the number of input and hidden neurons, respectively, Ws are connection weights, the superscripts 'i', 'h' and 'o' refer to input, hidden and output layers, respectively, and subscripts ' $\mathrm{k}$ ', ' $\mathrm{m}$ ' and ' $n$ ' refer to input, hidden and output neurons, respectively.

\subsection{Wetting volume size measurement}

Temperature mapping was made using the 'Contour' function and function 'showText', 'on' for the determination of the isotherms inside the fluid bed chamber to visualise the temperature variation (Figure 11). The difference of temperature between one isotherm and another one is a constant. The smallest distance between two adjacent isotherms limits two distinct thermal zones.

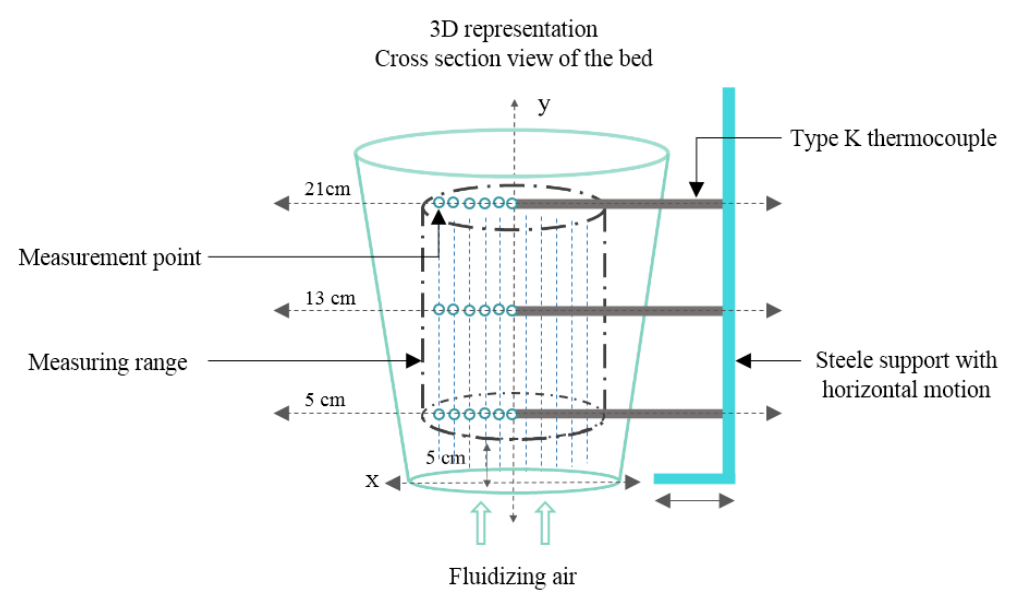

Figure 11: Experimental set-up for the acquisition of temperatures.

The radius between these limiting isotherms from one side of the bed to the other is characterized by the surface of the wetting zone. The determination of the wetting volume of two surfaces for a specific height inside the bed chamber will be similar to the volume of a truncated cone. The equation for the measurement of one sub-volume is as follows:

$V_{s b}=\frac{\pi}{3} \cdot h \cdot\left(R_{1}^{2}+R_{2}^{2}+R_{1}+R_{2}\right)$

where $h$ is the height of one sub-volume $(1 \mathrm{~cm}), R_{1}$ is the upper radius of the thermal surface in the conical bed chamber, and $\mathrm{r}$ is the lower radius of the thermal surface in the conical bed chamber. The total volume of the wetting zone is measured as the sum of all the sub-volumes 
and described as the ratio of the volume of the wetting zone divided by the volume of the conical bed chamber as follows:

$V_{w} \%=\frac{V_{w}}{V_{f b}} .100$

\subsection{Scanning electron microscopy}

The morphology of the agglomerate was investigated by Scanning Electron Microscopy (SEM) (Hitachi 4700, Hitachi Ltd., Tokyo, Japan), granule samples were coated with a gold film and both the whole and the cut granules were deposited on a double-adhesive carbon tape. The SEM images were obtained using a secondary electron detector.

\subsection{Porosity measurement}

The true density $\left(\rho_{\mathrm{a}}\right)$ of each sample was measured using a Quantachrome Helium Multipycnometer (QuantaChrome, USA). The bulk density $\left(\rho_{b}\right)$ was measured from the mass divided by the volume of the samples. Thus porosity was determined.

\subsection{Granule strength measurement and yield}

The breaking hardness was tested for all granules with a special hardness testing apparatus (University of Szeged). Ten parallel measurements were performed. The yield of the process (Y \%) is defined as the ratio of the mass of granules above $125 \mu \mathrm{m}$ and the batch mass.

\subsection{Geometrical parameters}

The shape of granules was evaluated by using a stereomicroscope (Zeiss Stemi 2000-C, Carl Zeiss GmbH, Austria). An Image J. image processing and analysis system (Wayne Rasband National Institutes of Health, USA) was used. 500 granules of each sample were checked.

\subsection{Flowability properties and moisture content}

The flowability test was conducted and the Carr and Hausner index was determined using a volumenometer (Erweka). The samples were analysed off-line for moisture content by loss-ondrying at $105^{\circ} \mathrm{C}$ using a Precisa XM60 moisture analyzer.

\subsection{Particle size analysis}

The particle size distributions of the granules were determined by laser scattering using Malvern (Malvern Mastersizer Scirocco 2000, Worcestershire, UK). Air was used as the dispersion 
medium for the granules from the entrance to the sample cell. Approximately $1 \mathrm{~g}$ of product was loaded into the feeder tray. The particle size distribution was characterized by the $\mathrm{D}(0.5)$ values and the specific surface area.

\subsection{Differential scanning calorimetry}

DSC measurements were performed with a DSC $821^{\mathrm{e}}$ (Mettler-Toledo GmbH, Switzerland) with a temperature interval of 25 to $500^{\circ} \mathrm{C}$, with a heating rate of $10^{\circ} \mathrm{C} \cdot \mathrm{min}^{-1}$ in a nonhermetically sealed $40 \mu 1$ aluminum pan in Argon atmosphere. The curves were normalized to sample size and evaluated with STARe Software.

\subsection{Thermogravimetric analysis-mass spectrometry}

TGA of the samples was carried out with a Mettler-Toledo TGA/DSC1 instrument (MettlerToledo GmbH, Switzerland) coupled to a Thermo Star (Pfeiffer) quadruple mass spectrometer (maximum $300 \mathrm{amu}$ ) for gas analysis. The measurements were carried out in nitrogen atmosphere $\left(70 \mathrm{~cm}^{3} \mathrm{~min}^{-1}\right)$ and aluminium pans $(100 \mu \mathrm{l})$ with a heating rate of $10^{\circ} \mathrm{C} \cdot \mathrm{min}^{-1}$, from 25 to $500^{\circ} \mathrm{C}$. Ions with various mass numbers were determined with the SEM MID measurement module of the Quadera software. The obtained results were exported and then plotted in one coordinate system with the TG curves using the Mettler Toledo Star ${ }^{\mathrm{e}}$ software.

\subsection{Dissolution and compression studies}

Granule size analysis was evaluated using a laser diffraction technique (Mastersizer S, Malvern Instruments Ltd., Worcestershire, UK) where the analysis was performed in dry mode. Granules were compressed using an eccentric tablet machine (Deltalab) at a compression force of $\mathrm{kN}$, using round-faced punches with a diameter of $9 \mathrm{~mm}$. The tablet weight was set to $500 \mathrm{mg}$. The hardness of granules was measured using a durometer (Erweka), which gave us the diameter, height and hardness of tablets.

The dissolution trials were performed in a paddle apparatus (Erweka, Germany) at $50 \mathrm{rpm}$ using $900 \mathrm{ml}$ of phosphate buffer of $\mathrm{pH} 5.8$ as a dissolution medium set at a temperature of $37^{\circ} \mathrm{C}$. Samples were withdrawn every $5 \mathrm{~min}$ and then diluted and analyzed by UV spectrometry (Shimadzu, Japan) at $243 \mathrm{~nm}$. 


\section{RESULTS AND DISCUSSION}

\subsection{Wet granulation}

\subsubsection{Characterisation and architecture of the ANN}

The ANN model in this research was generated from the remaining $70 \%$ of the temperature data. The factors for the input layer were the positions from the center axis of the bed (X), the distances from the distribution plate $(\mathrm{Y})$, the inlet air temperature $(\mathrm{Tm})$ and the liquid flow rate (Q1). The value for the output layer was the predicted temperature $(\mathrm{T})$. The input data points were combined with random weights as in a linear regression model $(\Sigma)$ and were then transformed through the non-linear function, which enables the non-linear modelling of an ANN model. After the analyses of the obtained results for each configuration, it showed that the network with two hidden layers and twelve neurons in each hidden layer (Figure 12) presented the smallest validation mean square error (VMSE) of 1.4·10-3.

All results obtained from experimental and predicted studies and residuals of the ANN model are given in Figure 13a and b. The $\mathrm{R}^{2}$ is of 0.995 .

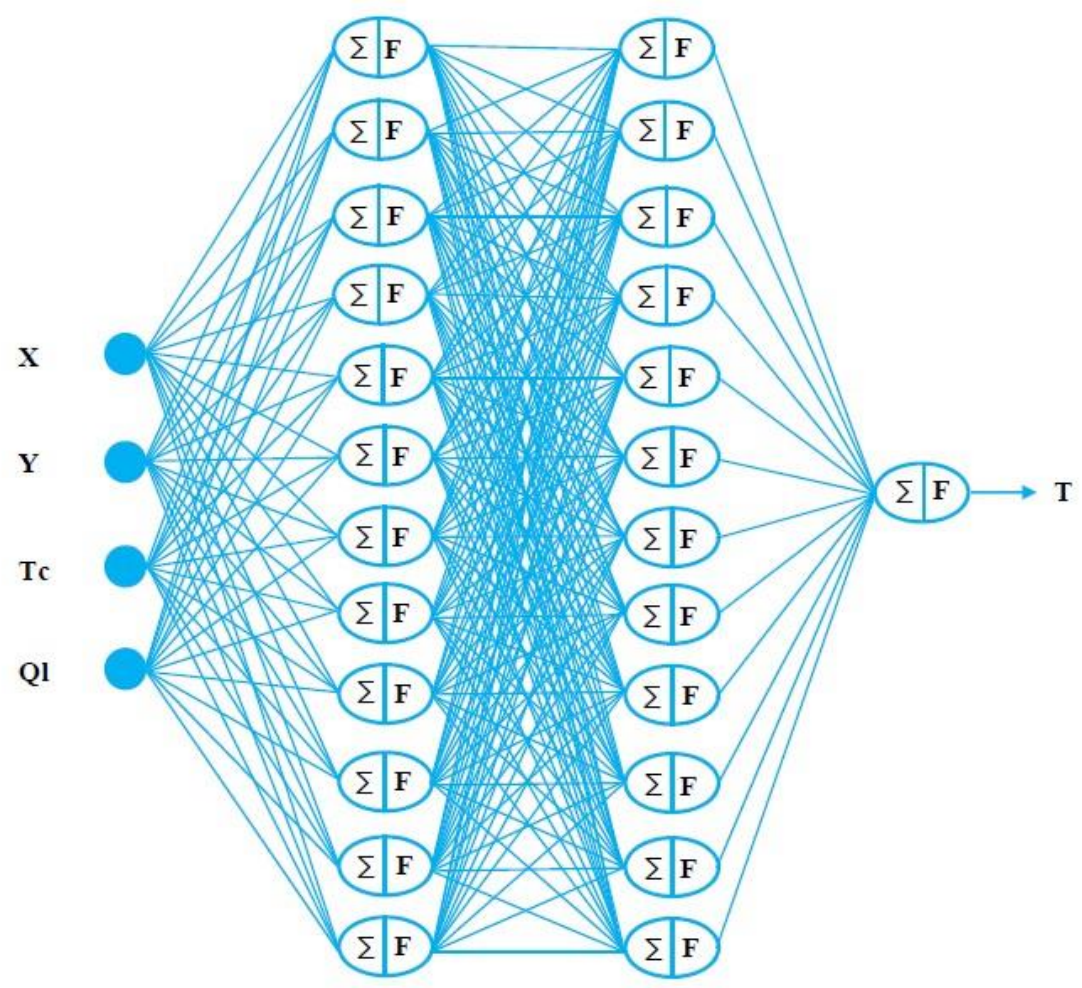

Figure 12: Schematic representation of the used ANN architecture.

The result of the testing phase shows that the ANN model is capable of generalizing between input and output variables with reasonable predictions and low error. 


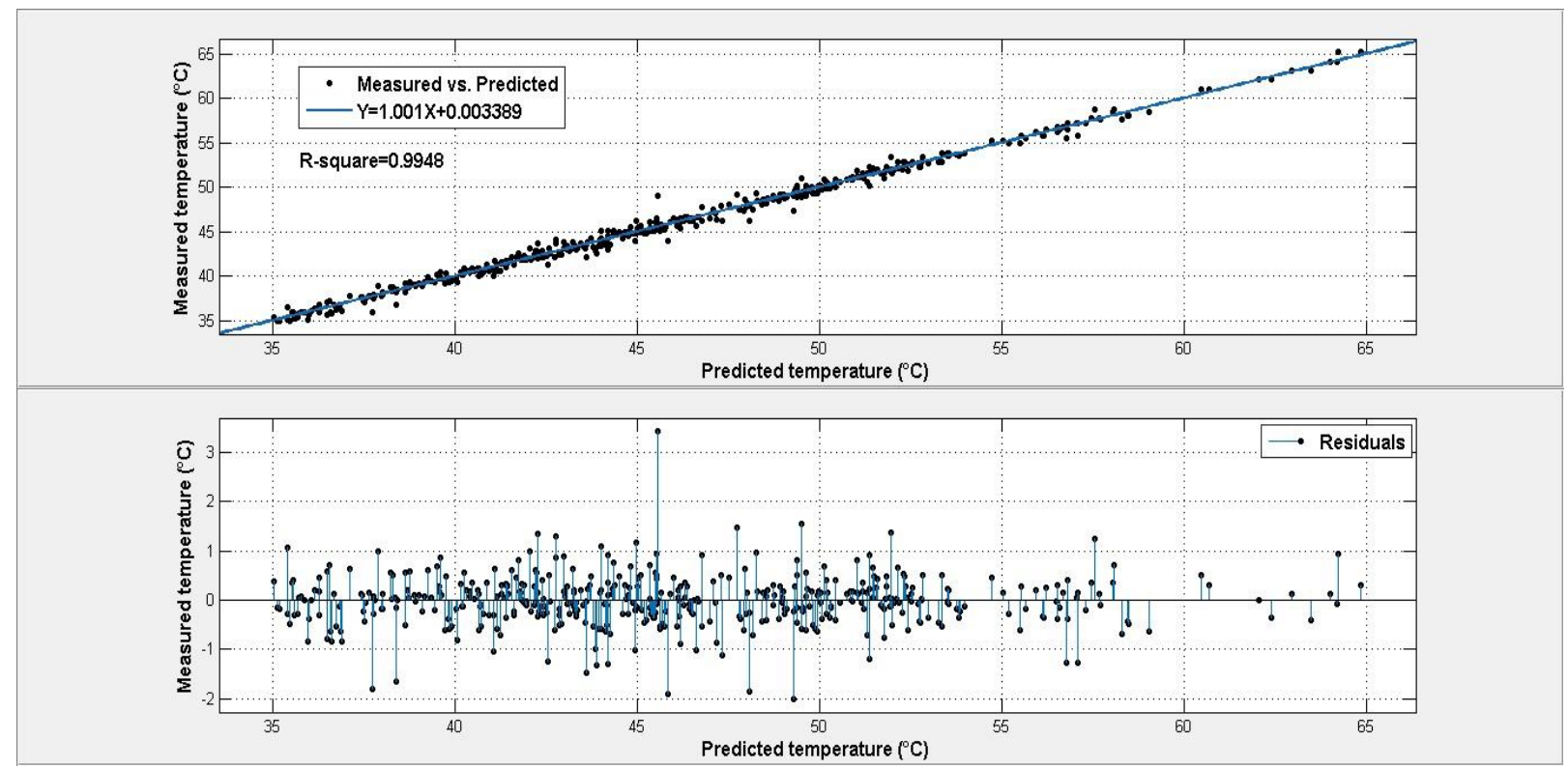

Figure 13: Validation of the ANN model: a) Predicted vs. measured values of temperature based on the artificial neural network model, b) Estimation of the residuals of measured vs predicted temperatures.

\subsubsection{Shapes of predicted temperature profiles and particle patterns}

The predicted temperature profiles from the granulation trails revealed the presence of a low temperature region located below the spraying nozzle, extending toward the walls and air distributor plate (Figs. 14 and 15). Temperatures then rose dramatically away from the center axis leading to increasingly close isotherms, which implies important temperature gradients. The latter are inversely proportional to the increase of the liquid feed rate. These temperature gradients correspond to the transition where the heat and mass transfer occurs due to the collision between the warm entering air and the cold spraying liquid. In the outer part of the bed, the predicted temperatures seemed to present a constant value between the top and bottom part of the measurement region, extending toward the bed's walls. The isotherms are getting further apart describing a stationary state, which indicates a second predominant zone.

The developed ANN model allowed a precise detection of the temperature variations and was specific for each operating condition. Hence, the identification and determination of thermal zones became possible. The first zone is near the spraying nozzle where dry solid particles get sprayed and wet by the binder liquid corresponding to the wetting zone, the second zone extends toward the bed's walls where the sprayed particles are dried and solidify to form liquid bridges and corresponds to the isothermal zone. The third zone is located near the air distribution plate 
where an important contact zone between the two hot and cold fluids is set corresponding to the heat transfer zone.

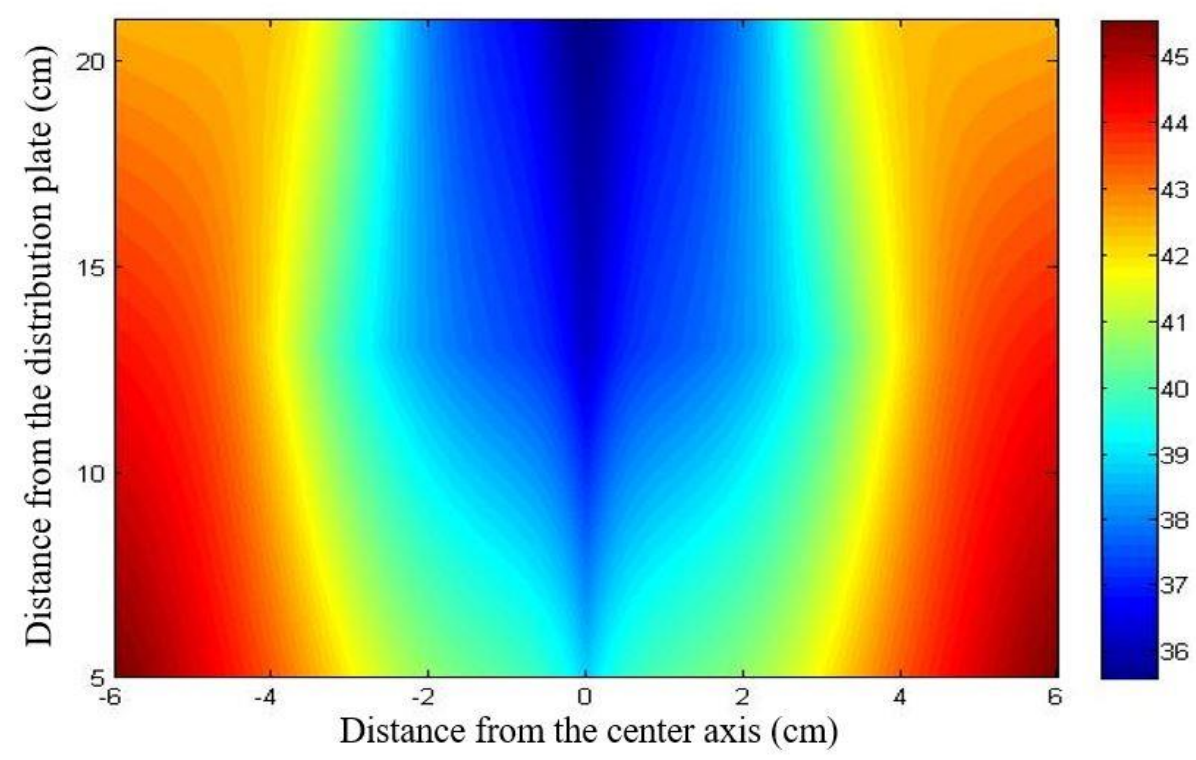

Figure 14: Bell shaped temperature mapping of predicted values by the ANN toolbox in a fluidized bed of lactose monohydrate in the presence of a wetting liquid spray $\left(\mathrm{T}=45^{\circ} \mathrm{C}\right.$,

$$
\mathrm{QL}=20 \mathrm{ml} / \mathrm{min}, \mathrm{P}=2 \text { bars, } \mathrm{M}=200 \mathrm{~g} \text { ). }
$$

The color map of the bed's diametric plane provides a clear description of the temperature intensity differences in all regions. The profiles obtained revealed that the outline of the low temperature zones is represented with a clear yellow band. These outlines depend on the granulation conditions and follow two main shapes. Both shapes differ in their expansion path toward the air distribution grid because of the particle circulation in the fluidized bed. Indeed, the outline of the low temperature zone formed a "bell" shape (Figure 14). It was observed for high liquid spraying rates and low inlet air temperature corresponding to an upward movement of the particles at the sides, near the container walls, and downwards through the center after wetting by the liquid droplets.

This circulation pattern is due to the binder flow rate overpowering the inlet air stream forcing the dried particles to deviate toward the bed walls, which makes it propitious to control agglomeration as this pattern favors an upward motion of the sufficiently dry granules which will not stick to the bed's walls.

The second shape is called "funnel" shape (Figure 15). It was observed for the lower liquid flow rate $(5 \mathrm{ml} / \mathrm{min})$ and both high and low inlet air temperatures. Particles would rise up in the 
center to the upper surface of the bed, get sprayed in the wetting zone by the binder solution droplets and then fall back to the bottom part along the bed's walls. In this case, the risk of insufficiently dried particles is very high and may cause them to stick to the walls, making it hard to control the agglomeration.

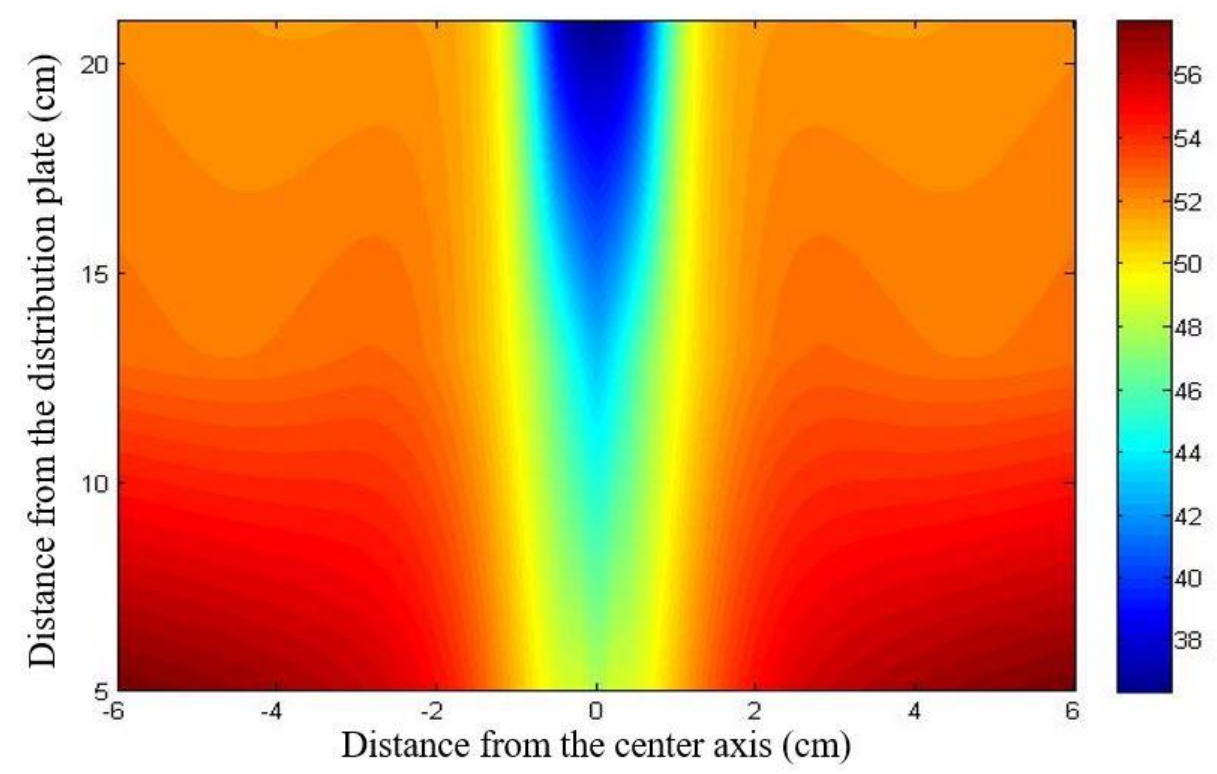

Figure 15: Funnel-shaped temperature mapping of predicted values by the ANN toolbox in a fluidized bed of lactose monohydrate in the presence of a wetting liquid spray $\left(\mathrm{T}=45^{\circ} \mathrm{C}\right.$,

$$
\mathrm{QL}=5 \mathrm{ml} / \mathrm{min}, \mathrm{P}=2 \text { bars, } \mathrm{M}=200 \mathrm{~g} \text { ). }
$$

These predicted profile shapes can be used to determine the proper distribution profile for a better controlled agglomeration process. Its boundaries can be delimited using the outline of the thermal zones where the gradient of temperature between two adjacent predicted temperatures is the smallest, as they represent a transition between the different thermal conditions and are specific for each operating condition.

\subsubsection{Particle growth and temperature profiles}

Particles can agglomerate only if they penetrate the wetting zone, where their surface is wetted by liquid droplets forming liquid bridges when they collide. The size of this zone and the transfer rate of particles to this portion of the fluidized bed are therefore very important factors for particle growth as they influence their final properties. In order to prove the connection between the temperature profiles and the critical quality attributes of the fluidized bed granulation product, tests were conducted on the final granules and the results are summarized in Table 5. 
Table 5: Influence of process variables on the medium particle size $\left(d_{50}\right)$, moisture content, Carr index, Hausner index and flowability (T: fluidizing inlet air temperature, $\mathrm{Q}_{\mathrm{L}}$ : liquid feed rate, $M=200 g, P=2$ bars).

\begin{tabular}{cccccccc}
\hline trial & $\mathbf{T}\left({ }^{\circ} \mathbf{C}\right)$ & $\begin{array}{c}\mathbf{Q}_{\mathbf{L}} \\
(\mathbf{m l} / \mathbf{m i n})\end{array}$ & $\begin{array}{c}\text { Particle size } \\
(\boldsymbol{\mu m})\end{array}$ & $\begin{array}{c}\text { Moisture } \\
\text { content }(\boldsymbol{\%})\end{array}$ & $\begin{array}{c}\text { Carr } \\
\text { index }\end{array}$ & $\begin{array}{c}\text { Hausner } \\
\text { ratio }\end{array}$ & $\begin{array}{c}\text { Flowability } \\
(\mathbf{s})\end{array}$ \\
\hline 1 & 45 & 5 & 846.317 & 0.46 & 0.16 & 1.19 & 13.96 \\
2 & 45 & 10 & 955.521 & 0.91 & 0.16 & 1.19 & 16.44 \\
3 & 45 & 15 & 1840.796 & 1.98 & 0.18 & 1.21 & 20.45 \\
4 & 45 & 20 & 2011.256 & 2.73 & 0.20 & 1.24 & $\infty$ \\
5 & 55 & 5 & 569.468 & 0.39 & 0.12 & 1.15 & 12.45 \\
6 & 55 & 10 & 595.341 & 0.66 & 0.13 & 1.17 & 15.53 \\
7 & 55 & 15 & 1313.561 & 1.84 & 0.15 & 1.19 & 16.98 \\
8 & 55 & 20 & 1545.014 & 2.42 & 0.18 & 1.21 & 19.64 \\
9 & 65 & 5 & 380.979 & 0.30 & 0.14 & 0.16 & 11.60 \\
10 & 65 & 10 & 499.487 & 0.52 & 0.15 & 0.17 & 13.63 \\
11 & 65 & 15 & 964.932 & 1.65 & 0.15 & 0.18 & 15.73 \\
12 & 65 & 20 & 1099.132 & 2.17 & 0.16 & 0.19 & 18.38 \\
\hline
\end{tabular}

The inlet air temperature determines the air capacity to solidify the liquid bridges. For low inlet temperatures $\left(45^{\circ} \mathrm{C}\right)$, the predicted volume of the wetting zone was large compared to the high inlet temperature conditions $\left(65^{\circ} \mathrm{C}\right)$, where temperature maps show a narrow profile due to fast liquid evaporation. These predictions are in accordance with the properties of granules as for low inlet air temperature they show higher mean particle size and moisture content (trials 1, 5, 9). Indeed, agglomeration occurs if enough liquid droplets reach the surface of the particles before evaporating, which enables them to bind with other wetted particles to result in bigger agglomerates. And the lower the temperatures, the bigger the particles' humidity content for less effective drying conditions.

The liquid feed rate highly influences both the agglomeration and drying conditions within the fluidized bed. When it was increased from 5 to $15 \mathrm{ml} / \mathrm{min}$, the median particle size increased from 846.32 to $2011.23 \mu \mathrm{m}$ (trials 1,4 ) due to an increase in the liquid droplets' diameter and the amount of liquid to evaporate, which also led to an increase in the final moisture content from 0.46 .to $2.73 \%$ and in the size of the wetting zone (Figures 14 and 15 ).

The Carr index and Hausner ratio values are under 0.21 and 1.25 , respectively, corresponding to the powder's good ability for compaction and flowability. Trial 4 shows the highest values, which indicates poor flowability caused by overwetted particles due to the large wetting zone and insufficient drying. The powder flow times increase with the increase of the median 
diameter of the particles due to flowability depending on particle shape. This results in defining particle size and moisture content as the critical quality attributes of the final granules, demonstrating the link between the characteristics of temperature profiles, critical process parameters and critical quality attributes.

\section{Summary}

Measurements of temperature under PAT in a conical fluidized bed served as a database for a developed artificial neural network model. The model showed a very good predicting ability determining the influence of process conditions on the temperature profiles. Their delimited boundaries using isotherms provide information about the hydrodynamic and thermodynamic conditions inside the bed, indicating a distinct connection between the established temperature profiles and the quality attributes of the final particles.

\subsection{Melt Granulation}

\subsubsection{In-situ FBMG - Placebo granules}

\subsubsection{Model architecture and simulation}

The database used for the training of the ANN model is the result of the quality attributes of the granule samples obtained from the size and size distribution, hardness and shape measurements. The values of these measurements are summarized in Table 6 .

The architecture was tested 20 times with different initializations of the weights to take into account the probability of converging to local minima for different numbers of hidden neurons in a single layer ANN. The lowest MSE is 0.01562 for 5 hidden neurons with an $\mathrm{R}=0.99$.

A performance evaluation of the limitations and capabilities of multilayer feedforward networks for the modelling of granule attributes was made. Network learning parameters and architectures were investigated for the determination of the best architecture and are summarized in Table 7.

The selected optimal, one hidden layer with 5-neuron architecture ANN model was trained using the feed-forward back propagation algorithm. The weights and bias selected are those corresponding to the minimum of the validation error and the highest coefficient of determination of the neural network [30]. 
Table 6: Responses of granule samples according to the process conditions.

\begin{tabular}{|c|c|c|c|c|c|c|c|c|c|}
\hline Sample & V.G. & $\mathrm{C}(\%)$ & P.S. $(\mu \mathrm{m})$ & $\mathrm{T}\left({ }^{\circ} \mathrm{C}\right)$ & $\mathrm{Y}(\%)$ & $\mathrm{D}_{50}(\mu \mathrm{m})$ & C.V. & $\mathrm{H}(\mathrm{N})$ & A.R. \\
\hline S01 & 2000 & 5 & $125-250$ & 60 & 42 & 110.236 & 70.845 & 0.37 & 1.723 \\
\hline S02 & 2000 & 10 & $125-250$ & 60 & 54 & 128.757 & 61.546 & 0.48 & 1.704 \\
\hline S03 & 2000 & 15 & $125-250$ & 60 & 61 & 213.654 & 57.005 & 0.56 & 1.654 \\
\hline S04 & 2000 & 20 & $125-250$ & 60 & 74 & 366.142 & 52.845 & 0.64 & 1.561 \\
\hline S05 & 2000 & 5 & $250-500$ & 60 & 59 & 423.426 & 83.454 & 0.44 & 1.639 \\
\hline S06 & 2000 & 10 & $250-500$ & 60 & 68 & 577.551 & 76.545 & 0.58 & 1.602 \\
\hline S07 & 2000 & 15 & $250-500$ & 60 & 75 & 670.795 & 69.616 & 0.67 & 1.554 \\
\hline S08 & 2000 & 20 & $250-500$ & 60 & 88 & 732.263 & 64.854 & 0.83 & 1.503 \\
\hline S09 & 2000 & 5 & $500-710$ & 60 & 72 & 534.869 & 95.639 & 0.78 & 1.287 \\
\hline S10 & 2000 & 10 & $500-710$ & 60 & 83 & 594.238 & 88.907 & 0.84 & 1.189 \\
\hline S11 & 2000 & 15 & $500-710$ & 60 & 91 & 661.114 & 79.789 & 0.92 & 1.119 \\
\hline S12 & 2000 & 20 & $500-710$ & 60 & 92 & 786.267 & 73.562 & 1.04 & 1.103 \\
\hline S13 & 2000 & 5 & $710-900$ & 60 & 84 & 716.576 & 103.845 & 1.16 & 1.303 \\
\hline S14 & 2000 & 10 & $710-900$ & 60 & 90 & 789.531 & 94.201 & 1.34 & 1.223 \\
\hline S15 & 2000 & 15 & $710-900$ & 60 & 92 & 814.019 & 83.722 & 1.58 & 1.184 \\
\hline S16 & 2000 & 20 & $710-900$ & 60 & 93 & 863.863 & 78.368 & 1.90 & 1.112 \\
\hline S17 & 2000 & 5 & $900-1120$ & 60 & 88 & 791.567 & 110.548 & 1.72 & 1.418 \\
\hline S18 & 2000 & 10 & $900-1120$ & 60 & 91 & 832.736 & 97.235 & 1.87 & 1.381 \\
\hline S19 & 2000 & 15 & $900-1120$ & 60 & 90 & 856.232 & 88.963 & 2.11 & 1.306 \\
\hline S20 & 2000 & 20 & $900-1120$ & 60 & 94 & 896.638 & 80.864 & 2.36 & 1.272 \\
\hline $\mathrm{S} 21$ & 6000 & 5 & $63-125$ & 70 & 44 & 95.400 & 59.709 & 0.31 & 1.662 \\
\hline $\mathrm{S} 22$ & 6000 & 10 & $63-125$ & 70 & 49 & 112.247 & 52.007 & 0.36 & 1.532 \\
\hline $\mathrm{S} 23$ & 6000 & 15 & $63-125$ & 70 & 54 & 139.605 & 45.081 & 0.42 & 1.591 \\
\hline $\mathrm{S} 24$ & 6000 & 20 & $63-125$ & 70 & 67 & 205.759 & 36.573 & 0.48 & 1.652 \\
\hline $\mathrm{S} 25$ & 6000 & 5 & $125-250$ & 70 & 50 & 120.956 & 88.545 & 0.40 & 1.336 \\
\hline S26 & 6000 & 10 & $125-250$ & 70 & 62 & 181.912 & 75.399 & 0.52 & 1.315 \\
\hline $\mathrm{S} 27$ & 6000 & 15 & $125-250$ & 70 & 77 & 259.451 & 63.636 & 0.60 & 1.286 \\
\hline $\mathrm{S} 28$ & 6000 & 20 & $125-250$ & 70 & 90 & 387.156 & 54.589 & 0.78 & 1.252 \\
\hline S29 & 6000 & 5 & $250-500$ & 70 & 77 & 448.569 & 113.749 & 0.91 & 1.486 \\
\hline $\mathrm{S} 30$ & 6000 & 10 & $250-500$ & 70 & 86 & 529.357 & 90.310 & 1.04 & 1.413 \\
\hline S31 & 6000 & 15 & $250-500$ & 70 & 89 & 579.609 & 73.934 & 1.13 & 1.268 \\
\hline $\mathrm{S} 32$ & 6000 & 20 & $250-500$ & 70 & 91 & 659.143 & 63.987 & 1.22 & 1.213 \\
\hline S33 & 6000 & 5 & $500-700$ & 70 & 84 & 687.241 & 129.087 & 1.15 & 1.481 \\
\hline S34 & 6000 & 10 & $500-710$ & 70 & 86 & 729.260 & 96.419 & 1.37 & 1.344 \\
\hline S35 & 6000 & 15 & $500-710$ & 70 & 90 & 791.245 & 79.218 & 1.68 & 1.316 \\
\hline S36 & 6000 & 20 & $500-710$ & 70 & 93 & 830.459 & 68.145 & 1.86 & 1.238 \\
\hline S37 & 6000 & 5 & $710-900$ & 70 & 85 & 783.548 & 133.128 & 2.07 & 1.403 \\
\hline S38 & 6000 & 10 & $710-900$ & 70 & 92 & 814.965 & 100.235 & 2.13 & 1.391 \\
\hline S39 & 6000 & 15 & $710-900$ & 70 & 94 & 859.861 & 84.169 & 2.32 & 1.357 \\
\hline S40 & 6000 & 20 & $710-900$ & 70 & 95 & 886.125 & 72.654 & 2.65 & 1.348 \\
\hline
\end{tabular}


Table 7: Variation of the Mean Square Error: MSE, epoch and the coefficient of correlation for the training and testing of the model as a function of the number of neurons.

\begin{tabular}{lllll}
\hline \multirow{2}{*}{ Number of neurons } & \multirow{2}{*}{ MSE } & Epoch & \multicolumn{2}{c}{ Coefficient of correlation } \\
\cline { 4 - 5 } & & 27 & training & testing \\
\hline 01 neuron & 0.24031 & 10 & 0.63093 & 0.63293 \\
02 neurons & 0.06958 & 65 & 0.85742 & 0.85791 \\
03 neurons & 0.03837 & 01 & 0.96977 & 0.94223 \\
04 neurons & 0.02633 & $\mathbf{1 6}$ & 0.92888 & 0.93924 \\
$\mathbf{0 5}$ neurons & $\mathbf{0 . 0 1 5 6 2}$ & 19 & 0.98706 & $\mathbf{0 . 9 8 6 3 5}$ \\
06 neurons & 0.01928 & 03 & 0.98701 & 0.98531 \\
07 neurons & 0.01777 & 19 & 0.98101 & 0.97534 \\
08 neurons & 0.01757 & 07 & 0.98456 & 0.97531 \\
09 neurons & 0.01817 & 18 & 0.98542 & 0.97635 \\
10 neurons & 0.02015 & & 0.94853 & 0.94434 \\
\hline
\end{tabular}

The structure of the multilayer perceptron neural network used in this study and its connections between layers are shown in Figure 16.

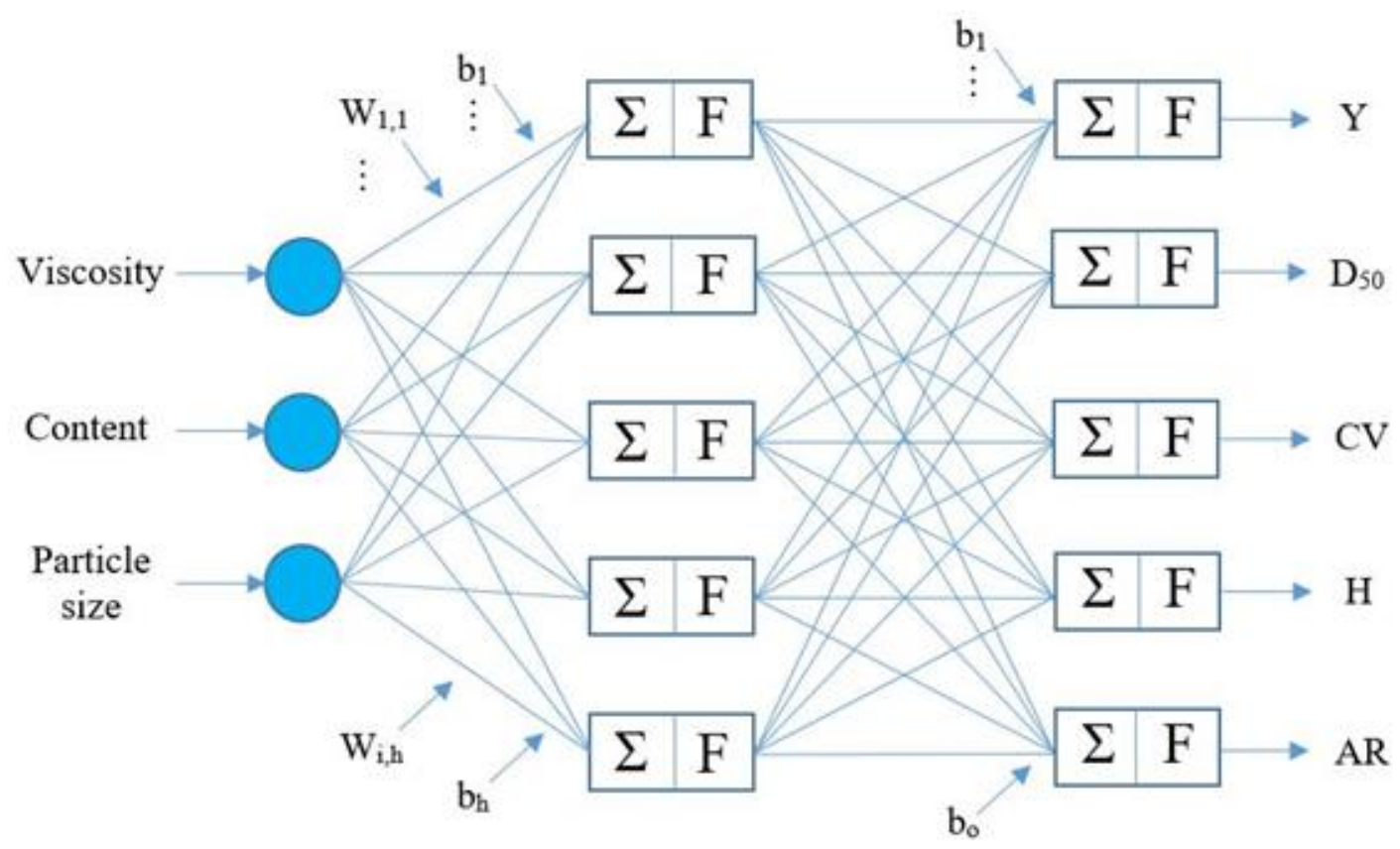

Figure 16: Schematic diagram of the ANN model architecture.

Figure 17 shows the parity plot with the $95 \%$ CI of the five predicted outputs of the neural network model compared to the measured experimental data. The results show that almost all data points are within the interval of confidence. Hence, this model was found to be efficient in predicting and simulating the granule properties. 

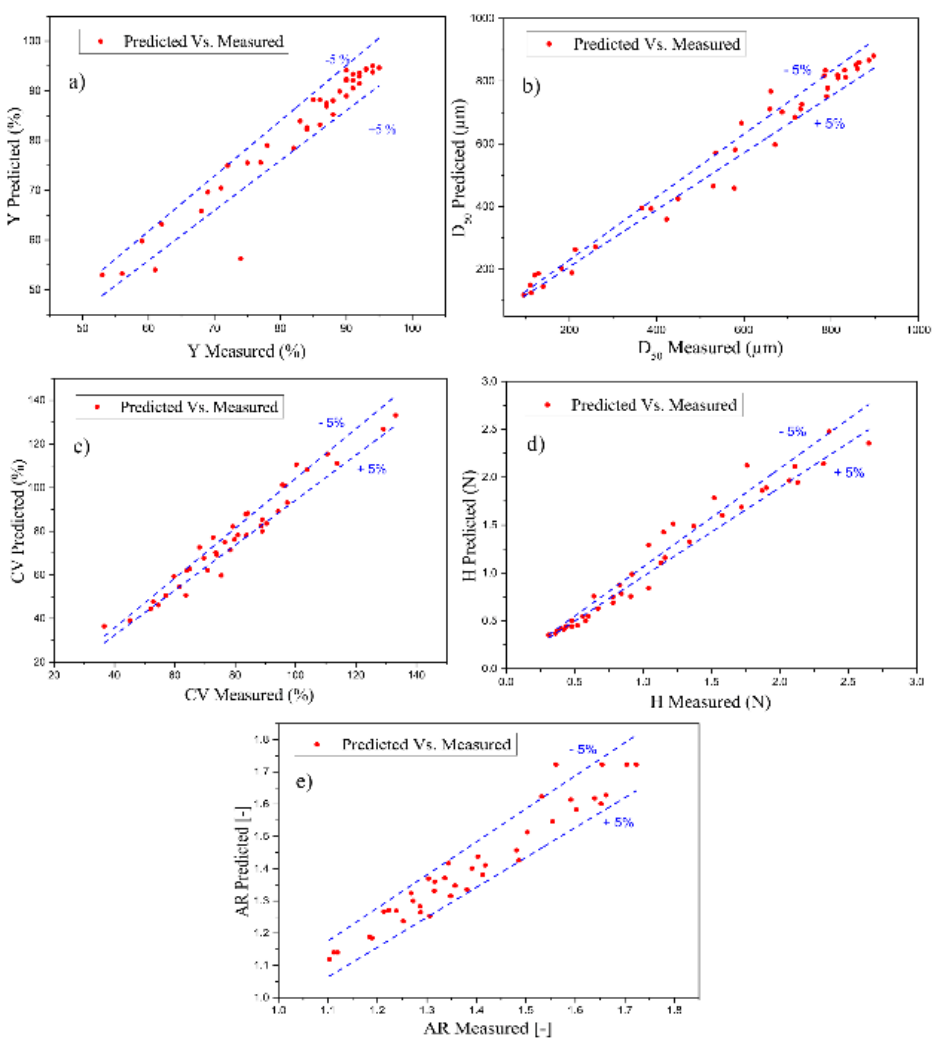

Figure 17: Parity plot with the $95 \%$ CI of the five predicted outputs versus the measured experimental data.

The influence of each parameter on the variable studied has been assessed in Table 8 .

Table 8: Weights of the designed ANN model and the relative importance (\%) of the inputs (Viscosity grade: V (grade), Content: C (\%) and Particle Size: S $(\mu \mathrm{m})$ ) on the outputs (Yield: Y (\%), Mean Diameter: $\mathrm{D}_{50}(\mu \mathrm{m})$, Coefficient of Variation: CV (\%), Hardness: H $(\mathrm{N})$, Aspect Ratio: AR, Relative Importance: R.I.).

\begin{tabular}{|c|c|c|c|c|c|c|c|c|}
\hline \multirow{2}{*}{$\begin{array}{l}\text { Hidden } \\
\text { neurons }\end{array}$} & \multicolumn{8}{|l|}{ Weights } \\
\hline & V (grade) & $\mathrm{C}(\%)$ & $S(\mu \mathrm{m})$ & $\mathrm{Y}(\%)$ & $\mathrm{D}_{50}(\mu \mathrm{m})$ & $\mathrm{CV}(\%)$ & $\mathrm{H}(\mathrm{N})$ & AR \\
\hline Hidden 1 & 0.32 & -0.76 & 0.39 & 0.75 & 0.49 & -3.99 & 1.07 & 0.05 \\
\hline Hidden 2 & 2.20 & 0.017 & -1.08 & 1.72 & -2.65 & -3.02 & 0.48 & 0.04 \\
\hline Hidden 3 & -0.02 & -0.22 & -0.19 & 3.06 & -1.79 & 0.42 & 0.27 & 0.09 \\
\hline Hidden 4 & 1.79 & -0.08 & 5.59 & 1.49 & -2.41 & -2.81 & -0.09 & 0.55 \\
\hline Hidden 5 & 2.91 & -0.34 & 1.29 & 0.33 & -2.23 & 1.48 & -4.19 & 1.09 \\
\hline R. I. (\%) & 36 & 22 & 42 & - & - & - & - & - \\
\hline
\end{tabular}

The initial particle size of the binder is the most significant factor affecting the granulation growth mechanism for FBMG as found in literature data [11, 40], followed by the binder viscosity grade and the binder content. 


\subsubsection{Agglomerate growth mechanism and morphology}

The investigation of granule morphology of the agglomerates is shown in Figure 18. For low particle size binder, granules are low in diameter (Figure 18a) with irregular morphology indicating agglomerates of smaller sub-granules. The recrystallization of melted PEG after cooling can be seen on the surface of lactose and on the solid bridges that coalesce nuclei together (Figure 18b).
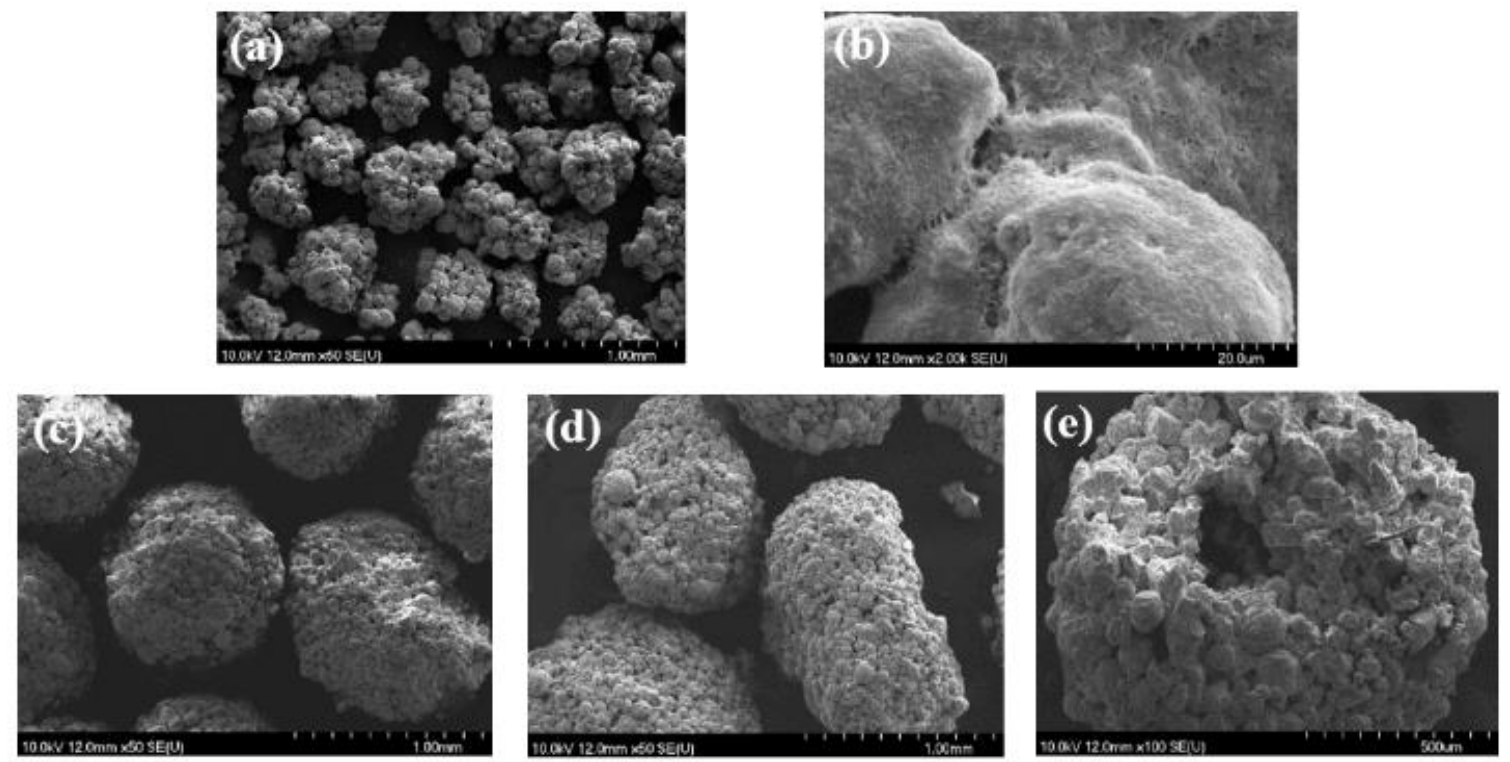

Figure 18: SEM pictures of: (a) granules prepared with $15 \%$ of PEG 6000 with binder particle size $(125-250 \mu \mathrm{m})$; (b) close up to the surface of granules prepared with $15 \%$ of PEG 6000 with binder particle size $(125-250 \mu \mathrm{m})$; (c) granules prepared with $10 \%$ of PEG 2000 with binder particle size $(500-710 \mu \mathrm{m})$; (d) granules prepared with $10 \%$ of PEG 6000 with binder particle size $(500-710 \mu \mathrm{m})$; (e) a cross section of a granule prepared with $10 \%$ of PEG 6000 with binder particle size $(500-710 \mu \mathrm{m})$.

The trapped binder particle will be squeezed to the surface due to densification and spreads around the lactose particles (Figure 18c). Low binder viscosity grade results in high sphericity for low binding strength of agglomerates and collision during fluidization. However, using high binder viscosity grade (Figure 18d) will result in a hollow core granule in irregularly shaped granules due to coalescence between large and small granules (Figure 18e).

Also, low binder content increases the fraction of ungranulated lactose with a small fraction of nuclei. These attributes are in accordance with the results predicted by the ANN model designating the binder particle size as the major factor influencing the granulation process, followed by the binder viscosity grade. 


\subsubsection{Effect of process variables on granule size, size distribution and yield}

For a small binder particle size, the mean diameter of granules showed low values, hence a low yield with broad size distribution, i.e. a high coefficient of variation value and a high aspect ratio (Figure 19). Higher binder particle resulted in greater sized granules with a higher yield due to the immersion mechanism and reduced the amount of fine particles. However, CV was higher as a result of the low deformability of the binder (Figure 19c). Increasing the binder viscosity grade supported a small but distinct increase in the fraction of larger granules. A high $\mathrm{CV}$ value was in accordance with the results of yield and mean diameter. Indeed, with a $36 \%$ effect, the growth in this system was minor, indicating small coalescence yield as granules above $150 \mu \mathrm{m}$ did not exceed 53\%. The size distribution was similar irrespective of the binder viscosity grade.

(a)
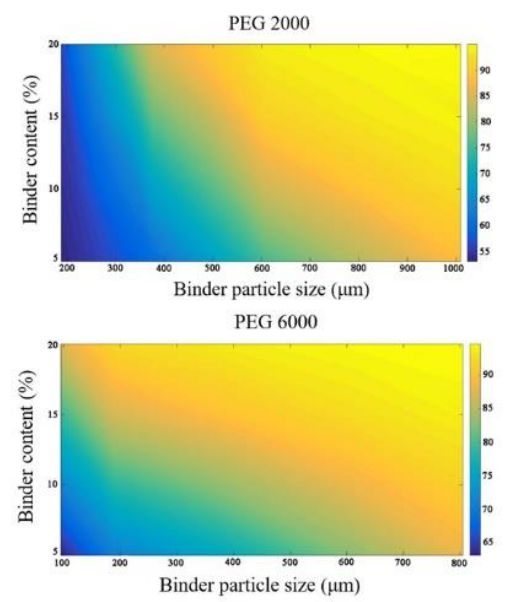

(b)

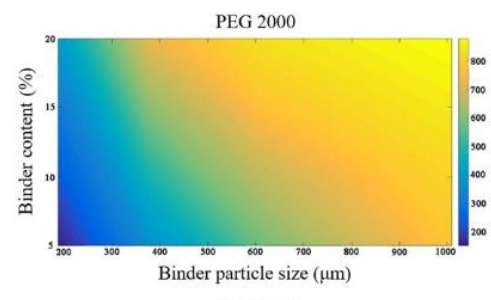

PEG 2000

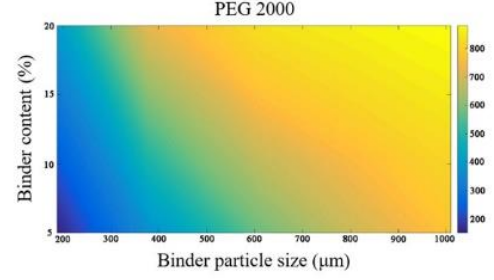

(c)

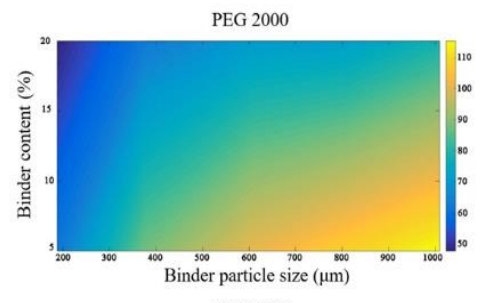

PEG 6000

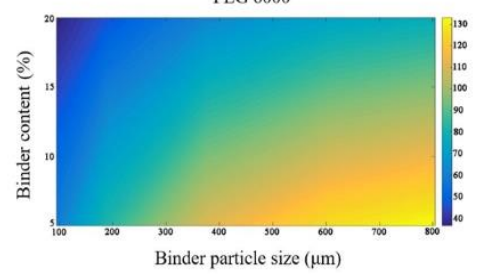

Figure 19: Contour plot of the variation of: a) the yield, b) the mean diameter, c) the CV as a function of the binder particle size and binder content for PEG 2000 and 6000, respectively.

With a high binder particle size, the binder liquid will be able to be drained from the inside of the agglomerate to the surface due to capillary pressure difference, thus resulting in a higher yield of granules with a higher mean particle size (Figure 19b). The increase in the binder content from $5 \%$ to $20 \%$ resulted first in a minor increase in the granule size with a large fraction of ungranulated lactose. However, too high binder amount results in large granules and a difluidized system. Particularly, lower values of coefficient of variation were obtained due to highly dense bonds leading to irregularly shaped granules.

\subsubsection{Effect of input variables on granule hardness}

A low binder viscosity grade prevented strong bond formation and resulted in granules with weak spherical structure and low strength at low binder particle size, as can be seen for granules 
S04 and S08 (Figure 20). However, a high binder viscosity grade decreases the deformability of agglomerates and results in denser, more compact granules adding mechanical strength, an elastic character and resistance to breakage seen in granule S40, where hardness was at the highest value.

(a)

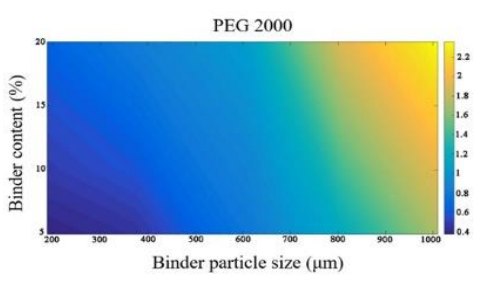

PEG 6000

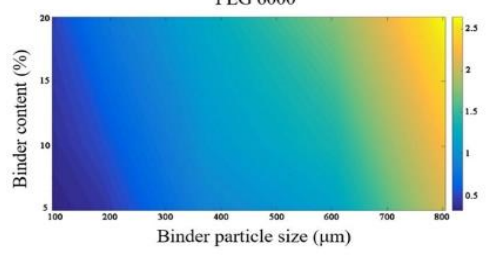

(b)

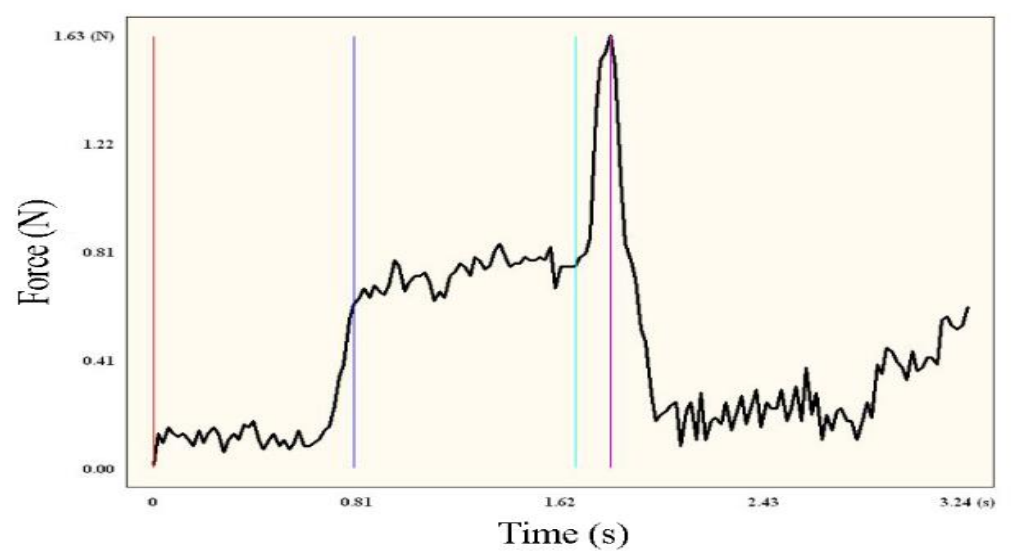

Figure 20: a) Contour plot of the variation of hardness $(\mathrm{H})$ as a function of the binder particle size and binder content for PEG 2000 and 6000, respectively and b) Deformation process of granule prepared with PEG 6000 (S35).

As for high binder particle size, at a low level with low binder viscosity grade, granules will be weak and breakage is likely to occur preventing effective nucleation. With a high viscosity grade, the rate of granule consolidation decreases as well as the average pore size for the higher strength of granules. The deformation process of granules showed an elastic section, then a viscoelastic deformation followed by an elastic section up to the breaking hardness point (Figure 20b). On the other hand, the hardness of the granules was low even at a high binder content for low binder particle size. The binder content hence plays a minor role in the improvement of the final granule attributes as predicted by the developed ANN model, which gave it $22 \%$, thus making it the least effective factor in the system.

\subsubsection{Effect of process variables on granule porosity}

Granule porosity is an important product property to control and optimize granule growth mechanisms. Smaller particles increase the volume density of interparticle contacts and also decrease the average pore size through which fluid must be squeezed during consolidation. Both these factors retard agglomeration growth. Decreasing the binder particle size also tends to increase the minimum porosity reached due to the greater strength of the assembly. An inversely proportional pattern is seen for both PEG grades in Figure 21. For low viscosity grade PEG 
2000, the increase in binder particle size revealed an increase in the porosity. The slope of the proportionality increases with the increase in the binder content.
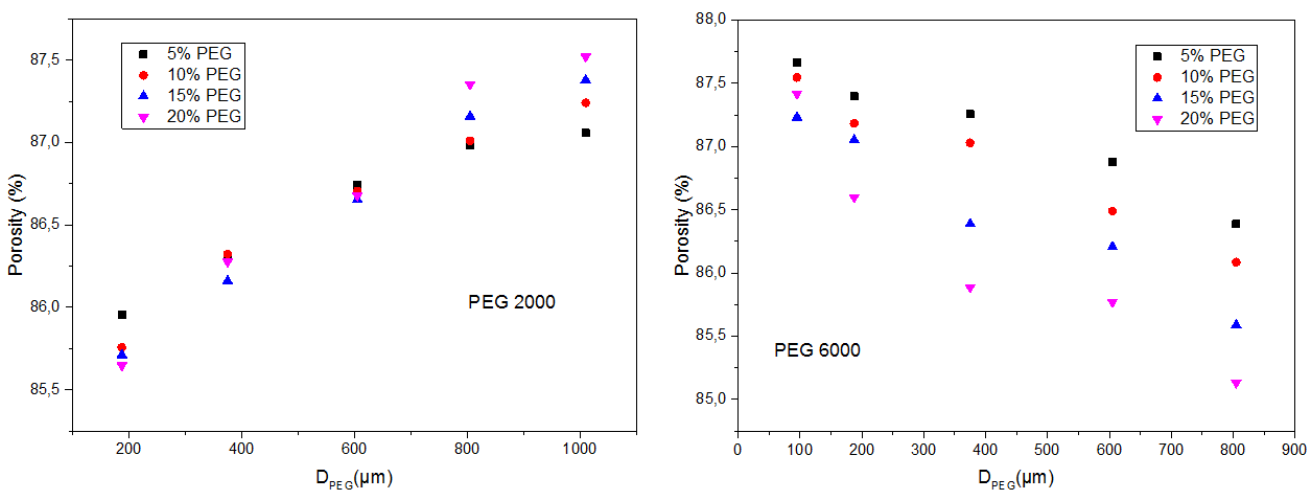

Figure 21: Evaluation of granule porosity as a function of binder diameter for different binder content and viscosity.

These can be explained by the fact that at low binder content and size the distribution mechanism is taking place. During nucleation, the nuclei of lactose and PEG particles will have a low porosity similar to the porosity of the raw materials. Increasing binder particle size allowed a higher granulation rate and decreased the amount of fine lactose particles, which resulted in the increase in the porosity of granules.

\subsubsection{Melt granulation optimization}

The selection of the optimal combination of input variables was based on the production of strong, spherical granules with a homogeneous size. Predicted and experimental values of all outputs were close, indicating that the ANN model was able to optimize the process (Table 9).

Table 9: Ideal values of inputs, predicted and experimental values of outputs. (Experimental Data: E.D., Predicted Data: P.D., Viscosity grade: V (grade), Content: C (\%) and Particle Size: S $(\mu \mathrm{m})$ Yield: Y $(\%)$, Mean Diameter: $\mathrm{D}_{50}(\mu \mathrm{m})$, Coefficient of Variation: CV $(\%)$, Hardness: H (N), Aspect Ratio: AR).

\begin{tabular}{lllllllll}
\hline \multirow{2}{*}{ Data } & Inputs & \multicolumn{7}{c}{ Outputs } \\
\cline { 2 - 9 } & $\mathrm{V}($ grade $)$ & $\mathrm{C}(\%)$ & $\mathrm{S}(\mu \mathrm{m})$ & $\mathrm{Y}(\%)$ & $\mathrm{D}_{50}(\mu \mathrm{m})$ & $\mathrm{CV}(\%)$ & $\mathrm{H}(\mathrm{N})$ & $\mathrm{AR}$ \\
\hline E.D. & 6000 & 20 & $710-900$ & 93 & 830.459 & 68.145 & 1.860 & 1.238 \\
P.D. & - & - & - & 94.271 & 834.662 & 70.663 & 2.012 & 1.226 \\
Residue & - & - & - & -1.271 & -4.203 & -2.518 & -0.152 & -0.012 \\
\hline
\end{tabular}

These results showed immersion as the favourable mechanism, which can be advantageous for sustained drug release when using a hydrophobic meltable binder, and a hydrophilic meltable binder will help increase the dissolution rate for fast drug release. 


\subsubsection{Thermoanalytical investigations}

\subsection{Differential scanning calorimetry}

The DSC curves of the raw materials are presented in Figure 22. From the heat flow curve of $\alpha$-lactose monohydrate, three endothermic peaks can be observed. The first corresponds to crystal water evaporation at around $142^{\circ} \mathrm{C}$. The second peak is the melting of lactose and has an onset at $217^{\circ} \mathrm{C}$ and a peak temperature at $222^{\circ} \mathrm{C}$. The third peak is a small endothermic peak observed at $245^{\circ} \mathrm{C}$, which corresponds to a mass loss step. A small exothermic peak at $310^{\circ} \mathrm{C}$ represents the sum of the exothermic degradation and the mass loss endotherm, which occurs in the same temperature region for $\alpha$-lactose monohydrate.

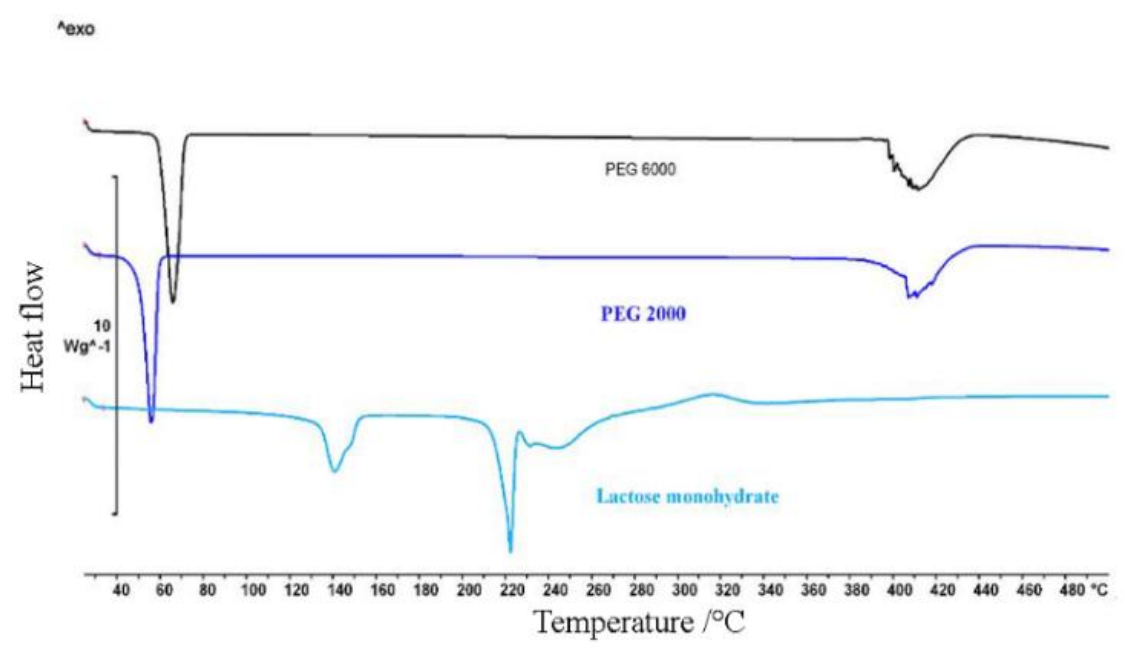

Figure 22: DSC curves of the raw materials: $\alpha$-lactose monohydrate, PEG 2000, PEG6000.

The DSC curve of PEG 2000 exhibited a melting peak at $52^{\circ} \mathrm{C}$ with an onset at $48^{\circ} \mathrm{C}$. On the other hand, PEG 6000 had a melting peak at $63^{\circ} \mathrm{C}$ with an onset at $57^{\circ} \mathrm{C}$ due to the difference in the molecular mass of the polymers. PEG is a crystalline polymer. Therefore, the influence of temperature elevation on the properties of the granules is negligible.

The melting point of PEG 6000 shifted about $5^{\circ} \mathrm{C}$ lower than observed in its pure form (Table 10). This is caused by the filler molecules that will get in between the polymer chains, space them out of each other and hence increase the free volume. Molecules can then slide past each other more easily, resulting in a decrease in the melting point. In addition, this mobility becomes more expressed at a higher filler concentration.

Indeed, the heat flow enthalpy of the melting of PEGs depends on binder concentration as can be seen for S28 and S26, where the filler content increased and the melting temperature of the binder decreased, respectively. 
Table 10: Melting peaks and heat flow data of granules prepared with PEG 2000 and 6000 samples (MR: Melting Range, MP: Melting Peak, PH: Peak Height, $1^{\text {st }}$ E.: First enthalpy of lactose).

\begin{tabular}{|c|c|c|c|c|c|c|c|c|}
\hline S.N. & $\begin{array}{l}\text { PEG } \\
\text { Grade }\end{array}$ & $\begin{array}{c}\mathrm{PEG} \\
1 \%\end{array}$ & $\begin{array}{l}\text { PEG } \\
/ \mu \mathrm{m}\end{array}$ & $\begin{array}{l}\mathrm{MR} \\
{ }^{\circ} \mathrm{C}\end{array}$ & $\begin{array}{c}\mathrm{MP} \\
\mathrm{PEG} \\
/{ }^{\circ} \mathrm{C}\end{array}$ & $1^{\text {st }}$ E. $/ \mathrm{Jg}^{-1}$ & $\begin{array}{c}\text { PH of } \alpha- \\
\text { lactose } / \mathrm{Jg}^{-1}\end{array}$ & $\begin{array}{c}\text { PH of } \beta- \\
\text { lactose } \\
/ \mathrm{Jg}^{-1}\end{array}$ \\
\hline S01 & 2000 & 5 & $125-250$ & $49.5-53.7$ & 51.85 & -96.57 & 3.77 & 1.04 \\
\hline S02 & 2000 & 10 & $125-250$ & $50.0-56.1$ & 53.06 & -72.23 & 1.63 & 2.13 \\
\hline S03 & 2000 & 15 & $125-250$ & $48.5-53.6$ & 51.44 & -73.93 & 2.48 & 1.35 \\
\hline S06 & 2000 & 10 & $250-500$ & $52.3-55.2$ & 51.77 & -99.61 & 1.10 & 0.80 \\
\hline S09 & 2000 & 5 & $500-710$ & $48.5-53.7$ & 52.44 & -74.02 & 2.48 & 1.35 \\
\hline S11 & 2000 & 10 & $500-710$ & $52.1-55.9$ & 52.08 & -100.36 & 1.98 & 1.65 \\
\hline S15 & 2000 & 10 & $710-900$ & $48.7-56.1$ & 52.07 & -108.11 & 1.67 & 2.28 \\
\hline S16 & 2000 & 15 & $710-900$ & $48.5-55.9$ & 51.99 & -95.96 & 1.33 & 2.16 \\
\hline S19 & 2000 & 15 & $900-1120$ & $48.6-55.8$ & 52.29 & -97.94 & 1.25 & 2.29 \\
\hline $\mathrm{S} 21$ & 6000 & 5 & $65-125$ & $56.4-61.7$ & 58.85 & -122.06 & 3.06 & 0.76 \\
\hline $\mathrm{S} 22$ & 6000 & 10 & $65-125$ & $60.3-62.5$ & 60.08 & -102.46 & 2.43 & 1.35 \\
\hline S26 & 6000 & 10 & $125-250$ & $56.0-62.4$ & 60.08 & -83.80 & 2.38 & 0.99 \\
\hline $\mathrm{S} 28$ & 6000 & 20 & $125-250$ & $63.5-68.3$ & 63.53 & -104.54 & 1.11 & 1.16 \\
\hline $\mathrm{S} 30$ & 6000 & 10 & $250-500$ & $61.1-64.5$ & 60.22 & -72.72 & 3.91 & 5.32 \\
\hline S37 & 6000 & 5 & $710-900$ & $63.1-67.1$ & 63.14 & -101.25 & 1.22 & 1.22 \\
\hline S40 & 6000 & 20 & $710-900$ & $57.9-67.0$ & 63.86 & -75.91 & 1.32 & 1.10 \\
\hline
\end{tabular}

On the other hand, the loss of crystal water from $\alpha$-lactose monohydrate did not appear in the same thermal range as in the raw material (Table 11), attributed to the free volume experienced when in contact with the polymer, lowering the crystal vaporization temperature. Also, the normalized integration of the signal intensity demonstrates a decrease when using a higher binder content. However, the most predominant observation was the presence of an endothermic peak between the melting of $\alpha$-lactose monohydrate and its decomposition (Figure 23). The peak had an onset at 225 and $227^{\circ} \mathrm{C}$ for PEG 2000 and 6000 , respectively, and a peak temperature at 229 and $227^{\circ} \mathrm{C}$ for PEG 2000 and 6000, respectively (Table 10) especially with low-viscosity polymer (PEG 2000) as the increase in content proportionally increased the intensity of the peak.

After the dehydration of lactose monohydrate and the melting of anhydrous $\alpha$-lactose, recrystallization into b-lactose occurred, followed by the melting of anhydrous $\beta$-lactose. $\beta$ lactose is a low hygroscopic material with high storage stability and appropriate for water sensitive drugs formulations, which is one of the key points of FBMG. 


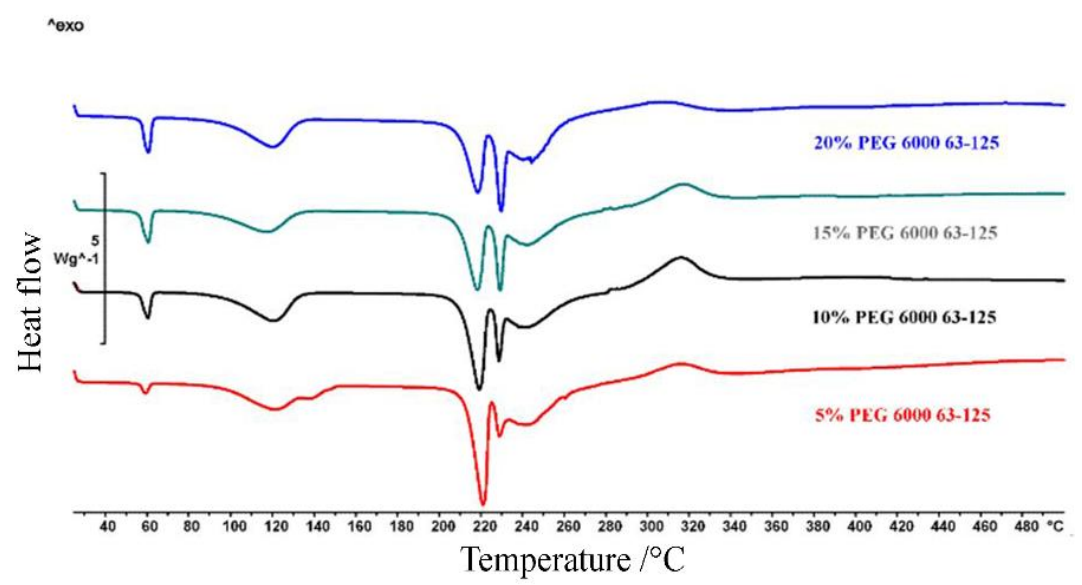

Figure 23: DSC curves of granules with PEG 6000 for different contents.

Figure 24 shows the evolution of the $\beta$-lactose melting peak with different binder particle sizes. The intensity of the peak is proportional to the increase in binder content, showing that the presence of PEG influences the conversion. Indeed, when using a low viscosity and a low binder content and size, the mechanism taking place is distribution. The lactose is exposed to the hot fluidizing air, and the transformation to $\beta$-lactose starts showing. However, the increasing binder particle size and content generate a higher wetting surface for more growth by coalescence. This increase is proportional to the intensity of the peak due to the high heat transfer occurring during the phase change of PEG 2000. On the other hand, the binder particle size had an inversely proportional effect on this endotherm peak (Figure 24). It can be seen that for granules with a high viscosity polymer 6000 and a high particle size of binder, the peak height for the melting of lactose is relatively close to the pure filler. Also, the enthalpy of melting of $\beta$-lactose is less pronounced.

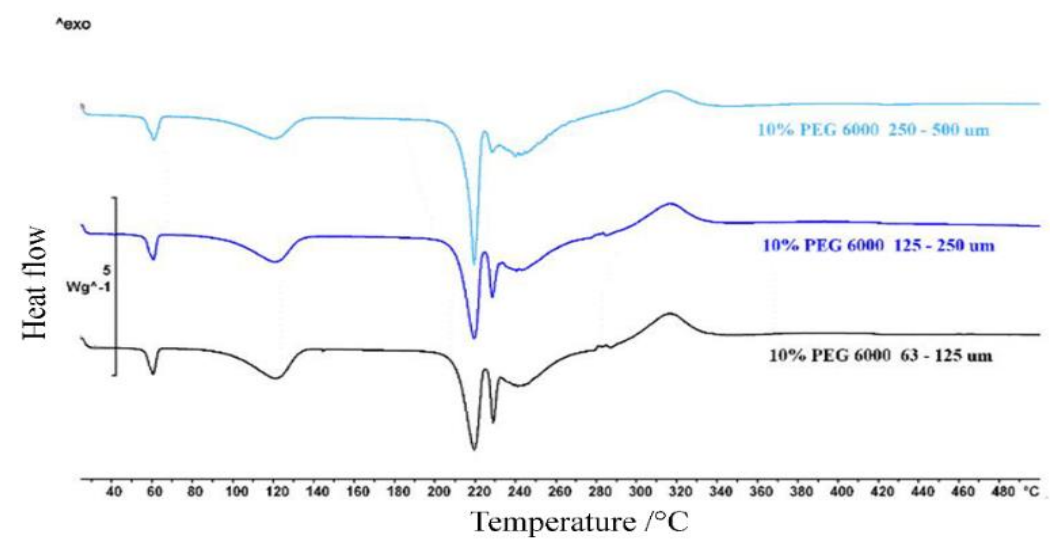

Figure 24: DSC curves of granules with PEG 6000 for different particle sizes.

The height of the $\alpha$-lactose melting peak is inversely proportional to the melting peak of $\beta$ lactose, which can be explained by the granulation growth during the process. 
Since in this system the immersion mechanism dominates, it causes the filler to stick to the surface of the polymer and get immersed, hence shielding it from the fluidizing air temperature and dehydration, and will result in the low $\beta$-lactose melting peak intensity. This indicates the possibility to determine the relative structure of the granules and their mechanism of formation. It helps validate the results obtained, suggesting the binder particle size as the parameter with the greatest influence on the growth mechanism [42].

\subsection{Thermogravimetric analysis - mass spectrometry}

The data of the samples obtained from thermogravimetric analysis can be used to effectively compare the decomposition characteristics of the raw materials and their blends in granules. The TG curve of $\alpha$-lactose monohydrate shows three distinctive stages (Figure 25). The first mass loss of $4.52 \%$ is observed between 136 and $160^{\circ} \mathrm{C}$ (Table 11) attributed to the elimination of crystal water.

Table 11: Decomposition behaviour of raw materials (lactose monohydrate, PEG 2000, PEG 6000).

\begin{tabular}{lccc}
\hline TG-DTG data & Lactose monohydrate & PEG 2000 & PEG 6000 \\
\hline \multicolumn{1}{c}{ First phase } & $132-155$ & $388-439$ & $389-438$ \\
Thermal range $/{ }^{\circ} \mathrm{C}$ & 3.99 & 103.29 & 101.03 \\
Mass loss $/ \%$ & -0.21 & - & -5.58 \\
Normalized integral $/ \mathrm{sC}^{-1}$ & 143.02 & 53.80 & 63.24 \\
Peak $/{ }^{\circ} \mathrm{C}$ & $2.35 \mathrm{e}-03$ & $31.52 \mathrm{e}-03$ & $29.33 \mathrm{e}-03$ \\
Peak height $/{ }^{\circ} \mathrm{C}^{-1}$ & & & \\
$\quad$ Second phase & $228-262$ & - & - \\
Thermal range $/{ }^{\circ} \mathrm{C}$ & 14.55 & - & - \\
Mass loss $/ \%$ & -0.18 & - & - \\
Normalized integral $/ \mathrm{sC}{ }^{-1}$ & 241.17 & - & - \\
Peak $/{ }^{\circ} \mathrm{C} \quad 1.94 \mathrm{e}-03$ & - & - \\
Peak height $/{ }^{\circ} \mathrm{C}^{-1}$ & & & - \\
Third phase & $287-328$ & - & - \\
Thermal range $/{ }^{\circ} \mathrm{C}$ & 55.68 & - & - \\
Mass loss $/ \%$ & -2.44 & - & \\
Normalized integral $/ \mathrm{sC}{ }^{-1}$ & 302.91 & - & \\
Peak $/{ }^{\circ} \mathrm{C} \quad$ Peak height $/{ }^{\circ} \mathrm{C}^{-1}$ & $15.75 \mathrm{e}-03$ & & \\
\hline
\end{tabular}

The second mass loss occurred between 222 and $265^{\circ} \mathrm{C}$ and peaked at $153^{\circ} \mathrm{C}$, accompanied by a mass loss of $14.55 \%$ caused by the thermal decomposition of lactose monohydrate. Another mass loss is observed between 290 and $330^{\circ} \mathrm{C}$ of $55.68 \%$ due to the decomposition of water 
and carbon dioxide. Regarding the TG profile of PEG 2000 and 6000 in Figure 24, only one mass loss was observed between 388 and $438^{\circ} \mathrm{C}$ and peaked at $415^{\circ} \mathrm{C}(98.79 \%)$ and it corresponds to the decomposition of the materials. It can be seen that mass loss in granules comes in four stages. The first stage occurred between 80 and $140^{\circ} \mathrm{C}$. This thermal range includes two stages of mass loss. The first dehydration between 80 and $100^{\circ} \mathrm{C}$ is attributed to the elimination of water molecules adsorbed on the external surfaces of the lactose particles as well as a second stage between 100 and $140^{\circ} \mathrm{C}$, corresponding to the loss of crystal water. When using a low binder particle size (Figure 26), the porosity and friability of the granules are increased, making the lactose particles subject to hot fluidizing air and hence to dehydration.

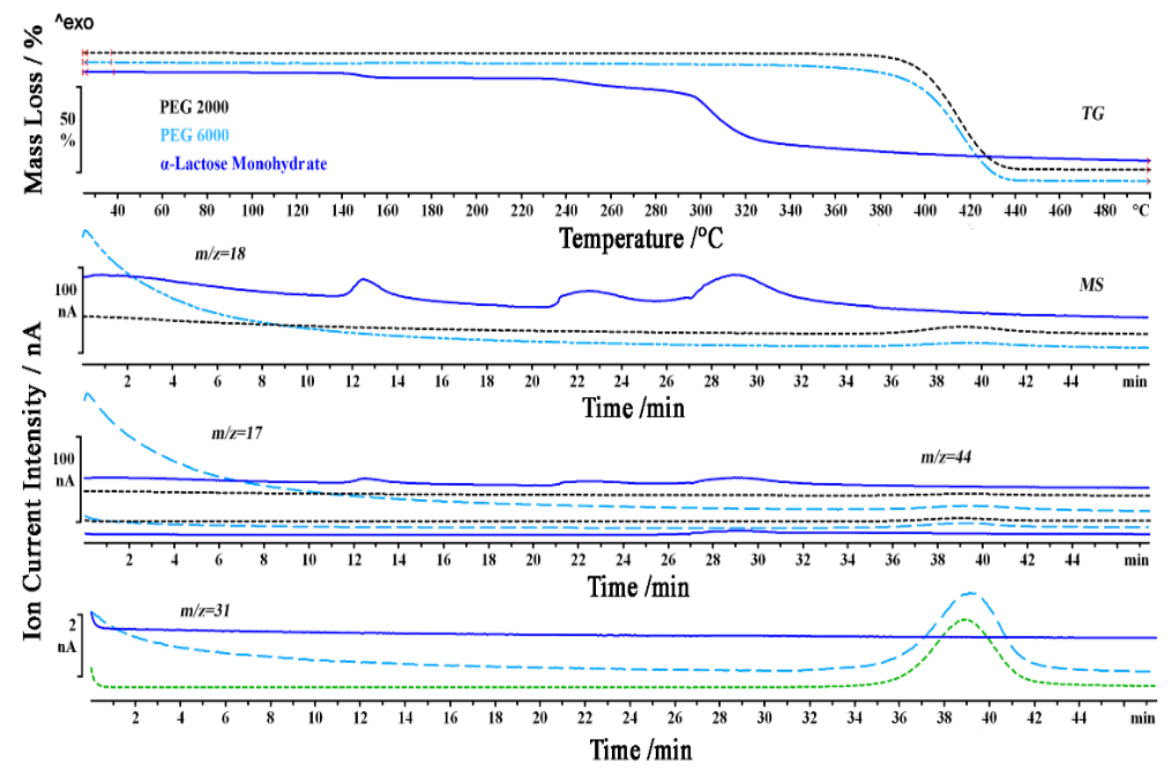

Figure 25: TG-MS curves of raw materials: $\alpha$-lactose monohydrate, PEG 2000 and 6000.

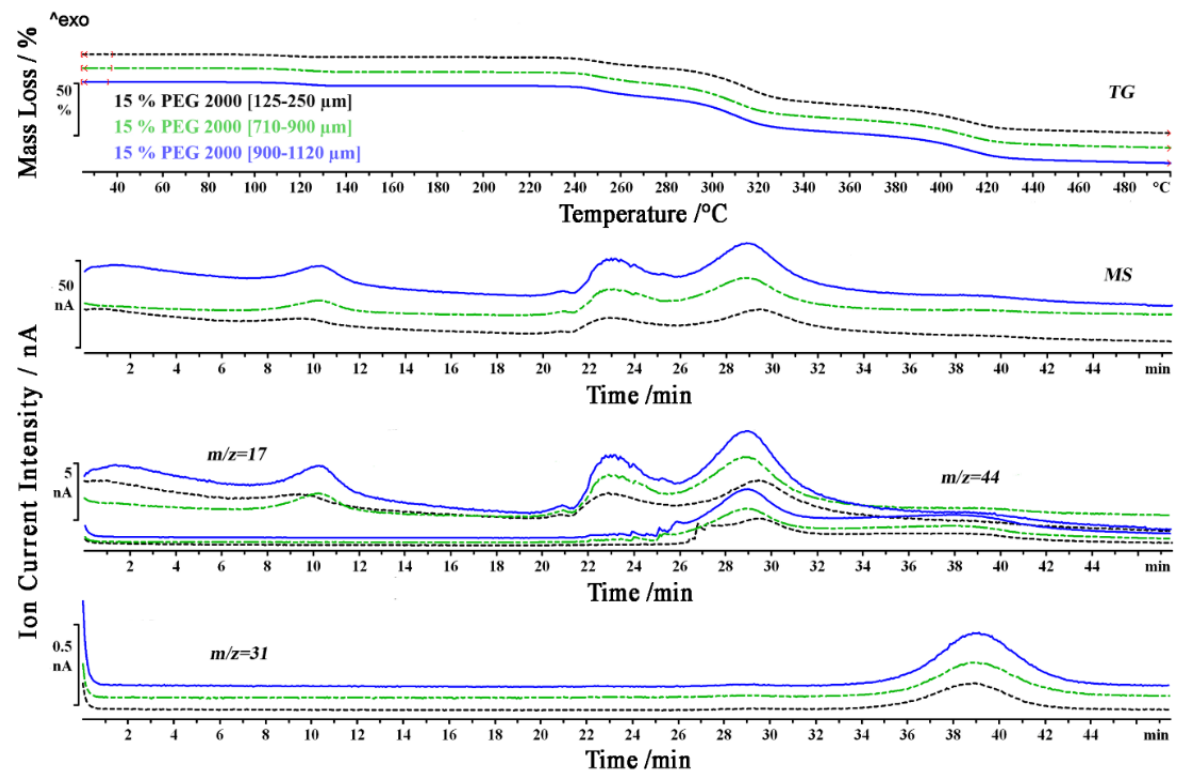

Figure 26: TG-MS curves of granules with PEG 2000 and different particle sizes. 
Indeed, there was a small reduction in mass between 80 and $131^{\circ} \mathrm{C}$ for S02 and S26 indicating that the raw material $\alpha$-lactose monohydrate contained more surface water than granules. Figure 27 shows that the mass loss slightly increased with the increase in binder content as it helped shield the lactose particle from the hot fluidizing air. Low-viscosity grade binder combined with a low binder content and particle size showed a poor mass loss in the first stage as lactose particles were submitted to high temperature during granulation. Quantified with TG, this mass loss was very low compared with the raw material and proportional to the increasing binder content. The increased binding surface resulted in lactose being covered and a low dehydration process. However, the increase in binder viscosity led to a mass loss which was slightly higher but not significant enough for a change in the granulation mechanism. The curves also revealed a shift in the melting point of the granules due to the presence of the polymer, which explains the temperature drop in the first mass loss stage and water that is given out around $80^{\circ} \mathrm{C}$.

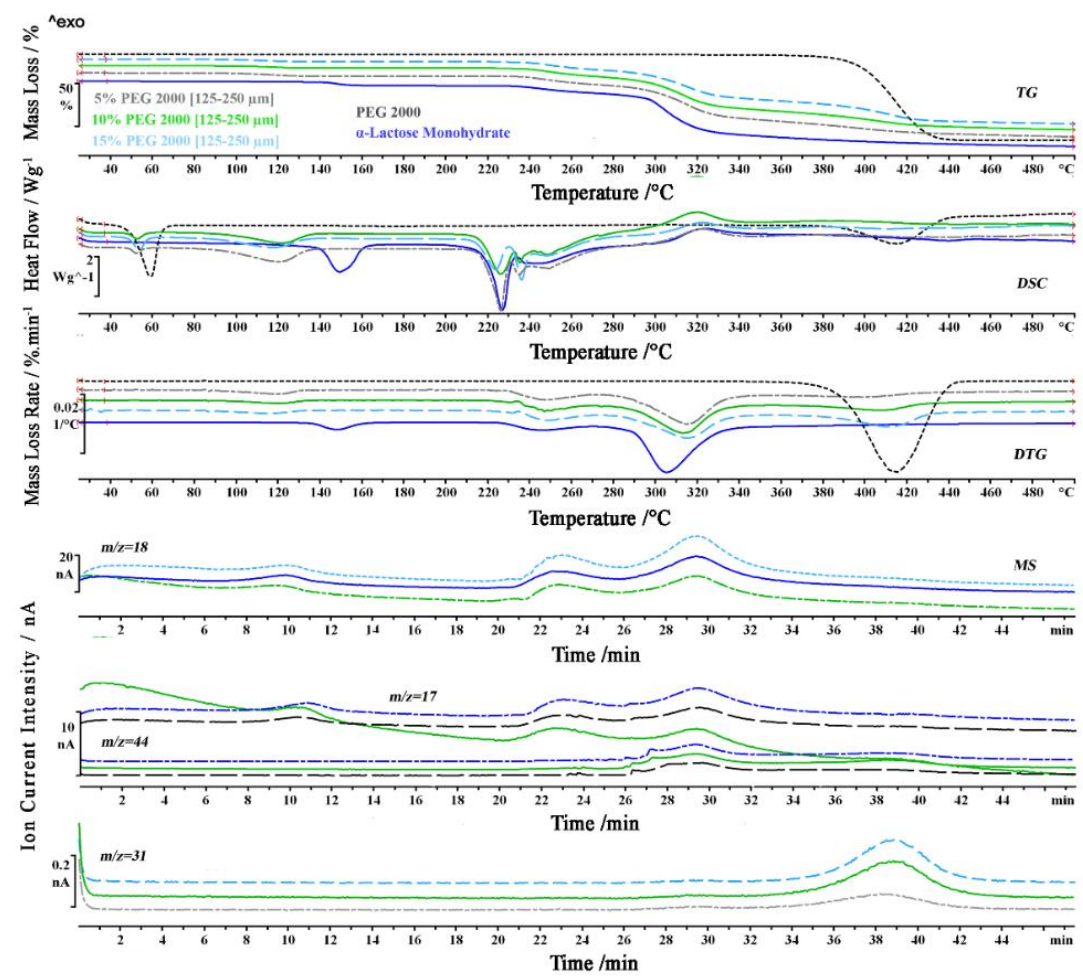

Figure 27: TG, DSC, DTG and MS curves of granules with PEG 2000 with different binder contents.

The interpretation of the mass spectra occurs on the basis of degassing profiles from the molecule ions. Peaks at 125,250 and $315^{\circ} \mathrm{C}$ are found in the ion current curve for $\mathrm{H}_{2} \mathrm{O}^{+}(\mathrm{m} / \mathrm{z}=$ $18)$; corresponding peaks are also found in the ion current curves for $\mathrm{OH}^{+}(\mathrm{m} / \mathrm{z}=17)$ and $\mathrm{O}^{+}$ $(\mathrm{m} / \mathrm{z}=16)$. It can be safely concluded that water is given out at those temperatures from the 
samples, which is consistent with the mass loss observed from the TG curves. Dehydration takes place in the minor step at around $125^{\circ} \mathrm{C}$, which is attributed to the dehydration of lactose monohydrate (Figure 28). Some change in intensities of the $\mathrm{m} / \mathrm{z}=44$ fragments was observed, probably as an oxidation effect caused by the intense oxygen evolution. Basically, this fragment ion indicates the evolution of $\mathrm{CO}_{2}$. The ion current curves for the evolved gases show for $\mathrm{m} / \mathrm{z}$ $=44$ an increase in concentration at around $250^{\circ} \mathrm{C}$ with a further increase in the concentration of $\mathrm{CO}_{2}$ at $415^{\circ} \mathrm{C}$, which is assigned to the decomposition of polyethylene glycol as was recorded for $\mathrm{m} / \mathrm{z}=31$ and $\mathrm{m} / \mathrm{z}=33$ due to the presence of the binder in the granules.

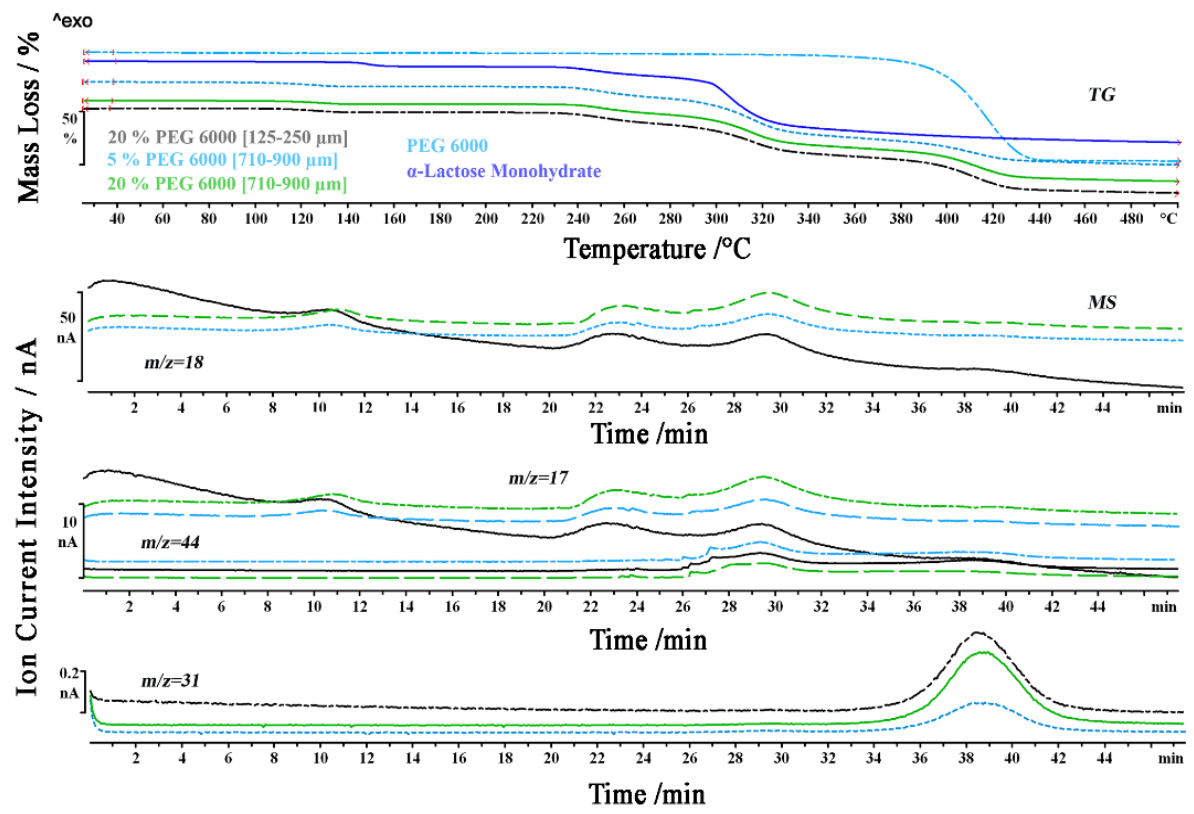

Figure 28: TG-MS curves of granules prepared with PEG 6000 with different contents and particle sizes.

The intensity of the peaks is proportional to the amount of PEG present in the composition of the granules. The comparison of the granules has shown that their thermal decomposition is determined by different factors, such as their structure and composition, and the increase in concentration in the MS curves corresponds precisely to the mass loss in the TG curves.

\subsubsection{In-situ FBMG - Granules with API}

\subsubsection{Temperature mapping and volume of the wetting zone}

During in-situ FBMG, the expansion of the granulation zone was from the bottom of the bed to the upper part with a height mostly dependent on the binder particle size, content and viscosity grade. Two distinct thermal zones were detected (Figure 29). The wetting zone starting from 
the bottom of the bed to the upper part is represented by yellow colour in the maps. This circulation pattern of the particles shows that the second zone is located in the upper part of the bed where the granules, after absorbing the thermal energy necessary to bring the solid binder into a molten state, will mix and circulate until their potential energy becomes higher than their kinetic energy and they fall back to the bottom of the bed, where they will collide with other freshly formed nuclei or break and restart the wetting process.

a)

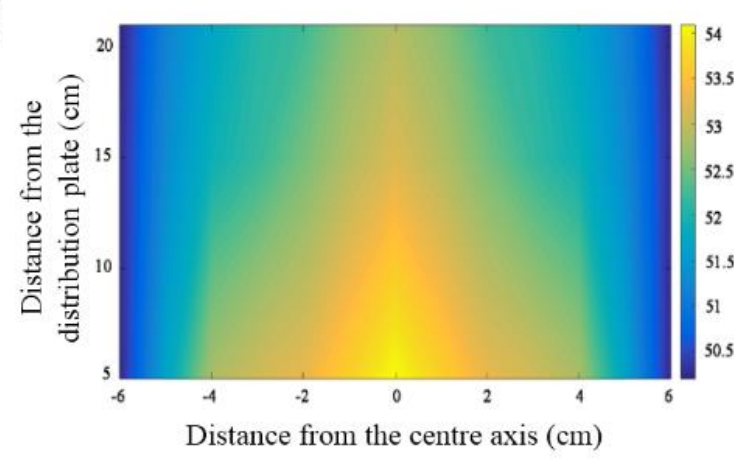

b)

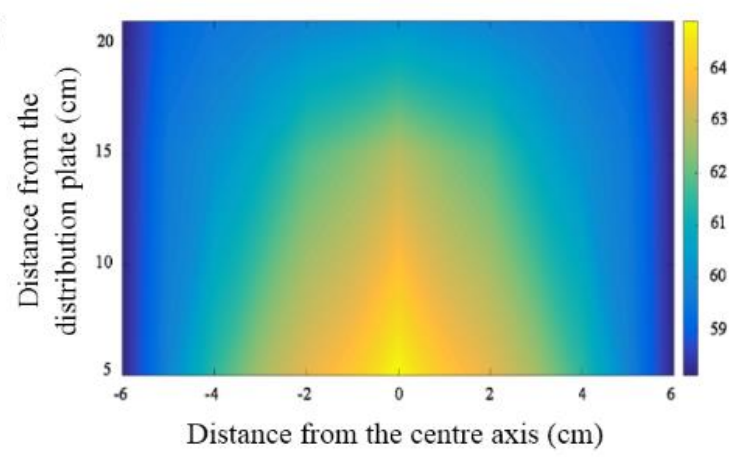

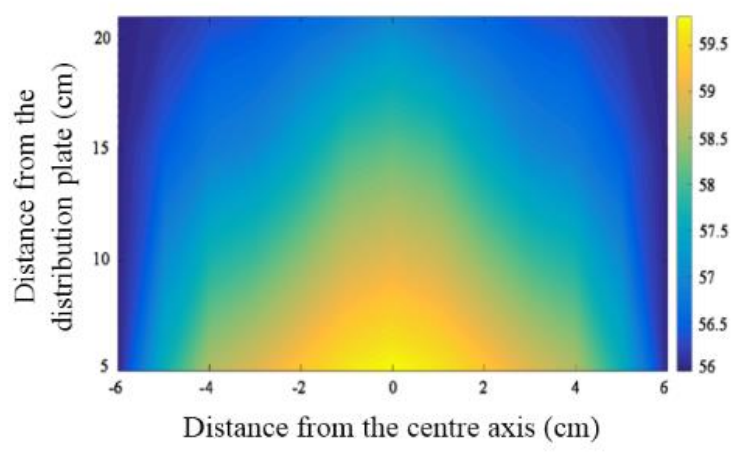

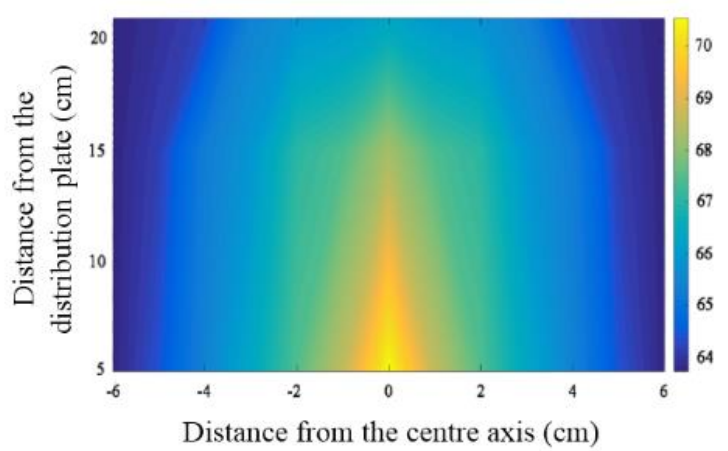

Figure 29: Temperature maps as a function of binder content for binder particle size between

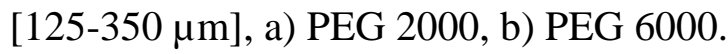

The volume of the wetting zone was highly dependent on the binder content as an increase from 10 to $20 \%$ resulted in fractions of $19 \%$ and $23 \%$, respectively, for PEG 2000 for a higher number of solid particles subject to wetting. Increasing the binder viscosity grade decreased the volume of the wetting bed to $18 \%$ and $21 \%$ due to the binder properties and the higher interparticle forces making spreading and deformation difficult, which results in a bad binder distribution in the granule. However, a low binder particle size [65-125 $\mu \mathrm{m}]$ resulted in high volumes of wetting zone and greatly influenced the binder distribution (Table 12). Most of the granulation was focused at the bottom part of the bed with a maximum wetting volume of $28 \%$ for PEG 2000 with $20 \%$ content. Thus the volume of the wetting zone increase is proportional to the binder content and inversely proportional to the binder particle size and viscosity grade. 
The air temperatures measured in the wetting zone were near the melting temperature of the PEG 2000 or PEG 6000 binder, respectively $\left(53-62^{\circ} \mathrm{C}\right)$ due to the thermal energy transferred from the hot fluidizing air to the solid binder particles to change their physical state from solid to molten, resulting in constant temperatures in the wetting zones. However, a low binder particle size or content absorbed lower thermal energy and hence temperatures in the wetting zone were near the temperature of the fluidizing air. Therefore, heat transfer zones and hence wetting zones are determined only by the difference between two isotherms.

\subsubsection{Granule size distribution and the volume of the wetting zone}

The size and size distribution of the granules were determined by the binder particle size and binder content. Low binder particle size and low binder content resulted in low granule mean diameter with a Gaussian tailing (Table 12).

Table 12: Influence of operating conditions on the volume fraction of the wetting zone and granule mean diameter for the in-situ technique.

\begin{tabular}{lccccc}
\hline $\begin{array}{l}\text { Binder } \\
\text { viscosity grade }\end{array}$ & $\begin{array}{c}\text { Binder particle } \\
\text { size }(\text { um })\end{array}$ & $\begin{array}{c}\text { Binder } \\
\text { content }(\%)\end{array}$ & $\begin{array}{c}\text { Wetting } \\
\text { volume }(\%)\end{array}$ & $\begin{array}{c}\text { Granule mean } \\
\text { diameter }(\mu \mathrm{m})\end{array}$ & Span \\
\hline PEG 2000 & $65-125$ & 10 & 13 & 136 & 2.8 \\
PEG 2000 & $65-125$ & 15 & 16 & 155 & 2.3 \\
PEG 2000 & $65-125$ & 20 & 20 & 167 & 1.9 \\
PEG 2000 & $125-300$ & 10 & 19 & 211 & 1.3 \\
PEG 2000 & $125-300$ & 15 & 20 & 276 & 1.1 \\
PEG 2000 & $125-300$ & 20 & 23 & 357 & 1.0 \\
PEG 2000 & $300-615$ & 10 & 25 & 456 & 2.2 \\
PEG 2000 & $300-615$ & 15 & 26 & 545 & 2.1 \\
PEG 2000 & $300-615$ & 20 & 29 & 651 & 2.6 \\
PEG 6000 & $65-125$ & 10 & 18 & 123 & 2.9 \\
PEG 6000 & $65-125$ & 15 & 21 & 143 & 2.6 \\
PEG 6000 & $65-125$ & 20 & 23 & 162 & 1.7 \\
PEG 6000 & $125-300$ & 10 & 18 & 217 & 1.6 \\
PEG 6000 & $125-300$ & 15 & 19 & 261 & 2.3 \\
PEG 6000 & $125-300$ & 20 & 21 & 315 & 2.9 \\
PEG 6000 & $300-615$ & 10 & 23 & 369 & 3.3 \\
PEG 6000 & $300-615$ & 15 & 25 & 421 & 3.8 \\
PEG 6000 & $300-615$ & 20 & 27 & 454 & 4.0 \\
\hline
\end{tabular}

However, when smaller binder particles [65-125 $\mu \mathrm{m}]$ were used in a higher content $(20 \%)$, the influence of binder content was more pronounced, with a higher mean diameter of $167 \mu \mathrm{m}$ compared to $136 \mu \mathrm{m}$ at $10 \%$. 
The size of the wetting volume also increased from 13 to $20 \%$ for binder PEG 2000. The lower viscosity grade binder allowed spreading and a favourable distribution and circulation pattern for uniform mixing and agglomeration.

Figure 30 shows the evaluation of the granule size distribution for granules prepared with PEG 6000. The increase in binder viscosity grade widened the size distribution of the granules, it was more pronounced for high binder particle size as the immersion mechanism will trap the binder particle inside layers of paracetamol and lactose and will increase the time necessary for the binder to completely melt, resulting in dense granules with particle sizes approximating the initial size of the binder particles. Lower volumes of wetting zone were recorded for PEG 2000 than 6000 (27 and 25\%, respectively, for $20 \%$ content and a binder size of [300-610 $\mu \mathrm{m}])$. The effect on the distribution of the granules was an increase in the mean diameter with a decrease in distribution uniformity.

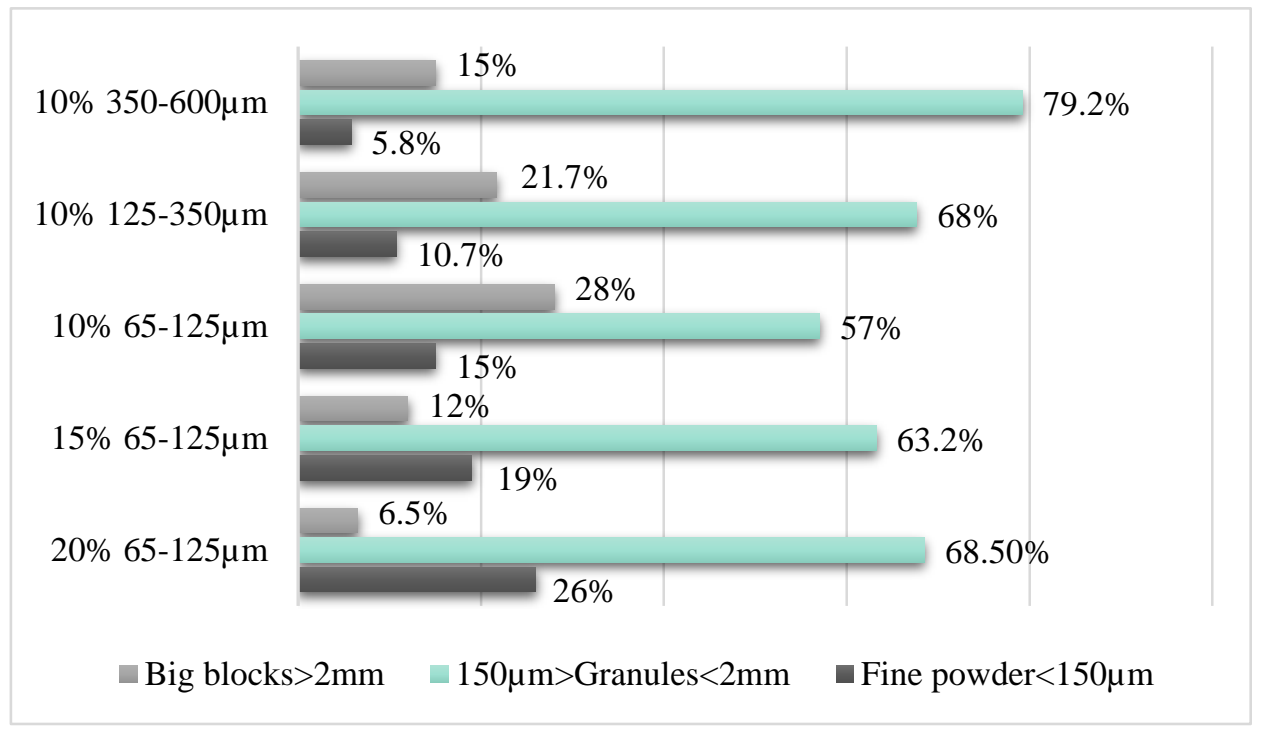

Figure 30: Variations of the size distribution of the granules as a function of binder particle/droplet size and content with PEG 6000 binder.

In the immersion mechanism, the uniformity of the distribution of the drug is harder to achieve because adhesion will be favoured for the lower dry particle sizes (paracetamol). The final batch will then have a higher content of drug in the granules with a higher amount of ungranulated lactose. Hence, the use of temperature maps for in-situ granulation showed that the small volume of the wetting zones resulted in growth by immersion. Too small volumes resulted in over-wetting and collapsing of the fluid bed. 


\subsubsection{Tablet hardness and dissolution testing}

Results showed that tablets prepared with in-situ FBMG resulted in high hardness when using high binder particle size and low binder particle resulted in lower hardness (Figure 31).

(a)

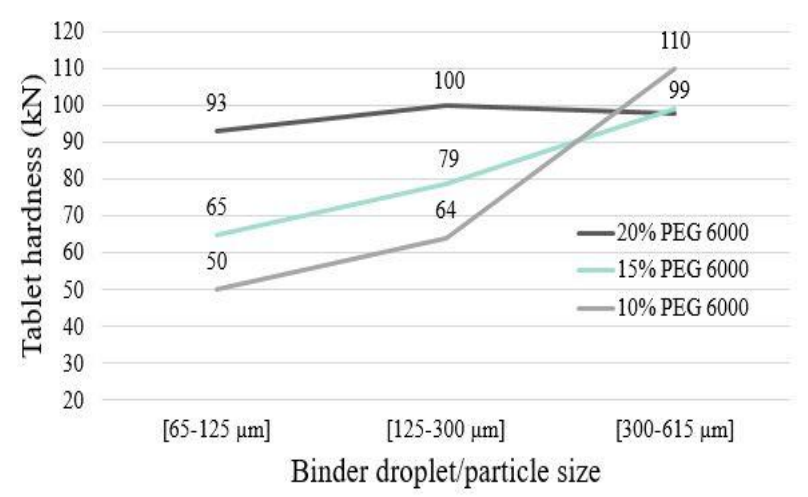

(b)

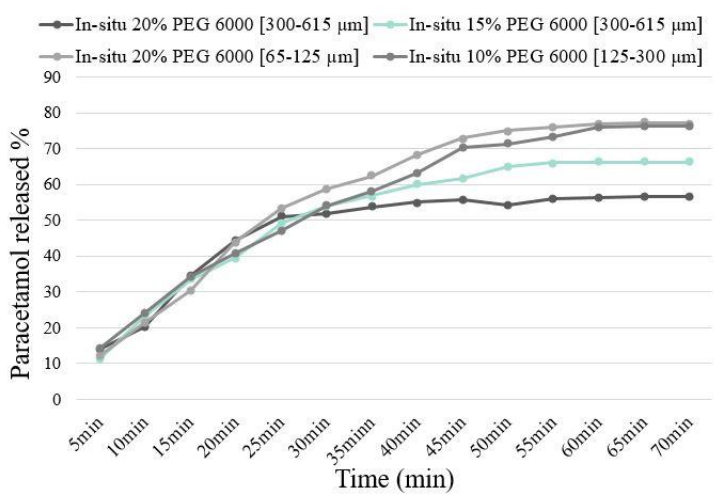

Figure 31: a) Variation of the hardness of tablets with different granule compositions, b) In vitro dissolution profiles of tablets prepared by spray-on and in-situ FBMG.

The in-situ FBMG showed a slower drug release attributed to the denser granules formed and hence a tighter tablet. The greatest influencing factor was found to be the binder content in the drug, therefore the binder distribution during the FBMG was of high importance.

\subsubsection{Spray-on FBMG - Granules with API}

\subsubsection{Spraying air pressure}

For low binder viscosity grade (PEG 2000), increasing spraying air pressure resulted in a lower spraying angle because air pressure will force the droplets to gather in a smaller volume (Figure 32). This evolution of the spraying angle was more pronounced at low binder spraying rates ( $5.2^{\circ}$ to $3^{\circ}$ for 4.13 to $6.19 \mathrm{ml} / \mathrm{min}$, respectively), but at higher values $(6.19$ to $8.26 \mathrm{ml} / \mathrm{min}$ ) the variation in the spraying angle was found to be lower $\left(1.6^{\circ}\right.$ to $\left.1.2^{\circ}\right)$.

For high binder viscosity grade, the binder will have a higher propensity to coalesce and form large droplets due to the higher intermolecular forces. Hence, for a high binder spraying rate, the increase in air pressure ( 2 to 3 bars) will lead to narrowed spraying angles but not with the same order of magnitude as for a low binder viscosity grade $\left(26.3^{\circ}\right.$ to $\left.23.4^{\circ}\right)$.

\subsubsection{Binder spraying rate}

For low viscosity grade PEG 2000, with relatively small spraying rates $(4.13 \mathrm{ml} / \mathrm{min})$, the growth rate will be affected by the formation of weak and low granule mean diameter attributed 
to the small wetted surfaces available for bridges to withstand the collisional kinetic forces and friability.
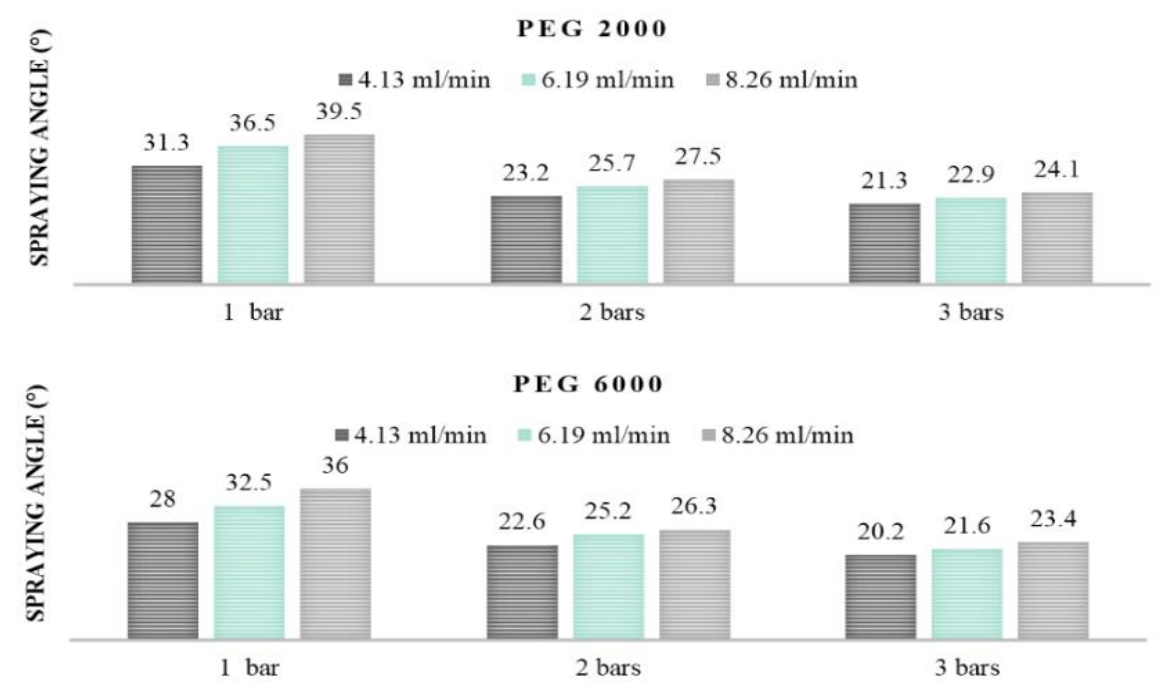

Figure 32: Variation of the spraying angle as a function of spraying pressure for different spraying rates and PEG viscosity grades.

For higher spraying rates, an increase in the spraying cone dimensions was detected as the spraying angle increased form $25.7^{\circ}$ to $27.5^{\circ}$ for an air pressure of 2 bars. Increasing the viscosity character of the binder results in a large droplet diameter and thus a narrower spraying zone with a spraying angle which increased with the spraying rate.

\subsubsection{Droplet size and size distribution}

A narrow size distribution will be achieved when equilibrium is reached between the spraying air pressure and the spraying rate (Figure 33). For PEG 2000 the droplet size distribution was Gaussian with a narrow spreading, which represents a homogeneous droplet formation. For PEG 6000 the distribution was also Gaussian but dragged to the right side for higher droplet sizes with tailing on the left for smaller droplet sizes and higher spreading of the distribution.

The binder droplet size is proportional to the spraying rate and inversely proportional to the air pressure, which was found to be the highest impacting factor. 


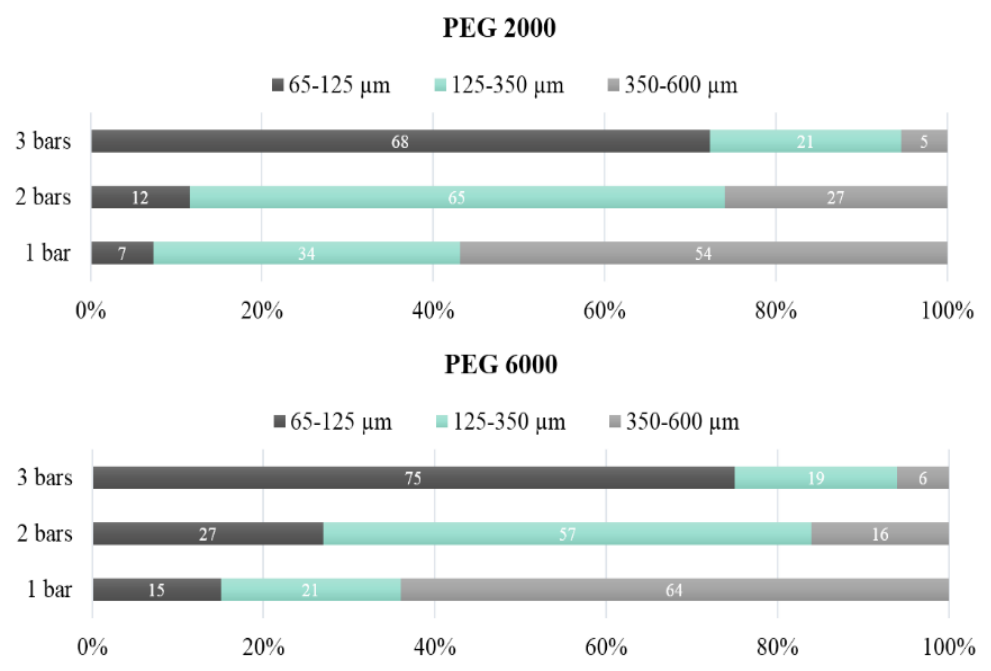

Figure 33: Variation of the surface as a function of spraying height for different pressures and spraying rates and spraying pressures, a) binder used: PEG 2000, b) binder used: PEG 6000.

\subsubsection{Temperature mapping and volume of the wetting zone}

A temperature distribution and isotherm maps are shown in Figure 34. The circulation patterns of the particles inside the bed chamber are identified and reproduced by arrows indicating three established thermal zones. The first zone is the bright yellow one under the spraying nozzle where the temperature of the bed is at maximum. In this zone, the sprayed binder droplets enter in contact with the solid particles of the powder mix.
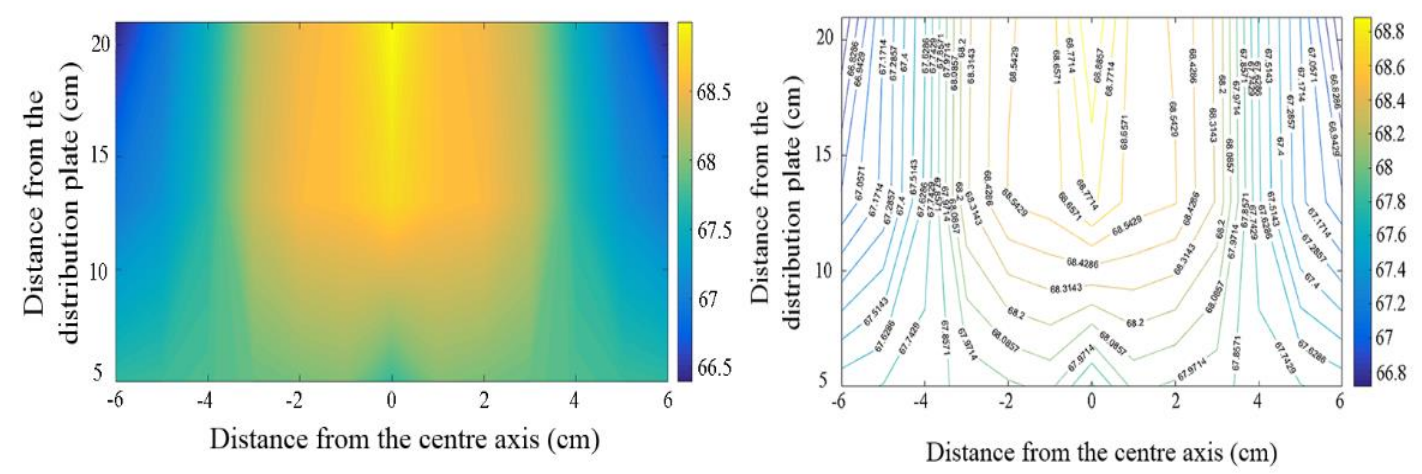

Figure 34: Temperature distribution and isotherm maps for spray-on FBMG (binder PEG $2000,8.26 \mathrm{ml} / \mathrm{min}, 2$ bars).

Low binder spraying rates with low spraying pressure resulted in a narrow spraying angle and hence a narrow spraying surface as can be seen in Figure 35. This low spraying volume represented $21 \%$ to $27 \%$ of the volume of the fluid bed that was wetted by the binder. The volume of the wetting zone decreased to $21 \%$ due to the smaller binder droplet size distribution for high spraying pressure. 

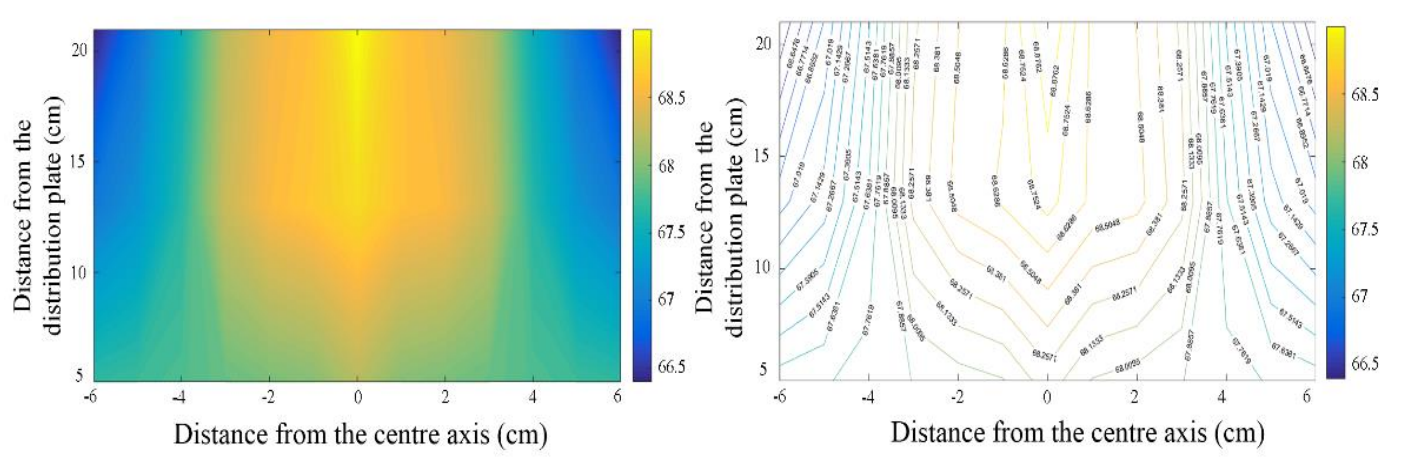

Figure 35: Temperature distribution and isotherm maps for spray-on FBMG (binder PEG 2000, $6.19 \mathrm{ml} / \mathrm{min}, 1 \mathrm{bar})$.

The increase in the viscosity grade decreased the volume of the wetting zone to $16 \%$ compared with binder PEG 2000 for the same operating conditions (Table 13).

Table 13: Influence of operating conditions on the volume fraction of the wetting zone and granule mean diameter for the spray-on technique.

\begin{tabular}{lccccc}
\hline $\begin{array}{l}\text { Binder } \\
\text { viscosity grade }\end{array}$ & $\begin{array}{c}\text { Spraying rate } \\
(\mathrm{ml} / \mathrm{min})\end{array}$ & $\begin{array}{c}\text { Air pressure } \\
(\text { bars })\end{array}$ & $\begin{array}{c}\text { Wetting } \\
\text { volume }(\%)\end{array}$ & $\begin{array}{c}\text { Granule mean } \\
\text { diameter }(\mu \mathrm{m})\end{array}$ & Span \\
\hline PEG 2000 & 4.13 & 1 & 21 & 155 & 2.6 \\
PEG 2000 & 4.13 & 2 & 18 & 141 & 2.3 \\
PEG 2000 & 4.13 & 3 & 16 & 136 & 2.2 \\
PEG 2000 & 6.19 & 1 & 27 & 328 & 2.3 \\
PEG 2000 & 6.19 & 2 & 22 & 356 & 1.9 \\
PEG 2000 & 6.19 & 3 & 19 & 347 & 1.1 \\
PEG 2000 & 8.26 & 1 & 31 & 421 & 3.9 \\
PEG 2000 & 8.26 & 2 & 26 & 560 & 2.5 \\
PEG 2000 & 8.26 & 3 & 21 & 578 & 1.9 \\
PEG 6000 & 4.13 & 1 & 22 & 145 & 2.2 \\
PEG 6000 & 4.13 & 2 & 19 & 159 & 2.9 \\
PEG 6000 & 4.13 & 3 & 14 & 122 & 3.3 \\
PEG 6000 & 6.19 & 1 & 25 & 434 & 3.5 \\
PEG 6000 & 6.19 & 2 & 20 & 484 & 2.2 \\
PEG 6000 & 6.19 & 3 & 17 & 495 & 1.8 \\
PEG 6000 & 8.26 & 1 & 28 & 410 & 3.9 \\
PEG 6000 & 8.26 & 2 & 21 & 421 & 3.7 \\
PEG 6000 & 8.26 & 3 & 19 & 453 & 3.6 \\
\hline
\end{tabular}

The second detected zone was the cooling zone or solidification zone (blue coloured zone) where the binder will solidify entering a lower temperature zone located at the bottom of the bed between 0 and $5 \mathrm{~cm}$. This zone was determined as the consolidation zone (green coloured zone). If enough wetting binder is available, then during consolidation the risk of attrition and 
breakage decreases. Hence a balance between the three thermal zones would result in granules with the desired quality attributes. The results showed that a wetting volume below $16 \%$ resulted in a large fraction of ungranulated material, with a mean diameter not higher than 130 $\mu \mathrm{m}$. This condition implies that particle growth was made mainly by layering. However, for wetting volumes above $28 \%$, massing of the powder bed and wet quenching occurred.

\subsubsection{Granule size distribution and the volume of the wetting zone}

A high binder spraying rate $(8.26 \mathrm{ml} / \mathrm{min})$ promoted higher mean diameters and high spraying air pressures (3 bars) resulted in lower granule diameters since lower binder droplets were formed (Figure 36). The hydrophilic property of both paracetamol and $\alpha$-lactose monohydrate made their different size the only factor influencing successful adhesion to the binder.

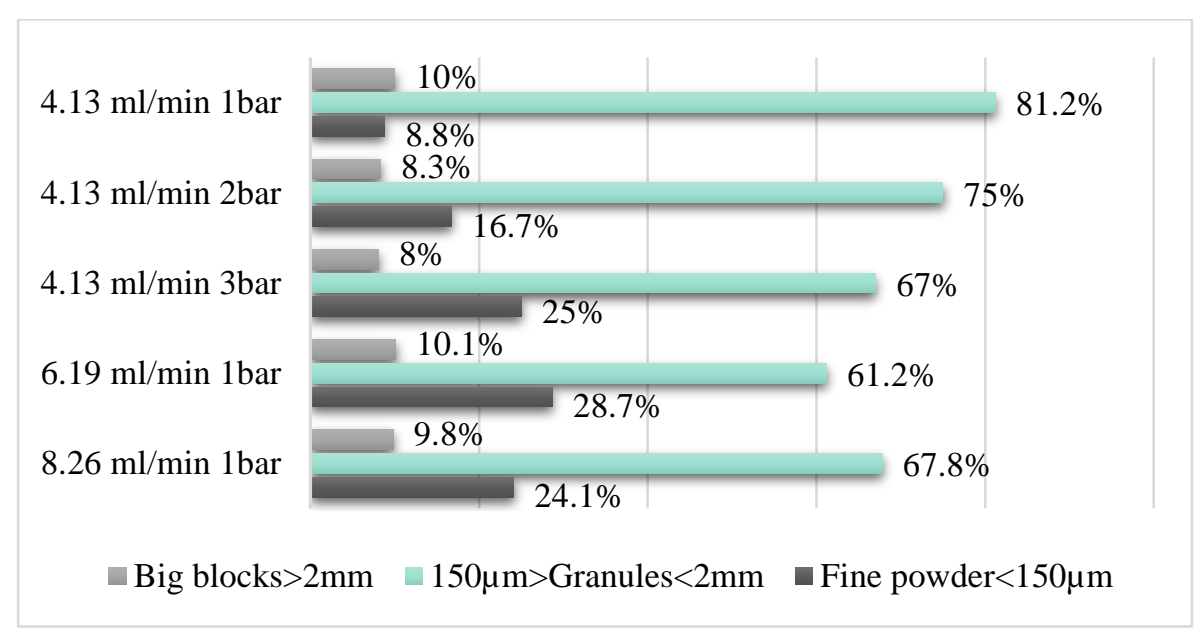

Figure 36: Variation of the granule size distribution as a function of binder particle/droplet size and content with PEG 6000 binder.

Low binder spraying rates $(4.13 \mathrm{ml} / \mathrm{min})$ lowered the wetting volume to $19 \%$ for spaying air pressure at 2 bars and gave rise to small granule mean diameter with a uniform size distribution. However, too small binder droplets resulted in inefficient wetting as the volume of the wetting zone was $14 \%$, giving rise to a Gaussian leaning towards the right side of the distribution with a low mean diameter of the granules. The latter result was observed with PEG 2000 but not with PEG 6000, where a broad droplet size distribution resulted in a slight bimodal with a higher amount of low granule sizes. Low droplet sizes will trap paracetamol particles and spread on the surface of lactose particles if enough binding liquid is available, favouring formation of paracetamol nuclei. As a result, the optimal wetting volume interval for a controlled granulation for both spray-on and in-situ techniques in the design space of our study is given in Table 14 . It will be helpful for the optimization of the size of the bed during scale-up, for example. 
Table 14: Optimized volume of the melting zone interval for spay-on and in-situ FMBG

\begin{tabular}{lcc}
\hline FBMG Technique & Minimum wetting volume \% & Maximum wetting volume \% \\
\hline Spray-on & 16 & 26 \\
In-situ & 16 & 27 \\
\hline
\end{tabular}

\subsubsection{Tablet hardness and dissolution testing}

Results showed that tablets prepared with spray-on FBMG resulted in high hardness when using a high spraying rate and small spraying air pressure. For spray-on FBMG, spray air pressure had the most significant influence on drug release time, but the binder feed rate was also found to be a significant factor (Figure 37).

(a)

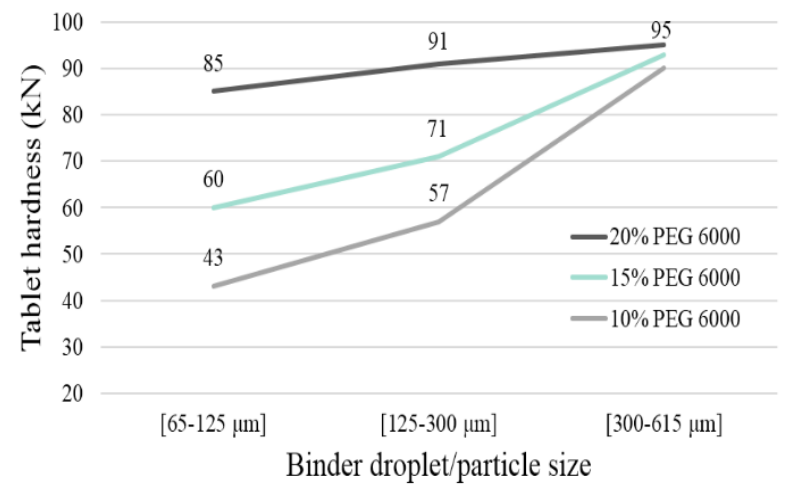

(b)

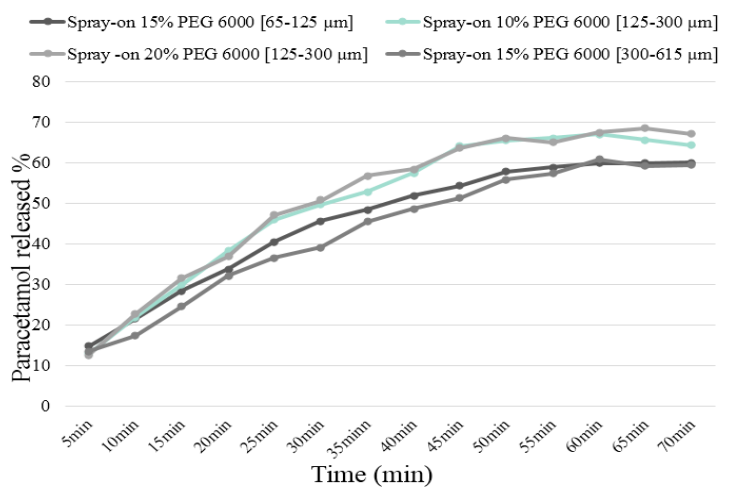

Figure 37: a) Variation of the hardness of tablets with different granule compositions, b) In vitro dissolution profiles of tablets prepared by spray-on and in-situ FBMG.

Drug release was slower from tablets compressed from granules obtained at higher spray air pressure and higher binder feed rate. When granules were compressed into tablets, a binder matrix was formed and kept the drug particles more tightly. After the gradual eroding and dissolving of the tablet matrix, a more uniform binder distribution led to a slower drug release.

\section{Summary}

This part of the experimental work gives a mechanistic understanding of the spray-on and in-situ techniques. First, the elucidation and optimization of the in-situ FBMG binding process were carried out by using ANN modelling. The thermal investigation of granules was a useful technique for the determination of the structure growth of granules and the volume of the melting zone enabled the optimization of granulation under different process conditions and powder mixture compositions. 


\section{CONCLUSIONS AND PRACTICAL USEFULNESS}

The in-line control of pharmaceutical granulation processes was investigated as a possible tool for the evaluation and follow-up of granule formation. In this study, a novel approach to the evaluation of conditions established in a conical fluid bed granulator during the wet and melt fluid bed granulation processes was developed. The two techniques were explored in order to distinguish their linking factors enabling optimal modelling processes.

I. First, the possibility to control the granulation process with predicted temperature distribution profiles was demonstrated. An experimental set-up for the acquisition of temperatures under the PAT in a conical fluidized bed was used for the wet granulation trials and served as a database for a developed artificial neural network model.

II. The hidden layers with a twelve-neuron architecture of the ANN model showed a very good predicting ability of $\mathrm{R}^{2}=0.994$ and allowed the prediction of temperature mappings and the establishment of temperature profiles.

III. These profiles provide information about the hydrodynamic and thermodynamic conditions inside the bed which directly influence particle behavior during granulation as two shapes were identified: bell and funnel shape.

IV. The properties of the final granules are in concordance with the predicted profiles, indicating a distinct connection between the established temperature profiles and the quality attributes of the final particles.

Melt granulation was used as a non-conventional, solvent free and energy friendly technique and the applied process control tool and model brought a new insight into the thermal conditions established during spray-on and in-situ techniques.

V. The Garson equation enabled the determination of the relative importance of each independent input variable and it predicted the particle size of the binder as having the highest impact on the properties of the final granules, followed by binder viscosity grade and binder content. These predictions were in perfect agreement with the experimental results and enabled a very good correlation with $\mathrm{R}=0.99$ for the simulation and prediction of the formation behavior of the granules.

VI. SEM was used as a complementary tool with particle size analysis to evaluate the effect of the material properties on the quality attributes of the final granules and to provide further insight into the growth mechanisms. 
VII. DSC showed that the binder particle size was responsible for the transition from the distribution to the immersion mechanism. This transition was identified by the conversion from $\alpha$-lactose into $\beta$-lactose monohydrate caused by the dehydration of lactose during the FHMG process.

VIII. MS has detected and monitored thermally evolved $\mathrm{H}_{2} \mathrm{O}^{+}(\mathrm{m} / \mathrm{z}=18), \mathrm{CO}_{2}(\mathrm{~m} / \mathrm{z}=44)$ and polyethylene glycol $(\mathrm{m} / \mathrm{z}=31,33)$. The temperature of the dehydroxylation of the granules is influenced by the free volume depending on the content and the particle size of the polymer.

IX. Regarding granule growth, the distribution mechanism occurred when using a low binder particle size and viscosity. The lactose particles lose a fraction of the adsorbed water during the heating phase of granulation. When a high binder particle size is used, the lactose particles will be trapped and immersed in the PEG particles, causing the adsorbed water to be trapped inside the granules.

X. The optimal melting zone volume for the in-situ and spray-on granulation was between 16 and $27 \%$ and 16 and $26 \%$, respectively.

Practical relevance and new approaches of this research work are the following:

1. Wet and melt fluid bed granulation processes can be monitored and controlled using the novel in-line temperature acquisition enabling the thermal characterization of the fluidized bed volume.

2. The correlation between the shape and volume of the wetting zones and the particle size distribution of granules can be used as means for further quality control factor.

3. Thermal analysis proved to be a promising technique for granulation growth control by giving a qualitative and quantitative insight into FBMG.

4. ANN is a potential and useful PAT tool in modelling and developing robust agglomeration processes. 


\section{REFERENCES}

[1] Ennis B. J., Litster J.D. Particle enlargement. Perry's Chemical Engineer's Handbook. $7^{\text {th }}$ ed. New York. 20-56-20-89 (1997)

[2] Parikh D. In: Parikh D. M., ed. Handbook of Pharmaceutical Granulation Technology. 2nd ed. Boca Raton 247-309 (2005)

[3] Banks M. and Aulton M. E.: Fluidized-bed granulation: a chronology, Drug Dev. Ind. Pharm. 17, 1437-1464 (1991)

[4] Watts D. C. and Hussain A. S.: Process Analytical Technology. Handbook of pharmaceutical granulation technology. $2^{\text {nd }}$ ed. Boca Raton. 544-550 (2005)

[5] Guidance for Industry: PAT - A Framework for Innovative Pharmaceutical Development, Manufacturing, and Quality Assurance. September (2004)

[6] Chan L., Tan L., Heng P.: Process analytical technology: application to particle sizing in spray drying, AAPS Pharm. Sci. Tech. 9, 259-266 (2008)

[7] Lister J.D. and Sarwono R.: Fluidized drum granulation: studies of agglomerate formation, Powder Technol. 88, 165-172 (1996)

[8] Dixit R. and Puthli S.: Fluidization technologies: aerodynamic principles and process engineering, J. Pharm. Sci. 98, 3933-60 (2009)

[9] Mašić I., Ilić I., Dreu R., Ibrić S., Parojčić J., Srčič S.: Melt granulation in fluidized bed: a comparative study of spray-on versus in situ procedure, Drug Dev. Ind. Pharm. 40, 23-32 (2014)

[10] Zhai H., Li S., Jones D. S., Walker G. M., Andrews G. P.: The effect of the binder size and viscosity on agglomerate growth in fluidized hot melt granulation, Chem. Eng. J. 164, 275-284 (2010)

[11] Mašić I., Ilić I., Dreu R., Ibrić S., Parojčić J., Đurić Z.: An investigation into the effect of formulation variables and process parameters on characteristics of granules obtained by in situ fluidized hot melt granulation, Int. J. Pharm. 423, 202-212 (2012)

[12] Macias K. A. and Carvajal M. T.: Advances in Process Controls and End-Point Determination. Handbook of pharmaceutical granulation technology. $3^{\text {rd }}$ ed. New York: 567 (2010)

[13] Tok A., Goh X., Ng W., Tan R. B. H.: Monitoring granulation rate processes using three PAT tools in a pilot-scale fluidized bed, AAPS Pharm. Sci. Tech. 9, 1083-1091 (2008)

[14] Food and Drug Administration. Guidance for industry on PAT - a framework for innovative pharmaceutical development, manufacturing, and quality assurance, September (2004)

[15] Frake P., Greenhalgh D., Grierson S. M., Hempenstall J. M., Rudd D. R.: Process control and end-point determination of a fluid bed granulation by application of near infra-red spectroscopy, Int. J. Pharm. 151, 75 (1997) 
[16] Närvänen T., Seppälä K., Antikainen O., Ylirussi J.: A new rapid on-line imaging method to determine particle size distribution of granules, AAPS Pharm. Sci. Tech. 9, 282-287 (2008)

[17] Lin S. Y., Cheng W. T., Wang S. L.: Thermal micro-Raman spectroscopic study of polymorphic transformation of famotidine under different compression pressures, J. Raman Spectrosc. 38, 39-43 (2007)

[18] Dao N. and Jouan M.: The Raman laser fiber optics (RLFO) method and its applications, Sens Actuators B. 3, 147-160 (1993)

[19] Litster J. and Ennis B. J.: The Science \& Engineering of Granulation Processes. Dordrecht, The Netherlands: Kluwer Academic, (2004)

[20] Korteby Y., Mahdi Y., Azizou A., Daoud K., Regdon G. jr, Implementation of an artificial neural network and a PAT tool for the prediction of the temperature distribution in a pharmaceutical fluidized bed granulator, Eur. J. Pharm. Sci. 88, 219-232 (2016)

[21] Jiménez T., Turchiuli C., Dumoulin E.: Particles agglomeration in a conical fluidized bed in relation with air temperature profiles, Chem. Eng. Sci. 61, 5954-5961 (2006)

[22] Rantanen J., Lehtola S., Rämet P., Mannermaa J. P., Ylirussi J.: On-line monitoring of moisture content in an instrumented fluidized bed granulator with multi-channel NIR moisture sensor. Powder Technol. 99, 163-170 (1998)

[23] Andersson M., Folestad S., Gottfires J., Johansson M. O., Josefson M., Wahlund K. G.: Quantitative analysis of film coating in a fluidized-bed process by in-line NIR spectroscopy and multivariate batch calibration, Anal. Chem. 72, 2099-2108 (2000)

[24] Vervaet C. and Remon J. P.: Handbook of pharmaceutical granulation technology: Melt Granulation. $3^{\text {rd }}$ ed. New York. 435-448 (2010)

[25] Shiino K., Iwao Y., Fujinami Y., Itai S.: Preparation and evaluation of granules with pHdependent release by melt granulation, Int. J. Pharm. 431, 70-77 (2012)

[26] Zhang S., Meng X., Wang Z., Fan A., Wang G., Zhao Y., Tang Y.: Engineering hot-melt extruded solid dispersion for controlled release of hydrophilic drugs, Eur. J. Pharm. Sci. 100, 109-115 (2017)

[27] Villa M.P., Bertin D.E., Cotabarren I.M., Pina J., Bucala V.: Fluidized-bed melt granulation: coating and agglomeration kinetics and growth regime prediction, Powder Technol. 300, 61-72 (2016)

[28] Abberger T., Seo A., Schaefer T.: The effect of droplet size and powder particle size on the mechanisms of nucleation and growth in fluid bed melt agglomeration, Int. J. Pharm. 249, 185-197 (2002)

[29] Johansen A. and Schaefer T.: Effect of interactions between powder particle size and binder viscosity on agglomerate growth mechanisms in a high shear mixer, Eur. J. Pharm. Sci. 12, 297-309 (2001) 
[30] Schaefer T.: Growth mechanisms in melt granulation in high shear mixers, Powder Technol. 117, 68-82 (2001)

[30] Korteby Y., Kristó K., Sovány T., Regdon G. jr.: Use of machine learning tool to elucidate and characterize the growth mechanism of an in-situ fluid bed melt granulation. Powder Technol. 331, 286-295 (2018)

[31] Walker G. M., Bell S. E. J., Greene K., Jones D. S, Andrews G. P.: Characterisation of fluidised bed granulation processes using in-situ Raman spectroscopy, Chem. Eng. Sci.64, 9198 (2009)

[32] De Matas M., De Beer T., Folestad S., Ketolainen J., Lindén H., Lopes J. A., Oostra W., Weimer M., Öhrngren P., Rantanen J.: Strategic framework for education and training in Quality by Design (QbD) and process analytical technology (PAT), Eur. J. Pharm. Sci. 90, 27 (2016)

[33] Lister J. D. and Sarwono R.: Fluidized drum granulation: studies of agglomerate formation, Powder Technol. 88, 165-172 (1996)

[34] Murtoniemi E., Yliruusi J., Kinnuen P., Merkku P., Leiviska K.: The advantages by the use of neural networks in modelling the fluidized bed granulation process, Int. J. Pharm. 108, 155-164 (1994)

[35] Chaibva F., Burton M., Walker R. B.: Optimization of salbutamol sulfate dissolution from sustained release matrix formulations using an artificial neural network, Pharmaceutics. 2, 182198 (2010)

[36] Sovány T., Tislér Zs., Kristó K., Kelemen A., Regdon G. jr.: Estimation of design space for an extrusion-spheronization process using response surface methodology and artificial neural network modelling, Eur. J. Pharm. Biopharm. 106, 79-87 (2016)

[37] Sun Y., Peng Y., Chen Y., Shukla A. J.: Application of artificial neural networks in the design of controlled release drug delivery systems, Adv. Drug Deliv. 55, 1201-1215 (2003)

[38] Mahdi Y. and Daoud K., Microdroplet size prediction in microfluidic systems via artificial neural network modelling for water-in-oil emulsion formulation, J. Dispers. Sci. Technol. 32, 1501-1508 (2017)

[39] Jha B. K., Tambe S. S., Kulkarni B. D.: Estimating diffusion coefficients of a micellar system using an ANN. J. Coll. Interface Sci.; 170, 392-398 (1995)

[40] Ansari M. A. and Stepanek F.: Formation of hollow core granules by fluid bed in situ melt granulation: modelling and experiments, Int. J. Pharm. 321, 108-116 (2006)

[41] Garson G. D.: Interpreting neural-network connection weights, A. I. Exp. 6, 47-51 (1991)

[42] Regdon, G. jr., Korteby, Y.: J. Therm. Anal. Calorim. https://doi.org/10.1007/s10973-0176848-5 (2017) 


\section{ACKNOWLEDGMENT}

I wish to thank Prof. Dr. Piroska Szabó-Révész, Head of the Pharmaceutical Technology Educational Program of the Doctoral School of Pharmaceutical Sciences and Dr. Ildikó Csóka, Head of the Institute of Pharmaceutical Technology and Regulatory Affairs for providing me with the opportunity to work in the department and to complete my assignments.

I would like to express my deepest gratitude to my supervisor Dr. Géza Regdon jr. for wisely helping me pave my way in a foreign field, for his immense patience, his encouragements, and guidance and mostly for believing in me in times of doubts. His work methodology shaped my research.

I would like to express my grateful thanks to Prof. Dr. Kamel Daoud for this guidance and useful advice during my Ph.D. work.

I express my kindest gratitude to Dr. Katalin Kristó and Dr. Tamás Sovány for their good advice, criticism and valuable help in my research experiments.

I am indebted to all my colleagues in the solid dosage form team, who lent me anything from technical support to a shoulder to cry on. I am grateful for their contribution.

I thank all members of the Institute of Pharmaceutical Technology and Regulatory Affairs for their help and providing a friendly atmosphere.

My heartfelt thanks to my parents, my brother, my fiancé and my friends for their unconditional love, support, understanding and patience. 


\section{ANNEX \\ Related articles}


I. 


\title{
Implementation of an artificial neural network as a PAT tool for the prediction of temperature distribution within a pharmaceutical fluidized bed granulator
}

\author{
Yasmine Korteby ${ }^{\text {a,b }}$, Yassine Mahdi ${ }^{\text {b }}$, Amel Azizou ${ }^{\text {b }}$, Kamel Daoud ${ }^{\text {b }}$, Géza Regdon Jr. ${ }^{\text {a,* }}$ \\ a Departement of Pharmaceutical Technology, University of Szeged, H-6720 Szeged, Eötvös utca, 6, Hungary

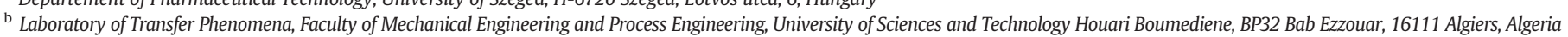

\section{A R T I C L E I N F O}

\section{Article history:}

Received 10 November 2015

Received in revised form 29 January 2016

Accepted 9 March 2016

Available online 15 March 2016

\section{Keywords:}

Fluidized bed

Granulation

Temperature profiles

Process Analytical Technology

Temperature prediction

Artificial Neural Networks

\begin{abstract}
A B S T R A C T
In this study, a novel in-line measurement technique of the air temperature distribution during a granulation process using a conical fluidized bed was designed and built for the purpose of measuring the temperature under the Process Analytical Technology (PAT) and introduced to predict the establishment of temperature profiles. Three sets of thermocouples were used, placed at different positions covering the whole operating range, connected to data acquisition measurement hardware, allowing an in-line acquisition and recording of temperatures every second. The measurements throughout the fluidized bed were performed in a steady state by spraying a solution of PVP onto a lactose monohydrate powder bed in order to make predictions of the temperature distribution and the hydrodynamics of the bed during the granulation process using Artificial Neural Networks (ANNs) and to establish the different temperature profiles for different process conditions through the precise predicted information by the constructed, trained, validated and tested neural network. The model's testing results showed a strong prediction capacity of the effects of process variables. Indeed, the predicted temperature values obtained with the ANN model were in good agreement with the values measured with in-line reference method and hence the method can have an application as a predictive control tool.
\end{abstract}

(c) 2016 Elsevier B.V. All rights reserved.

\section{Introduction}

Fluidized bed granulation is a very common and widely applied technique among different processes for solid granulation in the pharmaceutical industry. It leads to the production of high-quality, low dust and low attrition solids by modifying their physical properties (size, shape, density, porosity) (Banks and Aulton, 1991; Radichkov et al., 2006; Sherrington and Oliver, 1981; Pietch, 1984). Both the spraying and drying of the agglomerates are carried out in a single piece of equipment offering several advantages over other multi-step granulation and drying processes (Smith, 1980; Kivikero et al., 2007; Närvänen, 2008; Petrović et al., 2011). This results in the reduction of the manufacturing processes and manufacturing time, which benefits the Good Manufacturing Practice (GMP) requirements (Gao et al., 2002). Nowadays, the fluidized bed is applied for drying, agglomeration, and pellets coating (Nikowitz et al., 2013).

Process Analytical Technology (PAT) plays a central role in current regulations on pharmaceutical production processes. The proper understanding of all operations and variables connecting the raw materials to the end products is one of the key factors to ensuring the quality of the products and continuous improvement in their production (Rosas et al., 2012).

\footnotetext{
* Corresponding author.

E-mail address: geza.regdon@pharm.u-szeged.hu (G. Regdon).
}

Many attempts can be found to describe the relationship between temperatures within the fluidized bed and particle formation during granulation. Smith and Nienow (1983) showed the existence of an area next to the spraying nozzle where low temperatures cover the top surface of the bed, indicating a possibility for the medialization of the granulation in the fluid bed chamber. Maronga and Wnukowski (1997) established temperature and humidity profiles in a coating process and used them in optimizing the size of fluidized bed. This was complemented quite recently with the works of Jiménez et al. (2006) and Turchiuli et al. (2011), as three distinct temperature regions were identified and that the size of these zones varied with the operating parameters affecting the agglomeration efficiency.

Another powerful technique that is rapidly gaining importance in many research areas is Artificial Neural Networks (ANNs). It has been applied for the development and optimization of dosage forms (Chaibva et al., 2010; Takayama et al., 2003; Sun et al., 2003; Chen et al., 2001). The reason is the ANN high ability to learn and solve problems through patterns (Zurada, 1992; Haykin, 2009). A significant difference between an ANN model and a statistical model is that the ANN works well for solving nonlinear problems of multivariate and multiresponse systems.

The main objective of this paper is to use the training and prediction capacity of ANNs to describe the establishment of different temperature profiles by developing a model that takes account of the process 
parameters, depicts the characteristics of the temperature distribution in order to demonstrate the relationship between the process parameters and the final granule properties and investigates the possibility of controlling the granulation process using the developed model as a predictive control tool.

\section{Materials and methods}

\subsection{Materials}

In this study, lactose monohydrate (Biopharm Industry, Algeria) with a mean diameter of $29.56 \mu \mathrm{m}$ was used. A quantity of $5 \mathrm{~kg}$ was used for the establishment of the temperature profiles and granulation trials. An aqueous solution of $5 \% \mathrm{w} / \mathrm{w}$ of Povidone K30 (Prochima Sigma, Algeria) was used as a binder to granulate the dry lactose powder.

\subsection{Equipment}

Experiments were performed in a conical fluidized bed built for this study. The pilot plant had a capacity of up to $500 \mathrm{~g}$ operating in batch process where liquid was top sprayed by means of a bi-fluid nozzle placed vertically at $220 \mathrm{~mm}$ from the air distributor plate. The diameter of the conical part of the bed was $140 \mathrm{~mm}$ at the bottom and $280 \mathrm{~mm}$ with a tapered angle of $9.8^{\circ}$. To provide an even air distribution, the granulator was fitted with a calming zone filled with plastic spheres. This calming zone was designed to evenly distribute the airflow across the column and allows a fully developed equalized air flow (Yang, 2003; Gupta and Sathiyamoorthy, 1998). The distributor plate was made up of a steel punched plate, $30 \%$ perforated and $0.5 \mathrm{~cm}$ thick, and a steel wire mesh $(\mathrm{w}=0.325 \mathrm{~mm})$. Two filter bags were placed at the top providing the purge of the outlet air. Fig. 1 shows the main features of the fluidized bed granulator.

\subsection{Experiment}

For each trial, a $100 \mathrm{~g}$ batch of lactose particles was fluidized with hot air at a rate of $0.01 \mathrm{~m}^{3} / \mathrm{min}$. The fluidizing air flow rate was kept constant to ensure a constant bed height. Its temperature was measured and regulated with a thermocouple placed at the outlet of the heater and a second one placed right above the distribution plate. The binder solution $\left(20-22^{\circ} \mathrm{C}\right)$ was sprayed at a constant feed rate between 5 and $20 \mathrm{ml} / \mathrm{min}$ and a spraying pressure of 2 bars after a stationary condition of the bed was established. During all trials, process parameters (air inlet temperature, air flow rate, liquid feed rate and spraying pressure) were kept constant. Twelve conditions were tested changing one process variable at a time: liquid flow rate: $5,10,15$ and $20 \mathrm{ml} / \mathrm{min}$, inlet air temperature: 45,55 and $65^{\circ} \mathrm{C}$.

\subsection{Sampling}

Particles growth was followed along the trial by removing approximately $3 \mathrm{~g}$ of samples from the bed at 5 min intervals using a vacuum sampling system placed on the wall of the bed at $100 \mathrm{~mm}$ above the distribution plate. The samples were analyzed off-line for moisture content by loss-on-drying at $105^{\circ} \mathrm{C}$ using a Precisa XM60 moisture analyzer. The size distribution of the samples was measured using a Malvern Mastersizer 2000 (Malvern Instruments, Ltd., England). The flowability test was conducted and the Carr and Hausner index was determined using a volumenometer (Erweka).

\subsection{Data acquisition}

For the measurement of fluidizing air temperature at different parts of the bed, three sets of three, 100-mm-long, type $\mathrm{K}$ thermocouples were arranged and separated by an angle of $120^{\circ}$ at distances of 50 , 130, $210 \mathrm{~mm}$ from the air distribution plate, positioned horizontally and held by steel supports allowing a horizontal motion over the whole operating range from the center axis of the bed to the bed's wall (Fig. 2). Simultaneous measurements of temperature distribution were recorded enabling a verification of the symmetry of the bed because for each set of thermocouples located at the same level and the same distance from the center axis $\mathrm{a}=1{ }^{\circ} \mathrm{C}$ fluctuation of temperature was measured.

These thermocouples were connected to a multiple component data acquisition measurement hardware (Pico Technology, Germany), which made an interface between the signal and a computer connected by a USB port. All signals obtained with the data acquisition system were analyzed in-line with Pico program (Pico Technology, Germany), allowing the acquisition and recording of temperatures at each set of

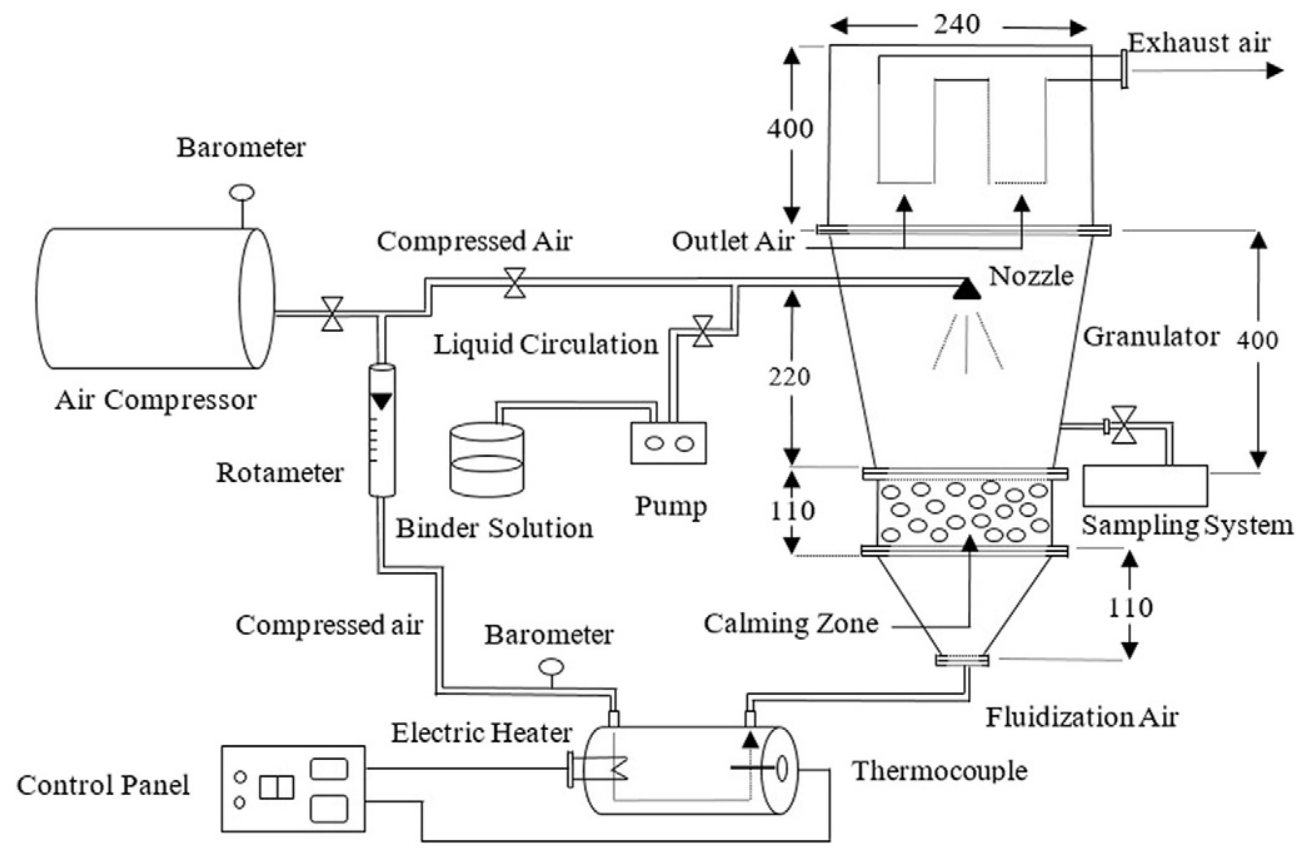

Fig. 1. Schematic diagram of the experimental layout of the fluidized bed granulator. 


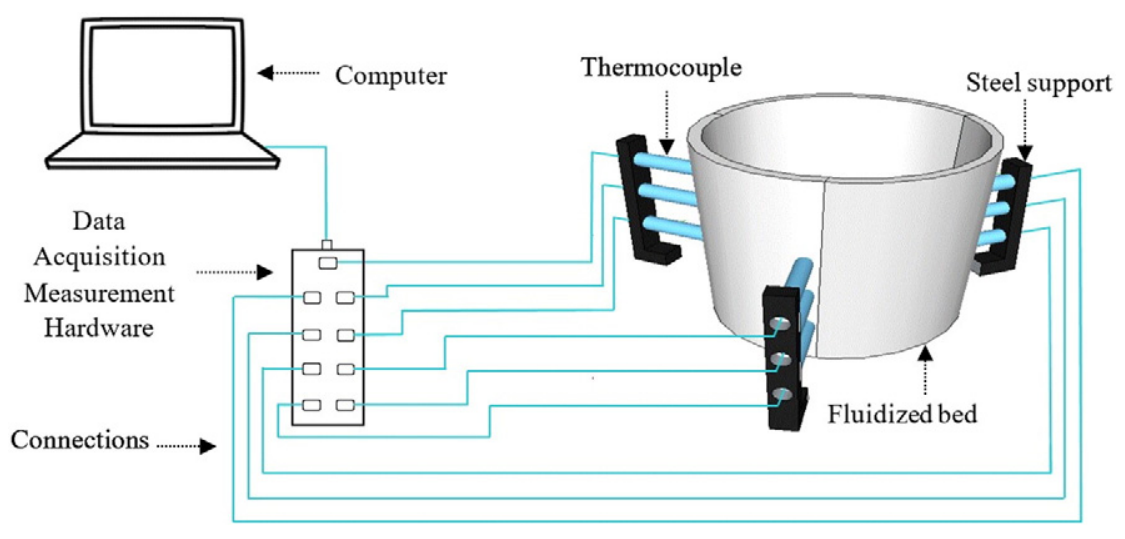

Fig. 2. Bed cross-section showing the position and path of the probes.

thermocouples every $1 \mathrm{~s}$. For each thermocouple located at the same level from the air distribution plate, 53 recordings were obtained in all and 15 recordings for measurements from different distances from the center axis of the bed, and for each thermocouple an average value of those temperatures was taken.

\subsection{Data processing}

For the establishment of temperature profiles, an ANNs toolbox on MATLAB ${ }^{\circledR}$ (R2014a, MathWorks ${ }^{\circledR}$ ) was used throughout this study enabling the selection of the number of hidden layers, hidden layer nodes, iterations used during model training, learning algorithm, and transfer functions. The trained ANN model is also able to provide values of input strengths, which indicate the significance of the effect of each input on the output (predicted) data. When each set of data is presented to the ANN network, the algorithm computes the error between the measured temperature and the ANN predicted output temperature.

In the present study, the input data for the prediction of the temperature distribution within the fluidized bed were the actual data measured by the thermocouples. The total error (sum of error squares) for each value is the sum of the squares of the differences between the actual and the ANN predicted (output) data. This error was used as a measurement for selection of the optimal ANN architecture, and the ANN architecture with the lowest error was selected as the calibration model.

\subsection{Artificial Neural Networks structure and model training}

In this study, the constructed ANN had a two hidden layer feedforward architecture. The back-propagation algorithm, as one of the well-known training algorithms for the multilayer perceptron, is a gradient descent technique to minimize the error for a particular training pattern in which it adjusts the weights by a small amount at a time (Guleser et al., 2012). The non-linear sigmoid activation function was used in the hidden layers and the neuron outputs at the output layer. Momentum rate and learning rate values were determined and the model was trained through iterations.

There were 432 input data that were used to train, test and validate the neural network. The data was split into three categories, the training, test and validation data sets, where $70 \%$ of the data set was used for training, $15 \%$ as the test data and $15 \%$ as the validation data.

\subsection{Characterization and architecture of the ANN}

To ensure the optimal ANN structure, the hyperbolic tangent transfer function, equation (1) was chosen as an activation function for all the neurons in the network. This function enables to limit the output amplitude between -1 and 1 , it is designated in MATLAB $®$ by TANSIG.

$(n)=\left(\exp ^{n}-\exp ^{-n}\right) /\left(\exp ^{n}+\exp ^{-n}\right)$.

The learning phase of the neural network is performed using the feedforward back propagation algorithm, the connection weights of the network are adjusted using the delta rule based on the Levenberg-Marquardt method, and it is designated in MATLAB ${ }^{\circledR}$ by TRAINLM.

When the number of iterations (epochs) exceeds 1000 , or the mean square error equals 0 , or the mean squared error of validation increases during 6 successive iterations, the algorithm stops corresponding to the end of the learning phase.

The selection of the appropriate ANN model (selection of the number of hidden layers and the number of hidden neurons) is based on its learning ability and predictability; hence, the model which presents the lowest mean square error of validation. This helps avoid the overtraining of the neural network.

An appropriate ANN calibration model with two hidden layers was generated from the remaining $70 \%$ of the data. The number of hidden layer nodes for the calibration models varied from 1 to 20 for the architecture with one hidden layer and from 1 to 20 for the architecture with two hidden layers. The architecture of the ANN model that yielded the least sum of error squares (i.e., error between the actual values and the predicted values of the validation data set) was selected as the optimal ANN calibration model. After the analyses of the obtained results for each configuration, it showed that the network with two hidden layers and twelve neurons in each hidden layer (Fig. 5) presented the smallest validation mean square error (VMSE) of $1.4 \cdot 10^{-3}$ as shown in Fig. 3.

The learning of the neural network stopped at 38 epochs because the mean square error on validation was only increasing for 6 epochs as shown in Fig. 4. The final connection weight values for the neural network will then be those corresponding to epoch 32 . Hence, this model is the optimal for the best prediction of the distribution of temperature within the fluidized bed granulator.

The ANN model in this research has twelve neurons in the first and second hidden layer, four in the input layer and one neuron in the output layer as demonstrated in Fig. 5. The factors for the input layer were the positions from the center axis of the bed (X), the distances from the distribution plate $(\mathrm{Y})$, the inlet air temperature $(\mathrm{Tm})$ and the liquid flow rate $(\mathrm{Ql})$. The value for the output layer was the predicted temperature $(\mathrm{T})$. The input data points are combined with random weights as in a linear regression model $(\Sigma)$ and then will be transformed through the non-linear function which enables the non-linear modeling of an ANN model. 


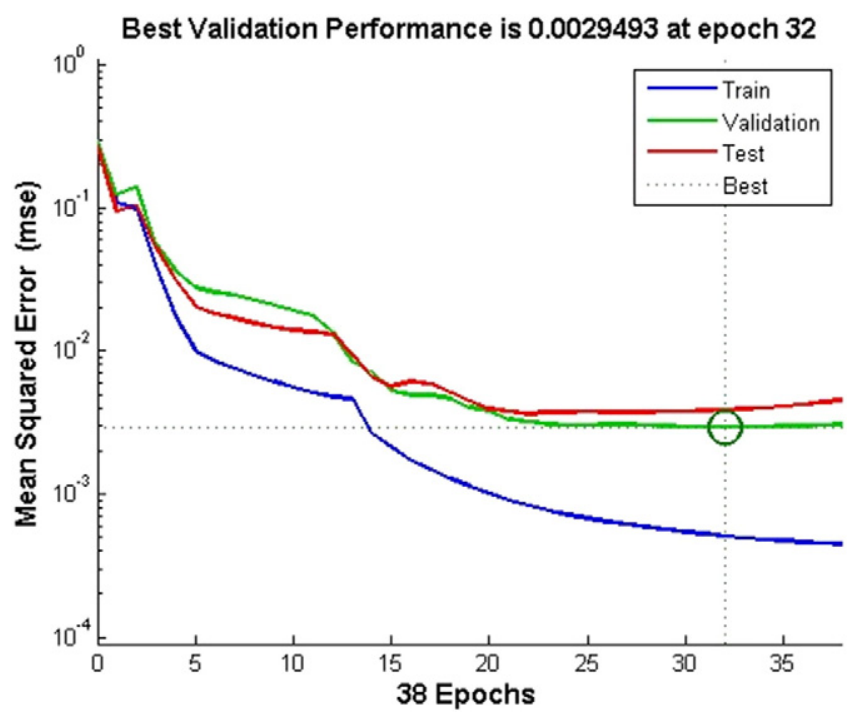

Fig. 3. Evolution of the MSE as a function of epochs.

\section{Results and discussion}

All of the results obtained from experimental studies and predicted by the training, validation and testing results of the ANN and model are given in Fig. 6a and b. The linear least square fit line, its equation and the $\mathrm{R}^{2}$ values are shown in these figures for the training, validation and testing data. Also, input values and experimental results with residuals obtained from the ANN model are presented in Fig. 6, the values obtained from the training, validation and testing in the ANN model are very close to the experimental results. The result of testing phase in Fig. 6 shows that the ANN model is capable of generalizing between input and output variables with reasonable predictions.

\subsection{Temperature distribution in the fluidized bed}

Fig. 7 shows a section of the chart of the fluidized bed temperature variation as a function of time, determined through the measurements of three sets of thermocouples placed at respective distances from the center axis of the distribution plate. Initially, the temperature of the granules increased until reaching the inlet air temperature set value, representing the pre-heating phase. Right after, the temperatures of the bed dropped significantly, representing the wetting phase where
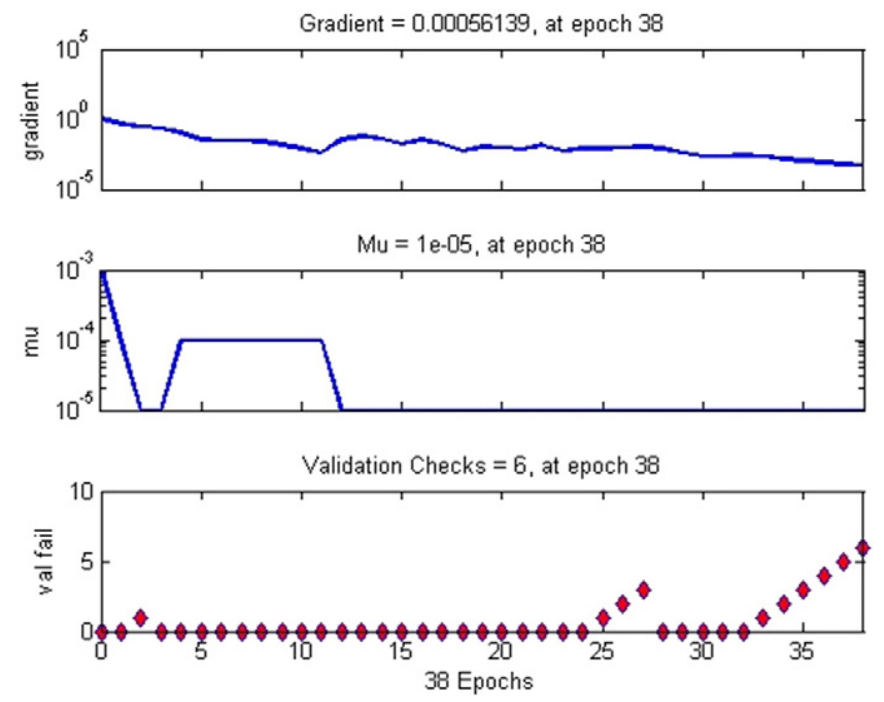

Fig. 4. Training state. Fig. 5. Schematic representation of the used ANN architecture. the binder liquid was deposited on the particles and some initial drying took place, when the temperatures are constant and a stationary phase is established, temperature measurements are performed for the model database, and then temperatures increased again in the drying phase until reaching a plateau at a temperature of about $45^{\circ} \mathrm{C}$, indeed; once the granules were surface dry, the bed temperature began to increase and approach the inlet air temperature.

In this study, the targeted period was the wetting phase, being an important phase in the granulation process. It enables to obtain much information about the established conditions that would describe the agglomeration process. All signals obtained with the data acquisition system helped make a matrix of temperature measurements for the different operating conditions, those measurements were analyzed with MATLAB ${ }^{\circledR}$ using the adequate ANN model and a built-in function 'contour' to establish the temperature mappings.

\subsection{Characteristics of the temperature profiles}

The predicted temperature profiles revealed that the bed contained a low temperature region located in the upper part of the bed right below the spraying nozzle, extending toward the bed's wall and air distributor plate (Figs. 8 and 9). The results show that in this region, air temperature was 15 to $20^{\circ} \mathrm{C}$ below the inlet air temperature and the lowest gas temperature value was situated at the top of the fluidized bed surface. Temperatures then rose dramatically away from the center axis leading to increasingly close isotherms, which implies important temperature gradients.

These gradients varied proportionally with the increase of the inlet air temperature and inversely proportionally with the increase of the liquid feed rate. Indeed, Figs. 8 and 9 show that for a flow rate of $5 \mathrm{ml} / \mathrm{min}$ and an inlet temperature of $65^{\circ} \mathrm{C}$, the temperature gradient predicted at a distance of $21 \mathrm{~cm}$ from the distribution plate was $21{ }^{\circ} \mathrm{C}$ while for measured at a distance of $6 \mathrm{~cm}$, the temperature gradient was $10^{\circ} \mathrm{C}$. Also, for a flow rate of $20 \mathrm{ml} / \mathrm{min}$, the temperature gradient went from $12^{\circ} \mathrm{C}$ for predictions at a distance of $21 \mathrm{~cm}$ from the distribution plate to $8{ }^{\circ} \mathrm{C}$ for measurement points at a distance of $6 \mathrm{~cm}$.

The tangent of the gradient in the upper part of the bed expresses the drastic thermal change in the narrow area closest to the center axis. In the lower part of the bed though (Fig. 9), this temperature variation appears slower and the tangent of gradient smaller and seems to extend toward the bed's wall. This corresponds to a transition between high and low temperature zones where heat and mass transfer occurs.

In the outer part of the bed, the predicted temperatures seemed to present a constant value between the top and bottom part of the measurement region, extending toward the bed's walls. The isotherms are getting further and further apart describing a stationary state, which indicates a second predominant zone.

In the lower part of the bed, a wide area of small gradual temperature variation is noticeable. In fact, the tangent gradient is relatively low and spreads over most of the bed's diametral plane (Fig. 9). It is due to the collision between the warm entering air and the cold spraying liquid.

The developed ANN model allowed the prediction of temperatures in every $1 \mathrm{~mm}$ distance (Figs. 8 and 9), which made the detection of the temperature variations clear, precise and more specific to each operating condition. Hence, the identification and determination of thermal zones became possible.

The first zone is near the spraying nozzle where dry solid particles get sprayed and wet by the binder liquid corresponding to the wetting zone, the second zone was found to extend toward the bed's walls where the sprayed particles are dried to solidify the formed liquid bridges from the wetting zone and it corresponds to the isothermal zone. The third zone is located near the air distribution plate where an important contact zone between the two hot and cold fluids is set corresponding to the heat transfer zone. 


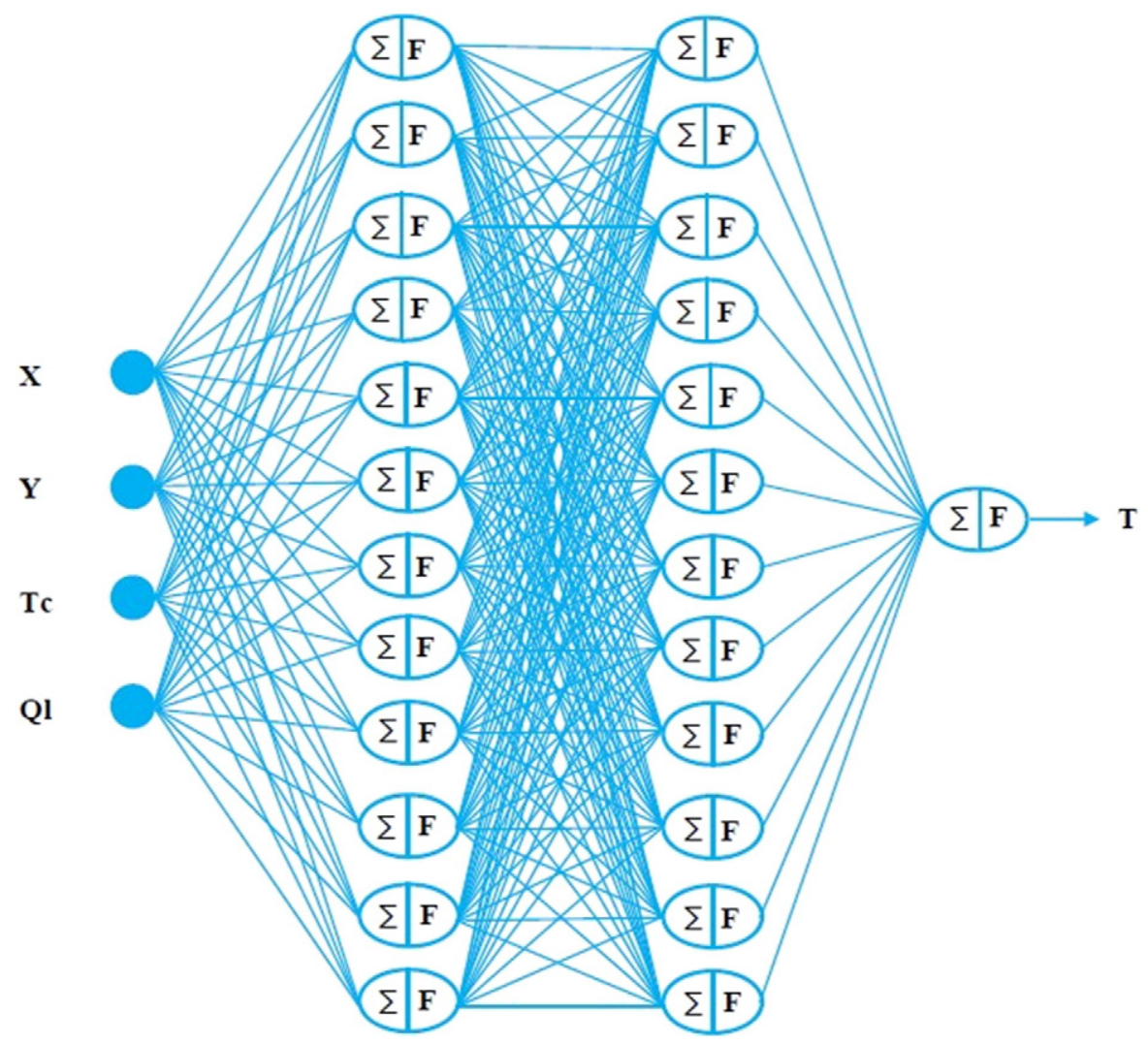

Fig. 5. Schematic representation of the used ANN architecture.

\subsection{Shapes of predicted temperature profiles and particle patterns}

Predicted temperature mappings for the lactose-PVP solution system are shown in Figs. 10 and 11. The profiles represent the top part of the bed close to the spraying nozzle with spraying rates of 5 and $20 \mathrm{ml} / \mathrm{min}$ and the bottom part with an inlet air temperature of $45^{\circ} \mathrm{C}$. The color map of the bed's diametric plane provides a clear description of the temperatures and temperature difference intensities in all regions of the bed, showing areas of high and low temperatures with warm and cold colors, respectively, and both are surrounded by contours.

The profiles obtained revealed that the outline of the low temperature zones is represented with a clear yellow band. These outlines depend on the process parameters and follow two main shapes. Both shapes differ in their expansion path toward the air distribution grid because of the particle circulation in the conical fluidized bed.

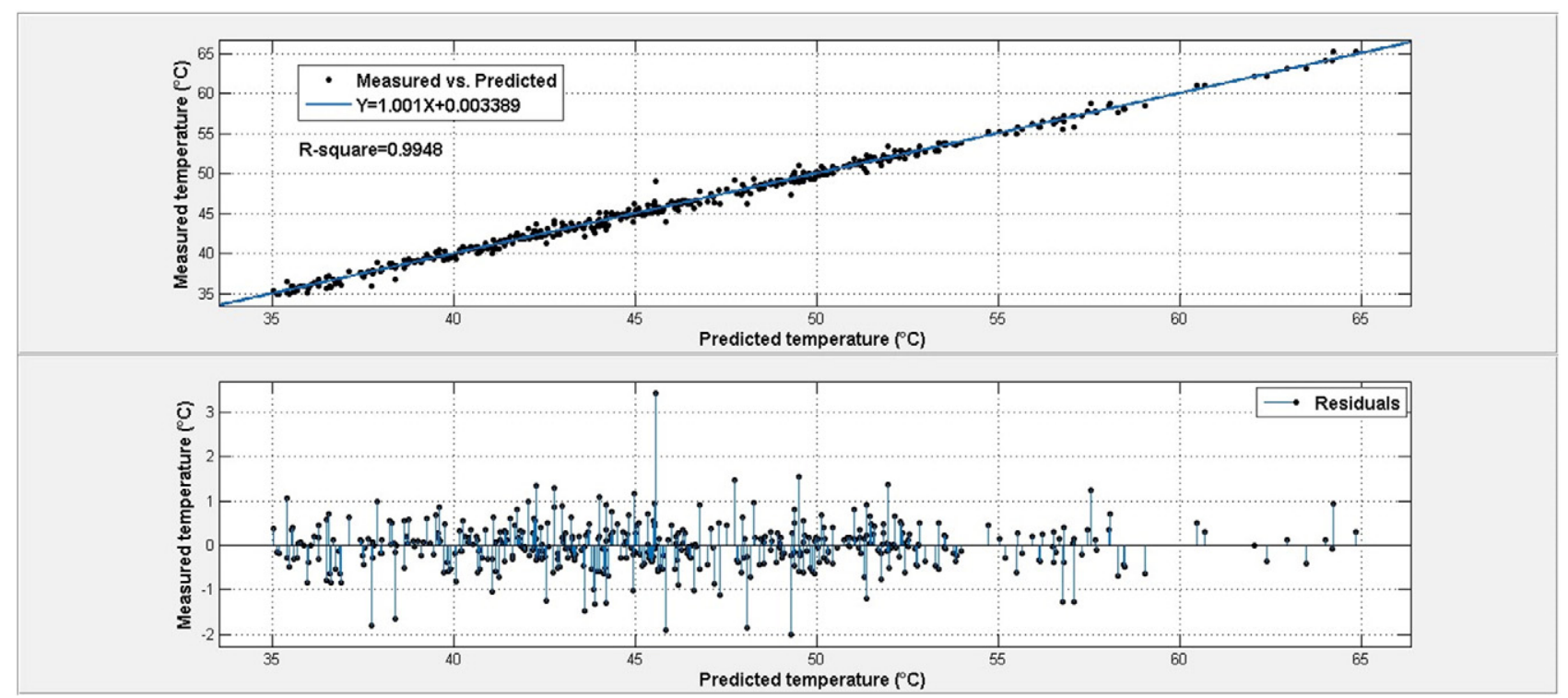

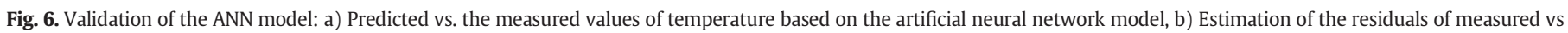
predicted temperatures. 


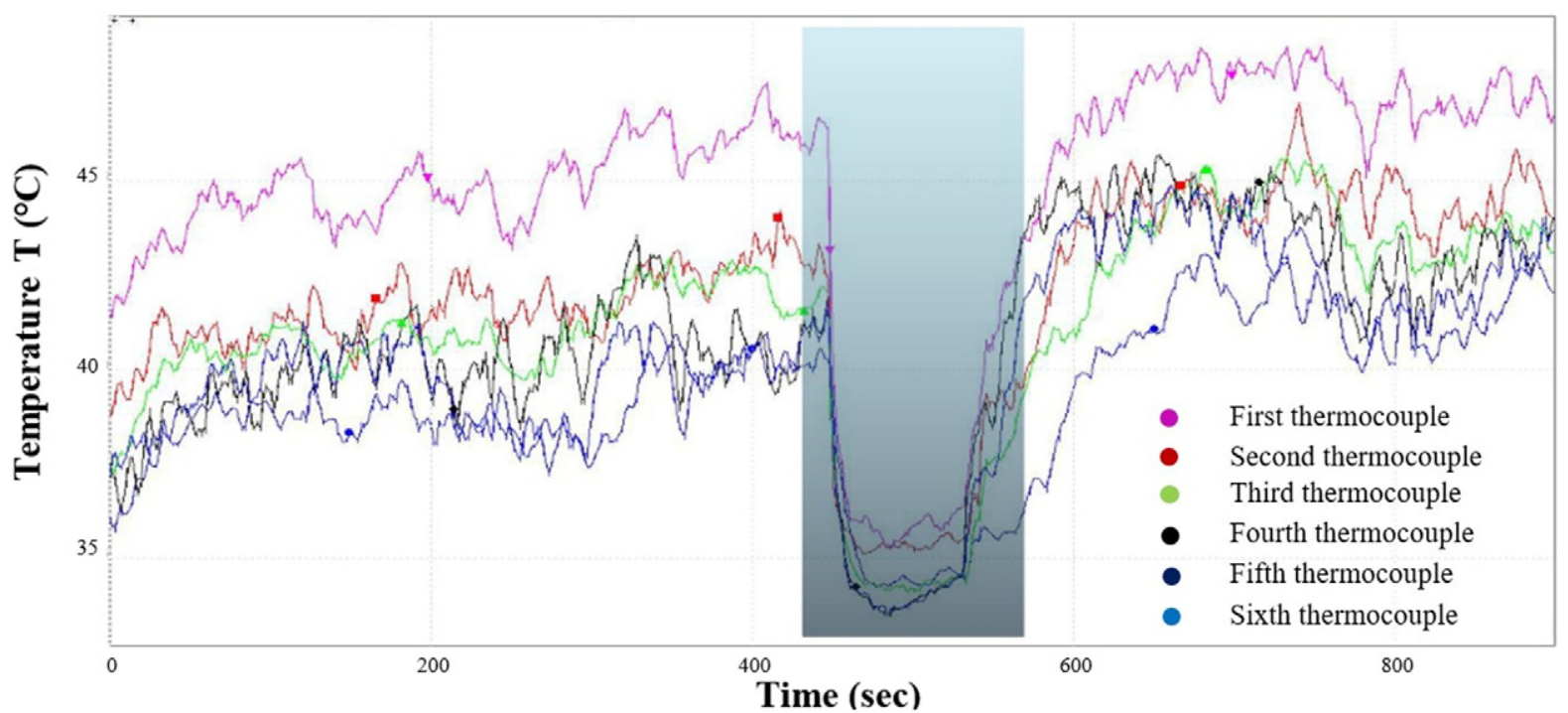

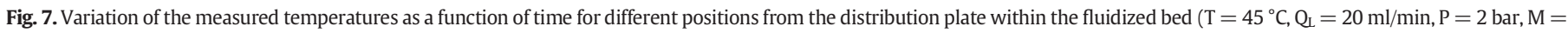
$200 \mathrm{~g})$.

Indeed, the outline of the low temperature zone formed a "bell" shape (Fig. 10). It was observed for high liquid spraying rates and low inlet air temperature corresponding to an upward movement of the particles at the sides, near the container walls, and downwards through the center after wetting by the liquid droplets. This circulation pattern is due to the fact that the binder flow rate overpowers the inlet air stream forcing the dried particles to deviate toward the bed walls without sticking, which makes it propitious to control agglomeration.

The second shape is called "funnel" shape (Fig. 11). It was observed for the lower liquid flow rate $(5 \mathrm{ml} / \mathrm{min}$ ) and both high and low inlet air temperatures. Particles would rise up in the center to the upper surface of the bed, get sprayed in the wetting zone by the binder solution droplets and then fall back to the bottom part along the container walls. In this case, the risk of insufficiently dried particles is very high and may cause them to stick to the walls, making it hard to control the agglomeration.

These predicted profile shapes can be used to determine the proper distribution profile for a better controlled agglomeration process. Its boundaries can be delimited using the outline of the thermal zones where the gradient of temperature between two adjacent predicted temperatures is closest to zero, as they represent a transition between

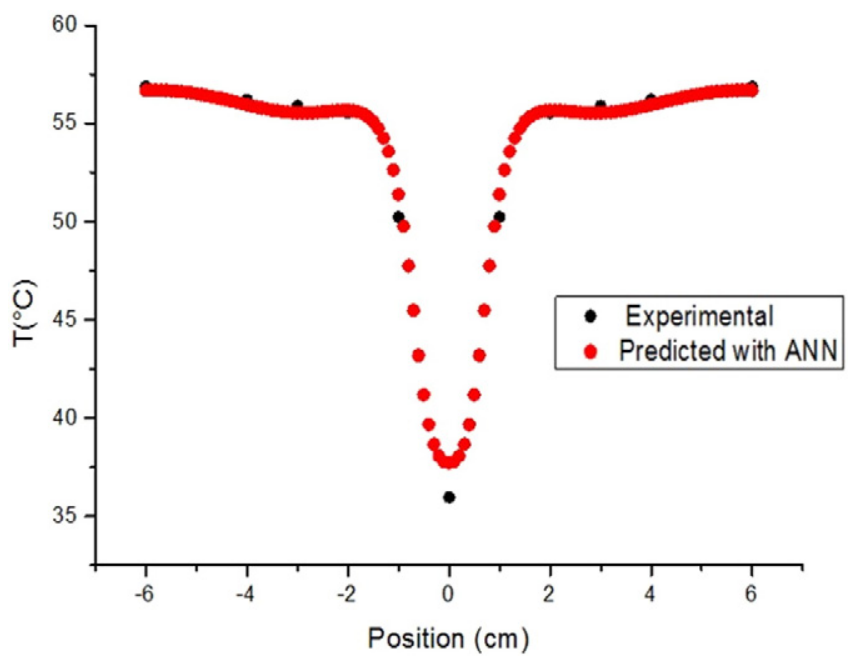

Fig. 8. Predicted vs measured temperatures for a distance of $21 \mathrm{~cm}$ from the distribution plate $\left(\mathrm{T}=65^{\circ} \mathrm{C}, \mathrm{Q}_{\mathrm{L}}=5 \mathrm{ml} / \mathrm{min}, \mathrm{P}=2\right.$ bars, $\left.\mathrm{M}=200 \mathrm{~g}\right)$. the different thermal conditions and a specificity for each operating condition.

\subsection{Particle growth and temperature profiles}

Particles can agglomerate only if they penetrate the wetting zone, where their surface is wetted by liquid droplets forming liquid bridges when they collide. The size of this zone and the transfer rate of particles to this portion of the fluidized bed are therefore very important factors for particle growth as they influence their final properties.

Particle growth by layering takes place when the predicted wetting zone occupies a very narrow area of the total volume of the bed (Saleh, 1998; Jiménez et al., 2006). Inversely, when this predicted wetting zone occupies a large area of the bed, the favored growth mechanism would be coating and the insufficiently dried granules would increase the risks of wet massing. Process conditions leading to a balanced size configuration between the three zones will therefore be favorable for particle growth by agglomeration.

In order to prove the connection between the temperature profiles and the critical quality attributes of the fluidized bed granulation product, tests were conducted on the final granules and the results are summarized in Table 1.

The inlet air temperature determines the air capacity to solidify the liquid bridges. For low inlet temperatures $\left(45^{\circ} \mathrm{C}\right)$, the predicted volume

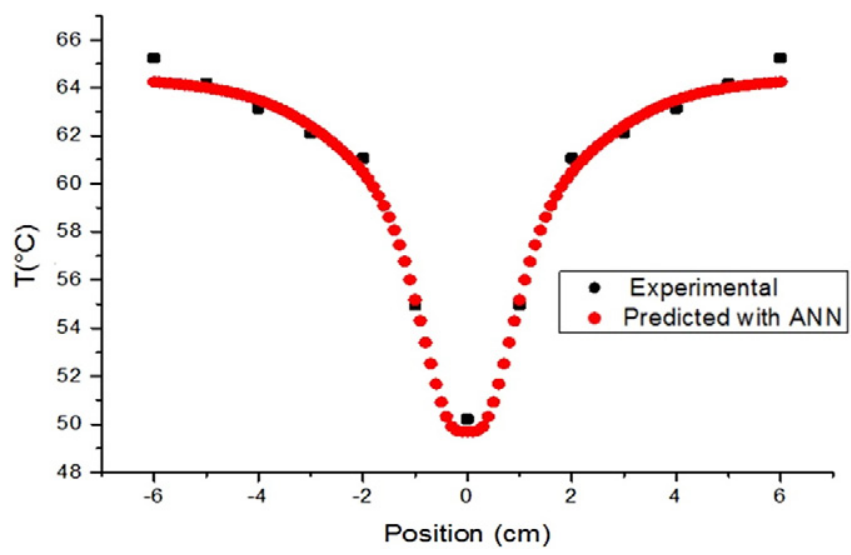

Fig. 9. Predicted vs measured temperatures for a distance of $5 \mathrm{~cm}$ from the distribution plate $\left(\mathrm{T}=65^{\circ} \mathrm{C}, \mathrm{Q}_{\mathrm{L}}=5 \mathrm{ml} / \mathrm{min}, \mathrm{P}=2\right.$ bars, $\left.\mathrm{M}=200 \mathrm{~g}\right)$. 


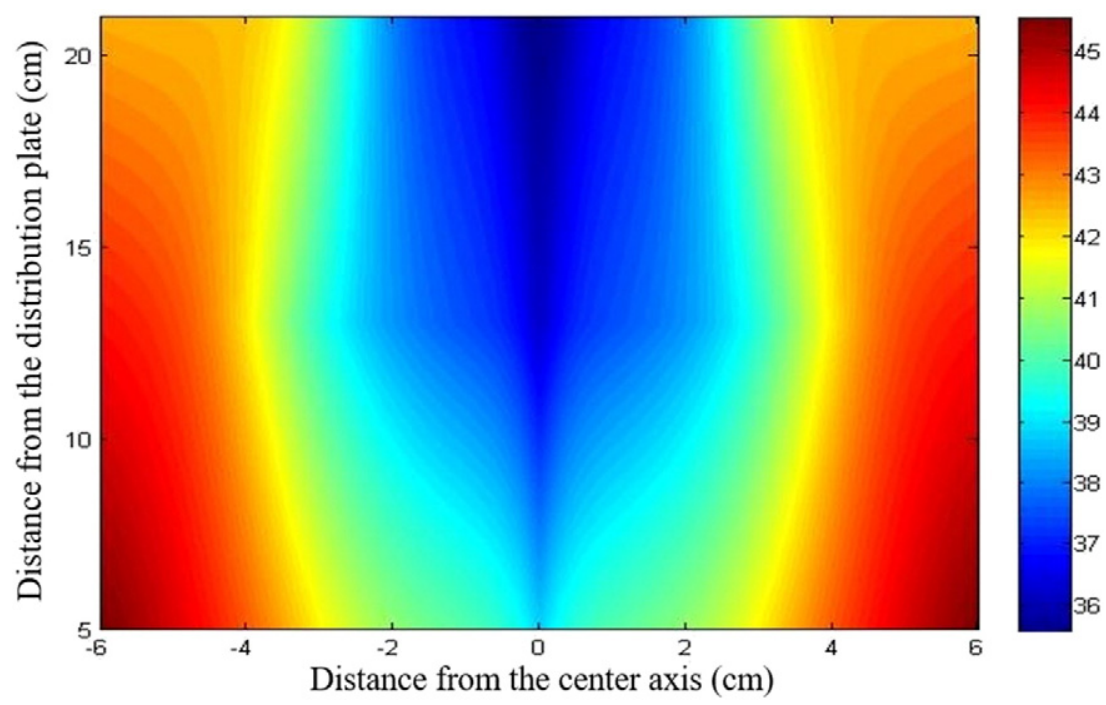

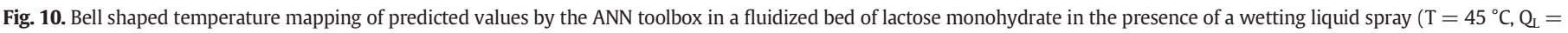
$20 \mathrm{ml} / \mathrm{min}, \mathrm{P}=2$ bar, $\mathrm{M}=200 \mathrm{~g}$ )

of the wetting zone was large compared to the high inlet temperature conditions $\left(65^{\circ} \mathrm{C}\right)$, where temperature maps show a narrow profile due to fast liquid evaporation. These predictions are in accordance with the properties of the final granules as they show for low inlet air temperature higher mean particle size and moisture content (trial 1 , 5,9 ). Indeed, agglomeration occurs if enough liquid droplets reach the surface of the particles before evaporating, which enables them to bind with other wetted particles to result in bigger agglomerates. And the lower the temperatures, the bigger the particles' humidity content for less effective drying conditions.

The liquid feed rate highly influences both the agglomeration and drying conditions within the fluidized bed. When it was increased from 5 to $15 \mathrm{ml} / \mathrm{min}$, the median particle size increased from 846.32 to $2011.23 \mu \mathrm{m}$ (trial 1, 4) due to an increase in the liquid droplets' diameter and the amount of liquid to evaporate, which also led to an increase in the final moisture content from 0.46 .to $2.73 \%$ and in the size of the wetting zone (Figs. 10 and 11).
Regarding the flowing properties of the particles, Table 1 shows that the Carr index and Hausner ratio values are under 0.21 and 1.25, respectively, and they correspond to a good ability to compaction of the powder and good behavior as it flows. Trial 4 shows the highest values, which indicates a poor flow ability caused by over-wet particles due to the large wetting zone and insufficient drying. The Carr index and Hausner ratio values are close, indicating a lower effect of the operating conditions on particles flowability and compaction than the median particle size and moisture content.

The measured powder flow times confirm the Hausner ratio values. It increases with the increase of the median diameter of the particles due to the fact that flowability also depends on particle shape. This can be seen for the granulations' relatively low spraying rate, they flow more easily than over-wet particles that might present irregular agglomerate shapes (trial 2,4).

This results in defining particle size and moisture content as the critical quality attributes of the final granules, demonstrating the link

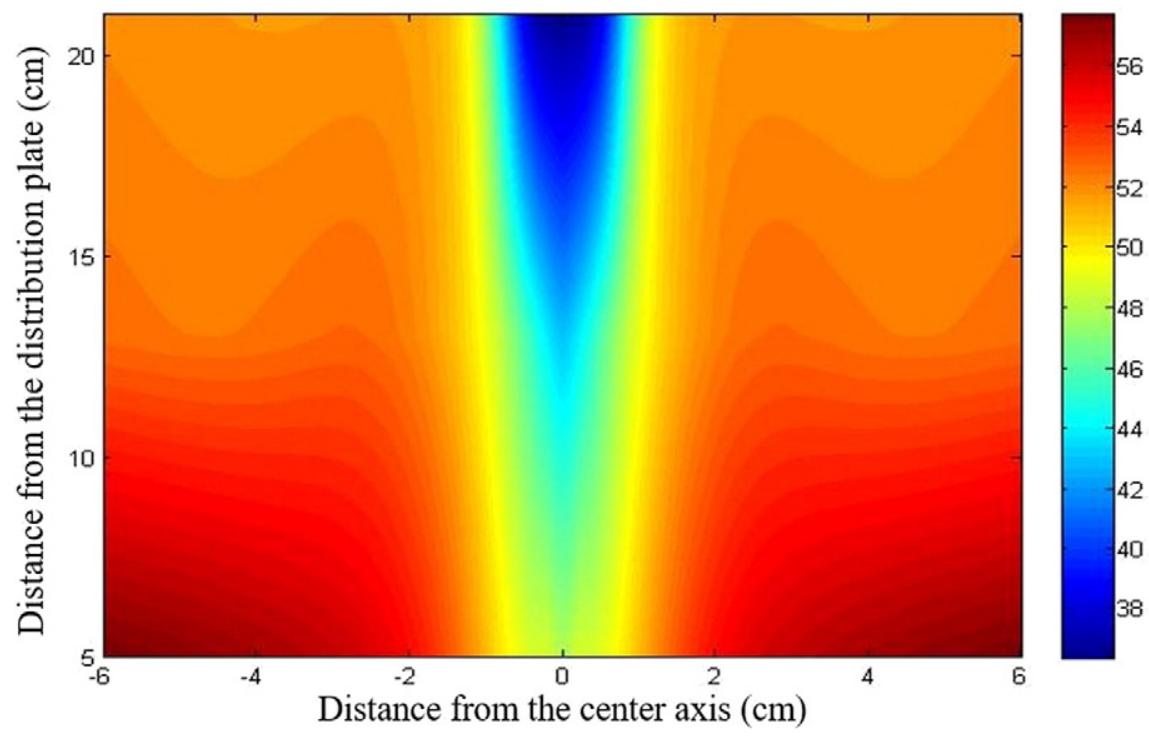

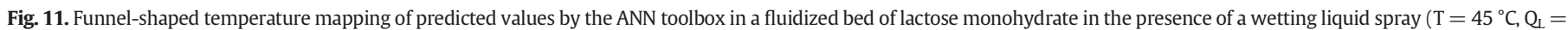
$5 \mathrm{ml} / \mathrm{min}, \mathrm{P}=2$ bar, $\mathrm{M}=200 \mathrm{~g}$ ). 
Table 1

Influence of process variables on the medium particle size $\left(d_{50}\right)$, moisture content, Carr index, Hausner index and the flowability.

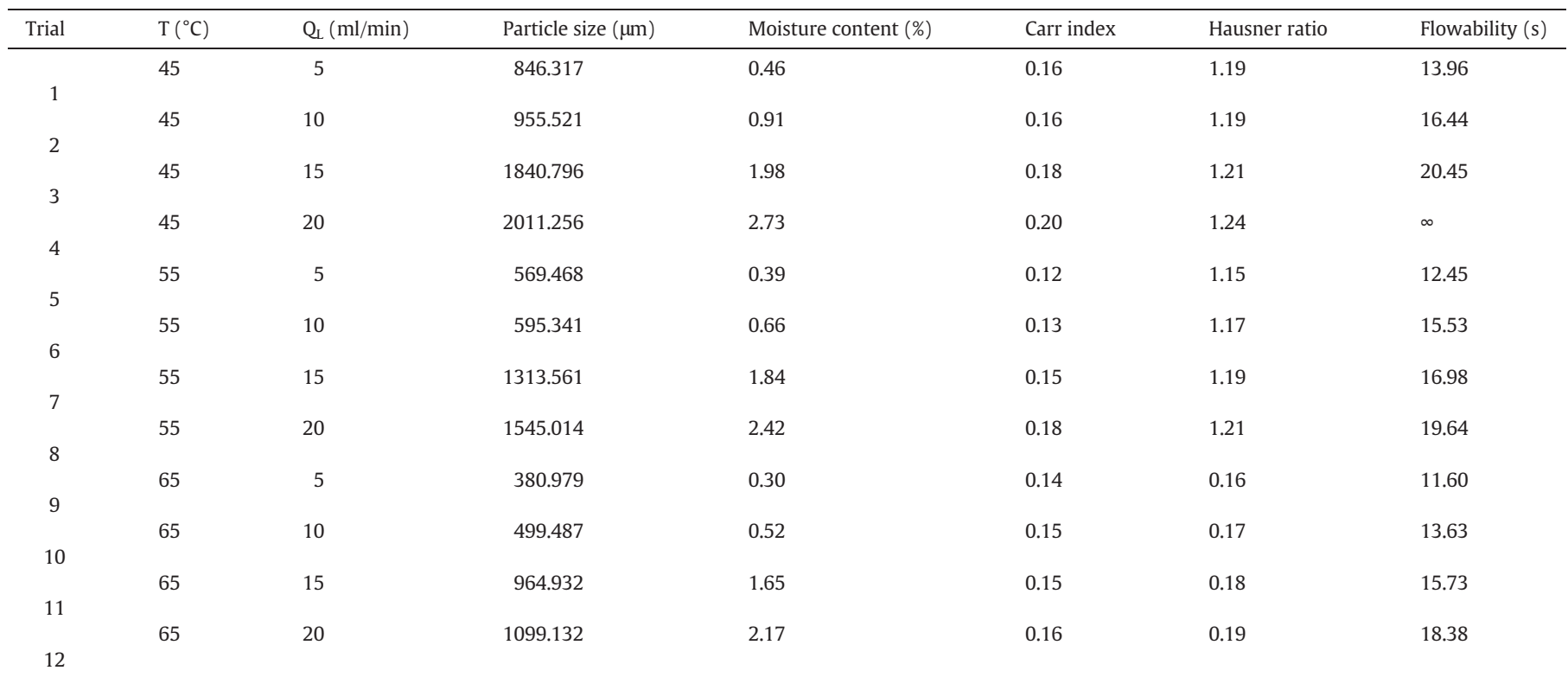

Reference: T: fluidizing inlet air temperature, $\mathrm{Q}_{\mathrm{I}}$ : liquid feed rate, $\mathrm{M}=200 \mathrm{~g}, \mathrm{P}=2$ bar.

between the characteristics of temperature profiles, critical process parameters and critical quality attributes.

\section{Conclusion}

In the present study, a possibility to control the granulation process with predicted temperature distribution profiles was demonstrated. An experimental set up for measurements of temperature under the Process Analytical Technology (PAT) in a conical fluidized bed was used for the granulation trials, which served as a database for a developed artificial neural network model. The model showed a very good predicting ability of $\mathrm{R}^{2}=0.994$ and allowed the prediction of temperature mappings and establishment of temperature profiles. Their characteristics were influenced by the process conditions and their boundaries delimited using the isotherms with the temperature gradient closest to zero. These profiles provide information about the hydrodynamic and thermodynamic conditions inside the bed which directly influence particle behavior during granulation. The properties of the final granules are in concordance with the predicted profiles, indicating a distinct connection between the established temperature profiles and the quality attributes of the final particles. These results emphasize the potential and usefulness of ANN as PAT tools in modeling and developing robust agglomeration processes.

\section{Acknowledgments}

The authors would like to thank the Welding and NDT Research Center (CSC) and the Laboratory of Transfer Phenomena of the University of Sciences and Technology Houari Boumediene, for their support in the making of the fluidized bed apparatus and the M.E.S.R.S. (Algeria) for the PhD scholarship provided to Yasmine Korteby.

\section{Appendix A}

$\mathrm{W}_{1}$ values are the interconnection weights between the inputs and the neurons of the first hidden layer. $\mathrm{W}_{2}$ values are the weights between the first hidden layer and the second hidden layer. $W_{3}$ values are the weights between the second hidden layer and the output neuron. $b_{1}$ and $b_{2}$ are the bias vector related to each neuron of the first (12 values) and second hidden layer (12 values) and $b_{3}$ is the output bias value.

$$
\mathbf{W}_{1}=\left[\begin{array}{cccc}
0.08486 & 1.40782 & 1.3229 & -1.1283 \\
0.226 & -1.6561 & -0.4055 & -1.0013 \\
1.40120 & 2.00940 & 0.6148 & 1.17950 \\
-0.2398 & -0.5207 & 3.0386 & -0.0655 \\
-2.7533 & -0.47564 & -0.6930 & 0.27303 \\
-0.54245 & -0.92186 & -0.8099 & -1.1799 \\
6.6692 & -0.51027 & -0.4471 & -0.1358 \\
-0.29785 & 0.93719 & -1.7605 & 0.39678 \\
-3.2857 & 0.004143 & -3.1879 & -0.2642 \\
0.35279 & -1.6746 & -1.0638 & -1.0550 \\
-0.60959 & -0.47978 & 0.56655 & -1.2222 \\
6.7407 & -0.17942 & -1.2426 & 0.05900
\end{array}\right]
$$


$\mathbf{W}_{2}=\left[\begin{array}{cccccccccccc}-0.567 & 0.1371 & -1.039 & -1.914 & -1.190 & 0.3997 & -0.937 & -1.128 & -0.192 & -1.245 & 0.313 & 1.935 \\ -0.121 & 1.5371 & 0.3683 & 1.8898 & -0.162 & 0.2018 & -0.991 & -0.395 & 0.6528 & -0.292 & 0.895 & 6.071 \\ -0.722 & -0.471 & -1.739 & -2.087 & -0.938 & 0.2343 & 2.1053 & -0.100 & -1.325 & -1.229 & 0.362 & -0.798 \\ 0.2319 & -1.366 & 0.0308 & -0.591 & -1.257 & -1.315 & 0.2328 & 0.5411 & 0.2988 & 0.3924 & -0.5 & -0.782 \\ 1.4553 & -0.087 & 0.3593 & 0.3692 & 2.6768 & -0.208 & -1.93 & -0.096 & 0.6884 & 0.4315 & 0.736 & 1.5504 \\ 0.064 & -0.037 & -0.589 & 1.007 & 0.181 & -0.477 & 1.084 & 0.618 & -0.329 & -0.091 & 0.065 & 0.235 \\ -0.805 & -0.879 & -0.103 & -0.951 & -0.042 & -0.495 & -0.376 & -2.010 & -0.167 & -0.334 & 0.925 & 1.1987 \\ -0.478 & -0.031 & 0.4529 & 0.4577 & 1.05 & 0.4433 & -0.051 & -0.435 & 0.2110 & 0.2148 & 1.100 & 1.1987 \\ 0.2431 & -0.387 & -0.852 & 0.4473 & -0.608 & 0.4510 & -0.124 & -0.446 & 1.0671 & -1.047 & 0.413 & 1.3401 \\ 0.3159 & -1.428 & 0.6220 & 0.9700 & -0.896 & -0.110 & -0.577 & 0.5636 & 0.8344 & 0.6875 & -1.55 & -0.622 \\ 0.4706 & -0.306 & -0.563 & 0.5928 & 0.1786 & 0.4378 & 0.7924 & 1.2065 & 1.5969 & -0.622 & -1.72 & -1.348 \\ -0.094 & 0.1870 & 0.0094 & 0.6434 & 0.9739 & -0.380 & 0.0371 & 0.1346 & -0.354 & 0.2855 & 1.951 & 0.3090\end{array}\right]$

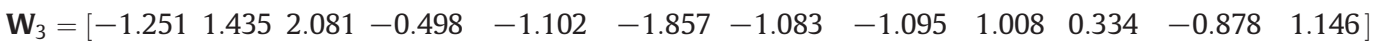

$$
\mathbf{b}_{1}=\left[\begin{array}{c}
-2.708 \\
-2.410 \\
-2.140 \\
-1.307 \\
1.680 \\
0.277 \\
0.559 \\
-0.355 \\
-0.646 \\
1.1747 \\
-2.156 \\
1.452
\end{array}\right] \quad \mathbf{b}_{2}=\left[\begin{array}{c}
1.5362 \\
-1.618 \\
2.0372 \\
-1.087 \\
-0.3773 \\
0.4393 \\
1.0664 \\
-0.029 \\
1.4569 \\
1.2243 \\
0.7742 \\
1.8378
\end{array}\right] \quad \mathbf{b}_{3}=[0.1331]
$$

Appendix B. Description of the database used for the development of the ANN model and the output response.

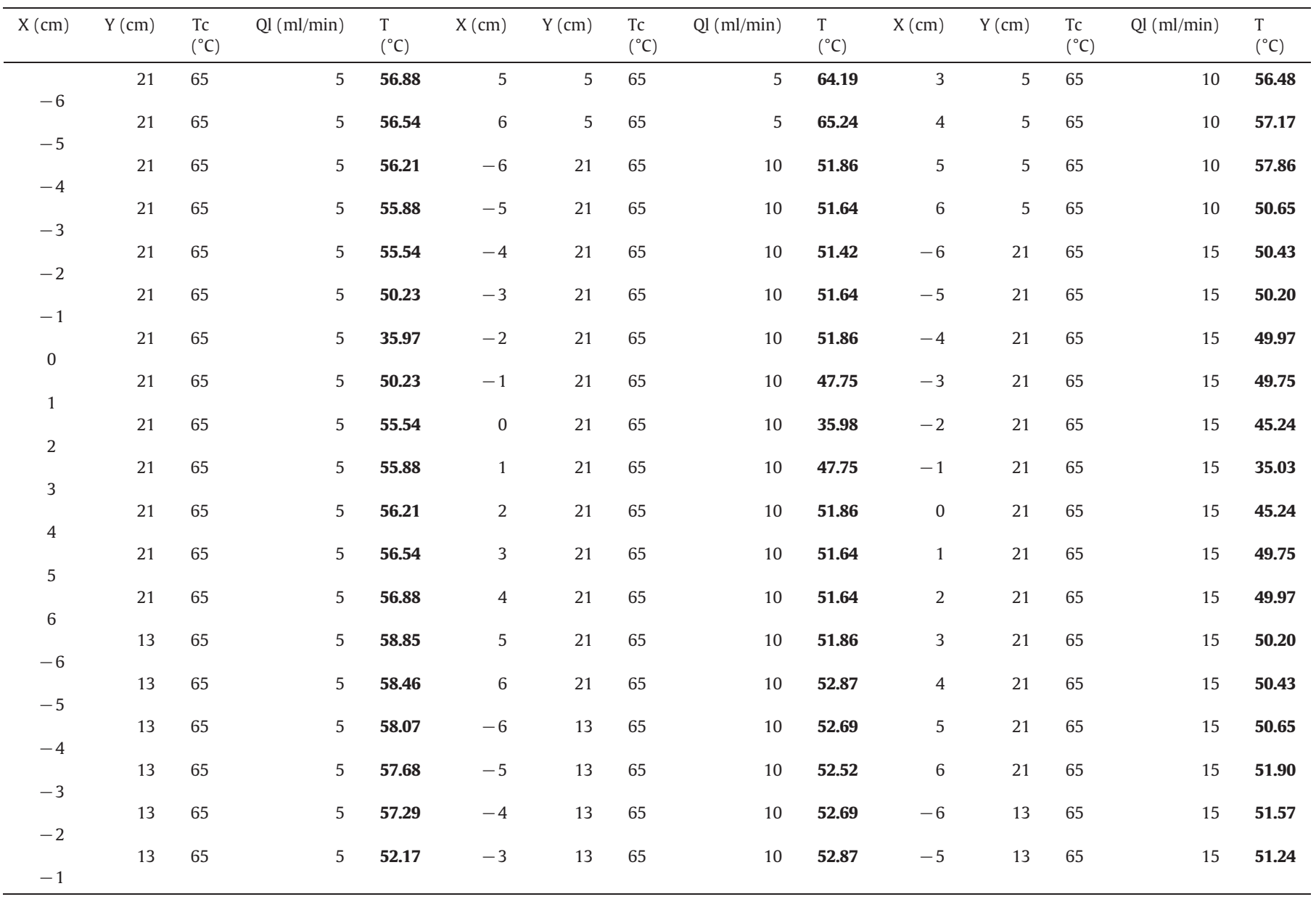


Appendix B (continued)

\begin{tabular}{|c|c|c|c|c|c|c|c|c|c|c|c|c|c|c|}
\hline $\mathrm{X}(\mathrm{cm})$ & $\mathrm{Y}(\mathrm{cm})$ & $\begin{array}{l}\text { Tc } \\
\left({ }^{\circ} \mathrm{C}\right)\end{array}$ & $\mathrm{Ql}(\mathrm{ml} / \mathrm{min})$ & $\begin{array}{l}\mathrm{T} \\
\left({ }^{\circ} \mathrm{C}\right) \\
\end{array}$ & $\mathrm{X}(\mathrm{cm})$ & $\mathrm{Y}(\mathrm{cm})$ & $\begin{array}{l}\text { Tc } \\
\left({ }^{\circ} \mathrm{C}\right)\end{array}$ & $\mathrm{Ql}(\mathrm{ml} / \mathrm{min})$ & $\begin{array}{l}\mathrm{T} \\
\left({ }^{\circ} \mathrm{C}\right)\end{array}$ & $\mathrm{X}(\mathrm{cm})$ & $\mathrm{Y}(\mathrm{cm})$ & $\begin{array}{l}\text { Tc } \\
\left({ }^{\circ} \mathrm{C}\right)\end{array}$ & $\mathrm{Ql}(\mathrm{ml} / \mathrm{min})$ & $\begin{array}{l}\mathrm{T} \\
\left({ }^{\circ} \mathrm{C}\right)\end{array}$ \\
\hline & 13 & 65 & 5 & 43.09 & -2 & 13 & 65 & 10 & 48.97 & -4 & 13 & 65 & 15 & 50.91 \\
\hline & 13 & 65 & 5 & 52.17 & -1 & 13 & 65 & 10 & 42.72 & -3 & 13 & 65 & 15 & 50.58 \\
\hline & 13 & 65 & 5 & 57.29 & 0 & 13 & 65 & 10 & 48.97 & -2 & 13 & 65 & 15 & 46.70 \\
\hline & 13 & 65 & 5 & 57.68 & 1 & 13 & 65 & 10 & 52.87 & -1 & 13 & 65 & 15 & 41.09 \\
\hline & 13 & 65 & 5 & 58.07 & 2 & 13 & 65 & 10 & 52.69 & 0 & 13 & 65 & 15 & 46.70 \\
\hline & 13 & 65 & 5 & 58.46 & 3 & 13 & 65 & 10 & 52.52 & 1 & 13 & 65 & 15 & 50.91 \\
\hline & 13 & 65 & 5 & 58.85 & 4 & 13 & 65 & 10 & 52.69 & 2 & 13 & 65 & 15 & 51.24 \\
\hline . & 5 & 65 & 5 & 65.24 & 5 & 13 & 65 & 10 & 52.87 & 3 & 13 & 65 & 15 & 51.57 \\
\hline & 5 & 65 & 5 & 64.19 & 6 & 13 & 65 & 10 & 57.86 & 4 & 13 & 65 & 15 & 51.90 \\
\hline-5 & 5 & 65 & 5 & 63.15 & -6 & 5 & 65 & 10 & 57.17 & 5 & 13 & 65 & 15 & 53.92 \\
\hline-4 & & & & & & & & & & & & & & \\
\hline-3 & $J$ & J & 5 & 62.11 & -5 & 5 & 65 & 10 & 56.48 & 6 & 13 & 65 & 15 & 33.19 \\
\hline-2 & 5 & 65 & 5 & 61.06 & -4 & 5 & 65 & 10 & 55.85 & -6 & 5 & 65 & 15 & 53.66 \\
\hline & 5 & 65 & 5 & 54.95 & -3 & 5 & 65 & 10 & 55.22 & -5 & 5 & 65 & 15 & 53.53 \\
\hline & 5 & 65 & 5 & 50.22 & -2 & 5 & 65 & 10 & 51.15 & -4 & 5 & 65 & 15 & 53.40 \\
\hline - & 5 & 65 & 5 & 54.95 & -1 & 5 & 65 & 10 & 49.45 & -3 & 5 & 65 & 15 & 48.20 \\
\hline & 5 & 65 & 5 & 61.06 & 0 & 5 & 65 & 10 & 51.15 & -2 & 5 & 65 & 15 & 47.14 \\
\hline & 5 & 65 & 5 & 62.11 & 1 & 5 & 65 & 10 & 55.22 & -1 & 5 & 65 & 15 & 48.20 \\
\hline & 5 & 65 & 5 & 63.15 & 2 & 5 & 65 & 10 & 55.85 & 0 & 5 & 65 & 15 & 53.40 \\
\hline 7 & 5 & 65 & 15 & 53.53 & -1 & 5 & 65 & 20 & 50.86 & -3 & 5 & 45 & 5 & 40.79 \\
\hline & 5 & 65 & 15 & 53.66 & 0 & 5 & 65 & 20 & 51.53 & -2 & 5 & 45 & 5 & 41.99 \\
\hline & 5 & 65 & 15 & 53.79 & 1 & 5 & 65 & 20 & 52.19 & -1 & 5 & 45 & 5 & 43.19 \\
\hline ك & 5 & 65 & 15 & 53.92 & 2 & 5 & 65 & 20 & 52.86 & 0 & 5 & 45 & 5 & 45.85 \\
\hline 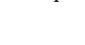 & 5 & 65 & 15 & 48.98 & 3 & 5 & 65 & 20 & 53.52 & 1 & 5 & 45 & 5 & 49.29 \\
\hline & 5 & 65 & 15 & 48.91 & 4 & 5 & 65 & 20 & 49.24 & 2 & 5 & 45 & 5 & 51.09 \\
\hline & 21 & 65 & 20 & 48.83 & 5 & 5 & 65 & 20 & 47.87 & 3 & 5 & 45 & 5 & 52.89 \\
\hline & 21 & 65 & 20 & 48.68 & 6 & 5 & 65 & 20 & 46.50 & 4 & 5 & 45 & 5 & 46.21 \\
\hline-5 & & & & & & & & & & & & & & \\
\hline-4 & 21 & 65 & 20 & 48.53 & -6 & 21 & 45 & 5 & 43.40 & 5 & 5 & 45 & 5 & 45.62 \\
\hline & 21 & 65 & 20 & 43.46 & -5 & 21 & 45 & 5 & 42.59 & 6 & 5 & 45 & 10 & 45.03 \\
\hline-3 & 21 & 65 & 20 & 35.00 & -4 & 21 & 45 & 5 & 39.16 & -6 & 21 & 45 & 10 & 42.11 \\
\hline-2 & & & & & & & & & & & & & & \\
\hline-1 & 21 & 65 & 20 & 43.46 & -3 & 21 & 45 & 5 & 35.73 & -5 & 21 & 45 & 10 & 37.54 \\
\hline-1 & 21 & 65 & 20 & 48.53 & -2 & 21 & 45 & 5 & 39.16 & -4 & 21 & 45 & 10 & 35.65 \\
\hline & 21 & 65 & 20 & 48.68 & -1 & 21 & 45 & 5 & 42.59 & -3 & 21 & 45 & 10 & 37.54 \\
\hline 1 & 21 & 65 & 20 & 48.83 & 0 & 21 & 45 & 5 & 43.40 & -2 & 21 & 45 & 10 & 39.42 \\
\hline 2 & 21 & 65 & 20 & 48.91 & 1 & 21 & 45 & 5 & 46.50 & -1 & 21 & 45 & 10 & 42.11 \\
\hline 3 & 21 & & 20 & 4898 & 2 & 21 & 45 & 5 & 4787 & 0 & 21 & 45 & 10 & 45,03 \\
\hline 4 & & & & . & & & & & & & & & & 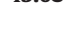 \\
\hline & 21 & 65 & 20 & 50.23 & 3 & 21 & 45 & 5 & 49.24 & 1 & 21 & 45 & 10 & 45.62 \\
\hline & 21 & 65 & 20 & 49.94 & 4 & 21 & 45 & 5 & 50.91 & 2 & 21 & 45 & 10 & 46.21 \\
\hline
\end{tabular}


Appendix B (continued)

\begin{tabular}{|c|c|c|c|c|c|c|c|c|c|c|c|c|c|c|}
\hline $\mathrm{X}(\mathrm{cm})$ & $\mathrm{Y}(\mathrm{cm})$ & $\begin{array}{l}\mathrm{Tc} \\
\left({ }^{\circ} \mathrm{C}\right)\end{array}$ & $\mathrm{Ql}(\mathrm{ml} / \mathrm{min})$ & $\begin{array}{l}\mathrm{T} \\
\left({ }^{\circ} \mathrm{C}\right)\end{array}$ & $\mathrm{X}(\mathrm{cm})$ & $\mathrm{Y}(\mathrm{cm})$ & $\begin{array}{l}\text { Tc } \\
\left({ }^{\circ} \mathrm{C}\right)\end{array}$ & $\mathrm{Ql}(\mathrm{ml} / \mathrm{min})$ & $\begin{array}{l}\mathrm{T} \\
\left({ }^{\circ} \mathrm{C}\right)\end{array}$ & $\mathrm{X}(\mathrm{cm})$ & $\mathrm{Y}(\mathrm{cm})$ & $\begin{array}{l}\text { Tc } \\
\left({ }^{\circ} \mathrm{C}\right)\end{array}$ & $\mathrm{Ql}(\mathrm{ml} / \mathrm{min})$ & $\begin{array}{l}\mathrm{T} \\
\left({ }^{\circ} \mathrm{C}\right)\end{array}$ \\
\hline \multicolumn{15}{|l|}{6} \\
\hline & 13 & 65 & 20 & 49.65 & 5 & 21 & 45 & 5 & 49.21 & 3 & 21 & 45 & 10 & 46.59 \\
\hline \multicolumn{15}{|l|}{-6} \\
\hline & 13 & 65 & 20 & 49.36 & 6 & 21 & 45 & 5 & 47.51 & 4 & 21 & 45 & 10 & 46.49 \\
\hline \multicolumn{15}{|l|}{-5} \\
\hline & 13 & 65 & 20 & 49.07 & -6 & 13 & 45 & 5 & 43.97 & 5 & 21 & 45 & 10 & 45.56 \\
\hline \multicolumn{15}{|l|}{-4} \\
\hline & 13 & 65 & 20 & 44.87 & -5 & 13 & 45 & 5 & 43.65 & 6 & 21 & 45 & 10 & 42.47 \\
\hline \multicolumn{15}{|l|}{-3} \\
\hline & 13 & 65 & 20 & 39.00 & -4 & 13 & 45 & 5 & 40.88 & -6 & 13 & 45 & 10 & 40.12 \\
\hline \multicolumn{15}{|l|}{-2} \\
\hline & 13 & 65 & 20 & 44.87 & -3 & 13 & 45 & 5 & 38.26 & -5 & 13 & 45 & 10 & 38.95 \\
\hline \multicolumn{15}{|l|}{-1} \\
\hline & 13 & 65 & 20 & 49.07 & -2 & 13 & 45 & 5 & 40.88 & -4 & 13 & 45 & 10 & 37.77 \\
\hline \multicolumn{15}{|l|}{0} \\
\hline & 13 & 65 & 20 & 49.36 & -1 & 13 & 45 & 5 & 43.65 & -3 & 13 & 45 & 10 & 38.95 \\
\hline 1 & 13 & 65 & 20 & 49.65 & 0 & 13 & 45 & 5 & 43.97 & -2 & 13 & 45 & 10 & 40.12 \\
\hline 2 & & & & & & & & & & & & & & \\
\hline & 13 & 65 & 20 & 49.94 & 1 & 13 & 45 & 5 & 47.51 & -1 & 13 & 45 & 10 & 42.47 \\
\hline 3 & & & & & & & & & & & & & & \\
\hline & 13 & 65 & 20 & 50.23 & 2 & 13 & 45 & 5 & 49.21 & 0 & 13 & 45 & 10 & 45.56 \\
\hline 4 & 13 & 65 & 20 & 53.52 & 3 & 13 & 45 & 5 & 50.91 & 1 & 13 & 45 & 10 & 46.49 \\
\hline 5 & & & & & & & & & & & & & & \\
\hline & 13 & 65 & 20 & 52.86 & 4 & 13 & 45 & 5 & 52.89 & 2 & 13 & 45 & 10 & 46.59 \\
\hline 6 & 5 & 65 & 20 & 52.19 & 5 & 13 & 45 & 5 & 51.09 & 3 & 13 & 45 & 10 & 48.65 \\
\hline-6 & & & & & & & & & & & & & & \\
\hline & 5 & 65 & 20 & 51.53 & 6 & 13 & 45 & 5 & 49.29 & 4 & 13 & 45 & 10 & 46.37 \\
\hline-5 & & & & & & & & & & & & & & \\
\hline & 5 & 65 & 20 & 50.86 & -6 & 5 & 45 & 5 & 45.85 & 5 & 13 & 45 & 10 & 46.09 \\
\hline-4 & & & & & & & & & & & & & & \\
\hline & 5 & 65 & 20 & 46.29 & -5 & 5 & 45 & 5 & 43.19 & 6 & 13 & 45 & 10 & 43.53 \\
\hline-3 & & & & & & & & & & & & & & \\
\hline & 5 & 65 & 20 & 46.29 & -4 & 5 & 45 & 5 & 41.99 & -6 & 5 & 45 & 10 & 41.78 \\
\hline-2 & & & & & & & & & & & & & & \\
\hline & 5 & 45 & 10 & 40.84 & 6 & 13 & 45 & 15 & 39.45 & 4 & 13 & 45 & 20 & 40.22 \\
\hline-5 & & & & & & & & & & & & & & \\
\hline & 5 & 45 & 10 & 39.89 & -6 & 5 & 45 & 15 & 38.90 & 5 & 13 & 45 & 20 & 37.83 \\
\hline-4 & & & & & & & & & & & & & & \\
\hline & 5 & 45 & 10 & 40.84 & -5 & 5 & 45 & 15 & 38.34 & 6 & 13 & 45 & 20 & 37.29 \\
\hline-3 & & & & & & & & & & & & & & \\
\hline & 5 & 45 & 10 & 41.78 & -4 & 5 & 45 & 15 & 38.90 & -6 & 5 & 45 & 20 & 36.75 \\
\hline-2 & & & & & & & & & & & & & & \\
\hline & 5 & 45 & 10 & 43.53 & -3 & 5 & 45 & 15 & 39.45 & -5 & 5 & 45 & 20 & 37.29 \\
\hline-1 & & & & & & & & & & & & & & \\
\hline & 5 & 45 & 10 & 46.09 & -2 & 5 & 45 & 15 & 41.34 & -4 & 5 & 45 & 20 & 37.83 \\
\hline 0 & & & & & & & & & & & & & & \\
\hline & 5 & 45 & 10 & 46.37 & -1 & 5 & 45 & 15 & 45.14 & -3 & 5 & 45 & 20 & 40.22 \\
\hline 1 & 5 & 45 & 10 & 48.65 & 0 & 5 & 45 & 15 & 44.96 & -2 & 5 & 45 & 20 & 42.86 \\
\hline 2 & & & & & & & & & & & & & & \\
\hline 3 & 5 & 45 & 10 & 45.08 & 1 & 5 & 45 & 15 & 45.14 & -1 & 5 & 45 & 20 & 42.90 \\
\hline & 5 & 45 & 10 & 44.10 & 2 & 5 & 45 & 15 & 42.16 & 0 & 5 & 45 & 20 & 42.94 \\
\hline 4 & 5 & 45 & 10 & 43.12 & 3 & 5 & 45 & 15 & 41.89 & 1 & 5 & 45 & 20 & 52.05 \\
\hline 5 & & & & & & & & & & & & & & \\
\hline & 5 & 45 & 15 & 40.57 & 4 & 5 & 45 & 15 & 41.62 & 2 & 5 & 45 & 20 & 50.02 \\
\hline 6 & & & & & & & & & & & & & & \\
\hline & 21 & 45 & 15 & 37.82 & 5 & 5 & 45 & 15 & 39.30 & 3 & 5 & 45 & 20 & 47.51 \\
\hline-6 & & & & & & & & & & & & & & \\
\hline & 21 & 45 & 15 & 36.49 & 6 & 5 & 45 & 20 & 35.80 & 4 & 5 & 45 & 20 & 46.42 \\
\hline-5 & & & & & & & & & & & & & & \\
\hline & 21 & 45 & 15 & 35.15 & -6 & 21 & 45 & 20 & 35.42 & 5 & 5 & 45 & 20 & 45.33 \\
\hline-4 & & & & & & & & & & & & & & \\
\hline & 21 & 45 & 15 & 36.49 & -5 & 21 & 45 & 20 & 35.03 & 6 & 5 & 45 & 20 & 44.25 \\
\hline-3 & & & & & & & & & & & & & & \\
\hline & 21 & 45 & 15 & 37.82 & -4 & 21 & 45 & 20 & 35.42 & -6 & 21 & 55 & 5 & 35.17 \\
\hline-2 & & & & & & & & & & & & & & \\
\hline & 21 & 45 & 15 & 40.57 & -3 & 21 & 45 & 20 & 35.80 & -5 & 21 & 55 & 5 & 44.25 \\
\hline-1 & 21 & 45 & 15 & 43.12 & -2 & 21 & 45 & 20 & 39.30 & -4 & 21 & 55 & 5 & 45.33 \\
\hline
\end{tabular}


Appendix B (continued)

\begin{tabular}{|c|c|c|c|c|c|c|c|c|c|c|c|c|c|c|}
\hline $\mathrm{X}(\mathrm{cm})$ & $\mathrm{Y}(\mathrm{cm})$ & $\begin{array}{l}\mathrm{Tc} \\
\left({ }^{\circ} \mathrm{C}\right)\end{array}$ & $\mathrm{Ql}(\mathrm{ml} / \mathrm{min})$ & $\begin{array}{l}\mathrm{T} \\
\left({ }^{\circ} \mathrm{C}\right)\end{array}$ & $\mathrm{X}(\mathrm{cm})$ & $\mathrm{Y}(\mathrm{cm})$ & $\begin{array}{l}\text { Tc } \\
\left({ }^{\circ} \mathrm{C}\right)\end{array}$ & $\mathrm{Ql}(\mathrm{ml} / \mathrm{min})$ & $\begin{array}{l}\mathrm{T} \\
\left({ }^{\circ} \mathrm{C}\right)\end{array}$ & $\mathrm{X}(\mathrm{cm})$ & $\mathrm{Y}(\mathrm{cm})$ & $\begin{array}{l}\mathrm{Tc} \\
\left({ }^{\circ} \mathrm{C}\right)\end{array}$ & $\mathrm{Ql}(\mathrm{ml} / \mathrm{min})$ & $\begin{array}{l}\mathrm{T} \\
\left({ }^{\circ} \mathrm{C}\right)\end{array}$ \\
\hline \multicolumn{15}{|l|}{0} \\
\hline & 21 & 45 & 15 & 44.10 & -1 & 21 & 45 & 20 & 41.62 & -3 & 21 & 55 & 5 & 46.42 \\
\hline 1 & 21 & 45 & 15 & 45.08 & 0 & 21 & 45 & 20 & 41.89 & -2 & 21 & 55 & 5 & 47.51 \\
\hline 2 & 21 & 45 & 15 & 46.10 & 1 & 21 & 45 & 20 & 42.16 & -1 & 21 & 55 & 5 & 50.02 \\
\hline 3 & 21 & 45 & 15 & 44.78 & 2 & 21 & 45 & 20 & 42.61 & 0 & 21 & 55 & 5 & 52.05 \\
\hline 4 & 21 & 45 & 15 & 40.66 & 3 & 21 & 45 & 20 & 42.18 & 1 & 21 & 55 & 5 & 52.35 \\
\hline 5 & 21 & 45 & 15 & 38.45 & 4 & 21 & 45 & 20 & 41.75 & 2 & 21 & 55 & 5 & 52.35 \\
\hline 6 & 13 & 45 & 15 & 37.59 & 5 & 21 & 45 & 20 & 39.23 & 3 & 21 & 55 & 5 & 49.35 \\
\hline \multirow[t]{2}{*}{-6} & & & & & & & & & & & & & & \\
\hline & 13 & 45 & 15 & 36.75 & 6 & 21 & 45 & 20 & 36.09 & 4 & 21 & 55 & 5 & 48.03 \\
\hline \multirow[t]{2}{*}{-5} & & & & & & & & & & & & & & \\
\hline & 13 & 45 & 15 & 37.59 & -6 & 13 & 45 & 20 & 36.00 & 5 & 21 & 55 & 5 & 46.71 \\
\hline-4 & 13 & 45 & 15 & 38.45 & -5 & 13 & 45 & 20 & 35.92 & 6 & 21 & 55 & 5 & 45.39 \\
\hline-2 & 13 & 45 & 15 & 40.66 & -4 & 13 & 45 & 20 & 36.00 & -6 & 13 & 55 & 5 & 42.84 \\
\hline \multirow[t]{2}{*}{-1} & 13 & 45 & 15 & 43.46 & -3 & 13 & 45 & 20 & 36.09 & -5 & 13 & 55 & 5 & 45.39 \\
\hline & 13 & 45 & 15 & 44.78 & -2 & 13 & 45 & 20 & 39.23 & -4 & 13 & 55 & 5 & 46.71 \\
\hline 0 & 13 & 45 & 15 & 46.1 & -1 & 13 & 45 & 20 & 41.75 & -3 & 13 & 55 & 5 & 48.03 \\
\hline 1 & 13 & 45 & 15 & 45.14 & 0 & 13 & 45 & 20 & 42.18 & -2 & 13 & 55 & 5 & 49.35 \\
\hline 2 & 13 & 45 & 15 & 44.96 & 1 & 13 & 45 & 20 & 42.61 & -1 & 13 & 55 & 5 & 52.35 \\
\hline 3 & 13 & 45 & 15 & 45.14 & 2 & 13 & 45 & 20 & 42.90 & 0 & 13 & 55 & 5 & 52.35 \\
\hline 4 & 13 & 45 & 15 & 41.34 & 3 & 13 & 45 & 20 & 42.86 & 1 & 13 & 55 & 5 & 52.06 \\
\hline 5 & 13 & 55 & 5 & 52.06 & 3 & 13 & 55 & 10 & 43.02 & 4 & 13 & 55 & 15 & 41.28 \\
\hline 2 & 13 & 55 & 5 & 51.07 & 5 & 13 & 55 & 10 & 41.43 & 5 & 13 & 55 & 15 & 40.28 \\
\hline 3 & 13 & 55 & 5 & 50.08 & 6 & 13 & 55 & 10 & 43.02 & 6 & 13 & 55 & 15 & 41.28 \\
\hline 4 & 13 & 55 & 5 & 49.09 & -6 & 5 & 55 & 10 & 44.61 & -6 & 5 & 55 & 15 & 42.48 \\
\hline 5 & 13 & 55 & 5 & 49.05 & -5 & 5 & 55 & 10 & 46.19 & -5 & 5 & 55 & 15 & 43.69 \\
\hline 6 & 5 & 55 & 5 & 49.09 & -3 & 5 & 55 & 10 & 46.27 & -4 & 5 & 55 & 15 & 44.89 \\
\hline-6 & & & & & & & & & & & & & & \\
\hline & 5 & 55 & 5 & 50.08 & -2 & 5 & 55 & 10 & 47.34 & -3 & 5 & 55 & 15 & 45.64 \\
\hline-4 & 5 & 55 & 5 & 51.07 & -1 & 5 & 55 & 10 & 43.61 & -2 & 5 & 55 & 15 & 46.02 \\
\hline-3 & & & & & & & & & & & & & & \\
\hline & 5 & 55 & 5 & 52.06 & 0 & 5 & 55 & 10 & 43.31 & -1 & 5 & 55 & 15 & 42.29 \\
\hline-2 & 5 & 55 & 5 & 52.06 & 1 & 5 & 55 & 10 & 43.91 & 0 & 5 & 55 & 15 & 42.14 \\
\hline-1 & & & & & & & & & & & & & & \\
\hline & 5 & 55 & 5 & 45.17 & 2 & 5 & 55 & 10 & 41.90 & 1 & 5 & 55 & 15 & 41.99 \\
\hline 0 & 5 & 55 & 5 & 44.75 & 3 & 5 & 55 & 10 & 39.89 & 2 & 5 & 55 & 15 & 40.07 \\
\hline 1 & 5 & 55 & 5 & 43.09 & 5 & 5 & 55 & 10 & 37.89 & 3 & 5 & 55 & 15 & 38.16 \\
\hline 2 & 5 & 55 & 5 & 41.43 & 6 & 5 & 55 & 15 & 35.89 & 4 & 5 & 55 & 15 & 36.24 \\
\hline 3 & 5 & 55 & 5 & 39.77 & -6 & 21 & 55 & 15 & 37.89 & 5 & 5 & 55 & 15 & 35.32 \\
\hline 4 & 5 & 55 & 10 & 35.91 & -5 & 21 & 55 & 15 & 39.89 & 6 & 5 & 55 & 20 & 36.24 \\
\hline 6 & 21 & 55 & 10 & 39.77 & -4 & 21 & 55 & 15 & 41.90 & -6 & 21 & 55 & 20 & 38.16 \\
\hline-6 & & & & & & & & & & & & & & \\
\hline . & 21 & 55 & 10 & 41.43 & -3 & 21 & 55 & 15 & 43.91 & -5 & 21 & 55 & 20 & 40.07 \\
\hline-4 & 21 & 55 & 10 & 43.09 & -2 & 21 & 55 & 15 & 43.31 & -4 & 21 & 55 & 20 & 41.99 \\
\hline
\end{tabular}


Appendix B (continued)

\begin{tabular}{|c|c|c|c|c|c|c|c|c|c|c|c|c|c|c|}
\hline $\mathrm{X}(\mathrm{cm})$ & $\mathrm{Y}(\mathrm{cm})$ & $\begin{array}{l}\mathrm{Tc} \\
\left({ }^{\circ} \mathrm{C}\right)\end{array}$ & $\mathrm{Ql}(\mathrm{ml} / \mathrm{min})$ & $\begin{array}{l}\mathrm{T} \\
\left({ }^{\circ} \mathrm{C}\right)\end{array}$ & $\mathrm{X}(\mathrm{cm})$ & $\mathrm{Y}(\mathrm{cm})$ & $\begin{array}{l}\text { Tc } \\
\left({ }^{\circ} \mathrm{C}\right)\end{array}$ & $\mathrm{Ql}(\mathrm{ml} / \mathrm{min})$ & $\begin{array}{l}\mathrm{T} \\
\left({ }^{\circ} \mathrm{C}\right)\end{array}$ & $\mathrm{X}(\mathrm{cm})$ & $\mathrm{Y}(\mathrm{cm})$ & $\begin{array}{l}\text { Tc } \\
\left({ }^{\circ} \mathrm{C}\right)\end{array}$ & $\mathrm{Ql}(\mathrm{ml} / \mathrm{min})$ & $\begin{array}{l}\mathrm{T} \\
\left({ }^{\circ} \mathrm{C}\right)\end{array}$ \\
\hline & 21 & 55 & 10 & 44.75 & -1 & 21 & 55 & 15 & 43.61 & -3 & 21 & 55 & 20 & 42.14 \\
\hline \multicolumn{15}{|l|}{-3} \\
\hline & 21 & 55 & 10 & 45.17 & 0 & 21 & 55 & 15 & 45.13 & -2 & 21 & 55 & 20 & 42.29 \\
\hline \multicolumn{15}{|l|}{-2} \\
\hline & 21 & 55 & 10 & 45.59 & 1 & 21 & 55 & 15 & 44.51 & -1 & 21 & 55 & 20 & 44.05 \\
\hline \multicolumn{15}{|l|}{-1} \\
\hline \multirow{2}{*}{0} & 21 & 55 & 10 & 46.29 & 2 & 21 & 55 & 15 & 42.20 & 0 & 21 & 55 & 20 & 43.15 \\
\hline & 21 & 55 & 10 & 45.27 & 3 & 21 & 55 & 15 & 40.52 & 1 & 21 & 55 & 20 & 42.23 \\
\hline 1 & 21 & 55 & 10 & 44.18 & 4 & 21 & 55 & 15 & 38.83 & 2 & 21 & 55 & 20 & 40.52 \\
\hline \multirow[t]{2}{*}{2} & & & & & & & & & & & & & & \\
\hline & 21 & 55 & 10 & 42.39 & 5 & 21 & 55 & 15 & 36.83 & 3 & 21 & 55 & 20 & 38.81 \\
\hline 3 & 21 & 55 & 10 & 40.61 & 6 & 21 & 55 & 15 & 38.83 & 4 & 21 & 55 & 20 & 37.10 \\
\hline 4 & 21 & 55 & 10 & 36.75 & -6 & 13 & 55 & 15 & 40.52 & 5 & 21 & 55 & 20 & 36.39 \\
\hline 5 & 21 & 55 & 10 & 40.61 & -5 & 13 & 55 & 15 & 42.20 & 6 & 21 & 55 & 20 & 37.10 \\
\hline 6 & 13 & 55 & 10 & 42.39 & -4 & 13 & 55 & 15 & 43.89 & -6 & 13 & 55 & 20 & 38.81 \\
\hline \multirow[t]{2}{*}{-6} & & & & & & & & & & & & & & \\
\hline & 13 & 55 & 10 & 44.18 & -3 & 13 & 55 & 15 & 44.51 & -5 & 13 & 55 & 20 & 40.52 \\
\hline \multirow{2}{*}{-5} & & & & & & & & & & & & & & \\
\hline & 13 & 55 & 10 & 45.27 & -2 & 13 & 55 & 15 & 45.13 & -4 & 13 & 55 & 20 & 42.23 \\
\hline \multirow[t]{2}{*}{-3} & & & & & & & & & & & & & & \\
\hline & 13 & 55 & 10 & 46.29 & -1 & 13 & 55 & 15 & 46.02 & -3 & 13 & 55 & 20 & 43.15 \\
\hline \multirow[t]{2}{*}{-2} & & & & & & & & & & & & & & \\
\hline & 13 & 55 & 10 & 47.34 & 0 & 13 & 55 & 15 & 45.64 & -2 & 13 & 55 & 20 & 44.05 \\
\hline \multirow[t]{2}{*}{-1} & & & & & & & & & & & & & & \\
\hline & 13 & 55 & 10 & 46.27 & 1 & 13 & 55 & 15 & 44.89 & -1 & 13 & 55 & 20 & 44.34 \\
\hline 0 & 13 & 55 & 10 & 46.19 & 2 & 13 & 55 & 15 & 43.69 & 0 & 13 & 55 & 20 & 43.19 \\
\hline 1 & 13 & 55 & 10 & 44.61 & 3 & 13 & 55 & 15 & 42.48 & 1 & 13 & 55 & 20 & 41.88 \\
\hline 2 & 13 & 55 & 20 & 37.10 & -5 & 5 & 55 & 20 & 44.34 & 1 & 5 & 55 & 20 & 39.28 \\
\hline 2 & 13 & 55 & 20 & 38.81 & -4 & 5 & 55 & 20 & 43.19 & 2 & 5 & 55 & 20 & 40.58 \\
\hline 3 & 13 & 55 & 20 & 40.52 & -3 & 5 & 55 & 20 & 41.88 & 3 & 5 & 55 & 20 & 41.88 \\
\hline & 13 & 55 & 20 & 42.23 & -2 & 5 & 55 & 20 & 40.58 & 4 & 5 & 55 & 20 & 43.19 \\
\hline 5 & 13 & 55 & 20 & 43.15 & -1 & 5 & 55 & 20 & 39.28 & 5 & 5 & 55 & 20 & 44.34 \\
\hline & 5 & 55 & 20 & 4405 & 0 & 5 & 55 & 20 & 3939 & 6 & 5 & 55 & 20 & 45.49 \\
\hline-6 & & & & & & & & & & & & & & \\
\hline
\end{tabular}

The bold numbers are the measured temperatures from the thermocouples.

\section{References}

Banks, M., Aulton, M.E., 1991. Fluidized-bed granulation: a chronology. Drug Dev. Ind Pharm. 17, 1437-1464.

Chaibva, F., Burton, M., Walker, R.B., 2010. Optimization of salbutamol sulfate dissolution from sustained release matrix formulations using an artificial neural network. Pharmaceutics 2, 182-198.

Chen, Y., Thosar, S.S., Forbess, R.A., Kemper, M.S., Rubinovitz, R.L., Shukla, A.J., 2001. Prediction of drug content and hardness of intact tablets using artificial neural network and near-infrared spectroscopy. Drug Dev. Ind. Pharm. 27, 623-631.

Gao, J.Z.H., Jain, A., Motheram, R., Gray, D.B., Hussain, M.A., 2002. A fluid bed granulation of a poorly water soluble, low density, micronized drug: comparison with high shear granulation. Int. J. Pharm. 237, 1-14.

Guleser, K., Dural, M.U., Alyuruk, H., Cavas, L., 2012. Artificial neural network model for biosorption of methylene blue by dead leaves of Posidonia oceanica (L.) delile. neural netw. World 12, 479-494.

Gupta, C.K., Sathiyamoorthy, D., 1998. Fluid Bed Technology in Materials Processing. CRC Press, Florida.

Haykin, S., 2009. Neural Networks and Learning Machines. Prentice-Hall, New Jersey.

Jiménez, T., Turchiuli, C., Dumoulin, E., 2006. Particles agglomeration in a conical fluidized bed in relation with air temperature profiles. Chem. Eng. Sci. 61, 5954-5961.

Kivikero, N., Ingelbeen, B., Murtomaa, M., Antikainen, O., Räsänen, E., Mannermaa, J.-P., Juppo, A., 2007. Fluid bed granulations in microscale fluid bed powder processor (MFP). Eur. J. Pharm. Sci. 32, 46.
Maronga, S.J., Wnukowski, P., 1997. Establishing temperature and humidity profiles in fluidized bed particulate coating. Powder Technol. 94, 181-185.

Närvänen, T., 2008. Particle size determination during fluid bed granulation-challenges and opportunities. Eur. J. Pharm. Sci. 34, 12.

Nikowitz, K., Pintye-Hódi, K., Regdon Jr., G., 2013. Study of the recrystallization in coated pellets: effect of coating on API crystallinity. Eur. J. Pharm. Sci. 48, 563-571.

Petrović, J., Chansanroj, K., Meier, B., Ibrić, S., Betz, G., 2011. Analysis of fluidized bed granulation process using conventional and novel modeling techniques. Eur. J. Pharm. Sci. 44, 227-234.

Pietch, W.B., 1984. Fluidization phenomena and fluidized bed technology. In: Fayed, M.E., Otten, L. (Eds.), Handbook of Powder Science and Technology. Van Nostrand Reinhold, New York, pp. 231-252.

Radichkov, R., Muller, T., Kienle, A., Heinrich, S., Peglowd, M., Mörl, L., 2006. A numerical bifurcation analysis of continuous fluidized bed spray granulation with external product classification. Chem. Eng. Process. 45, 826-837.

Rosas, J.G., Blanco, M., González, J.M., Alcala, M., 2012. Real-time determination of critical quality attributes using near-infrared spectroscopy: a contribution for Process Analytical Technology (PAT). Talanta 97, 163-170.

Saleh, K., 1998. Contribution à l'étude de l'enrobage des poudres en lit fluidisé: Etude expérimentale et modélisation du processus. INP Toulouse, France, PhD Thesis.

Sherrington, P.J., Oliver, R., 1981. Granulation monograph (chapter 3). In: Goldberg, A.S. (Ed.), Powder Science and Technology. Heyden and Son Ltd., London, pp. $118-140$

Smith, P.G., 1980. A Study of Fluidized Bed Granulation (Ph.D. Thesis) University College London, England. 
Smith, P.G., Nienow, A.W., 1983. Particle growth mechanisms in fluidized bed granulation-I. Chem. Eng. Sci. 38, 1223-1240.

Sun, Y., Peng, Y., Chen, Y., Shukla, A.J., 2003. Application of artificial neural networks in the design of controlled release drug delivery systems. Adv. Drug Deliv. Rev. 55 (9), 1201-1215.

Takayama, K., Fujikawa, M., Obata, Y., Morishita, M., 2003. Neural network based optimization of drug formulations. Adv. Drug Deliv. Rev. 9, 1217-1231.
Turchiuli, C., Jimenèz, T., Dumoulin, E., 2011. Identification of thermal zones and population balance modelling of fluidized bed spray granulation. Powder Technol. 208, 542-552.

Yang, W.C., 2003. Handbook of Fluidization and Fluid-Particle Systems. Marcel Dekker, Inc., New York, U.S.A.

Zurada, J.M., 1992. Introduction to Artificial Neural Systems. West Publishing Company, Minnesota. 
II. 


\title{
Quantitative and qualitative use of thermal analysis for the investigation of the properties of granules during fluid bed melt granulation
}

\author{
Géza Regdon $\mathrm{Jr}^{1}$ (D) $\cdot$ Yasmine Korteby ${ }^{1}$
}

Received: 27 July 2017 / Accepted: 20 November 2017

(c) Akadémiai Kiadó, Budapest, Hungary 2017

\begin{abstract}
This study describes a novel approach for the use of thermal analysis to study the aftermath of the fluid bed melt granulation process and to depict the growth mechanism of the granules by quantifying the enthalpies of the granules at every physicochemical change using DSC and their mass loss through TG coupled to MS for a qualitative determination of the composition and amount of the evolved gases for the corresponding fragment ion. The experiments were made in situ with lactose monohydrate and two viscosity grades of PEG (2000 and 6000) as meltable binders with different contents and size fractions. DSC showed the presence of a beta lactose endotherm peak after the melting of alpha lactose and a proportional increase in its intensity with the increase in the particle size and the content of the binder, which suggested a relation with the agglomeration growth. Interestingly, TG and MS showed a larger reduction in the water content from lactose with the increase in the binder particle size, making it possible to evaluate the dehydration during the melt granulation. Indeed, during the distribution mechanism the low binder particle size and viscosity exposed lactose to a high heat transfer from the fluidizing air. However, a high binder particle size results in lactose immersed in the PEG particles, causing water to be trapped inside the granules and hence a larger reduction in water mass loss indicating the immersion mechanism. Therefore, thermal analysis is a promising tool for granulation growth control.
\end{abstract}

Keywords Fluid bed melt granulation · Mass spectrometry $\cdot$ TG-MS $\cdot$ DSC $\cdot$ Lactose monohydrate $\cdot$ PEG

\section{Introduction}

Hot melt technology is a commonly used robust method in pharmaceutical research as it allows the influence of the bioavailability of drugs and numerous applications such as the preparation of eutectic mixtures $[1,2]$ and solid dispersions in order to provide time-controlled, modified, extended and targeted drug delivery as well as taste masking of bitter active pharmaceutical ingredients (APIs) $[3,4]$. Fluid bed melt granulation (FBMG) is another technique that is gaining popularity in the pharmaceutical industry due to its multiple advantages [5,6]. It uses a

Géza Regdon Jr

geza.regdon@pharm.u-szeged.hu

1 Institute of Pharmaceutical Technology and Regulatory Affairs, University of Szeged, SzegedEötvös utca 6, 6720, Hungary molten binder to agglomerate the pharmaceutical powder particles. Following particle agglomeration and consolidation, the granules are cooled to room temperature and a solid end product with a granular structure is formed [7-10]. For this granulation method, the drying step, which is required after wet granulation, is eliminated; hence, the process time and energy requirements are significantly reduced. Since no liquids are used, HMG has the possibility to agglomerate moisture-sensitive materials [11, 12]. Furthermore, melt granulation can be used to develop highdose formulations with up to $90 \%$ of active pharmaceutical ingredient (API) [13, 14]. During melt granulation, the thermal energy involved in the melting of the binding material will be induced by the heat transfer from the conveying fluidizing air to the power bed. The latter will bring about changes in the physicochemical properties of the final product; therefore, the determination of the favorable process condition for the desired quality attributes of the granules must be established. For years, 
thermal analysis techniques were used in research to give an insight into the properties of materials and could advantageously be used in the quality control of drug products [15]. The methods are commonly used in preformulation for the study of polymorphism and for the study of the interactions between the drug substance and the excipients, since these physical interactions can be the basis of dosage form performance [16]. For the routine control of the drug products and raw materials, these methods which are quick, automated and require only a few $\mathrm{mg}$ of the samples are very attractive for routine analysis $[15,17]$. In preformulation, these techniques are particularly valuable for the construction of phase diagrams $[18,19]$ and the study of the interactions between the drug substance and the excipients. Polymorphism or hydrate formation may be studied by these techniques in granulation and lyophilization for the development of solid dispersions and even in the dosage form [20, 21].

Differential scanning calorimetry (DSC) is a technique used to investigate the response of materials to heating, such as the melting of a crystalline polymer or glass transition [22]. Also, thermal gravimetric analysis (TGA) provides information on the continuous mass loss characteristics of the samples to clarify their behavior at a hightemperature region, whereas the combination of thermogravimetry and mass spectrometry (TG-MS) allows obtaining especially qualitative information about the composition of evolved gases during the thermal decomposition of solids [23, 24]. A single scan can give several pieces of qualitative and quantitative information about components in the galenical form [25-27]. While the application of thermal analysis began in research, it is now used for development in the control of processes and product quality. Today, thermal analysis is an essential tool for materials research and development, while quality assurance is now one of the hot topics in thermal analysis [28-31].

This study focuses on the off-line analyzed properties of granules prepared by a FBMG process. The different powder compositions and process conditions will determine the structure, growth and properties of the granules. Our approach describes the evaluation of the characteristic thermal responses of granules through the quantification of the mass loss of granules and their enthalpies at every physicochemical change and through a qualitative determination of the composition of the evolved gases (relative amount and shifts in characteristic peaks). This investigation suggests a relation with the agglomeration growth and demonstrates the use of thermal analysis in designing the optimal conditions for the desired quality attributes of products.

\section{Materials and methods}

\section{Materials}

Alpha-lactose monohydrate (Ph. Eur.) was used as a model filler with a mean particle size of $100.16 \mu \mathrm{m}$. Two low melting point polymers: polyethylene glycol 2000 (PEG 2000) and polyethylene glycol 6000 (PEG 6000) (Fluka, Switzerland), were used as meltable binders. The PEG flakes were finely ground using the planetary ball mill PM 100 (Retsch, Dusseldorf, Germany) at $150 \mathrm{rpm}$ for $30 \mathrm{~min}$ and then sieved using laboratory test sieves (Retsch, Germany) into different size fractions (63-125, 125-250, 250-500, 500-710, 710-900, 900-1120 $\mu \mathrm{m}$ ).

\section{Fluid bed melt granulation process}

PEG and lactose monohydrate were granulated in a Strea-1 (Niro Aeromatic, Bubendorf, Switzerland) fluid bed chamber. A batch size of $200 \mathrm{~g}$ was used. The materials were mixed for $5 \mathrm{~min}$ in a Turbula mixer (Willy A. Bachofen Maschienenfabrik, Basel, Switzerland) to homogenize the physical mixture since there are not enough shear forces in the fluid bed granulator. Then, they were inserted and fluidized in the preheated chamber for a period of $10 \mathrm{~min}$ and at constant air velocity of $2.5 \mathrm{~m} \mathrm{~s}^{-1}$. The experiments are summarized in Table 1 . The varied factors were the viscosity since PEG 2000 and PEG 6000 have different molecular masses and chain lengths, the meltable binder content ranging from 5 to $20 \%$ with a step of $5 \% \mathrm{~W} / \mathrm{W}$ and the binder particle size in 5 different size fractions. The size fractions 125-250, 250-500, 500-710, 710-900, 900-1120 $\mu \mathrm{m}$ were used regarding PEG 2000 and the size fractions 63-125, 125-250, 250-500, 500-710, 710-900 regarding PEG 6000. The inlet air temperatures were 90 and $100{ }^{\circ} \mathrm{C}$ for PEG 2000 and 6000, respectively. The outlet air temperatures were 60 and $70{ }^{\circ} \mathrm{C}$ for PEG 2000 and 6000 , respectively, since the melting point of PEG 2000 and 6000 is 53 and $63{ }^{\circ} \mathrm{C}$, respectively.

\section{Differential scanning calorimetry}

Differential scanning calorimetry (DSC) measurements were performed with a DSC $821^{\mathrm{e}}$ (Mettler-Toledo $\mathrm{GmbH}$, Switzerland) instrument on raw materials and the corresponding granules after melt granulation. The samples were heated steadily from 25 to $500{ }^{\circ} \mathrm{C}$ in a non-hermetically sealed $40 \mu \mathrm{L}$ aluminum pan. The heating rate was $10{ }^{\circ} \mathrm{C} \mathrm{min}{ }^{-1}$. The mass of the samples was $8 \pm 1 \mathrm{mg}$, and the measurements were performed in an Argon atmosphere at a rate of $100 \mathrm{~mL} \mathrm{~min}{ }^{-1}$. Three parallel examinations 
Table 1 Factors and process parameters of the granulation experiments

\begin{tabular}{|c|c|c|c|c|c|}
\hline Model filler & PEG grade & PEG content $/ \%$ & PEG size/ $\mu \mathrm{m}$ & Inlet temperature $/{ }^{\circ} \mathrm{C}$ & $\overline{\text { Outlet temperature } /{ }^{\circ} \mathrm{C}}$ \\
\hline \multirow[t]{10}{*}{ Lactose monohydrate } & \multirow[t]{5}{*}{2000} & 5 & $125-250$ & \multirow[t]{5}{*}{90} & \multirow[t]{5}{*}{60} \\
\hline & & 10 & $250-500$ & & \\
\hline & & 15 & $500-710$ & & \\
\hline & & 20 & $710-900$ & & \\
\hline & & & $900-1120$ & & \\
\hline & \multirow[t]{5}{*}{6000} & 5 & $65-125$ & \multirow[t]{5}{*}{100} & \multirow[t]{5}{*}{70} \\
\hline & & 10 & $125-250$ & & \\
\hline & & 15 & $250-500$ & & \\
\hline & & 20 & $500-710$ & & \\
\hline & & & $710-900$ & & \\
\hline
\end{tabular}

were done for all samples. The curves were evaluated with STARe Software.

\section{Thermogravimetric analysis-mass spectrometry}

The thermal gravimetric analysis (TGA) of the samples was carried out with a Mettler-Toledo TGA-DSC1 instrument (Mettler-Toledo $\mathrm{GmbH}$, Switzerland) in a flowing nitrogen atmosphere $\left(70 \mathrm{~cm}^{3} \mathrm{~min}^{-1}\right)$. Approximately $16 \mathrm{mg}$ of each sample in aluminum pans $(100 \mu \mathrm{L})$ underwent thermal analysis, with a heating rate of $10^{\circ} \mathrm{K} \mathrm{min}^{-1}$, from 25 to $500{ }^{\circ} \mathrm{C}$.

The examination of the granules was supplemented with gas analysis. The TG instrument was coupled to a Thermo Star (Pfeiffer) quadruple mass spectrometer (maximum $300 \mathrm{amu}$ ) for gas analysis. The measurements were carried out in nitrogen atmosphere. Ions with various mass numbers were determined with the SEM MID measurement module of the Quadera software. Continuous recordings of sample temperature, sample mass and heat flow were performed. The obtained results were exported and then plotted in one coordinate system with the TG curves using the Mettler-Toledo Star ${ }^{\mathrm{e}}$ software.

\section{Results and discussion}

\section{Differential scanning calorimetry}

The DSC curves of the raw materials are presented in Fig. 1. From the heat flow curve of $\alpha$-lactose monohydrate, three endothermic peaks can be observed. The first endothermic peak corresponds to crystal water evaporation around $142{ }^{\circ} \mathrm{C}$. The second peak corresponds to the melting of lactose and has an onset at $217^{\circ} \mathrm{C}$ and a peak temperature at $222{ }^{\circ} \mathrm{C}$, as shown in Table 2. The third peak

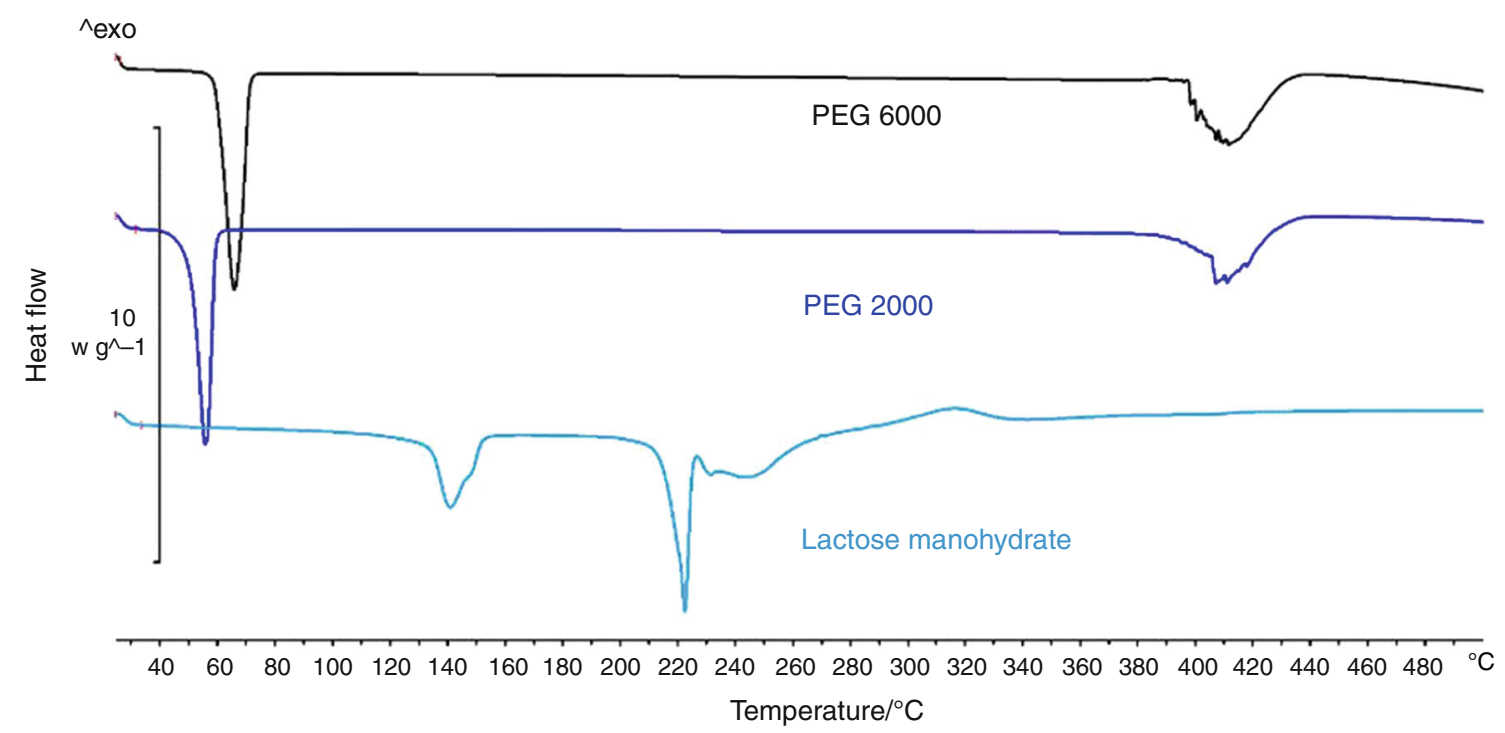

Fig. 1 DSC curves of the raw materials: $\alpha$-lactose monohydrate, PEG 2000, PEG6000 
Table 2 Melting peaks and heat flow data of granules prepared with PEG 2000 and 6000 samples

\begin{tabular}{|c|c|c|c|c|c|c|c|c|}
\hline Sample & PEG Grade & PEG/\% & $\mathrm{PEG} / \mu \mathrm{m}$ & $\mathrm{MR} /{ }^{\circ} \mathrm{C}$ & $\mathrm{MP} \mathrm{PEG} /{ }^{\circ} \mathrm{C}$ & 1 st $E / \mathrm{J} \mathrm{g}^{-1}$ & PH of $\alpha$-lactose $/ \mathrm{J} \mathrm{g}^{-1}$ & $\mathrm{PH}$ of $\beta$-lactose $/ \mathrm{J} \mathrm{g}^{-1}$ \\
\hline S01 & 2000 & 5 & $125-250$ & $49.5-53.7$ & 51.85 & -96.57 & 3.77 & 1.04 \\
\hline S02 & 2000 & 5 & $500-710$ & $48.5-53.7$ & 52.44 & -74.02 & 2.48 & 1.35 \\
\hline S03 & 2000 & 10 & $125-250$ & $50.0-56.1$ & 53.06 & -72.23 & 1.63 & 2.13 \\
\hline S04 & 2000 & 10 & $250-500$ & $52.3-55.2$ & 51.77 & -99.61 & 1.10 & 0.80 \\
\hline S05 & 2000 & 10 & $500-710$ & $52.1-55.9$ & 52.08 & -100.36 & 1.98 & 1.65 \\
\hline S06 & 2000 & 10 & $710-900$ & $48.7-56.1$ & 52.07 & -108.11 & 1.67 & 2.28 \\
\hline S07 & 2000 & 15 & $125-250$ & $48.5-53.6$ & 51.44 & -73.93 & 2.48 & 1.35 \\
\hline S08 & 2000 & 15 & $710-900$ & $48.5-55.9$ & 51.99 & -95.96 & 1.33 & 2.16 \\
\hline S09 & 2000 & 15 & $900-1120$ & $48.6-55.8$ & 52.29 & -97.94 & 1.25 & 2.29 \\
\hline $\mathrm{S} 10$ & 6000 & 5 & $65-125$ & $56.4-61.7$ & 58.85 & -122.06 & 3.06 & 0.76 \\
\hline S11 & 6000 & 5 & 710-900 & $63.1-67.1$ & 63.14 & -101.25 & 1.22 & 1.22 \\
\hline $\mathrm{S} 12$ & 6000 & 10 & $65-125$ & $60.3-62.5$ & 60.08 & -102.46 & 2.43 & 1.35 \\
\hline S13 & 6000 & 10 & $125-250$ & $56.0-62.4$ & 60.08 & -83.80 & 2.38 & 0.99 \\
\hline $\mathrm{S} 14$ & 6000 & 10 & $250-500$ & $61.1-64.5$ & 60.22 & -72.72 & 3.91 & 5.32 \\
\hline $\mathrm{S} 15$ & 6000 & 20 & $125-250$ & $63.5-68.3$ & 63.53 & -104.54 & 1.11 & 1.16 \\
\hline S16 & 6000 & 20 & $710-900$ & $57.9-67.0$ & 63.86 & -75.91 & 1.32 & 1.10 \\
\hline
\end{tabular}

$M R$ melting range, $M P$ melting peak, $P H$ peak height, $1 s t E$ first enthalpy of lactose

is a small endothermic peak observed at $245^{\circ} \mathrm{C}$, which corresponds to a mass loss step. A small exothermic peak is clearly seen from the DSC curve at $310^{\circ} \mathrm{C}$. This peak is the sum of the exothermic degradation and the mass loss endotherm, which occurs in the same temperature region for $\alpha$-lactose monohydrate [5].

The DSC curve of PEG 2000 exhibited a melting peak at $52{ }^{\circ} \mathrm{C}$ with an onset at $48{ }^{\circ} \mathrm{C}$. On the other hand, PEG 6000 has a melting peak at $63{ }^{\circ} \mathrm{C}$ with an onset at $57{ }^{\circ} \mathrm{C}$ due to the difference in the molecular mass of the polymers. From the heat flow curves of raw materials, no glass transition temperature $T_{\mathrm{g}}$ can be identified. This can be explained by the fact that PEG is a crystalline polymer. When the melting point of a crystalline material is reached, the solid state transfers abruptly from the solid to the molten state and makes the PEG binder melt. Therefore, the influence of temperature elevation on the properties of the granules is negligible [4].

In Fig. 2, the DSC curves of the granule samples prepared with PEG 2000 and 6000 are presented for different binder contents and a fixed binder particle size. We noticed from the heat flow curves that the melting point of PEG 6000 , appearing in all samples, has shifted about $5{ }^{\circ} \mathrm{C}$ lower than observed in its pure form. A wide range of papers describe that polymeric chains exhibit a different organization and properties (i.e., thermal transition, chain conformation) in the presence of a solid surface (i.e., filler, plasticizer) compared to polymeric chains in the bulk [4]; this is caused by the filler molecules that will get in between the polymer chains, space them out of each other and hence increase the free volume. Molecules can then slide past each other more easily, resulting in a decrease in the melting point. In addition, this mobility becomes more expressed at a higher filler concentration. Indeed, the heat flow enthalpy of the melting of PEGs depends on binder concentration as can be seen for $\mathrm{S} 15$ and $\mathrm{S} 13$, where the filler content increased and the melting temperature of the binder decreased, respectively.

On the other hand, the loss of crystal water from $\alpha$ lactose monohydrate did not appear in the same thermal range as in the raw material (Table 3 ), attributed to the free volume experienced when in contact with the polymer, lowering the crystal vaporization temperature. Also, the normalized integration of the signal intensity demonstrates a decrease when using a higher binder content [8].

However, the most predominant observation was the presence of an endothermic peak between the melting of $\alpha$ lactose monohydrate and its decomposition (Fig. 2). The peak had an onset at 225 and $227^{\circ} \mathrm{C}$ for PEG 2000 and 6000 , respectively, and a peak temperature at 229 and $227{ }^{\circ} \mathrm{C}$ for PEG 2000 and 6000, respectively (Table 2). This peak is present only in granulated samples, which suggests that it is a result of the melt granulation process. This reveals important information on granule formation, namely that low-viscosity polymer (PEG 2000) in a low content generated this small endotherm peak, while with the increase in content the intensity of the peak increased proportionally. 


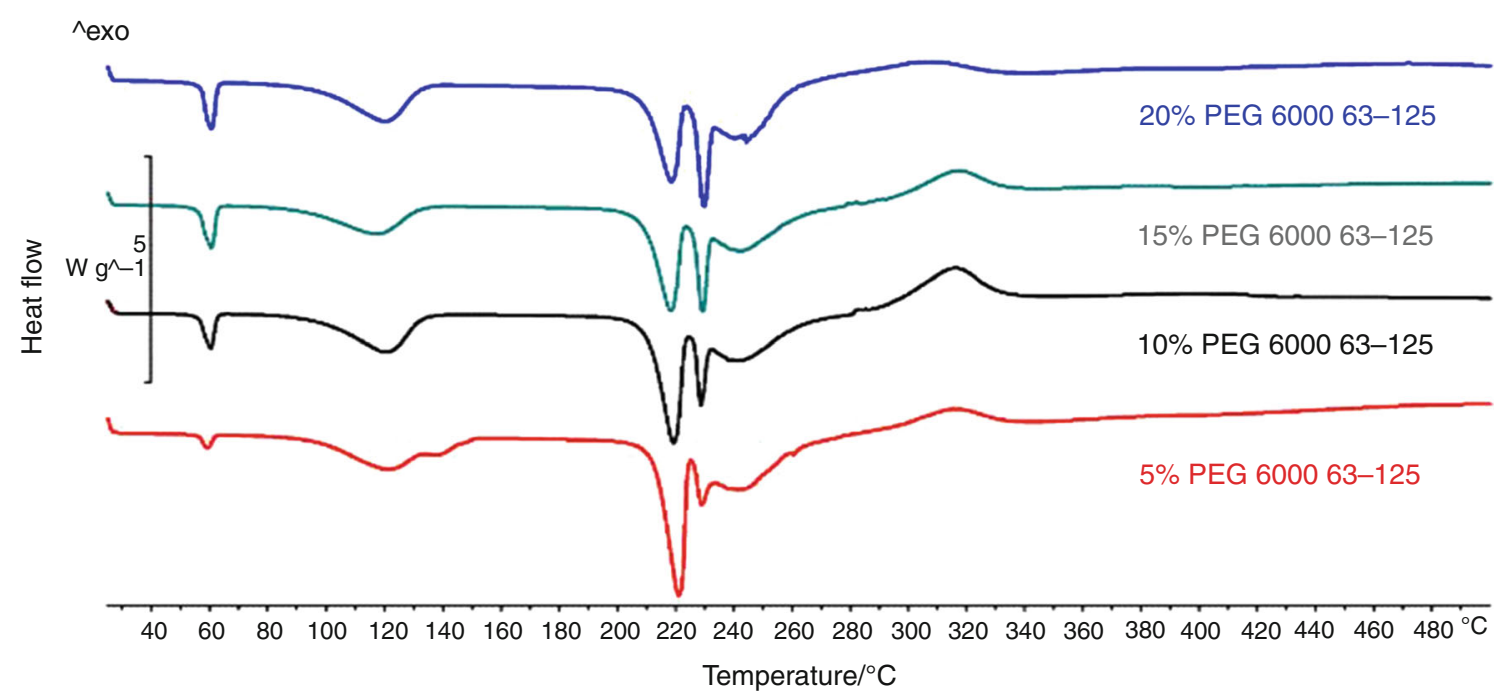

Fig. 2 DSC curves of granules with PEG 6000 for different contents

Table 3 Decomposition behavior of raw materials (lactose monohydrate, PEG 2000, PEG 6000)

\begin{tabular}{|c|c|c|c|}
\hline TG-DTG data & Lactose monohydrate & PEG 2000 & PEG 6000 \\
\hline \multicolumn{4}{|l|}{ First phase } \\
\hline Thermal range $/{ }^{\circ} \mathrm{C}$ & $132-155$ & $388-439$ & $389-438$ \\
\hline Mass loss $/ \%$ & 3.99 & 103.29 & 101.03 \\
\hline Normalized integral/sC $\mathrm{S}^{-1}$ & -0.21 & - & -5.58 \\
\hline Peak $/{ }^{\circ} \mathrm{C}$ & 143.02 & 53.80 & 63.24 \\
\hline Peak height $/{ }^{\circ} \mathrm{C}^{-1}$ & $2.35 \mathrm{e}-03$ & $31.52 \mathrm{e}-03$ & $29.33 e-03$ \\
\hline \multicolumn{4}{|l|}{ Second phase } \\
\hline Thermal range $/{ }^{\circ} \mathrm{C}$ & $228-262$ & - & - \\
\hline Mass loss $/ \%$ & 14.55 & - & - \\
\hline Normalized integral/sC $\mathrm{C}^{-1}$ & -0.18 & - & - \\
\hline Peak $/{ }^{\circ} \mathrm{C}$ & 241.17 & - & - \\
\hline Peak height $/{ }^{\circ} \mathrm{C}^{-1}$ & $1.94 \mathrm{e}-03$ & - & - \\
\hline \multicolumn{4}{|l|}{ Third phase } \\
\hline Thermal range $/{ }^{\circ} \mathrm{C}$ & $287-328$ & - & - \\
\hline Mass loss $/ \%$ & 55.68 & - & - \\
\hline Normalized integral/s $\mathrm{S}^{-1}$ & -2.44 & - & - \\
\hline Peak $/{ }^{\circ} \mathrm{C}$ & 302.91 & - & - \\
\hline Peak height $/{ }^{\circ} \mathrm{C}^{-1}$ & $15.75 e-03$ & - & - \\
\hline
\end{tabular}

According to the hypothesis of Mašić et al. [12], after the dehydration of lactose monohydrate and the melting of anhydrous $\alpha$-lactose, recrystallization into $\beta$-lactose occurred, followed by the melting of anhydrous $\beta$-lactose (which corresponds to the above-mentioned endotherm melting peak). So first it is needed to know that beta lactose is a low hygroscopic material with high storage stability and appropriate for water sensitive drugs formulations, which is one of the key points of FBMG [32]. Figure 3 shows the evolution of the $\beta$-lactose melting peak with different binder particle sizes. The intensity of the peak is proportional to the increase in binder content, showing that the presence of PEG influences the conversion of $\alpha$-lactose monohydrate into anhydrous $\beta$-lactose. Indeed, when using a low viscosity and a low binder content and size, the mechanism taking place is the distribution mechanism. The lactose is exposed to the hot fluidizing air, and the transformation to $\beta$-lactose starts showing. However, the increasing binder particle size and content generate a higher wetting surface for more growth by coalescence. This increase is proportional to the intensity of the peak due to the high heat transfer occurring during the phase 


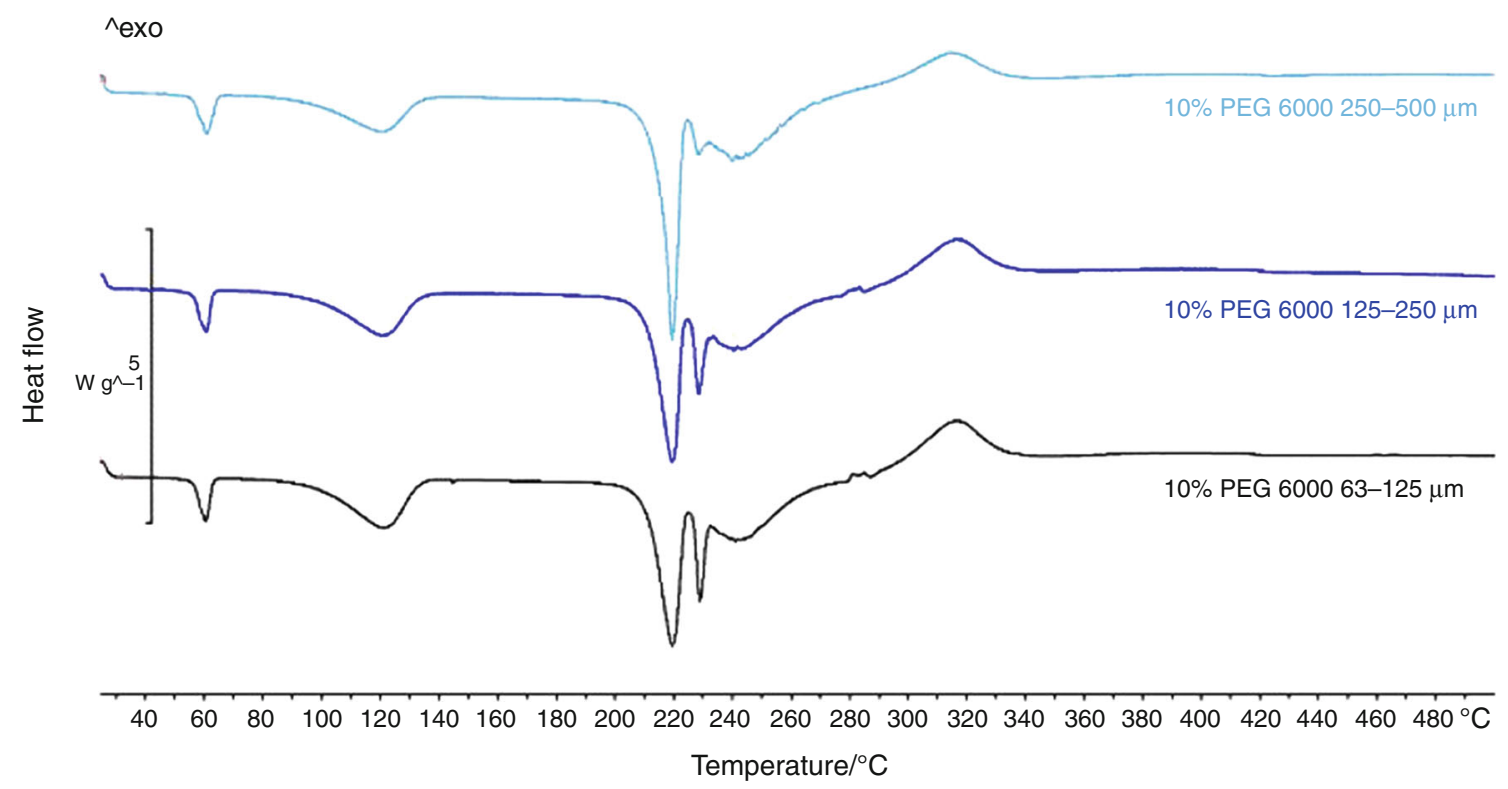

Fig. 3 DSC curves of granules with PEG 6000 for different particle sizes

change of PEG 2000. On the other hand, the binder particle size had an inversely proportional effect on this endotherm peak (Fig. 3). It can be seen that for granules with a highviscosity polymer 6000 and a high particle size of binder, the peak height for the melting of lactose is relatively close to the pure filler. Also, the enthalpy of melting $\beta$-lactose is less pronounced.

It is clear that the height of the $\alpha$-lactose melting peak is inversely proportional to the melting peak of $\beta$-lactose, which can be explained by the granulation growth during the process. Since in this system the immersion mechanism dominates, the particles of lactose will be immersed inside the PEG particle, which will have a restricted mobility; this will cause the filler to stick to the surface of the polymer and get immersed, shielding it from the fluidizing air temperature and hence from dehydration, and will result in the low $\beta$-lactose melting peak intensity. This indicates the possibility to determine the relative structure of the granules and their mechanism of formation. It helps validate the results obtained, suggesting the binder particle size as the parameter with the greatest influence on the growth mechanism.

\section{Thermogravimetric analysis}

The burning characteristics of the samples obtained from thermogravimetric analysis (TG-DTG) may be used to effectively compare the decomposition characteristics of the raw materials and their blends in granules. The TG curve of $\alpha$-lactose monohydrate shows three distinctive stages. The first mass loss of $4.52 \%$ is observed between 136 and $160{ }^{\circ} \mathrm{C}$ (Table 3).
This mass loss is attributed to the elimination of crystal water as it clearly illustrates that the heating resulted in the loss of $1 \mathrm{~mol}$ of bound water and is in agreement with the theoretical value of $1 \mathrm{~mol}$ of water in lactose monohydrate (5\%) [32]. However, researchers reported that the first and major mass loss of water occurred between 40 and $130{ }^{\circ} \mathrm{C}$ and was presumably the loss of surface water $[1,22,32]$. The second mass loss occurred between 222 and $265{ }^{\circ} \mathrm{C}$ and peaked at $153{ }^{\circ} \mathrm{C}$, accompanied by a mass loss of $14.55 \%$ caused by the thermal decomposition of lactose monohydrate. This process is called pyrolysis. The primary reaction products of pyrolysis tend to polymerize, resulting in brown- and black-colored macromolecules. Eventually, lactose becomes black on heating. Another mass loss is observed between 290 and $330{ }^{\circ} \mathrm{C}$ with a mass loss of $55.68 \%$. This step can be interpreted as being due to the addition of the mass loss of decomposition of water and carbon dioxide. Regarding the TG profile of PEG 2000 and 6000 , only one mass loss was observed between 388 and 438 and peaked at $415{ }^{\circ} \mathrm{C}$ with a mass loss of $98.79 \%$, and it corresponds to the decomposition of the materials. The TG and DTG curves of the raw materials are shown in Fig. 4.

Table 4 shows the temperature ranges, peak temperatures, mass loss and the normalized integral of granule samples. The main characteristics of the samples derived from TG-DTG curves such as reaction regions and corresponding mass loss values were used to define the thermal behavior and combustion characteristics of granules. In these regions, one of the most important thermal reactions is the elimination of water molecules through dehydroxylation. The dehydroxylation temperature can be influenced 


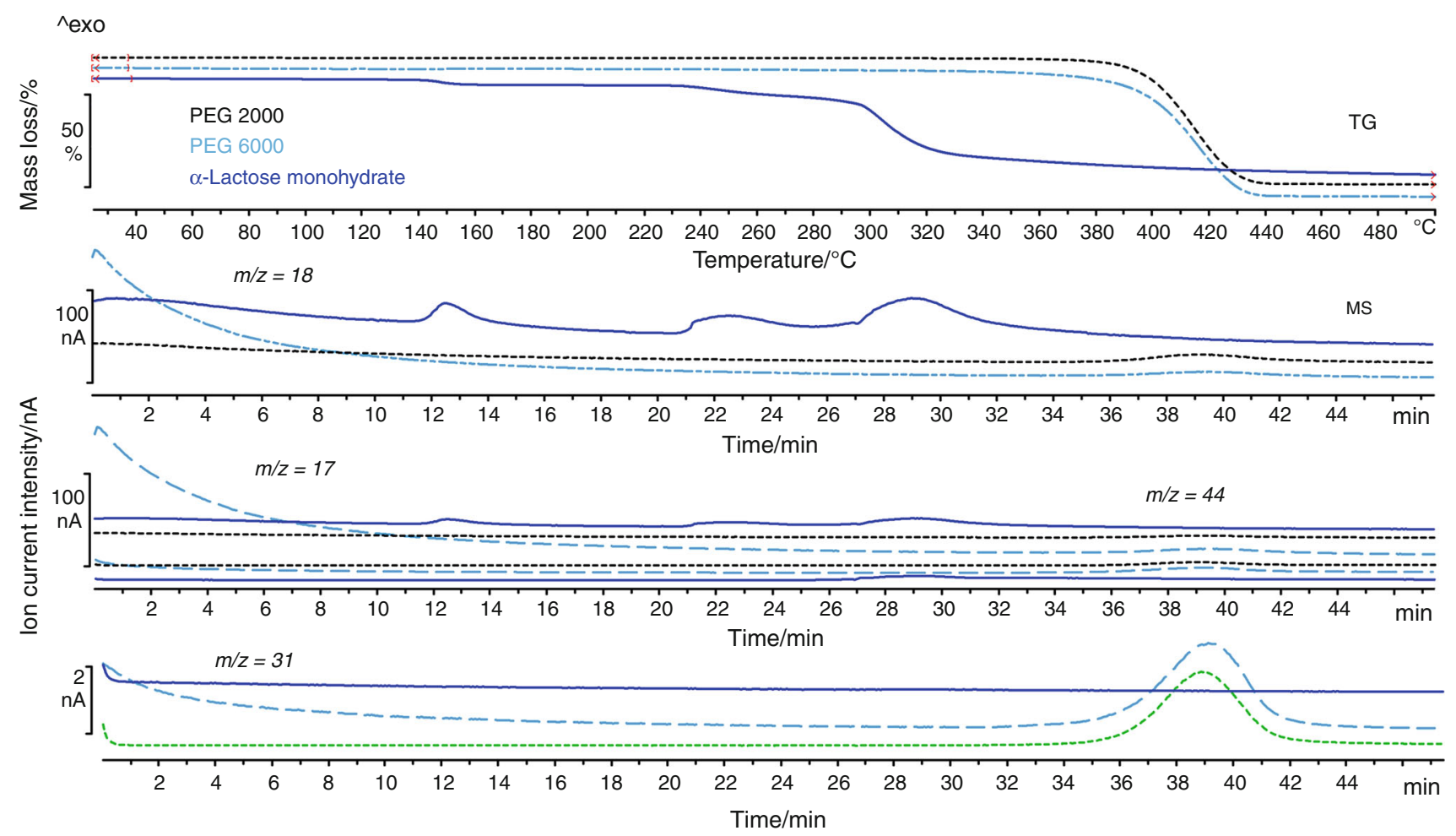

Fig. 4 TG-MS curves of raw materials: lactose monohydrate, PEG 2000 and PEG 6000

by the amount of impurities present in the material and the degree of disorder in the granules. Regarding the latter, the amount of lactose is higher than the PEG and the temperatures of dehydroxylation were found to be in relation with the crystallinity of lactose for a lower crystallinity index when increasing the PEG content. Hence, the operating parameters during the FBMG will determine the final attributes of the granules, giving an insight into the design space that must be assured for the desirable final product.

It can be seen that mass loss in granules comes in four stages. The first mass loss occurred between 80 and $140{ }^{\circ} \mathrm{C}$. This thermal range includes two stages of mass loss. The first dehydration between 80 and $100{ }^{\circ} \mathrm{C}$ is attributed to the elimination of water molecules adsorbed on the external surfaces of the lactose particles as well as a second stage between 100 and $140{ }^{\circ} \mathrm{C}$, corresponding to the loss of crystal water. This theory is based on the known stages of mass loss of lactose monohydrate as well as the presence of the polymer that shifted the mass loss of the granules by $2-5^{\circ} \mathrm{C}$, which is caused by the increase in the free volume in the granules.

The differences in the thermal range of the first mass loss in granules were due to the granules' structure and composition. The evolution of the second stage is illustrated in Fig. 5.

It describes the evolution of the water content of the granules during the granulation process. The intensity of the mass loss varies with the binder content and with the binder particle size. This variation is linked to the formation of granules. When using a low binder particle size, the growth mechanism taking place is the distribution, and the binder in a molten state will spread on the surface of the lactose enabling the formation of nuclei and hence the formation of granules. This growth mechanism gives definite attributes to the structure of granules [12]. The porosity and friability of the granules are increased, making the lactose particles subject to hot fluidizing air and hence to dehydration. The amount of water content in the granules will be described as water release. Indeed, there was a small reduction in mass between $80{ }^{\circ} \mathrm{C}$ and $131{ }^{\circ} \mathrm{C}$ for $\mathrm{S} 03$ and S13 indicating that the raw material $\alpha$-lactose monohydrate contained more surface water than the granule, which leads to the conclusion of the granule growth being in relation to the composition of the granules, determined by the conditions established during the granulation process. The increase in the binder content slightly affected the water content of the granules. Figure 5 shows that the mass loss slightly increased with the increase in binder content, which can be interpreted as a prevention of mass reduction as it helped shield the lactose particle from the hot fluidizing air. As for the viscosity grade, its influence could be seen when in high grade, as in the case of PEG 6000. Table 4 shows the variation of the four stages of mass loss for both PEG 2000 and 6000 viscosity gradients. 


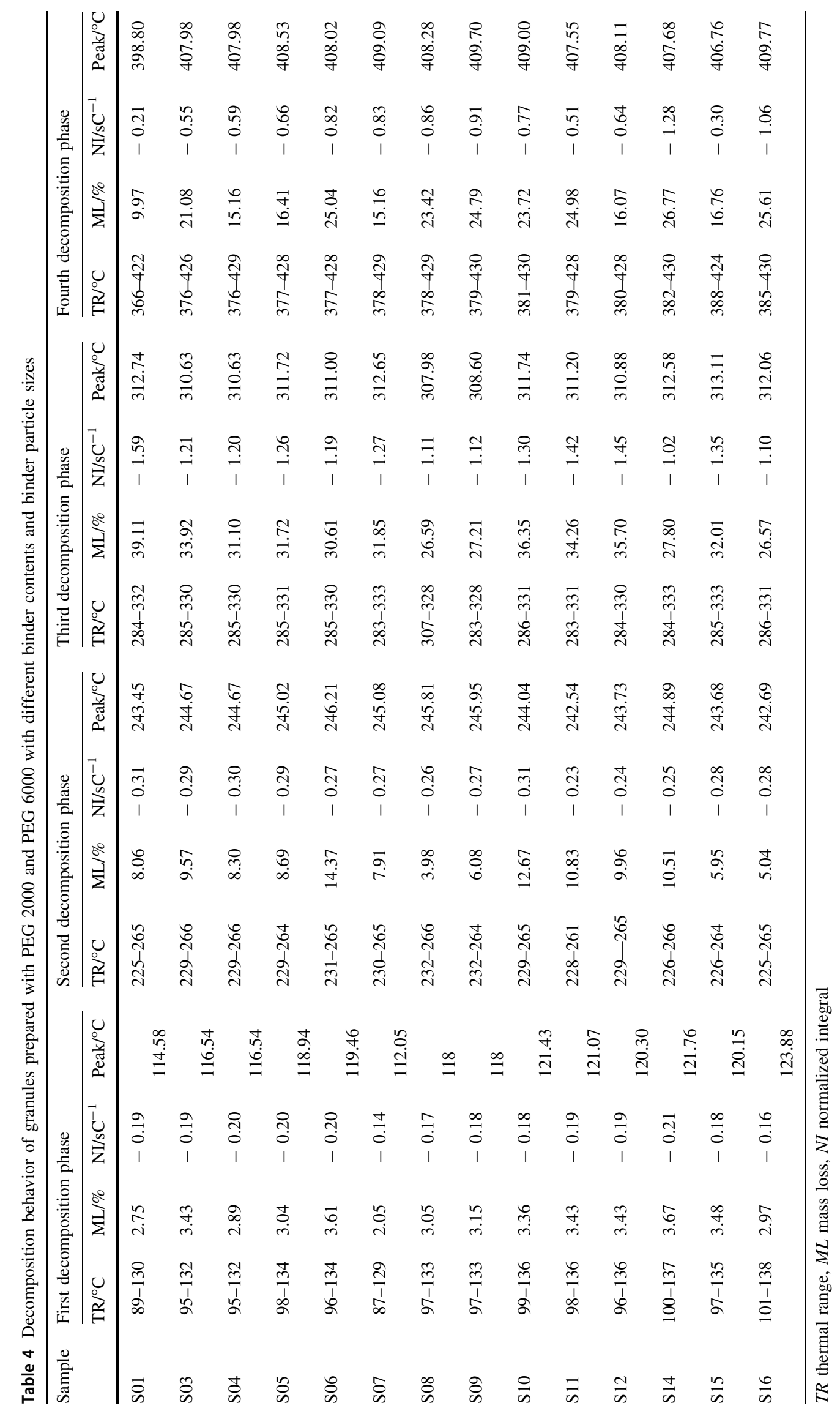




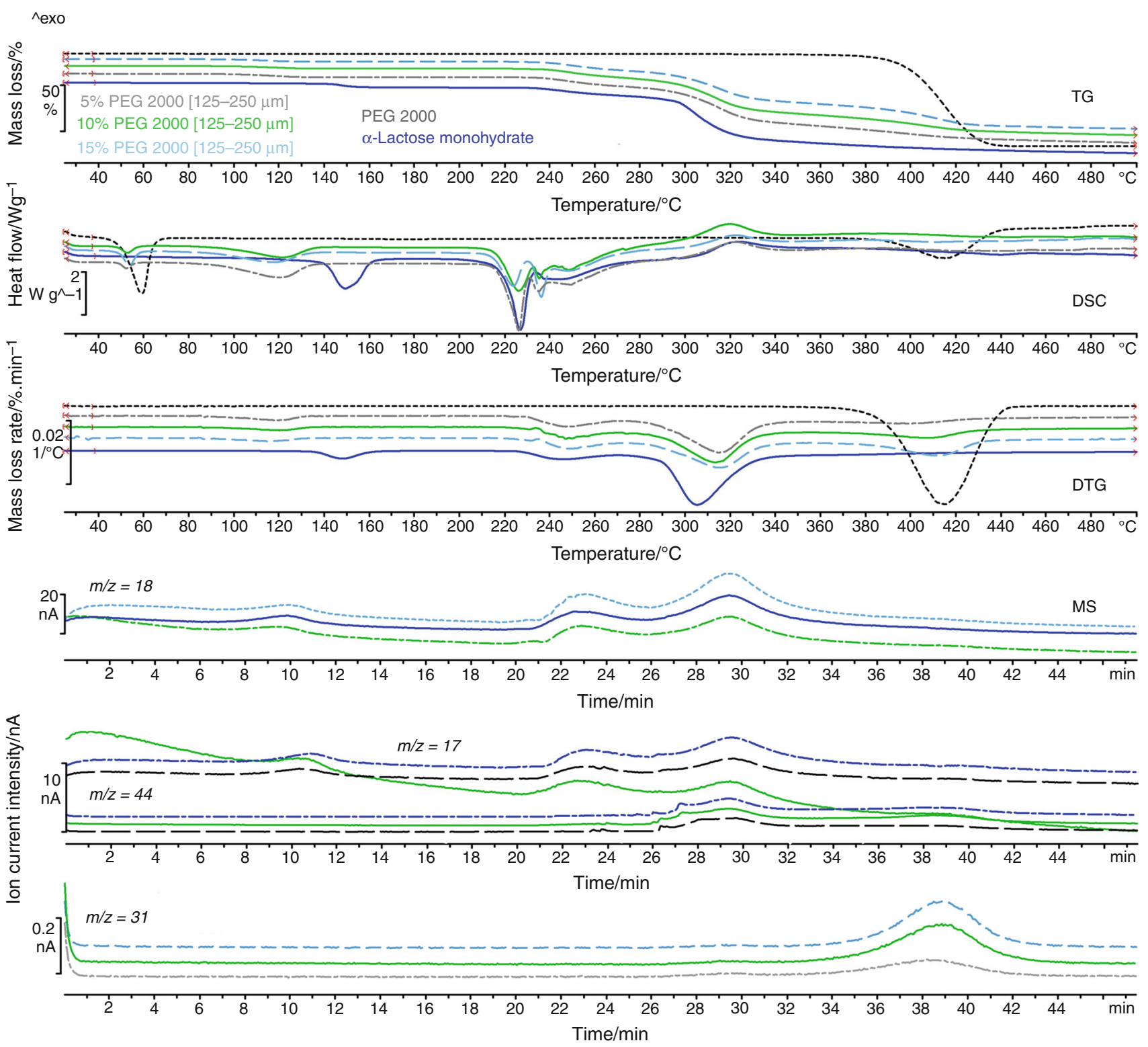

Fig. 5 TG, DSC, DTG and MS curves of granules with PEG 2000 with different binder contents

The use of a low-viscosity grade binder combined with a low binder content and particle size showed a poor mass loss in the first stage, which is attributed to a specific growth mechanism. The distribution of the melted binder over the lactose particles will result in adhesion and formation of nuclei. The latter will agglomerate if enough binding surface is available and will form granules. Their final structure gives the latter defined quality attributes. The lactose particles will be submitted to high temperature during granulation, and with the distribution mechanism, only a small part of the granules will be covered with the binder PEG 2000.

This result could be quantified with TG. A mass loss in the lactose crystal water was identified. This mass loss was very low compared with the raw material due to the dehydration of crystal water during the heating phase of the melt granulation. The mass loss was proportional to the increasing binder content. The increased binding surface resulted in lactose being covered and a low dehydration process (Table 4). However, the increase in binder viscosity led to a mass loss which was slightly higher but not significant enough for a change in the granulation mechanism. Indeed, the viscosity plays only a secondary role in the growth of the granules. It is the binder particle size that has the primary effect, and the results showed that the increase in binder content even at low binder content and viscosity grade resulted in a significant mass loss in the first stage of the decomposition of the granules (Fig. 5). 

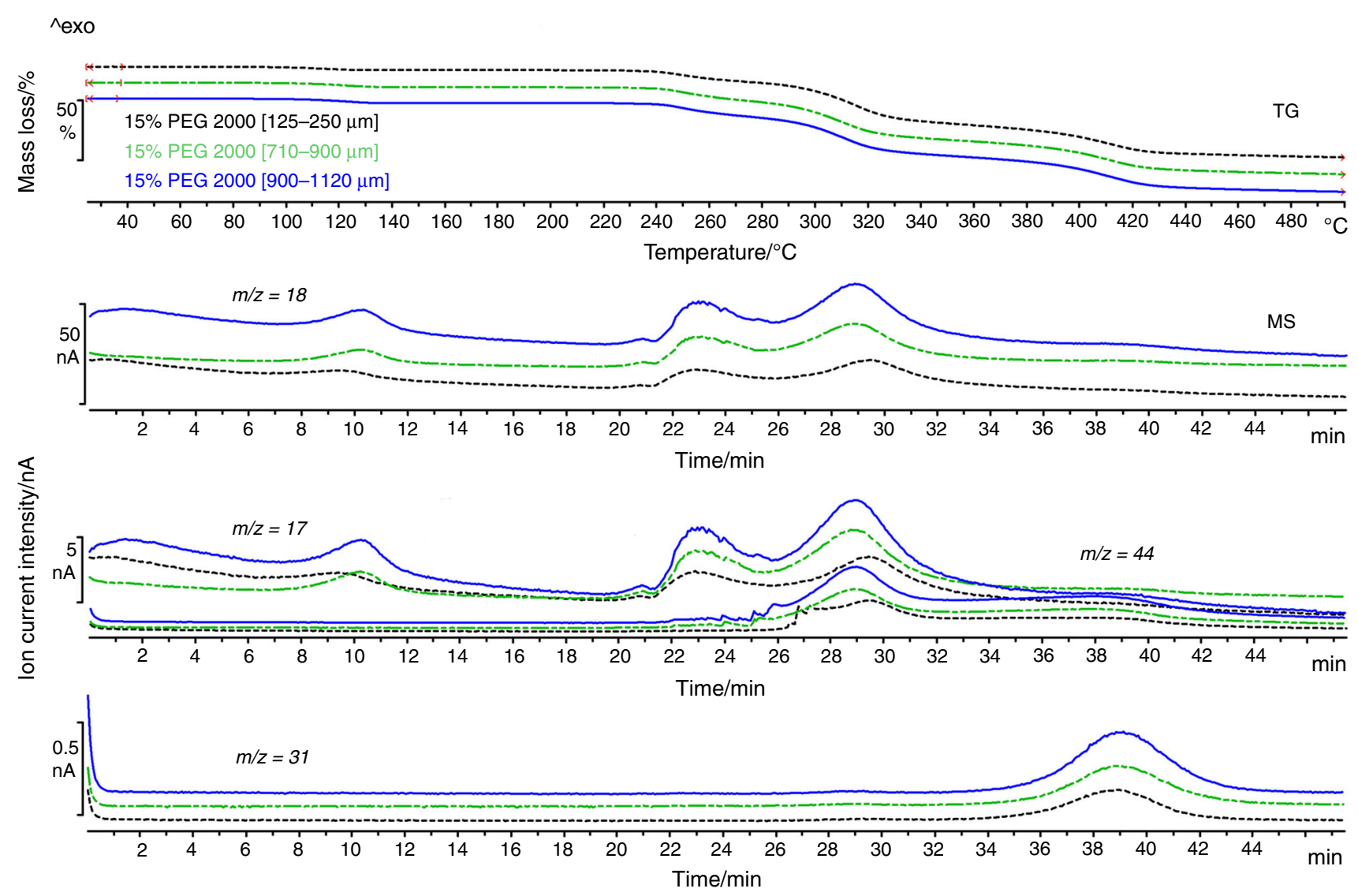

Fig. 6 TG-MS curves of granules with PEG 2000 and different particle sizes

The curves also revealed a shift in the melting point of the granules (Table 4). Indeed, the presence of the polymer helped increase the free volume and this explains the temperature drop in the first mass loss stage and water will be given out around $80{ }^{\circ} \mathrm{C}$. The higher the amount of the polymer, the lower the temperature at which water is given out. The same can be said when increasing the binder content. The free volume is at its highest value, and the shift in temperature is more predominant (Fig. 6).

\section{Mass spectrometry}

In order to clarify the decomposition mechanism of the granules, the mass loss during each decomposition process should be characterized by the identified evolution components. The interpretation of the mass spectra occurs on the basis of degassing profiles from the molecule ions of water $\left(\mathrm{H}_{2} \mathrm{O}^{+}: \mathrm{m} / \mathrm{z}=16,17,18\right)$ and ethylene glycol $\left(\mathrm{CH}_{2} \mathrm{OH}^{+}: m / z=31,32\right)$ as well as hydrocarbons as $\mathrm{CH}_{4}^{+}$ $(\mathrm{m} / \mathrm{z}=16)$ and $\mathrm{C}_{2} \mathrm{H}_{4}^{+}(\mathrm{m} / \mathrm{z}=28)$; carbon oxides as $\mathrm{CO}^{+}$ $(m / z=28)$ and $\mathrm{CO}_{2}^{+}(\mathrm{m} / \mathrm{z}=44)$; and other molecules ions summarized in Table 5 .

The evolution of gas species has been followed in situ by the coupled TG-MS system. The evolution curves of ion fragments of various gases released are shown as ion current versus time curves. The characterization of water release by means of MS is possible with the molecule ion $\mathrm{H}_{2} \mathrm{O}^{+}(\mathrm{m} /$ $z=18)$ together with the fragment ion $\mathrm{OH}^{+}(\mathrm{m} / \mathrm{z}=17)$ and $\mathrm{O}^{+}(\mathrm{m} / \mathrm{z}=16)$. Peaks at 125,250 and $315{ }^{\circ} \mathrm{C}$ are found in the ion current curve for $\mathrm{H}_{2} \mathrm{O}^{+}(\mathrm{m} / \mathrm{z}=18)$; corresponding peaks are also found in the ion current curves for $\mathrm{OH}^{+}(\mathrm{m} / \mathrm{z}=17)$ and $\mathrm{O}^{+}(\mathrm{m} / \mathrm{z}=16)$. It can be safely concluded that water is given out at about 125,250 and $315{ }^{\circ} \mathrm{C}$ from the samples, which is consistent with the mass loss observed from the TG curves. The dehydration takes place in the minor step at around $125{ }^{\circ} \mathrm{C}$, which is attributed to the dehydration of lactose monohydrate (Fig. 7).

The ion fragment $\mathrm{m} / \mathrm{z}=16\left(\mathrm{O}^{+}\right)$originates mainly from the evolution of both $\mathrm{H}_{2} \mathrm{O}^{+}$and $\mathrm{O}_{2}^{+}$. Some change in intensities of the $m / z=44$ fragments was observed, probably as an oxidation effect caused by the intense oxygen evolution. Basically, this fragment ion indicates the evolution of $\mathrm{CO}_{2}^{+}$. The ion current curves for the evolved gases show for $\mathrm{m} / \mathrm{z}=44$ an increase in concentration at around $250{ }^{\circ} \mathrm{C}$, which is attributed to the decomposition of a material. A further increase in the concentration of $\mathrm{CO}_{2}$ occurs at $415{ }^{\circ} \mathrm{C}$, which is assigned to the decomposition of polyethylene glycol (Table 5). 


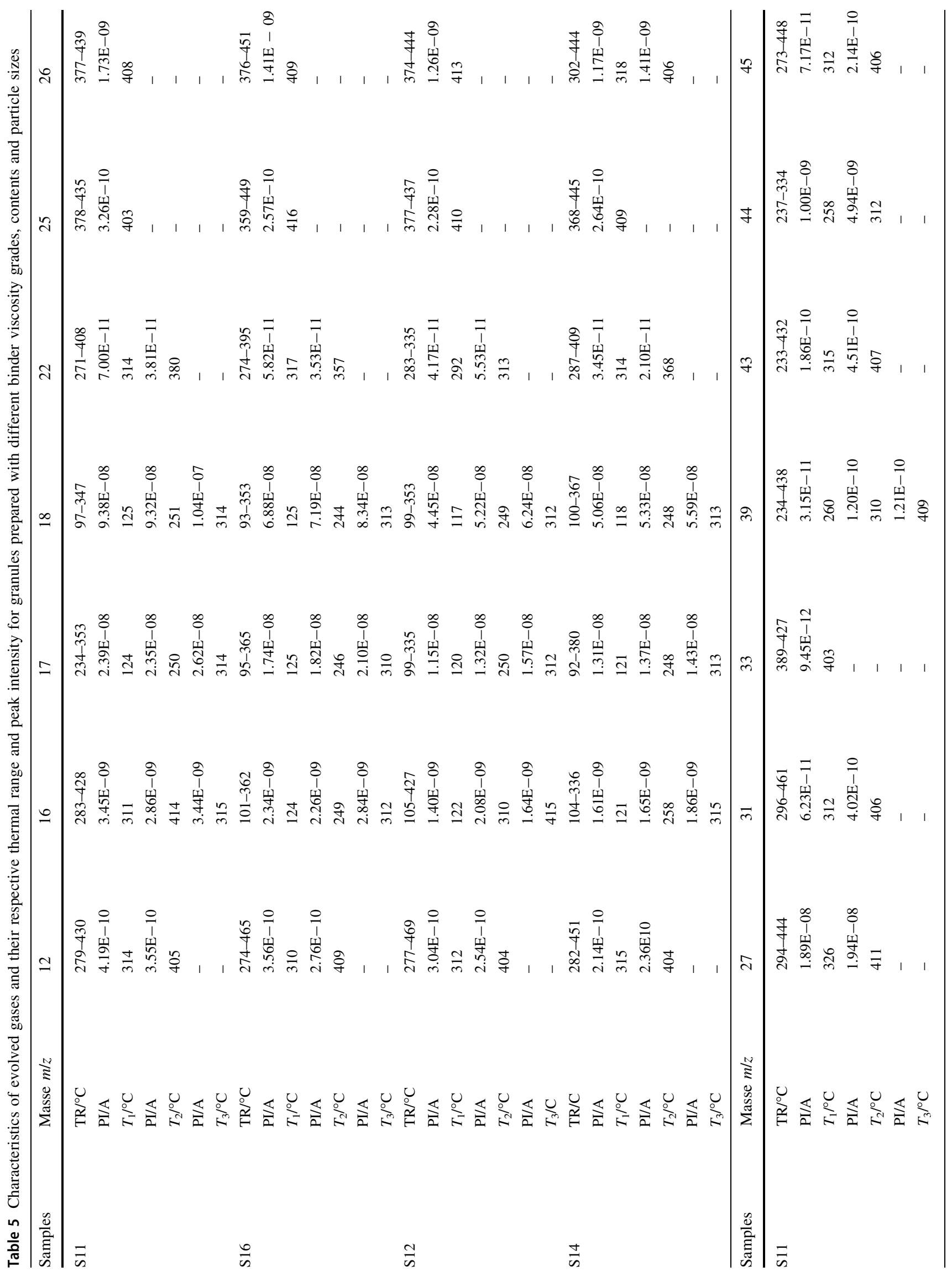




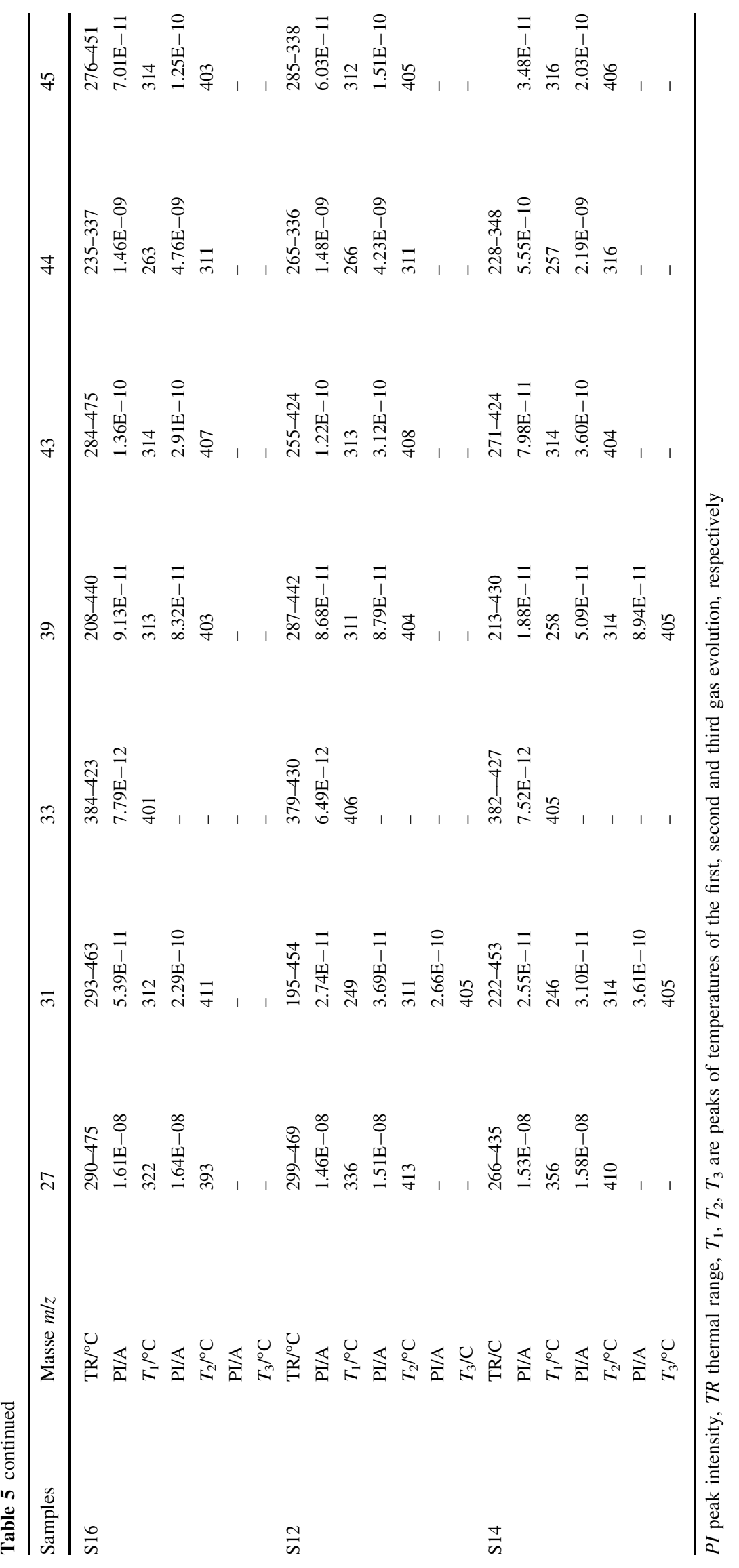




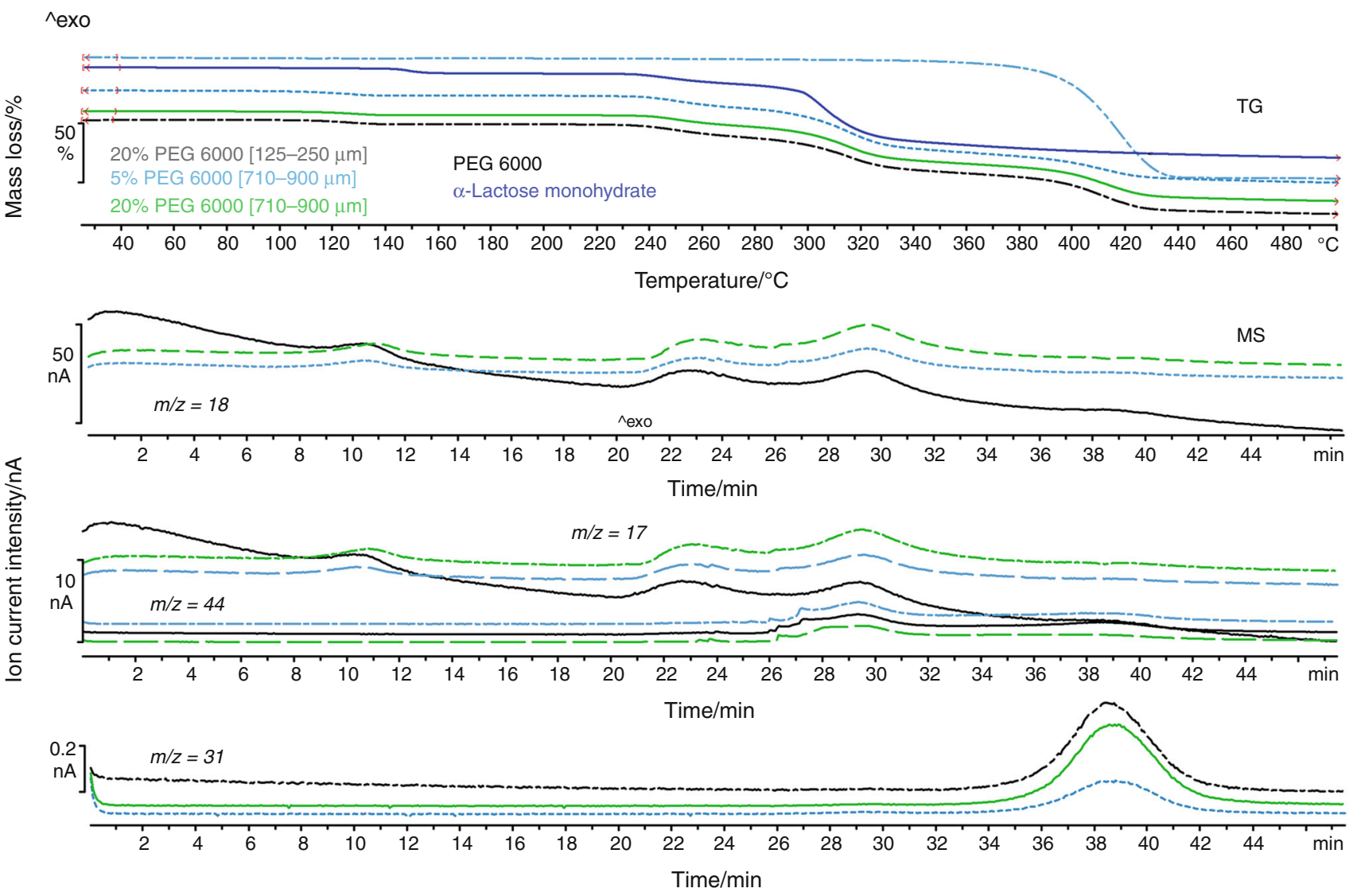

Fig. 7 TG-MS curves of granules prepared with PEG 6000 with different contents and particle sizes

An important increase in the concentration of polyethylene glycol is recorded for $\mathrm{m} / \mathrm{z}=31$ and $\mathrm{m} / \mathrm{z}=33$ due to the presence of the binder in the granules. The intensity of the peaks is proportional to the amount of PEG present in the composition of the granules, proving the relative correlation between the quantity of PEG and the evolved gases. The comparison of the granules has shown that their thermal decomposition is determined by different factors, such as their structure and composition, and the increase in concentration in the MS curves corresponds precisely to the mass loss in the TG curves.

\section{Conclusions}

The thermal decomposition of granules made through in situ fluid bed melt granulation has been examined using DSC and TG-MS, which proved to be very useful techniques for the determination of the thermal decomposition and structure of these pharmaceutical drug delivery products. DSC showed that the binder particle size was responsible for the transition from the distribution to the immersion mechanism. This transition was identified by the conversion from $\alpha$-lactose into $\beta$-lactose monohydrate caused by the dehydration of lactose during the FHMG process.
TG-MS have detected and monitored thermally evolved $\mathrm{H}_{2} \mathrm{O}^{+}(\mathrm{m} / \mathrm{z}=18), \mathrm{CO}_{2}(\mathrm{~m} / \mathrm{z}=44)$ and polyethylene glycol $(\mathrm{m} / \mathrm{z}=31,33)$. The temperature of the dehydroxylation of the granules is influenced by the free volume depending on the content and the particle size of the polymer. The increase in concentration in the MS curves corresponds precisely to the mass loss in the TG curves. Regarding the growth mechanism, the distribution mechanism occurred when using a low binder particle size and viscosity. The lactose particles will lose a fraction of the adsorbed water during the heating phase of granulation. However, when using a high binder particle size, the lactose particles will be trapped and immersed in the PEG particles, causing the adsorbed water to be trapped inside the granules.

This theory was proven as a larger reduction in water mass loss indicates the immersion mechanism. The morphology and the structure of the granules were observed to be in relation to their mass loss profiles and helped identify the growth mechanisms through the quantitative evaluation of the TG data and the qualitative determination of the evolved gases. This makes thermal analysis a promising technique for granulation growth control by giving a qualitative and quantitative insight into FBMG. 
Acknowledgements The authors would like to thank the Ministry of Higher Education and Scientific Research of Algeria and the Tempus Public Foundation for the Stipendium Hungaricum scholarship provided to Yasmine Korteby for her PhD studies.

\section{References}

1. Szűts A, Sorrenti M, Catenacci L, Bettinetti G, Szabó-Révész P. Investigation of the thermal and structural behavior of diclofenac sodium-sugar ester surfactant systems. J Therm Anal Calorim. 2009;95:885-90.

2. Sekiguchi K, Obi N. Studies on absorption of eutectic mixtures. I. A comparison of the behavior of eutectic mixtures of sulfathiazole and that of ordinary sulfathiazole in man. Chem Pham Bull. 1961;9:866-87.

3. Maniruzzaman M, Boateng JS, Snowden MJ, Douroumis D. A review of hot-melt extrusion: process technology to pharmaceutical product. ISRN Pharm. 2012; https://doi.org/10.5402/2012/ 436763.

4. Monteyne T, Heeze L, Mortier STFC, Oldörp K, Cardinaels R, Nopens I, Vervaet C, Remon JP, De Beer T. The use of rheology combined with differential scanning calorimetry to elucidate the granulation mechanism of an immiscible formulation during continuous twin-screw melt granulation. Pharm Res. 2016;510:271-84.

5. Roumeli E, Tsiapranta A, Pavlidou E, Vourlias G, Kachrimanis K, Bikiaris D, Chrissafis K. Compatibility study between trandolapril and natural excipients used in solid dosage forms. J Therm Anal Calorim. 2013;111:2109-15.

6. Ansari MA, Stepanek F. Formation of hollow core granules by fluid bed in situ melt granulation: modelling and experiments. Int J Pharm. 2006;321:108-16.

7. Kidokoro M, Sasaki K, Haramiishi Y, Matahira N. Effect of crystallization behavior of polyethylene glycol 6000 on the properties of granules prepared by fluidized hot-melt granulation (FHMG). Chem Pham Bull. 2003;51:487-93.

8. Mangwandi C, Zainal NA, JiangTao L, Glocheux Y, Albadarin $\mathrm{AB}$. Investigation of influence of process variables on mechanical strength, size and homogeneity of pharmaceutical granules produced by fluidised hot melt granulation. Powder Technol. 2015;272:173-80.

9. Prado HJ, Bonelli PR, Cukierman AL. In situ fluidized hot melt granulation using a novel meltable binder: effect of formulation variables on granule characteristics and controlled release tablets. Powder Technol. 2014;264:498-506.

10. Zhai H, Li S, Andrews G, Jones D, Bell S, Walker G. Nucleation and growth in fluidized hot melt granulation. Powder Technol. 2009;189:230-7.

11. Mašić I, Ilić I, Dreu R, Ibrić S, Parojčić J, Đurić Z. An investigation into the effect of formulation variables and process parameters on characteristics of granules obtained by in situ fluidized hot melt granulation. Int J Pharm. 2012;423:202-12.

12. Mašić I, Ilić I, Dreu R, Ibrić S, Parojčić J, Srčič S. Melt granulation in fluidized bed: a comparative study of spray-on versus in situ procedure. Drug Dev Ind Pharm. 2014;40:23-32.

13. Walker GM, Holland CR, Ahmad MMN, Craig DQM. Influence of process parameters on fluidised hot-melt granulation and tablet pressing of pharmaceuticals powders. Chem Eng Sci. 2005;60:3867-77.

14. Mu B, Thompson MR, Sheskey PJ, O'Donnell KP. Hot-melt granulation in a twin-screw extruder. Chem Eng Sci. 2012;81:46-56.

15. Weatherley S, Mu B, Thompson MR, Sheskey PJ, O'Donnell KP. Hot-melt granulation in a twin screw extruder: effects of processing on formulations with caffeine and ibuprofen. J Pharm Sci. 2013;102:4330-6.

16. Giron D, Goldbronn C. Use of DSC and TG for identification and quantification of the dosage form. $J$ Therm Anal. 1997;48:473-83.

17. Vasanthavada M, Wang Y, Haefele T, Lakshman JP, Mone M, Tong W, Joshi YM, Serajuddin ATM. Application of melt granulation technology using twin-screw extruder in development of high-dose modified-release tablet formulation. J Pharm Sci. 2011;100:1923-34.

18. Giron D. Thermal analysis and calorimetric methods in the characterisation of polymorphs and solvates. Thermochim Acta. 1995;248:1.

19. Ozawa T. Thermal analysis—review and prospect. Thermochim Acta. 2000;355:5-42.

20. Reitz C, Kleinebudde P. Influence of thermal and thermo-mechanical treatment, Comparison of two lipids with respect to their suitability for solid lipid extrusion. J Therm Anal Calorim. 2007;89:669-73.

21. Mojumdar SC, Sain M, Prasad RC, Sun L, Venart JES. Selected thermoanalytical methods and their applications from medicine to construction. J Therm Anal Calorim. 2007;90:653-62.

22. Gombás Á, Szabó-Révész P, Kata M, Regdon G Jr, Erős I. Quantitative determination of crystallinity of $\alpha$-lactose monohydrate by DSC. J Therm Anal Calorim. 2002;68:503-10.

23. Jayaraman K, Kok MV, Gokalp I. Combustion properties and kinetics of different biomass samples using TG-MS technique. J Therm Anal Calorim. 2017;127:1361-70.

24. Wang Z, Li H, Zheng J. TG-MS study on the effect of multi-walled carbon nanotubes and nano- $\mathrm{Fe}_{2} \mathrm{O}_{3}$ on thermo-oxidative stability of silicone rubber. J Therm Anal Calorim. 2016;126:733-42.

25. Li S, Yang C, Li C, Yan S. Synthesis, characterization of new bisphenol-based benzoxazines and the thermal properties of their polymers. J Therm Anal Calorim. 2017;128(3):1711-7.

26. Zohari N, Abrishami F, Sheibani N. A novel simple correlation for predicting glass transition temperature of energetic azidoester plasticizers through molecular structures. J Therm Anal Calorim. 2017;127:2243-51.

27. Hotová G, Slovác V. Quantitative TG-MS analysis of evolved gases during the thermal decomposition of carbon containing solids. Thermochim Acta. 2016;632:23-8.

28. Esfe MH. Designing an artificial neural network using radial basis function (RBF-ANN) to model thermal conductivity of ethylene glycol-water-based $\mathrm{TiO}_{2}$ nanofluids. J Therm Anal Calorim. 2017;127:2125-31.

29. Esfe MH, Rejvani M, Karimpour R, Arani AAA. Estimation of thermal conductivity of ethylene glycol-based nanofluid with hybrid suspensions of SWCNT- $\mathrm{AL}_{2} \mathrm{O}_{3}$ nanoparticles by correlation and ANN methods using experimental data. J Therm Anal Calorim. 2017;128:1359-71.

30. Kullyakool S, Siriwong K, Noisong P, Danvirutai C. Kinetic triplet evaluation of a complicated dehydration of $\left(\mathrm{CO}_{4}\right)_{2} \cdot 8 \mathrm{H}_{2} \mathrm{O}$ using the deconvolution and the simplified master plots combined with nonlinear regression. $\mathrm{J}$ Therm Anal Calorim. 2017;127:1963-74.

31. Çepelioğullar Ö, Mutlu I, Yaman S, Haykiri-Acma H. A study to predict pyrolytic behaviors of refuse-derived fuel (RDF): artificial neural network application. J Anal Appl Pyrolysis. 2016;122:84-94.

32. Raut DM, Allada R, Pavan KV, Deshpande G, Patil D, Patil A, Deshmukh A, Sakharkar DM, Bodke PS, Mahajan DT. Dehydration of lactose monohydrate: analytical and physical characterization. Der Pharma Lett. 2011;3:202-12. 
III. 


\title{
Use of machine learning tool to elucidate and characterize the growth mechanism of an in-situ fluid bed melt granulation
}

\author{
Yasmine Korteby, Katalin Kristó, Tamás Sovány, Géza Regdon Jr * \\ Institute of Pharmaceutical Technology and Regulatory Affairs, University of Szeged, H-6720 Szeged, Eötvös utca 6, Hungary
}

\section{A R T I C L E I N F O}

\section{Article history:}

Received 9 September 2017

Received in revised form 20 January 2018

Accepted 19 March 2018

Available online 20 March 2018

\section{Keywords:}

Fluid hot melt granulation

Granulation mechanism

Artificial neural network

Scanning electron microscopy

Surface response methodology

Process optimization

\begin{abstract}
A B S T R A C T
The aim of this work is to follow the agglomeration mechanism of an in situ Fluid Bed Melt Granulation (FBMG) by means of machine learning with Artificial Neural Network (ANN) modelling. Scanning Electron Microscopy (SEM) was used as a complementary tool with particle size analysis to evaluate the effect of the material properties on the quality attributes of the final granules and provide further insight into the growth mechanisms. The experiments were performed using lactose monohydrate as model filler and two grades of polyethylene glycol (PEG 2000 and 6000) as meltable binders in different contents and in different size fractions, respectively. A multilayer perceptron neural network was developed using MATLAB neural network toolbox and the evaluated quality attributes of the final granules were used as a database for the development and selection of the optimal architecture of the ANN model. The Garson equation was used to quantify the relative importance of each independent variable and thus it was established that the particle size had the highest impact on the granule properties. The distribution and immersion granule growth mechanisms were determined to occur for low and high binder particle size, respectively, as confirmed by the SEM pictures, and the response surfaces helped determine the optimal design space of the process and the optimal FBMG conditions.
\end{abstract}

(c) 2018 Elsevier B.V. All rights reserved.

\section{Introduction}

Hot melt granulation (HMG) is an emerging alternative granulation technique based on the use of low melting point materials heated to near or above their melting point as molten binders in order to improve the quality attributes of the excipient and active pharmaceutical ingredients (APIs) mixture, such as particle size, compressibility, compactability, flowability, for the production of solid dosage forms [1]. Unlike the wet granulation, melt granulation does not require liquids or solvents, which makes the process suitable to process moisture sensitive APIs. Also, the wetting and drying phase are eliminated, making the process more acceptable from an economic and an ecological point of view [2,3]. HMG can be performed in a high shear mixer or a fluidized bed unit, with the former being the most common [4] as it is a developing process for the preparation of pharmaceutical granules for tableting [5]. HMG in fluidized beds can be performed with two techniques, depending on the binder addition procedure. The binder can be added either in a molten state sprayed onto the fluidized solid particles (Spray-on procedure) or as solid binder particles added and fluidized together with drug particles and excipients (In-situ/Co-melt procedure), which melt during the increase in air temperature $[1,6]$. Fluid bed melt granulation (FBMG) has gained increased research

\footnotetext{
* Corresponding author.

E-mail address: geza.regdon@pharm.u-szeged.hu (G. Regdon).
}

attention and depending on granule requirements, either modified release dosage forms can be prepared [7-9] for the higher binder to substrate ratio, higher density and reduced porosity [10] or immediate release dosage forms [11]. Also, the improvement of the bioavailability of poorly water soluble drugs [12,13] and $\mathrm{PH}$-dependent drug release $[14,15]$ can be achieved; therefore, understanding the mechanisms prevailing in the granulation process is a prerequisite for obtaining proper control over the quality attributes of the products [16]. Consequently, many authors have focused on revealing the influence of some of the most important experimental variables on product quality, starting with the work of Schaefer's group [6,17-19] on the effects of binder spray rate, binder viscosity, droplet size, bed temperature on the performance of spray-on fluid bed melt granulation, showing that the granule growth mechanism is dependent on the ratio of binder droplet size to powder size and that a low ratio led to the nucleation mechanism and gave rise to coalescence enabling further granule growth [20]. However, when the binder droplet is larger than the size of the powder particles, the dominating agglomeration formation mechanism will be the immersion mechanism, where nuclei are formed where the powder particles adhere to the surface of the molten binder and get immersed. With regards to in-situ granulation, studies of the effect of formulation variables on the characteristics of granules by using different types of meltable binders were made $[5,10]$. Additionally, results showed that binder melt viscosity influenced the granule size enlargement of granules [21]. As for co-melt granulation, granulation time, binder/granule mass ratio, 
binder viscosity and binder particle size were investigated to study the granules size, size distribution and growth mechanism [22-24] hence making FBMG a complex process with numerous variables that affect the agglomeration process. In addition, all these processes involved seeds of very small size, similar to or even smaller than the sprayed binder droplets. For this reason, the particles preferentially grew by agglomeration, the growth by pure coating being negligible [25]. Therefore its use relies more on the understanding of the relationships among various formulation and process factors in order to control the final product quality [26]. In this frame, the quality by design approach suggests the establishment of a relevant design space that leads to the development of a controllable and robust manufacturing process, emphasizing that quality should be built into the product during the development phase [27]. Two approaches have been reported to predict the growth regime in fluidized-bed granulation: a) the use of the Population Balance Equation (PBE) coupled with kinetics of particle size change [28] and b) models based on dimensionless numbers [29].

The application of artificial neural networks (ANNs) is a widely used technique for the modelling and optimization, gaining importance in many areas of pharmaceutical research. It has been applied for the development and control of dosage forms and worked well for solving nonlinear problems of multivariate and multiresponse systems [28-34].

Also, to our knowledge, only one study on the use of ANN for modelling and optimizing FBMG has been reported. The authors applied surface response methodology and ANNs and compared both techniques regarding their modelling ability and predictability [26].

The aim of this paper is to further use the potential of ANNs in predicting the relative importance of the operating conditions (binder content, viscosity grade, particle size) regarding the final quality attributes (yield, mean size diameter, coefficient of variation of the size distribution, hardness, aspect ratio) of the granules in an in-situ fluid bed melt granulation and to characterize the mechanisms taking place during growth) to finally enable the process optimization.

\section{Materials and methods}

\subsection{Materials}

Alpha-lactose monohydrate (Ph. Eur.) was used as a model filler with a mean particle size of $100.16 \mu \mathrm{m}$. Two low melting point polymers (polyethylene glycol 2000; PEG 2000 and polyethylene glycol 6000; PEG 6000, Fluka, Switzerland) were used as meltable binders. The PEG flakes were finely ground using the planetary ball mill PM 100 (Retsch, Germany) at 150 rpm for $30 \mathrm{~min}$ and then sieved using laboratory test sieves (Retsch, Germany) into different size fractions (63-125, 125250, 250-500, 500-710, 710-900, 900-1120 $\mu \mathrm{m}$ ).

\subsection{Fluidized bed melt granulation}

The PEG and lactose monohydrate were granulated in a Strea-1 (Niro Aeromatic, Bubendorf, Switzerland) fluid bed chamber. A batch size of $200 \mathrm{~g}$ was used. The materials were mixed for $5 \mathrm{~min}$ in a Turbula mixer (Willy A. Bachofen Maschinenfabrik, Basel, Switzerland) to homogenize the physical mixture since there are not enough shear forces in the fluid bed granulator and then inserted and fluidized in the preheated chamber for a period of $10 \mathrm{~min}$ and at constant air velocity of $2.5 \mathrm{~m} / \mathrm{s}$. The experiments are summarized in Table 1 . The varied factors were the binder grade (viscosity) since PEG 2000 and PEG 6000 have different molecular weights and chain lengths, the meltable binder content ranging from $5 \%$ to $20 \%$ with a step of $5 \% \mathrm{~W} / \mathrm{W}$ and the binder particle size in 5 different size fractions. The size fractions 125-250, 250-500, 500-710, 710-900, 900-1120 $\mu \mathrm{m}$ were used regarding PEG 2000 and the size fractions $63-125,125-250,250-500,500-710$, 710-900 regarding PEG 6000. The outlet air temperatures were set at $60{ }^{\circ} \mathrm{C}$ and $70{ }^{\circ} \mathrm{C}$ for PEG 2000 and 6000 , respectively, since the melting points of PEG 2000 and 6000 were set at $53^{\circ} \mathrm{C}$ and $63^{\circ} \mathrm{C}$, respectively.
Table 1

Process parameters of the granulation experiments.

\begin{tabular}{|c|c|c|c|c|}
\hline Sample & $\begin{array}{l}\text { PEG viscosity } \\
\text { grade }\end{array}$ & $\begin{array}{l}\text { PEG content } \\
(\%)\end{array}$ & $\begin{array}{l}\text { PEG particle size } \\
(\mu \mathrm{m})\end{array}$ & $\begin{array}{l}\text { Outlet temperature } \\
\left({ }^{\circ} \mathrm{C}\right)\end{array}$ \\
\hline S01 & 2000 & 5 & $125-250$ & 60 \\
\hline S02 & 2000 & 10 & $125-250$ & 60 \\
\hline S03 & 2000 & 15 & $125-250$ & 60 \\
\hline S04 & 2000 & 20 & $125-250$ & 60 \\
\hline S05 & 2000 & 5 & $250-500$ & 60 \\
\hline S06 & 2000 & 10 & $250-500$ & 60 \\
\hline S07 & 2000 & 15 & $250-500$ & 60 \\
\hline S08 & 2000 & 20 & $250-500$ & 60 \\
\hline S09 & 2000 & 5 & $500-710$ & 60 \\
\hline S10 & 2000 & 10 & $500-710$ & 60 \\
\hline S11 & 2000 & 15 & $500-710$ & 60 \\
\hline S12 & 2000 & 20 & $500-710$ & 60 \\
\hline S13 & 2000 & 5 & $710-900$ & 60 \\
\hline S14 & 2000 & 10 & $710-900$ & 60 \\
\hline S15 & 2000 & 15 & $710-900$ & 60 \\
\hline S16 & 2000 & 20 & $710-900$ & 60 \\
\hline S17 & 2000 & 5 & $900-1120$ & 60 \\
\hline S18 & 2000 & 10 & $900-1120$ & 60 \\
\hline S19 & 2000 & 15 & $900-1120$ & 60 \\
\hline S20 & 2000 & 20 & $900-1120$ & 60 \\
\hline S21 & 6000 & 5 & $63-125$ & 70 \\
\hline S22 & 6000 & 10 & 63-125 & 70 \\
\hline S23 & 6000 & 15 & 63-125 & 70 \\
\hline S24 & 6000 & 20 & $63-125$ & 70 \\
\hline S25 & 6000 & 5 & $125-250$ & 70 \\
\hline S26 & 6000 & 10 & $125-250$ & 70 \\
\hline S27 & 6000 & 15 & $125-250$ & 70 \\
\hline $\mathrm{S} 28$ & 6000 & 20 & $125-250$ & 70 \\
\hline S29 & 6000 & 5 & $250-500$ & 70 \\
\hline S30 & 6000 & 10 & $250-500$ & 70 \\
\hline S31 & 6000 & 15 & $250-500$ & 70 \\
\hline S32 & 6000 & 20 & $250-500$ & 70 \\
\hline S33 & 6000 & 5 & $500-700$ & 70 \\
\hline S34 & 6000 & 10 & $500-710$ & 70 \\
\hline S35 & 6000 & 15 & $500-710$ & 70 \\
\hline S36 & 6000 & 20 & $500-710$ & 70 \\
\hline S37 & 6000 & 5 & $710-900$ & 70 \\
\hline S38 & 6000 & 10 & $710-900$ & 70 \\
\hline S39 & 6000 & 15 & $710-900$ & 70 \\
\hline S40 & 6000 & 20 & $710-900$ & 70 \\
\hline
\end{tabular}

The yield of the process (Y\%) is defined as the percentage of the product which meets the size requirements and is measured according to this equation [35]:

$\mathrm{Y}=\left(\frac{\mathrm{m}_{\mathrm{r}}}{\mathrm{m}_{\mathrm{b}}}\right) \times 100$

where $m_{r}$ and $m_{b}$ are the mass of granules in the specified size range (above $125 \mu \mathrm{m}$ ) and the batch size, respectively.

\subsection{Scanning electron microscopy}

The morphology of the agglomerate was investigated by Scanning Electron Microscopy (SEM) (Hitachi 4700, Hitachi Ltd., Tokyo, Japan), granule samples were coated with a gold film and both the whole and the cut granules were deposited on a double-adhesive carbon tape. The SEM images were obtained using a secondary electron detector.

\subsection{Granule size distribution}

For each experiment, the particle size distribution of granules was determined using a laser diffraction technique (Mastersizer S, Malvern Instruments Ltd., Worcestershire, UK) where the analysis was performed in dry mode. The laser diffractometer yields the particle size distribution in volume, with particle measurement in the size range 0.1 to $2000 \mu \mathrm{m}$. Approximately $2 \mathrm{~g}$ of each sample was transferred in dried and clean sample feeder tray, vibration feed rate $50 \%$ and dispersive 
air pressure 2 bar were applied. Three parallel measurements were performed for each sample. For the evaluation of the size distribution of the granules, the coefficient of variation (CV) was used for it better describes a relative variation and puts the variability in perspective relative to the magnitude of the measurements [36]. Often expressed as a percentage, it is the ratio of the standard deviation to the mean. The percentile ratio value approaches unity as the distribution becomes narrower.

\subsection{Porosity measurement}

Porosity $\varepsilon$, is defined as the ratio of the volume of liquid and pores to the total volume shown in Eq. (2):

$\varepsilon=\frac{V_{l}+V_{g}}{V_{s}+V_{l}+V_{g}}$.

The porosity was determined for each granule sample. The true density $\left(\rho_{\mathrm{a}}\right)$ of each sample was measured using a Quantachrome helium Multipycnometer (QuantaChrome, USA). The true density of the tablets was determined with the use of a Quantachrome Helium Multipycnometer (Quantachrome, USA). The bulk density $\left(\rho_{\mathrm{b}}\right)$ was measured from the mass of an object divided by volume including the pore volume [37]. The porosity is then calculated using Eq. (3) given below:

$\varepsilon=1-\left(\frac{\rho_{b}}{\rho_{a}}\right)$

\subsection{Granule strength measurement and yield}

The breaking hardness was tested for all granules with a special hardness testing apparatus developed at the Institute of Pharmaceutical Technology and Regulatory Affairs, University of Szeged. This device contains a sample holder and a special vertically moving breaking tool with continuous speed. The force measurement cell is placed under the sample holder table, and it is connected to a computer via an interface; thus, not only can the ultimate deformation force be measured, but the process (force-time and force-displacement curves) can also be followed. If the measured plot (force-time) is parallel to the x-axis, the deformation is viscoelastic; if the plot rises linearly, the deformation is elastic [38].

Ten parallel measurements were performed. The measuring range was $0-200 \mathrm{~N}$, the speed of the stamp was $20 \mathrm{~mm} / \mathrm{min}$, the output was $0-5 \mathrm{~V}$, and the sensitivity was $\pm 0.5 \% \pm 0.1$ digit. The sensor was UNICELL force measuring equipment, calibrated with the C9B $20 \mathrm{kN}$ cell.

\subsection{Aspect ratio}

The particle size and the shape of the granules were studied by using a stereomicroscope (Zeiss Stemi 2000-C, Carl Zeiss GmbH, Vienna, Austria). An Image J. image processing and analysis system (Wayne Rasband National Institutes of Health, USA) was used. The aspect ratio was used for the evaluation of the shape of the particles. 500 granules of each sample were checked. The aspect ratio (AR) was calculated with the following equation [39]:

$A R=\frac{d_{\max }}{d_{\min }}$

where the longest and shortest diameters were measured.

\subsection{Modelling using artificial neural networks}

For the evaluation of the experimental data, a multilayer perceptron neural network was developed. The ANNs toolbox on MATLAB ${ }$
(R2015b, MathWorks ${ }^{\circledR}$ ) was used in this study to design the architecture of the model. It enables the selection of neurons in each layer. The input layer constitutes the first layer (independent variables) and the last one forms the output layer (dependent variables). One or more hidden layers can be located between them and its number of neurons is determined by the desired accuracy in the neural predictions [40]. The ANN model is also provides values of input strengths (Weights), which indicate the significance of the effect of each input on the output [31].

The selected input data for model were the studied factors (viscosity grade, content and particle size of binder) and the outputs were the final product properties to predict (Yield: Y, Mean Diameter: $\mathrm{D}_{50}$, Coefficient of Variation: CV, Hardness: H, Aspect Ratio: AR). Forty experiments were used as input data to build the neural network model. The data was divided into three categories, where $70 \%$ was used for training, $15 \%$ as the test and $15 \%$ as the validation randomly selected from the available database. The input data were combined with random weights as in a linear regression model $(\Sigma)$ and then were transformed through a non-linear function, which enabled the modelling of an ANN. The activation function in the hidden layer and output layer is Tangent hyperbolic according to the following equation:

$$
F(n)=\left(\exp ^{n}-\exp ^{-n}\right) /\left(\exp ^{n}+\exp ^{-n}\right)
$$

For this, all inputs must be normalized to facilitate the calculation with the transfer function.

The training phase of the neural network is performed using the feedforward back propagation algorithm, the connection weights of the network are adjusted using the delta rule based on the LevenbergMarquardt method, and it is designated in MATLAB ${ }^{\circledR}$ by TRAINLM. The selection of the appropriate ANN model is based on its learning ability and predictability i.e. the model which presents the lowest mean square error (MSE) between the experimental and predicted (output) data. The latter (MSE) is calculated according to the following equation:

$\mathrm{MSE}=\frac{1}{n} \sum_{m=1}^{n}\left(y_{\text {exp }}, m-y_{\text {pred }, m}\right)^{2}$

where $\mathrm{N}$ is the number of data point, $\mathrm{y}_{\text {exp, } \mathrm{m}}$ is the experimental response, $\mathrm{y}_{\text {pred,m }}$ is the network prediction and $\mathrm{m}$ is an index of data.

The experimental and predicted data are compared through a linear regression model with the equation $\mathrm{Y}=\mathrm{a} * \mathrm{x}+\mathrm{b}$. The coefficient of correlation indicates the proportion of the variance in the predicted response that is predictable from the experimental input data, according to the following equation:

$$
R^{2}=1-\frac{\sum_{m=1}^{n}\left(y_{\text {exp }}, m-y_{\text {pred }, m}\right)^{2}}{\sum_{m=1}^{n}\left(y_{\text {exp }}, m-\bar{y}_{\text {pred }, m}\right)^{2}}
$$

If the coefficient of determination is equal to 1 , there is perfect correlation between targets and outputs. The simulation of a neural network model in MATLAB $®$ is done with the sim command. The values are denormalized for the comparison with the targeted data.

\section{Results and discussion}

\subsection{Model architecture and simulation}

In this study, the database used for the training of the ANN model and the determination of the optimal structure are the actual results of the quality attributes of the granule samples obtained from the investigations realized with the size and size distribution, hardness and shape measurements. The values of these measurements are summarized in Table 2.

A performance evaluation of the limitations and capabilities of multilayer feedforward networks for the modelling of granule attributes 
Table 2

Responses of granules samples according to the process conditions.

\begin{tabular}{|c|c|c|c|c|c|}
\hline Sample & Yield (\%) & $\mathrm{D}_{50}(\mu \mathrm{m})$ & Coefficient of variation & Hardness & Aspect ratio \\
\hline S01 & 42 & 110.236 & 70.845 & 0.37 & 1.723 \\
\hline SO2 & 54 & 128.757 & 61.546 & 0.48 & 1.704 \\
\hline S03 & 61 & 213.654 & 57.005 & 0.56 & 1.654 \\
\hline S04 & 74 & 366.142 & 52.845 & 0.64 & 1.561 \\
\hline S05 & 59 & 423.426 & 83.454 & 0.44 & 1.639 \\
\hline S06 & 68 & 577.551 & 76.545 & 0.58 & 1.602 \\
\hline S07 & 75 & 670.795 & 69.616 & 0.67 & 1.554 \\
\hline S08 & 88 & 732.263 & 64.854 & 0.83 & 1.503 \\
\hline S09 & 72 & 534.869 & 95.639 & 0.78 & 1.287 \\
\hline S10 & 83 & 594.238 & 88.907 & 0.84 & 1.189 \\
\hline S11 & 91 & 661.114 & 79.789 & 0.92 & 1.119 \\
\hline $\mathrm{S} 12$ & 92 & 786.267 & 73.562 & 1.04 & 1.103 \\
\hline $\mathrm{S} 13$ & 84 & 716.576 & 103.845 & 1.16 & 1.303 \\
\hline S14 & 90 & 789.531 & 94.201 & 1.34 & 1.223 \\
\hline S15 & 92 & 814.019 & 83.722 & 1.58 & 1.184 \\
\hline S16 & 93 & 863.863 & 78.368 & 1.90 & 1.112 \\
\hline S17 & 88 & 791.567 & 110.548 & 1.72 & 1.418 \\
\hline S18 & 91 & 832.736 & 97.235 & 1.87 & 1.381 \\
\hline S19 & 90 & 856.232 & 88.963 & 2.11 & 1.306 \\
\hline S20 & 94 & 896.638 & 80.864 & 2.36 & 1.272 \\
\hline S21 & 44 & 95.400 & 59.709 & 0.31 & 1.662 \\
\hline S22 & 49 & 112.247 & 52.007 & 0.36 & 1.532 \\
\hline S23 & 54 & 139.605 & 45.081 & 0.42 & 1.591 \\
\hline S24 & 67 & 205.759 & 36.573 & 0.48 & 1.652 \\
\hline S25 & 50 & 120.956 & 88.545 & 0.40 & 1.336 \\
\hline S26 & 62 & 181.912 & 75.399 & 0.52 & 1.315 \\
\hline S27 & 77 & 259.451 & 63.636 & 0.60 & 1.286 \\
\hline S28 & 90 & 387.156 & 54.589 & 0.78 & 1.252 \\
\hline S29 & 77 & 448.569 & 113.749 & 0.91 & 1.486 \\
\hline S30 & 86 & 529.357 & 90.310 & 1.04 & 1.413 \\
\hline S31 & 89 & 579.609 & 73.934 & 1.13 & 1.268 \\
\hline S32 & 91 & 659.143 & 63.987 & 1.22 & 1.213 \\
\hline S33 & 84 & 687.241 & 129.087 & 1.15 & 1.481 \\
\hline S34 & 86 & 729.260 & 96.419 & 1.37 & 1.344 \\
\hline S35 & 90 & 791.245 & 79.218 & 1.68 & 1.316 \\
\hline S36 & 93 & 830.459 & 68.145 & 1.86 & 1.238 \\
\hline S37 & 85 & 783.548 & 133.128 & 2.07 & 1.403 \\
\hline S38 & 92 & 814.965 & 100.235 & 2.13 & 1.391 \\
\hline S39 & 94 & 859.861 & 84.169 & 2.32 & 1.357 \\
\hline S40 & 95 & 886.125 & 72.654 & 2.65 & 1.348 \\
\hline
\end{tabular}

was made. Network learning parameters and architectures were investigated for the determination of the best architecture.

Single hidden-layer neural network architecture with different hidden neuron sizes was tested to decide on the optimal configuration. The architecture was tested 20 times with different initializations of the weights to take into account the probability of converging to local minima. Table 3 shows the Mean Square Error (MSE) of the validation set and the coefficient of correlation for different numbers of hidden neurons in a single layer ANN. According to the results, the lowest MSE is 0.01562 for 5 hidden neurons with a coefficient of correlation

Table 3

Variation of the Mean Square Error: MSE, epoch and the coefficient of correlation for the training and testing of the model as a function of the number of neurons.

\begin{tabular}{lllll}
\hline Number of neurons & MSE & Epoch & \multicolumn{2}{l}{ Coefficient of correlation } \\
\cline { 4 - 5 } & & & Training & Testing \\
\hline 01 neuron & 0.24031 & 27 & 0.63093 & 0.63293 \\
02 neurons & 0.06958 & 10 & 0.85742 & 0.85791 \\
03 neurons & 0.03837 & 65 & 0.96977 & 0.94223 \\
04 neurons & 0.02633 & 01 & 0.92888 & 0.93924 \\
$\mathbf{0 5}$ neurons & $\mathbf{0 . 0 1 5 6 2}$ & $\mathbf{1 6}$ & 0.98706 & $\mathbf{0 . 9 8 6 3 5}$ \\
06 neurons & 0.01928 & 19 & 0.98701 & 0.98531 \\
07 neurons & 0.01777 & 3 & 0.98101 & 0.97534 \\
08 neurons & 0.01757 & 19 & 0.98456 & 0.97531 \\
09 neurons & 0.01817 & 07 & 0.98542 & 0.97635 \\
10 neurons & 0.02015 & 18 & 0.94853 & 0.94434 \\
\hline
\end{tabular}

of $R=0.99$. MSE increases as the number of hidden neurons is increased beyond 5 .

The selected optimal, one hidden layer with 5 neurons architecture ANN model was trained using the feed-forward back propagation algorithm. The stopping criterion used for the learning of the neural network is that of early learning. The validation error decreases during the initial phase of learning. However, when the network starts to adjust too finely to the training data, the error on the validation set increases. When the validation error increases for a predetermined number of iterations, learning is stopped prematurely, that is to say, before full convergence of the algorithm and the limited on-adjustment. The weights and bias selected are those corresponding to the minimum of the validation error and the highest coefficient of determination $\mathrm{R}^{2}$ of each neural network [32]. After the mean square error on validation increases for 6 consecutive epochs, the final connection weight and bias values for the neural network will then be those corresponding to epoch 16 . Hence, this model was found to be efficient in predicting the granule properties. The structure of the multilayer perceptron neural network used in this study and its connections between layers are shown in Fig. 1.

Fig. 2 shows the parity plot with the $95 \% \mathrm{Cl}$ of the five predicted outputs of the neural network model compared to the measured experimental data. The results show that almost all data points are within the interval of confidence. This reveals that the values obtained from the ANN model are very close to the experimental data indicating good predictability and accuracy. Hence, this model was found to be efficient in predicting and simulating the granule properties.

All final properties predicted by the model were evaluated using a built-in function 'Contour' to establish the response surface plots enabling a clear visualization of the effect of the input variables on the a quality attributes of granules.

\subsubsection{Relative importance of input variables}

The ANN used provides the weights that are coefficients between the artificial neurons. This neural network weight matrix can help assess the relative importance of the various input data (independent variables) on the output (dependent variables) using the equation based on partitioning of connection weights proposed by Garson [41]:

$$
I_{j}=\frac{\sum_{m=1}^{m=N h}\left(\left(\left|W_{j m}^{i h}\right| / \sum_{k=1}^{N i}\left|W_{k m}^{i h}\right|\right) \times\left|W_{m n}^{h o}\right|\right)}{\sum_{k=1}^{k=N i}\left\{\sum_{m=1}^{m=N h}\left(\left|W_{k m}^{i h}\right| / \sum_{k=1}^{N i}\left|W_{k m}^{i h}\right|\right) \times\left|W_{m n}^{h o}\right|\right\}}
$$

where $\mathrm{I}_{\mathrm{j}}$ is the relative importance of the $\mathrm{j}^{\text {th }}$ input variable on output variable, $\mathrm{Ni}$ and $\mathrm{Nh}$ are the number of input and hidden-neurons, respectively, Ws are connection weights, the superscripts ' $i$ ', 'h' and 'o' refer to input, hidden and output layers, respectively, and subscripts ' $\mathrm{k}$ ', ' $\mathrm{m}$ ' and ' $\mathrm{n}$ ' refer to input, hidden and output neurons, respectively [40].

The influence of each parameter on the variable studied has been assessed in Table 4. The initial particle size of the binder is the most significant factor affecting the granulation growth mechanism for FBMG as found in literature data $[2,26,42]$, followed by the binder viscosity grade and the binder content.

\subsection{Agglomerate growth mechanism and morphology}

From the developed model, the variation of the responses (quality attributes of granules) according to the process condition was investigated in order to elucidate the effect of every factor and of the combined factors on each output.

For the evaluation of the granulation, mechanisms indicated in Section 3.1 are confirmed through the investigation of granule morphology made by SEM micrographs of the agglomerates. As previously reported in literature, there are two different nucleation and growth mechanisms during melt granulation: distribution and immersion $[17,23]$. The distribution mechanism is described as the distribution of 


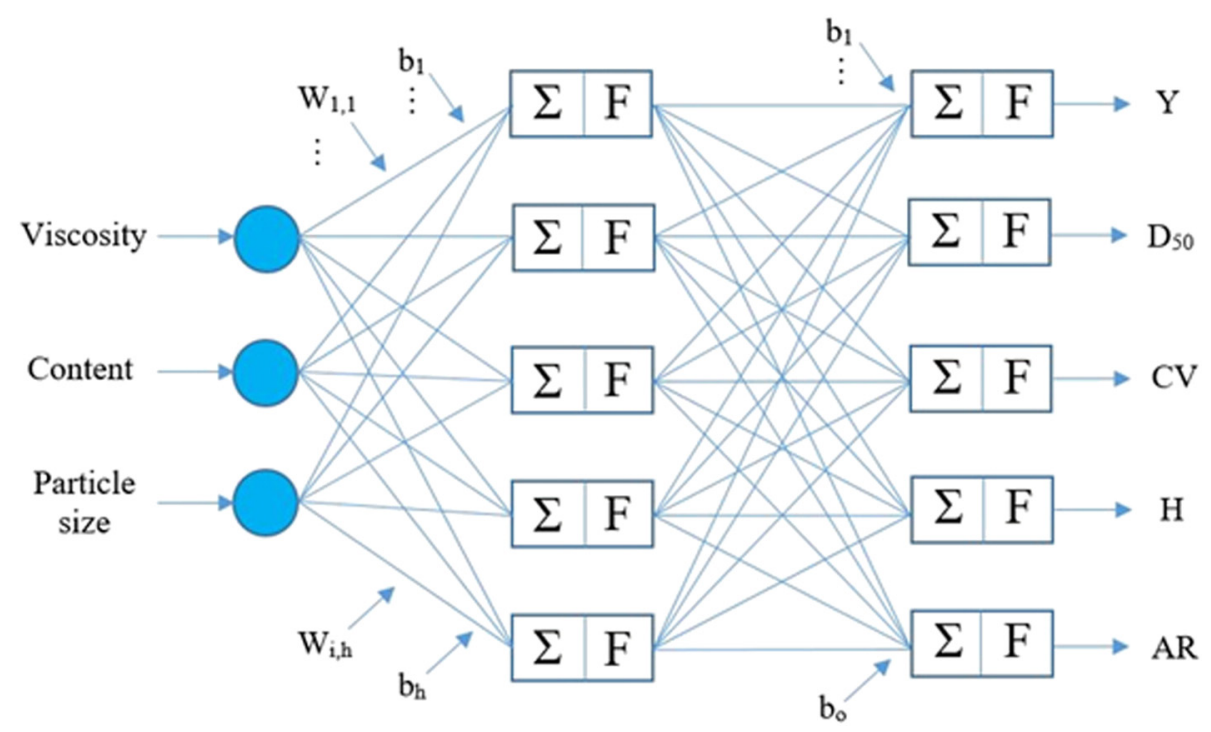

Fig. 1. Schematic diagram of the ANN model architecture.

the meltable binder on to the surface of filler particles creating liquid bonds for wetting, and hence, enabling growth by the coalescence of the formed nuclei. On the other hand, the distribution mechanism is characterized by the adhesion followed by the immersion of the filler particle on the surface of the meltable binder resulting in granule growth [43].

The occurrence of either the distribution or the immersion mechanism is according to the operating conditions and parameters influencing the agglomeration process. Fig. 3 shows the SEM micrographs of granules.

It is reported that the particle size of the binder plays a major role in granulation growth and growth mechanism $[23,26]$ as in case of a low particle size binder, i.e. the filler particle similar or higher in size than the binder particle, the dominant mechanism will be distribution since the melted binder will spread on the surface of the filler particles during contact and enable the formation of liquid bonds responsible for the adhesion and coalescence of nuclei. This system shows granules with a low mean diameter (Fig. 3a) and irregular in morphology, which indicates that they are an agglomerate of smaller sub-granules even at high binder viscosity grade.

The recrystallization of melted PEG after cooling can be seen on the surface of lactose and on the solid bridges that coalesce nuclei together (Fig. 3b). As for a high binder particle size, i.e. the filler particle lower in size than the binder particle, the size of agglomerates increases in a different granulation mechanism, the filler particles will adhere and immerse in the binder particle (Fig. 3c).

Growth will continue by layering of lactose on the surface of the agglomerates. The trapped binder particle will be squeezed to the surface due to densification [44] and spreads around the lactose particles (Fig. 3d). In case of low binder viscosity grade, it will result in high sphericity for the agglomerate will not have enough binding strength to attach to another agglomerate and the collision during fluidization will give it a rounded attribute. However, when high binder viscosity grade is applied (Fig. 3e), the mechanism of granulation will not be affected and the trapped binder will result in a hollow core granule, but the higher binding strength will enable the adhesion of agglomerates with each other and will result in irregularly shaped granules because of coalescence between one large and one smaller granule (Fig. 3f).

On the other hand, the binder content will affect the rate of agglomeration and the amount of granules with high diameter as well as the granule strength. Indeed, when a low binder content was used, the fraction of ungranulated lactose was high with a small fraction of nuclei that might be included, indicating that nucleation is the dominant mechanism. Fragile and low density granules with low degree of sphericity will be formed (Fig. S1a, Supplementary materials).

The increase in binder content will allow further growth by coalescence [19] for the higher available wetted surface during granulation. This also leads to denser granules, a higher yield and a higher particle size for the possibility of additional agglomeration between nuclei (Fig. S1b, Supplementary materials). These attributes are in accordance with the results predicted by the ANN model designating the binder particle size as the major factor conducting the granulation process, followed by the binder viscosity grade, which can result in further growth when used in high level. As a tertiary effect, the content of binder moves forward the granulation growth without interfering in the growth mechanism, confirming the good prediction of the relative importance of the factors on FBMG process.

\subsection{Effect of process variables on granule size, size distribution and yield}

Due to the small particle size of the binder, the mean particle size of the granules showed low values because the binder size is the parameter with the greatest effect and this process condition promotes the distribution mechanism. Hence, low yield values of granulated fine particles were found, which explains the broad size distribution, i.e. the high coefficient of variation value and the high aspect ratio (Figs. S2 and S3, Supplementary materials).

On the other hand, the higher binder particle resulted in greater sized granules with a higher yield due to the immersion mechanism that took place and reduced the amount of fine particles. However, the coefficient of variation was higher than with the small sized binder as a result of the low binder viscosity grade and deformability of the binder, which made the gap between fine particles and great sized granules more expressed (Fig. S2, Supplementary materials), confirming the prediction of the ANN model, which attributed a relative importance of $42 \%$ to the binder size.

Despite a low binder content and particle size, increasing the binder viscosity grade supported a small but distinct increase in the fraction of larger granules. Seo et al. [6] found that a small binder size results in small nuclei, and due to the high binder viscosity grade only a small fraction will be distributed on lactose particles, which will reduce growth by coalescence.

A high coefficient of variation value was in accordance with the results of yield and mean diameter as granules will not coalesce until 

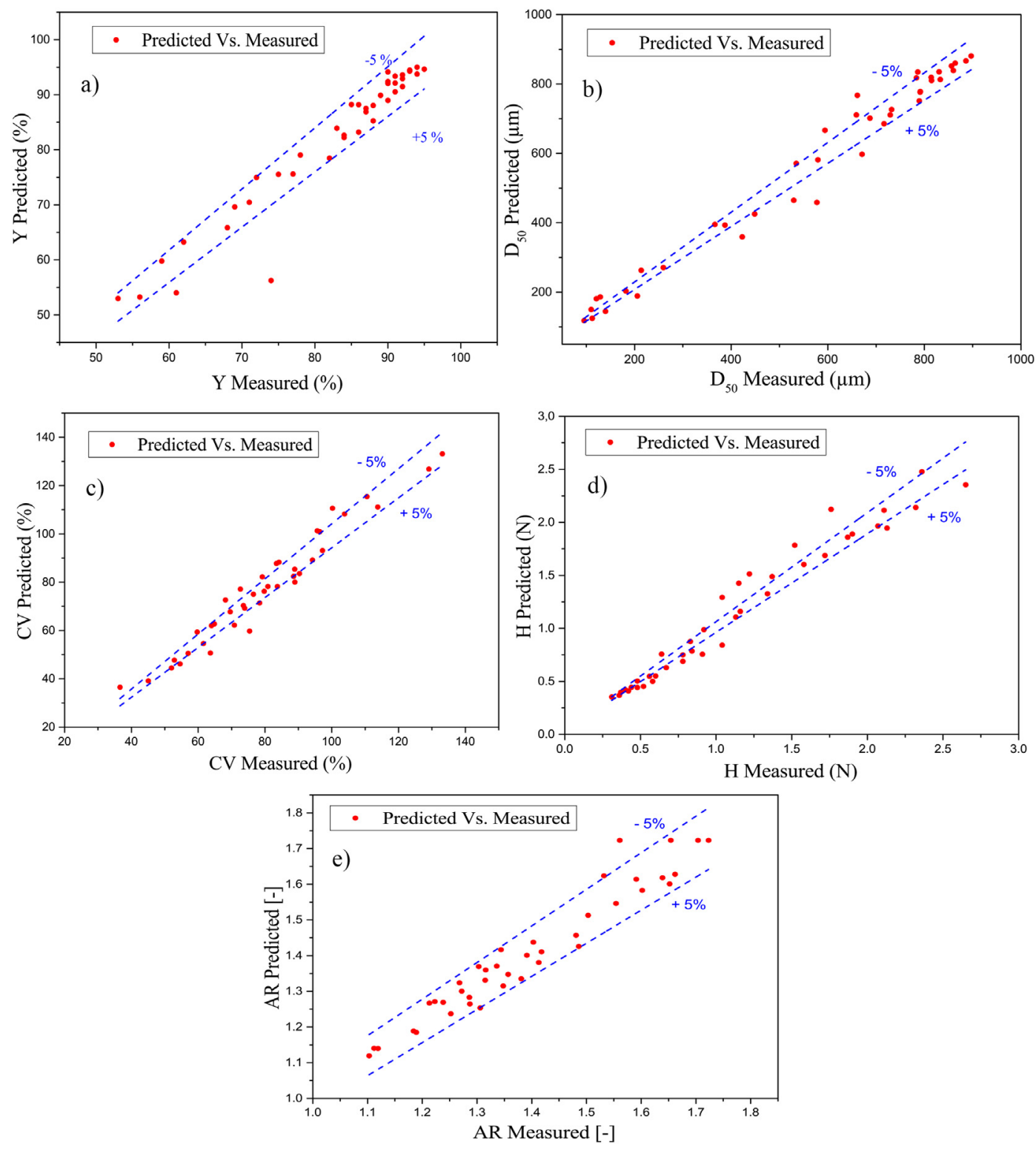

Fig. 2. Parity plot with the $95 \% \mathrm{CI}$ of the five predicted outputs versus the measured experimental data.

the major part of fine particles is agglomerated, since agglomeration growth is inversely proportional to the amount of particles according to $[6,45]$.

According to the predicted results of the ANN model, the binder viscosity grade of the binder plays a secondary role in the granulation

\section{Table 4}

Weights of the designed ANN model and the relative importance (\%) of the inputs (viscosity grade: $\mathrm{V}$ (grade), content: $\mathrm{C}(\%)$ and particle size: $\mathrm{S}(\mu \mathrm{m})$ ) on the outputs (yield: $\mathrm{Y}(\%)$, mean diameter: $\mathrm{D}_{50}(\mu \mathrm{m})$, coefficient of variation: $\mathrm{CV}(\%)$, hardness: $\mathrm{H}(\mathrm{N})$, aspect ratio: AR, relative importance: R.I.).

\begin{tabular}{|c|c|c|c|c|c|c|c|c|}
\hline \multirow{2}{*}{$\begin{array}{l}\text { Hidden } \\
\text { neurons }\end{array}$} & \multicolumn{8}{|l|}{ Weights } \\
\hline & $\begin{array}{l}\text { V } \\
\text { (grade) }\end{array}$ & C (\%) & $\begin{array}{l}\mathrm{S} \\
(\mu \mathrm{m})\end{array}$ & $\begin{array}{l}\mathrm{Y} \\
(\%)\end{array}$ & $\begin{array}{l}\mathrm{D}_{50} \\
(\mu \mathrm{m})\end{array}$ & $\begin{array}{l}\text { CV } \\
(\%)\end{array}$ & $\mathrm{H}(\mathrm{N})$ & $\mathrm{AR}$ \\
\hline Hidden 1 & 0.32 & -0.76 & 0.39 & 0.75 & 0.49 & -3.99 & 1.07 & 0.05 \\
\hline Hidden 2 & 2.20 & 0.017 & -1.08 & 1.72 & -2.65 & -3.02 & 0.48 & 0.04 \\
\hline Hidden 3 & -0.02 & -0.22 & -0.19 & 3.06 & -1.79 & 0.42 & 0.27 & 0.09 \\
\hline Hidden 4 & 1.79 & -0.08 & 5.59 & 1.49 & -2.41 & -2.81 & -0.09 & 0.55 \\
\hline Hidden 5 & 2.91 & -0.34 & 1.29 & 0.33 & -2.23 & 1.48 & -4.19 & 1.09 \\
\hline R. I. (\%) & 36 & 22 & 42 & - & - & - & - & - \\
\hline
\end{tabular}

growth. Indeed, with a $36 \%$ effect, the growth in this system was minor, indicating the small coalescence yield as granules above $150 \mu \mathrm{m}$ did not exceed $53 \%$.

The low binder viscosity grade enables the formation of very spherical granules since the deformation is higher (Table 2). A large particle size with high binder viscosity promotes the successful attachment of filler particles to the surface of the binder according to [23]. It is noticeable that the size distribution of the final granules remained almost unchanged as we can see in (Fig. S2, Supplementary materials), the size distribution was similar irrespective of the binder viscosity grade of the molten binder. Hence, the particle size of the initial binder was the principal factor affecting the size distribution of the granules, which is in accordance with the findings of [23].

With a high binder particle size, the driving mechanism of granule formation is immersion. Schaafsma et al. [46] and Seo et al. [6] found that with low viscosity, the binder liquid will be able to be drained from the inside of the agglomerate to the surface due to capillary pressure difference, increasing the possibility for lactose particles to be immersed and hence a higher yield of granules with a higher mean particle size (Figs. 4 and 5). However, we could see that the granule 

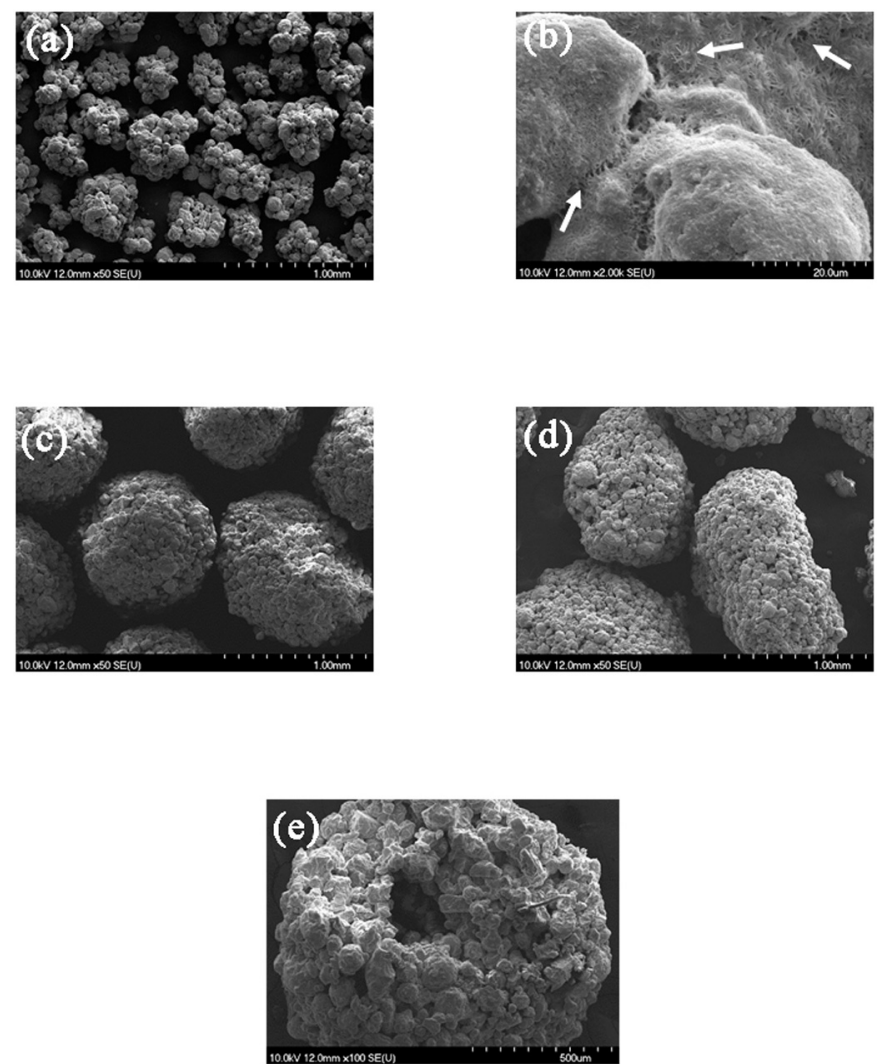

Fig. 3. SEM pictures of: (a) granules prepared with $15 \%$ of PEG 6000 with binder particle size (125-250 um); (b) close up to the surface of granules prepared with 15\% of PEG 6000 with binder particle size $(125-250 \mu \mathrm{m})$; (c) granules prepared with $10 \%$ of PEG 2000 with binder particle size $(500-710 \mu \mathrm{m})$; (d) cross section of nuclei of a granule prepared with $10 \%$ of PEG 6000 with binder particle size $(500-710 \mu \mathrm{m})$; (e) granules prepared with $10 \%$ of PEG 6000 with binder particle size $(500-710 \mu \mathrm{m})$; (f) a cross section of a granule prepared with $10 \%$ of PEG 6000 with binder particle size $(500-710 \mu \mathrm{m})$.

size distribution was larger because the low binder content and binder viscosity grade increased the gap between the lactose particles and the spherical granules with higher density.

The increase in the binder content from $5 \%$ to $20 \%$ resulted first in a minor increase in the granule size with a large fraction of ungranulated lactose. This was due to the loss of powder particles from the surface of the granules. The collision with the fluidized particles produced weak granules caused by low available wetted surface for nucleation, which is in agreement with the finding of Walker et al. [5] (Fig. 4). This system favors the production of broad granule size distribution, with high coefficient of variation values and limits the growth rate.

The ungranulated fraction was slightly reduced with the increase of the binder content and the formed liquid bridges resulted in a bigger fraction of granules with greater sizes (Fig. 5). The increase in binder content resulted in a narrower agglomerate size distribution, i.e. a lower coefficient of variation (Fig. S2, Supplementary materials), indicating growth by coalescence between particles which were spherically shaped and had a more packed structure.

However, studies showed that when the binder amount becomes too high, the liquid bridges will amalgamate, resulting in very large granules and a di-fluidized system [47,48]. Particularly, lower values of coefficient of variation were obtained, as a consequence of the high density, sufficient bonds leading to irregularly shaped granules as well as the high difference that resulted between the size of fine particles and agglomerates (Fig. S2, Supplementary materials).

The results showed that the binder content induces smaller changes in the granule characteristics in comparison with the binder particle size and binder viscosity grade. Indeed, these process conditions - with a low
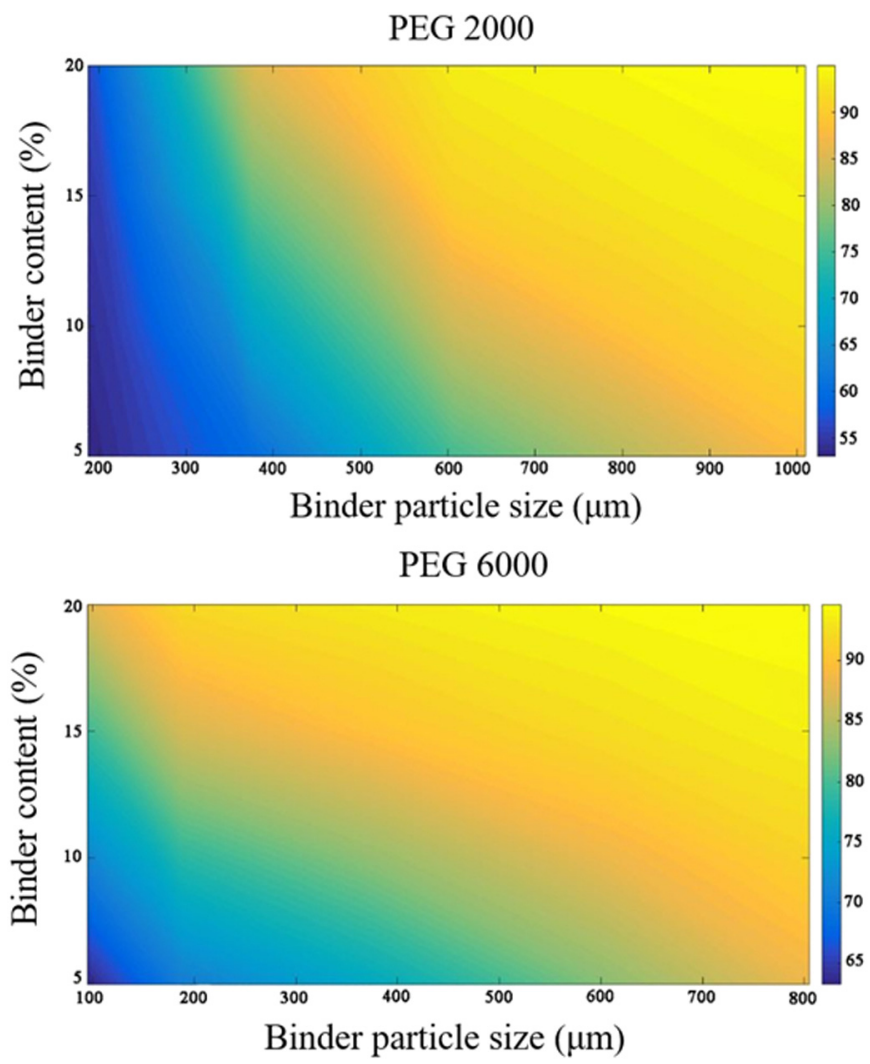

Fig. 4. Contour plot of the variation of the yield $(\mathrm{Y})$ as a function of the binder particle size and binder content for PEG 2000 and 6000, respectively.
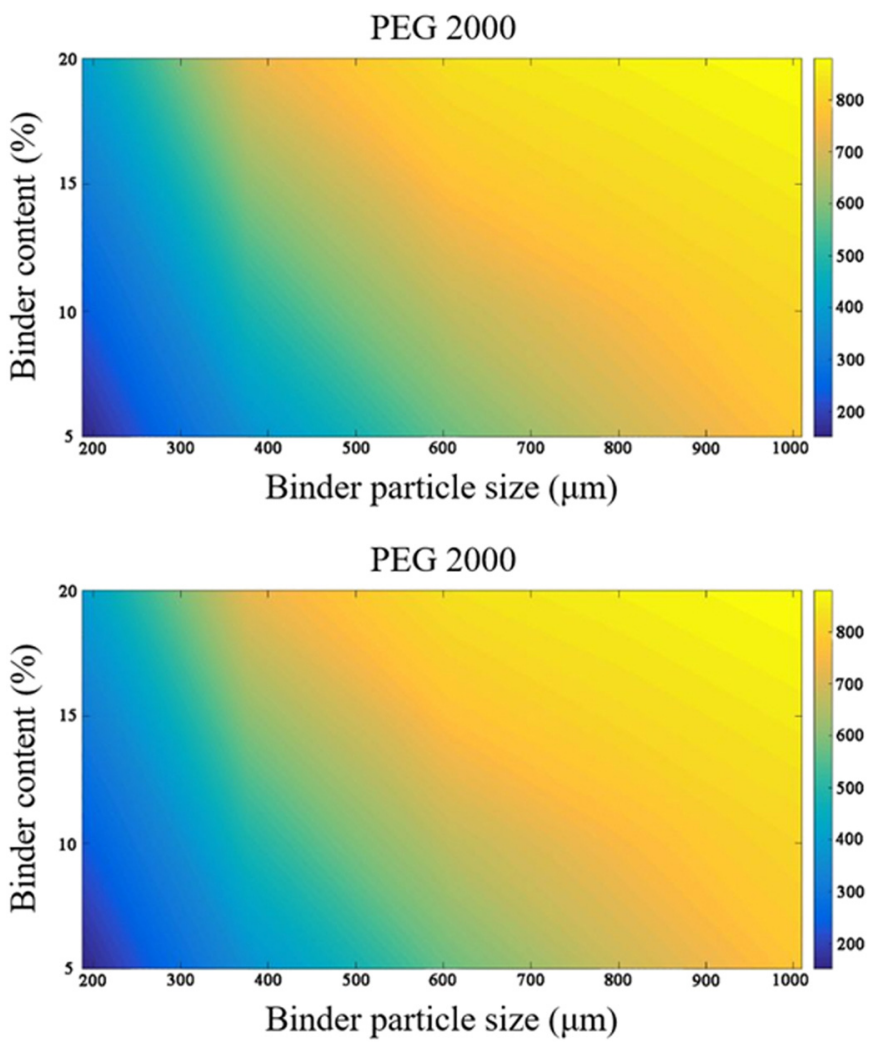

Fig. 5. Contour plot of the variation of the mean diameter $\left(D_{50}\right)$ as a function of the binder particle size and binder content for PEG 2000 and 6000, respectively. 
binder content - yielded more than $90 \%$ of granules above $150 \mu \mathrm{m}$ (Fig. 4). The coefficient of variation showed high values with low binder content as a result of the change in growth mechanism, since the high binder particle size induces immersion and the binder saturation generates a small fraction of fine particles.

\subsection{Effect of input variables on granule hardness}

Granule breakage is an important process affecting binder distribution and granule size processing. Hence it is important to establish the conditions under which breakage will take place [49]. The results of the variation of the hardness of granules as a function of the binder particle size and content are shown in (Fig. 6). Reported studies indicate that granule strength decreases with the decrease in the binder surface tension as the capillary suction pressure is proportional to the liquid surface tension [3]. This is in accordance with our result where the low binder viscosity grade prevented strong bond formation and resulted in granules with weak spherical structure and low strength at low binder particle size, as can be seen for granules S04 and S08, but the increase in binder particle size increased the density and hardness of granules enabling the immersion mechanism to take place (Fig. S4, Supplementary materials).

However, a high binder viscosity grade decreases the deformability of agglomerates, decreasing binder distribution [50], and results in denser, more compact granules as can be seen with the increase in hardness (Fig. 6), adding mechanical strength, an elastic character and resistance to breakage seen in granule S40, where hardness was at the highest values due to high content of binder with high viscosity [23].

As for the effect of binder particle size, at a low level with low binder viscosity grade, granules will be weak and breakage is likely to occur by preventing effective nucleation, as can be seen for the strength measurement where the breaking force is very low (Fig. 5). With a high viscosity grade, the rate of granule consolidation decreases as well as the
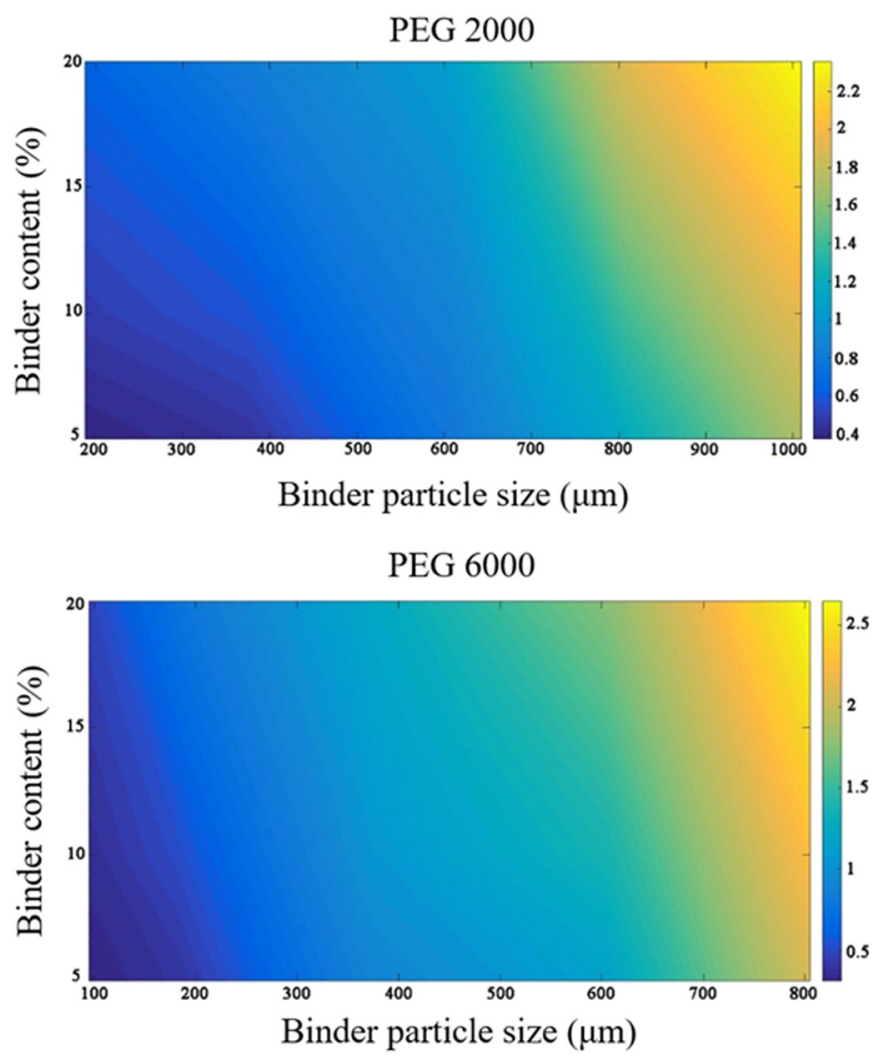

Fig. 6. Contour plot of the variation of hardness $(\mathrm{H})$ as a function of the binder particle size and binder content for PEG 2000 and 6000, respectively.

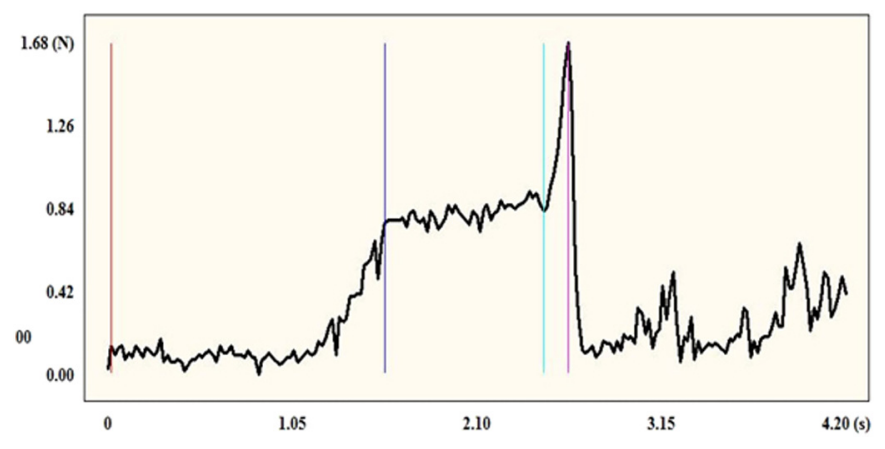

Fig. 7. Deformation process of granule prepared with PEG 6000 (S35).

average pore size for the higher strength of granules [50]. The increase in binder content at high binder particle size also improved the density of granules due to the higher possibility of bridge formation between the nuclei (Fig. S5, Supplementary materials).

Also, a low binder content resulted in low available wetted surface for nucleation, producing weak granules, which is in agreement with the finding of Walker et al. [5] (Table 2). However, a high binder content allowed a higher breaking hardness due to the physically stable granule structure. The deformation process of granules showed an elastic section, then a viscoelastic deformation followed by an elastic section up to the breaking hardness point (Fig. 7).
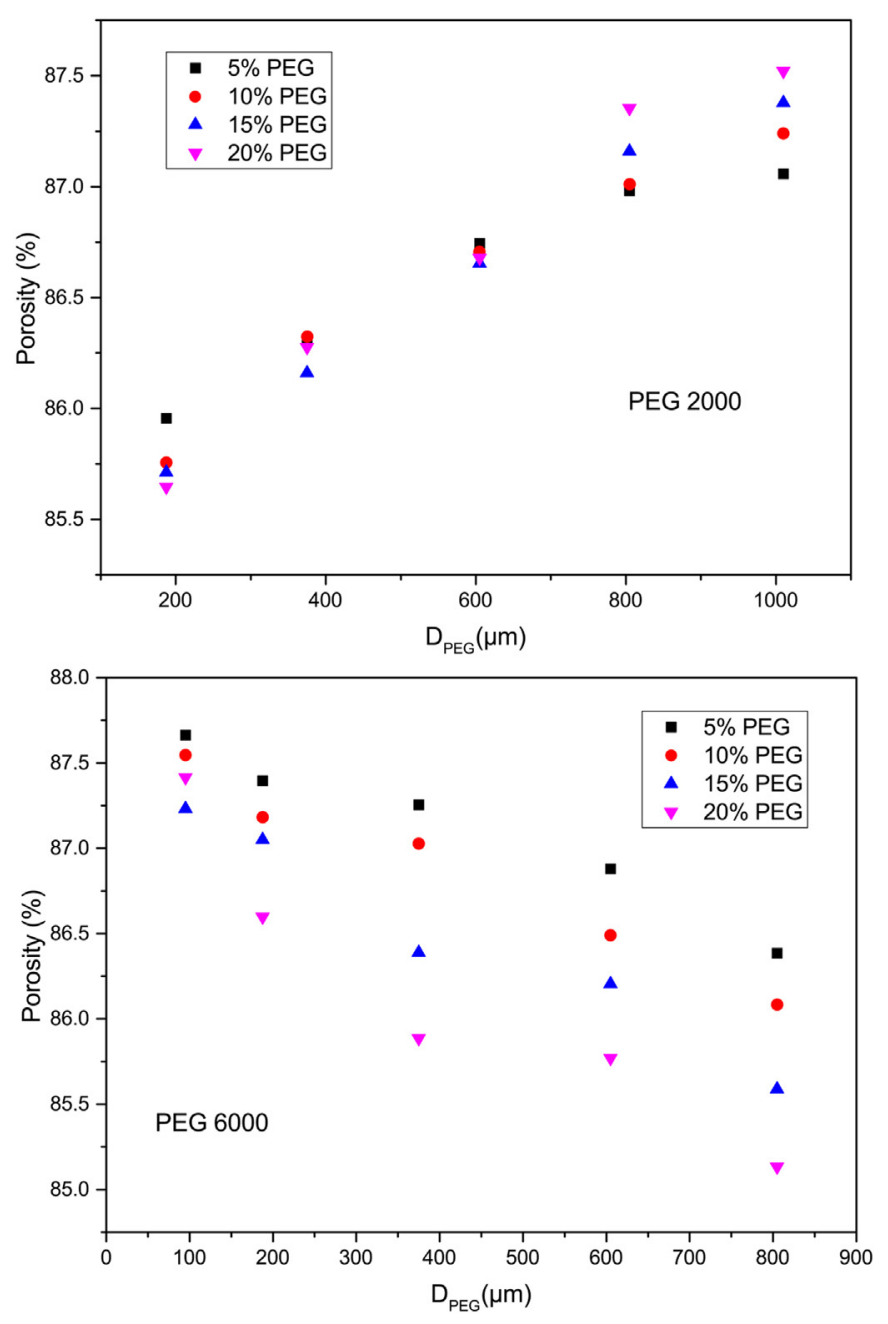

Fig. 8. Evaluation of granule porosity as a function of binder diameter for different binder content and viscosity. 
Table 5

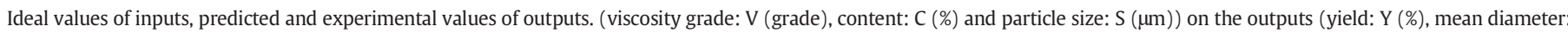
$\mathrm{D}_{50}(\mu \mathrm{m})$, coefficient of variation: $\mathrm{CV}(\%)$, hardness: $\mathrm{H}(\mathrm{N})$, aspect ratio: $\left.A R\right)$.

\begin{tabular}{|c|c|c|c|c|c|c|c|c|}
\hline \multirow[t]{2}{*}{ Data } & \multicolumn{3}{|l|}{ Inputs } & \multicolumn{5}{|l|}{ Outputs } \\
\hline & $\mathrm{V}$ (grade) & $\mathrm{C}(\%)$ & $\mathrm{S}(\mu \mathrm{m})$ & $\mathrm{Y}(\%)$ & $\mathrm{D}_{50}(\mu \mathrm{m})$ & $\mathrm{CV}(\%)$ & $\mathrm{H}(\mathrm{N})$ & $\mathrm{AR}$ \\
\hline Experimental data & 6000 & 20 & $710-900$ & 93 & 830.459 & 68.145 & 1.860 & 1.238 \\
\hline Predicted data & - & - & - & 94.271 & 834.662 & 70.663 & 2.012 & 1.226 \\
\hline Residue & - & - & - & -1.271 & -4.203 & -2.518 & -0.152 & -0.012 \\
\hline
\end{tabular}

On the other hand, the hardness of the granules was low even at a high binder content for low binder particle size (Fig. 5 and Fig. S6, Supplementary materials), revealing the low effect on the agglomerate, growth into strong granules. Both the viscosity grade and the particle size of the binder highly affect the final granule properties and the results showed that the binder content induced smaller changes in the characteristics of the granules in comparison with the above latter factors of this system. The binder content hence plays a minor role in the improvement of the final granule attributes as predicted by the developed ANN model, which gave it $22 \%$, thus making it the least effective factor in the system.

\subsection{Effect of process variables on granule porosity}

Granule porosity is an important product property to control and optimize granule growth mechanisms [49].

Decreasing average particle size decreases the rate of granule consolidation. Smaller particles increase the volume density of interparticle contacts and also decrease the average pore size through which fluid must be squeezed during consolidation. Both these factors retard agglomeration growth. Decreasing the binder particle size also tends to increase the minimum porosity reached due to the greater strength of the assembly. However, the particle morphology and size distribution will also strongly influence the minimum porosity reached.

Fig. 8 shows the variation of the porosity of granules as a function of the binder diameter for different Binder content and viscosity grade. An inversely proportional pattern is seen for both PEG grades (2000 and $6000)$. For low viscosity grade PEG 2000, the increase in binder particle size revealed an increase in the porosity. The slope of the proportionality increases with the increase in the binder content. These can be explained by the fact that at low binder content and size the distribution mechanism is taking place. During nucleation, the nuclei of lactose and PEG particles will have a low porosity similar to the porosity of the raw materials. Increasing binder particle size allowed a higher granulation rate and decreased the amount of fine lactose particles, which resulted in the increase in the porosity of granules.

\subsection{Melt granulation optimization}

Table 5 summarizes the results of the optimization of the agglomeration process with varied material attributes. The selection of the optimal combination of input variable was based on the production of strong, spherical granules with a homogeneous size distribution and the response variables obtained were in an optimal range. Predicted and experimental values of all outputs were close and with a residue inferior to 5 , indicating that the ANN model was able to successfully optimize the process. These results showed immersion as the favorable mechanism, which can be advantageous for sustained drug release when using a hydrophobic meltable binder, and a hydrophilic meltable binder will help increase the dissolution rate for fast drug release.

\section{Conclusion}

This study focuses on the elucidation and optimization of the in-situ fluid hot melt granulation binding process by means of modelling using
ANN. The novelty of these techniques lies in the possibility to determine the effect of material properties on the quality attributes of the final granules and their growth mechanism. The ANN model and the Garson equation enabled the determination of the relative importance of each independent input variable and it predicted the particle size of the binder as having the highest impact on the properties of the final granules, followed by binder viscosity grade and binder content. These predictions were in perfect agreement with the experimental results and enabled a very good correlation with $\mathrm{R}=0.99$ for the simulation and prediction of the formation behavior of the granules. The selected ANN model also enabled the acquisition, from the predicted responses, of response surfaces for the determination of their variation under the process, selection of the optimal input variables and for the optimal output variables and the mechanism dominating the agglomeration process. These techniques show their applicability in the determination of the critical material attributes regarding the desired quality attributes of the final granules and hence allowing the Quality by Design (QbD) approach for the control the FBMG process.

Supplementary data to this article can be found online at https://doi. org/10.1016/j.powtec.2018.03.052.

\section{Acknowledgment}

The authors would like to thank the Ministry of Higher Education and Scientific Research of Algeria and Tempus public foundation for the Stipendium Hungaricum scholarship provided to Yasmine Korteby for her PhD studies.

\section{References}

[1] I. Mašić, I. Ilić, R. Dreu, S. Ibrić, J. Parojčić, S. Srčič, Melt granulation in fluidized bed: a comparative study of spray-on versus in situ procedure, Drug Dev. Ind. Pharm. 40 (2014) 23-32.

[2] I. Mašić, I. Ilić, R. Dreu, S. Ibrić, J. Parojčić, Z. Đurić, An investigation into the effect of formulation variables and process parameters on characteristics of granules obtained by in situ fluidized hot melt granulation, Int. J. Pharm. 423 (2012) 202-212.

[3] H. Zhai, S. Li, G. Andrews, D. Jones, S. Bell, G. Walker, Nucleation and growth in fluidised hot melt granulation, Powder Technol. 189 (2009) 230-237.

[4] C. Mangwandi, N.A. Zainal, L. JiangTao, Y. Glocheux, A.B. Albadarin, Investigation of influence of process variables on mechanical strength, size and homogeneity of pharmaceutical granules produced by fluidised hot melt granulation, Powder Technol. 272 (2015) 173-180.

[5] G.M. Walker, C.R. Holland, M.M.N. Ahmad, D.Q.M. Craig, Influence of process parameters on fluidised hot-melt granulation and tablet pressing of pharmaceuticals powders, Chem. Eng. Sci. 60 (2005) 3867-3877.

[6] A. Seo, P. Holm, T. Schaefer, Effect of droplet size and type of binder on the agglomerate growth mechanisms by melt agglomeration in a fluidized bed, Eur. J. Pharm. Sci. 16 (2002) 95-105.

[7] R. Thies, P. Kleinebudde, Melt pelletization of a hygroscopic drug in high shear mixer. Part1. Influence of process variables, Int. J. Pharm. 188 (1999) 131-143.

[8] D. Voinovich, M. Moneghini, B. Perissutti, J. Filipovic-Grcic, I. Grabnar, Preparation in high shear mixer of sustained release pellets by melt pelletisation, Int. J. Pharm. 203 (2000) 235-244.

[9] S. Zhang, X. Meng, Z. Wang, A. Fan, G. Wang, Y. Zhao, Y. Tang, Engineering hot-melt extruded solid dispersion for controlled release of hydrophilic drugs, Eur. J. Pharm. Sci. 100 (2017) 109-115.

[10] H.J. Prado, P.R. Bonelli, A.L. Cukierman, In situ fluidized hot melt granulation using a novel meltable binder: effect of formulation variables on granule characteristics and controlled release tablets, Powder Technol. 264 (2014) 498-506.

[11] G.B. Borini, T.C. Andrade, L.A.P. Freitas, Hot melt granulation of coarse pharmaceutical powders in a spouted bed, Powder Technol. 189 (2009) 520-527.

[12] N. Passerini, G. Calogerà, B. Albertini, L. Rodriguez, Melt granulation of pharmaceutical powders: a comparison of high-shear mixer and fluidized bed processes, Int J. Pharm. 391 (2010) 177-186. 
[13] D. Yang, R. Kulkarni, R.J. Behme, P. Kotiyan, Effect of melt granulation technique on the dissolution characteristics of griseofulvin, Int. J. Pharm. 329 (2007) 72-80.

[14] H. Patil, R.V. Tiwari, S.B. Upadhye, R.S. Vladyka, M.A. Repka, Formulation and development of $\mathrm{pH}$-independent/dependent sustained release matrix tablets of ondansetron $\mathrm{HCl}$ by a continuous twin-screw melt granulation process, Int. J. Pharm. 496 (2015) 33-41.

[15] K. Shiino, Y. Iwao, Y. Fujinami, S. Itai, Preparation and evaluation of granules with pH-dependent release by melt granulation, Int. J. Pharm. 431 (2012) 70-77.

[16] S.V. Moraga, M.P. Villa, D.E. Bertín, I.M. Cotabarren, J. Pina, M. Pedernera, V. Bucalá, Fluidized-bed melt granulation: the effect of operating variables on process performance and granules properties, Powder Technol. 286 (2015) 654-667.

[17] T. Schaefer, Growth mechanisms in melt granulation in high shear mixers, Powder Technol. 117 (2001) 68-82.

[18] T. Abberger, J.O. Henck, Kornbildungsmechanismen bei der Schmelzgranulierung in der Wirberlschicht und ihre Auswirkungen auf die Tablettierung, Pharmazie 55 (2000) 521-526.

[19] T. Abberger, A. Seo, T. Schaefer, The effect of droplet size and powder particle size on the mechanisms of nucleation and growth in fluid bed melt agglomeration, Int. J. Pharm. 249 (2002) 185-197.

[20] A. Johansen, T. Schaefer, Effect of interactions between powder particles size and binder viscosity on agglomerate growth mechanisms in a high shear mixer, Eur. J. Pharm. Sci. 12 (2001) 297-309.

[21] M. Kidokoro, K. Sasaki, Y. Haramiishi, N. Matahira, Effect of crystallization behavior of polyethylene glycol 6000 on the properties of granules prepared by fluidized hot-melt granulation (FHMG), Chem. Pharm. Bull. 51 (2003) 487-493.

[22] G.M. Walker, S.E.J. Bell, G. Andrews, D. Jones, Co-melt fluidized bed granulation of pharmaceutical powders: improvements in drug bioavailability, Chem. Eng. Sci. 62 (2007) 451-462.

[23] H. Zhai, S. Li, D.S. Jones, G.M. Walker, G.P. Andrews, The effect of the binder size and viscosity on agglomerate growth in fluidized hot melt granulation, Chem. Eng. J. 164 (2010) 275-284.

[24] J. Grau-Bove, C. Mangwandi, G. walker, D. Ring, K. Cornin, Studies into the effect of temperature on the impact of model particles in co-melt granulation, Powder Technol. 294 (2016) 411-420.

[25] M.P. Villa, D.E. Bertin, I.M. Cotabarren, J. Pina, V. Bucala, Fluidized-bed melt granulation: coating and agglomeration kinetics and growth regime prediction, Powder Technol. 300 (2016) 61-72.

[26] I. Aleksić, J. Đuriš, I. Ilić, S. Ibrić, J. Parojčić, S. Srčič, In silico modeling of in situ fluidized bed melt granulation, Int. J. Pharm. 466 (2014) 21-30.

[27] M. De Matas, T. De Beer, S. Folestad, J. Ketolainen, H. Lindén, J.A. Lopes, W. Oostra, M. Weimer, P. Öhrngren, J. Rantanen, Strategic framework for education and training in Quality by Design (QbD) and process analytical technology (PAT), Eur. J. Pharm. Sci. 90 (2016) 2-7.

[28] J.D. Lister, R. Sarwono, Fluidized drum granulation: studies of agglomerate formation, Powder Technol. 88 (1996) 165-172.

[29] E. Murtoniemi, J. Yliruusi, P. Kinnuen, P. Merkku, K. Leiviska, The advantages by the use of neural networks in modelling the fluidized bed granulation process, Int. J. Pharm. 108 (1994) 155-164.

[30] F. Chaibva, M. Burton, R.B. Walker, Optimization of salbutamol sulfate dissolution from sustained release matrix formulations using an artificial neural network, Pharmaceutics 2 (2010) 182-198.

[31] Y. Korteby, Y. Mahdi, A. Azizou, K. Daoud, G. Regdon jr, Implementation of an artificial neural network and a PAT tool for the prediction of the temperature distribution in a pharmaceutical fluidized bed granulator, Eur. J. Pharm. Sci. 88 (2016) 219-232.
[32] Y. Mahdi, K. Daoud, Microdroplet size prediction in microfluidic systems via artificial neural network modelling for water-in-oil emulsion formulation, J. Dispers. Sci. Technol. 32 (2017) 1501-1508.

[33] T. Sovány, Zs. Tislér, K. Kristó, A. Kelemen, G. Regdon Jr, Estimation of design space for an extrusion-spheronization process using response surface methodology and artificial neural network modelling, Eur. J. Pharm. Biopharm. 106 (2016) 79-87.

[34] Y. Sun, Y. Peng, Y. Chen, A.J. Shukla, Application of artificial neural networks in the design of controlled release drug delivery systems, Adv. Drug Deliv. 55 (2003) 1201-1215.

[35] C. Mangwandi, A.B. Albadarin, A.H. Al-Muhtaseb, S.J. Allen, G.M. Walker, Optimisation of high shear granulation of multicomponent fertilizer response surface methodology, Powder Technol. 238 (2013) 142-150.

[36] S. Bolton, C. Bon, Pharmaceutical Statistics, fifth ed Informa Healthcare, New York, 2010.

[37] R. Ramachandran, J.M.H. Poon, C.F.W. Sanders, T. Glaser, C.D. Immanuel, F.J. Doyle III, J.D. Litster, F. Stepanek, F.Y. Wang, I.T. Cameron, Experimental studies on distributions of granule size, binder content and porosity in batch drum granulation: inferences on process modelling requirements and process sensitivities, Powder Technol. 188 (2008) 89-101.

[38] T. Sovány, K. Csordás, A. Kelemen, G. Regdon Jr, K. Pintye-Hódi, Development of pellets for oral lysozyme delivery by using a quality by design approach, Chem. Eng. Res. Des. 106 (2016) 92-100.

[39] K. Kristó, O. Kovács, A. Kelemen, F. Lajkó, G. Klivényi, B. Jancsik, K. Pintye-Hódi, G. Regdon jr, Process analytical technology (PAT) approach to the formulation of thermosensitive protein-loaded pellets: multi-point monitoring of temperature in a high-shear palletization, Eur. J. Pharm. Sci. 95 (2016) 62-71.

[40] A.R. Khataee, M.B. Kasiri, Artificial neural networks modeling of contaminated water treatment processes by homogeneous and heterogeneous nanocatalysis, J. Mol. Catal. 331 (2010) 86-100.

[41] G.D. Garson, Interpreting neural-network connection weights, A. I. Exp. 6 (1991) 47-51.

[42] M.A. Ansari, F. Stepanek, Formation of hollow core granules by fluid bed in situ melt granulation: modelling and experiments, Int. J. Pharm. 321 (2006) 108-116.

[43] P.R. Mort, Scale-up of binder agglomeration processes, Powder Technol. 150 (2005) 86-103.

[44] T. Schaefer, D. Johnsen, A. Johansen, Effect of powder particle size and binder viscosity on intergranular and intragranular particle size heterogeneity during high shear granulation, Eur. J. Pharm. Sci. 21 (2004) 525-531.

[45] G.I. Tardos, M. Irfan Khan, P.R. Mort, Critical parameters and limiting conditions in binder granulation of fine powders, Powder Technol. 94 (1997) 245-258.

[46] S.H. Schaafsma, P. Vonk, P. Sergers, N.W.F. Kossen, Description of agglomerate growth, Powder Technol. 97 (1998) 183-190.

[47] T. Monteyne, L. Heeze, S.T.F.C. Mortier, K. Oldörp, R. Cardinaels, I. Nopens, C. Vervaet, J.P. Remon, T. De Beer, The use of rheology combined with differential scanning calorimetry to elucidate the granulation mechanism of an immiscible formulation during continuous twin-screw melt granulation, Pharm. Res. 510 (2016) 271-284.

[48] B. Mu, M.R. Thompson, P.J. Sheskey, K.P. O'Donnell, Hot-melt granulation in a twinscrew extruder, Chem. Eng. Sci. 81 (2012) 46-56.

[49] S.M. Iveson, J.D. Litster, K. Hapgood, B.J. Ennis, Nucleation, growth and breakage phenomena in agitated wet granulation processes: a review, Powder Technol. 117 (2001) 3-39.

[50] T. Schaefer, C. Mathiesen, Melt pelletization in high shear mixer. VIII. Effect of binder viscosity, Int. J. Pharm. 134 (1996) 105-117. 